\title{
PHYSIOLOGICAL AND PERCEIVED EFFECTS OF HEAD COOLING DURING SIMULATED FIREFIGHTING ACTIVITY
}

\author{
A thesis \\ Presented to \\ The College of Graduate and Professional Studies \\ Department of Applied Medicine and Rehabilitation \\ Indiana State University \\ Terre Haute, Indiana \\ In Partial Fulfillment \\ of the Requirements for the Degree \\ Master of Science in Athletic Training \\ by \\ Amy L. McKenzie \\ May 2011 \\ (C) Amy L. McKenzie 2011
}

Keywords: heat; cooling; firefighting; exertional heat illness; thermal physiology 


\section{COMMITTEE MEMBERS}

Committee Chair: Susan W. Yeargin, PhD, ATC

Assistant Professor, Graduate Program Director

Indiana State University

Committee Member: Lindsey E. Eberman, PhD, ATC

Assistant Professor, Undergraduate Program Director

Indiana State University

Committee Member: J. Derek Kingsley, PhD

Assistant Professor

Indiana State University 


\begin{abstract}
Accessory cooling devices have been developed to protect firefighters (FF) from suffering an exertional heat illness by attenuating the rise in core body temperature. Head cooling (HC) via a cold gel pack placed inside the helmet is one cooling mechanism marketed to FF, but the research regarding its efficacy is limited.

PURPOSE: To investigate the physiological and perceived effects of HC during simulated firefighting activity (FFA).

METHODS: Participants (males; $40 \pm 8 \mathrm{y} ; 168 \pm 7 \mathrm{~cm} ; 91.8 \pm 14.2 \mathrm{~kg}$ ) were randomly assigned to either the HC group ( $n=9)$, who completed FFA while wearing a cold gel pack inside their helmet, or the control $(\mathrm{CON})$ group $(\mathrm{n}=10)$, who received no accessory cooling during FFA. FF completed four FFA stations in full turnout gear and self-contained breathing apparatus (SCBA) (23.3 $\pm 1.4 \mathrm{~kg})$. FFA stations lasted $15 \mathrm{~min}$ and included an obstacle course, a high-rise drill, a two-story search and rescue drill, and car extrication. Stations were completed in random order. After each station, FF replaced their air cylinder and HC replaced their gel pack; FF then completed a different station. After every two stations, the FF rested for $15 \mathrm{~min}$ in the shade by removing their turnout gear and SCBA and drinking water ad libitum. Gastrointestinal temperature (GI), heart rate (HR), Stroop Test interference score (ST), rating of perceived exertion (RPE), perceived thermal strain (PTS), and hydration status were measured. Repeatedmeasures ANOVAs were used to compare groups across time.
\end{abstract}


RESULTS: No significant demographic differences were found between groups (p>0.05). GI $\left(39.18 \pm 0.49^{\circ} \mathrm{C}\right)$ and $\mathrm{HR}(163 \pm 22 \mathrm{bpm})$ increased during FFA. No significant interactions were found for GI, HR, ST, PTS, or RPE ( $>>0.05$ ). There were no differences in sweat loss $(2.5 \pm 0.8 \mathrm{~L})$, hypohydration $(0.9 \pm 0.8 \%)$, or post FFA urine specific gravity $(1.020 \pm 0.008)$ between groups $(\mathrm{p}>0.05)$. Weak relationships were noted between perceived thermal sensation and gastrointestinal temperature $(\mathrm{r}=.248)$.

CONCLUSION: HC did not attenuate the rise in GI or reduce HR during FFA. The discrepancy between perception and actual body temperature may be dangerous for FF, as it may allow them to work beyond their central drive and the critical GI threshold. 


\section{PREFACE}

Like many young graduate students, I wanted to immediately make a difference. I wanted my research to find the ultimate prevention for all exertional heat illnesses. And like many good and experienced advisors, my committee steered me toward a much more manageable piece to the puzzle that would still make a significant impact. As the ideas came together and took shape, we created a project that would not only contribute to the body of literature, but also to some members of our community. This allowed me to weave my own desire to work with firefighters, the atypical yet professional athlete many of my family members have become, into my plan to help prevent exertional heat illnesses.

Although the numbers and statistics from the study taught me about head cooling, the firefighters who volunteered their time, sweat, talent, and expertise taught me about people. Their interest and excitement throughout the project were driving factors in the completion of the study. Their desire to learn about thermal physiology and their own reactions to exercise in the heat led to sharing their personal data collected during the study with them to increase their selfawareness and improve how they care for themselves. The experience of working with these firefighters is one that cannot be replaced and was truly the personal significance I found during this study. 


\section{ACKNOWLEDGMENTS}

To my advisor, Susan. You have taught me everything you know from heat illnesses to thermal physiology to the type of mentor I'd like to be some day. Your guidance, expertise, passion and compassion (and frequent Starbucks trips), truly made it possible for me to complete a project I will always be proud of. Thank you.

To my committee, Dr. Eberman and Dr. Kingsley. You have shown me the ins and outs of study design and statistics and were always there to listen and turn blank stares into understanding. Thank you for sharing your knowledge and kindness with me.

To the Terre Haute Fire Department, Fire Chief Jeff Fisher, and Training Chief Norm Loudermilk. Your time, talents, and cooperation truly made this study happen and taught me a thing or two about how to be selfless and always willing to help. Thank you for everything.

To my classmates, especially Meg, Yoder, Dave, Andy, and Meghan. Thank you for your support- everything from listening and questioning to data collecting and just making everything work when it wasn't.

To the undergraduate research assistants, Janie, Tiff, Jennifer, and Dana. Thank you for your high spirits and willingness to help in any way possible. 
vii

To my big strong men, Kevin and Max. Thank you for your time and your big muscles to make my day a little easier and for politely taking orders from me while I had a million things on my mind.

To my friends, Max and Pfrank. You were always there to give me a little pep talk when I was flustered and to keep me awake on long bus trips to get work done (yes, that's what she said, I know...). Thanks!

To my big brother, Scott. Thank you for the long (sometimes seemingly endless) phone calls and encouragement, the 24-hour tech support, overnight shipping of old PC laptops and cables, and the love!

To my parents. Thank you for instilling a love for learning and the drive and passion to conquer any obstacle set in front of me at a young age. I hope you know you taught me well. 


\section{TABLE OF CONTENTS}

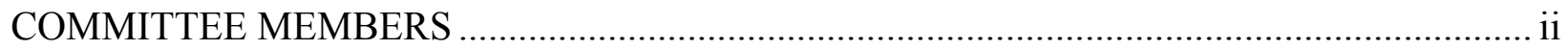

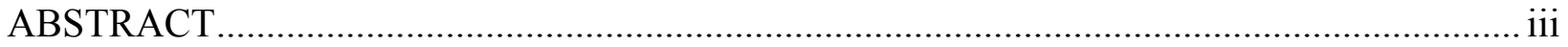

PREFACE … - ...

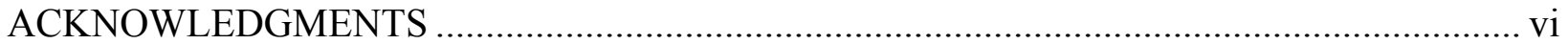

LIST OF TABLES

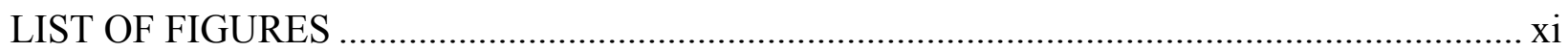

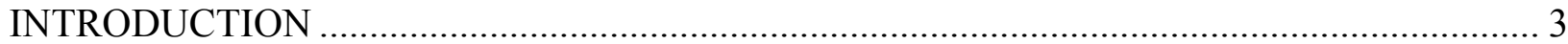

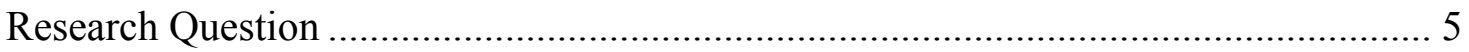

Experimental Hypotheses .................................................................................... 5

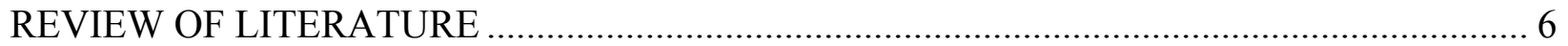

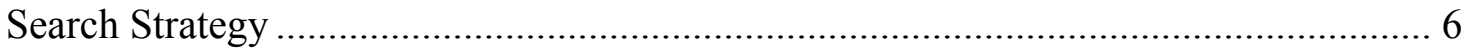

Environmental Exercise Physiology ……………….................................................. 7

Acute Physiological Responses to Heat in Firefighters.............................................. 11

Acclimatization to Exercise in Heat ...................................................................... 13

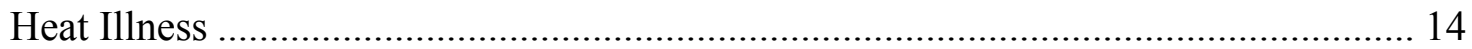

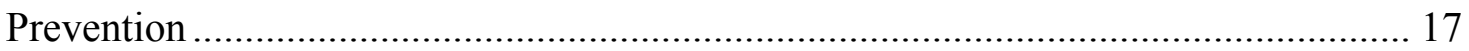

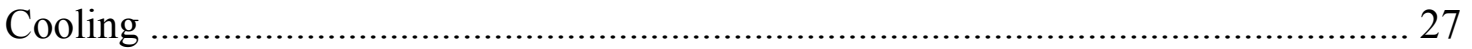

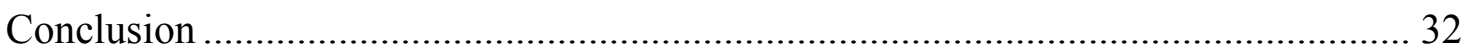




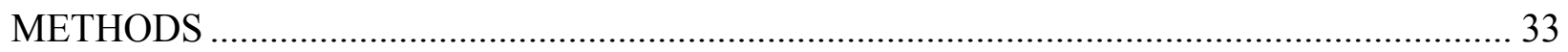

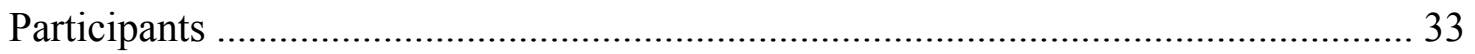

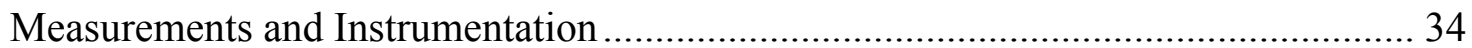

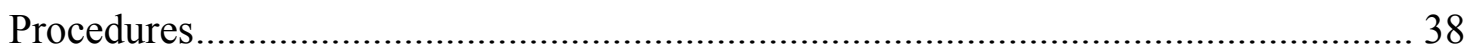

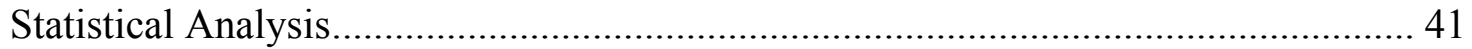

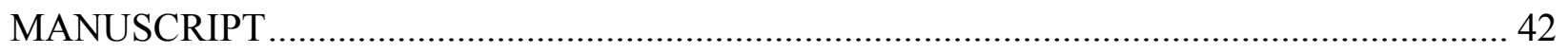

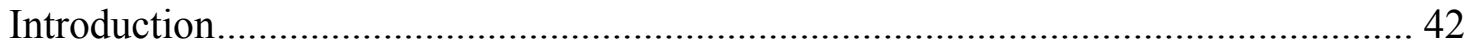

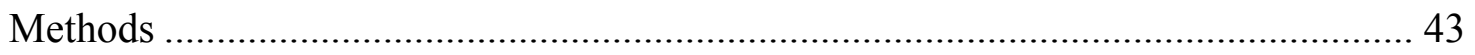

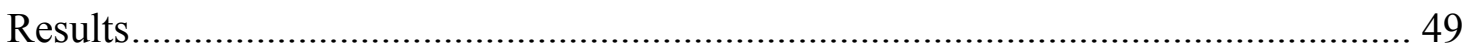

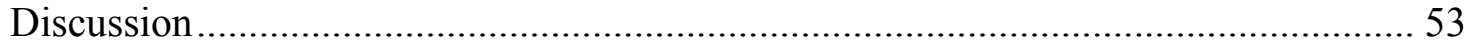

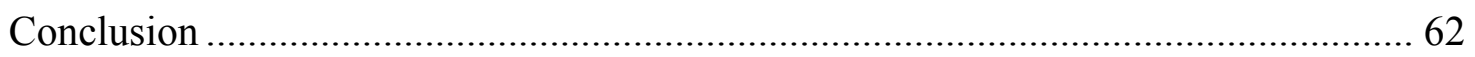

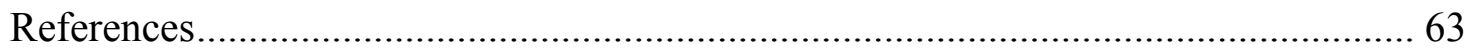

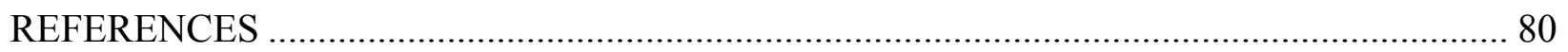

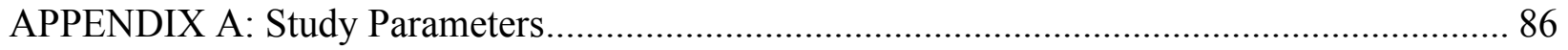

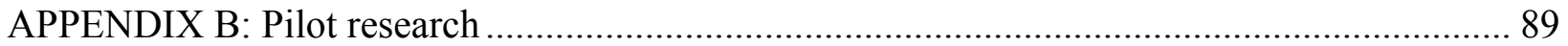

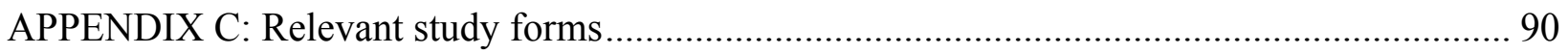

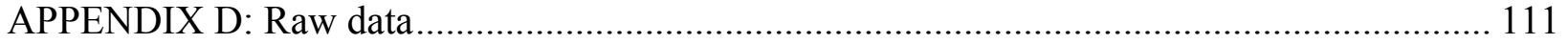

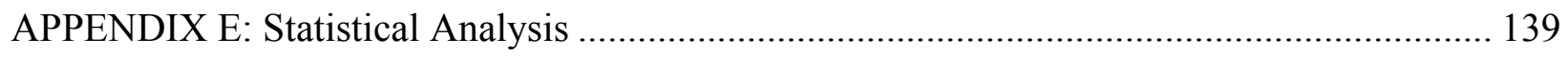

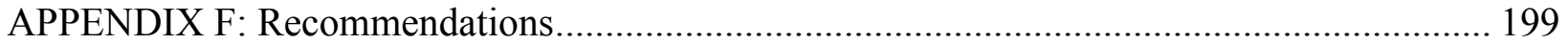




\section{LIST OF TABLES}

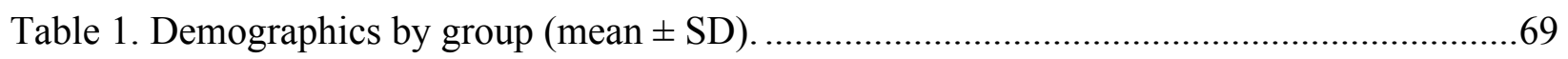

Table 2. Average and maximum WBGT outdoors over days and inside the training facility.......69 


\section{LIST OF FIGURES}

Figure 1. Head cooling gel pack and firefighting helmet. ......................................................

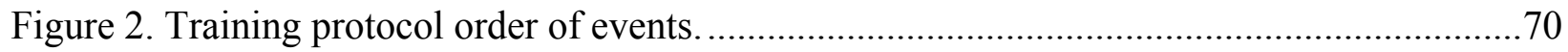

Figure 3. Gastrointestinal temperatures by group at the end of each station................................... 71

Figure 4. Heart rate by group at the end of each drill and rehab. ................................................72

Figure 5. Average Physiological Strain Index score at the end of each drill and rehab................73

Figure 6. Urine specific gravity before and after training by group.............................................74

Figure 7. Sweat loss, sweat rate, and fluid consumed during training protocol...........................75

Figure 8. Percent dehydration after training protocol...............................................................

Figure 9. Stroop test interference scores throughout training protocol. .........................................77

Figure 10. Rating of perceived exertion during training protocol. ................................................78

Figure 11. Perceived thermal sensation during training protocol................................................. 79 


\section{CHAPTER 1}

\section{INTRODUCTION}

Firefighters are forced to handle a variety of physiological stressors while on the job. He or she must repeatedly enter burning buildings with temperatures as high as $278^{\circ} \mathrm{C}^{1}$ and sustain long periods of physical exertion while working to extinguish fires and rescue victims. Further, they must complete all of these tasks while wearing heavy protective clothing and a self-contained breathing apparatus. ${ }^{2}$ With the combination of their protective clothing, the hot environment, and their physical exertion, firefighters' core body temperatures (CBT) increase ${ }^{3}$ and they become unable to dissipate the heat. As they work hard to extinguish a fire, heart rate (HR) also increases ${ }^{3-6}$ resulting in an increased physiological strain. ${ }^{2}$ With this increased physiological stress, firefighters also perceive that they feel hotter and feel as though they are working harder. ${ }^{6}$

As the body stores heat CBT continues to rise, increasing the risk of developing an exertional heat illness (EHI). ${ }^{7-11}$ Many types of EHIs exist, including cramps, syncope, exhaustion, and stroke. The temperature, humidity, intensity of work, length of exposure to the environment, protective clothing, dehydration, illness, and lack of sleep may contribute to the development of a heat illness. ${ }^{8-11}$ Any EHI can render a firefighter unable to continue working to extinguish a fire, thus reducing the work force; it may even lead to a firefighter's death. 
Heat illness in firefighters is not uncommon. ${ }^{12-14}$ The National Fire Protection Association's Research and Analysis Division reported that between 2003 and 2006, 2330 illnesses due to exhaustion or fatigue, including heat exhaustion were reported. ${ }^{12}$ Over 1300 firefighters reported dizziness, fainting, weakness, dehydration, or nausea as the primary symptom. ${ }^{12}$ All of these symptoms may be related to an EHI; however, specific data on the occurrence of EHIs is lacking in firefighters. Among the firefighters who suffer from an EHI, not everyone survives. In both 2008 and 2009, one firefighter died as a result of heat stroke and heat exhaustion, respectively. ${ }^{13,14}$ Additionally, 52 firefighters in 2009 and 41 in 2008 died due to stress and overexertion. ${ }^{13}$

Several safety procedures exist to help protect firefighters during training and on the job. ${ }^{15-19}$ Accessory cooling devices and methods, such as ice vests, fan and water mists, and forearm and hand cold-water submersion may also assist in preventing EHIs. ${ }^{6}$, 20-23 These devices function to attenuate the rise in CBT, thus reducing the firefighter's risk of developing an EHI. Head cooling is one method that has been studied in various settings and activity levels ${ }^{24-26}$, but not among firefighters. One product, the GelCool gel pack, is cooled in a freezer and then is worn inside a firefighter's helmet during activity to help keep the firefighter cool. The manufacturer claims that the device cools cranial blood thus reducing metabolic activity. They claim that this will slow vital organ (heart and lungs) activity. ${ }^{27}$ They also claim that with cooler blood circulating, the need to dissipate heat will decrease, thus reducing perspiration. ${ }^{27}$ Although this product makes many claims that seem to benefit the firefighters, the manufacturer has provided no evidence to support their claims. The purpose of this study is to determine if a GelCool 
gel pack worn inside of firefighting helmets during activity is beneficial to firefighters by attenuating the rise in $\mathrm{CBT}$ and thus reducing the risk of developing an EHI.

\section{Research Question}

What effect does superior head cooling have on physiological, perceptual, and cognitive responses during simulated firefighting activity?

\section{Experimental Hypotheses}

- Wearing the GelCool gel pack will not attenuate the rise of gastrointestinal (GI) temperature, HR, or Physiological Strain Index (PSI) score.

- Wearing the GelCool gel pack will reduce firefighters' rate of perceived exertion (RPE) and perceived thermal strain (PTS).

- Wearing the GelCool gel pack will not reduce body mass loss, sweat rate, or sweat loss or improve urine specific gravity measurements.

- Wearing the GelCool gel pack will not improve cognitive function on the Stroop Word Test. 


\section{CHAPTER 2}

\section{REVIEW OF LITERATURE}

Firefighters are praised for their bravery and courage as they repeatedly enter burning buildings to help those in need. They are constantly under stress from the heat of the flames, their protective clothing, and their physical exertion that causes their CBT to rise while they work. This review of literature describes how firefighters' bodies store and dissipate heat, the physiological responses to the storage of that heat in the general population, as well as specific responses in firefighters. Since the incidence of EHI in

firefighters is high, exertional heat stroke and exertional heat exhaustion are discussed, as well as predisposing factors that contribute to the development of an EHI. Many methods of prevention, including safety protocols and various cooling methods, are also included in this review of literature.

\section{Search Strategy}

Searches on the topic were completed in the following databases: Cochrane, PubMed, PubMed Central, CINAHL, PreCINAHL, and Medline, and by hand searching. The following key words were used individually and in combination to search the literature: exertional heat illness, exertional heat stroke, exertional heat exhaustion, firefighter, physiology, perceived, perceptual, temperature, heart rate, heat, 
acclimatization, prevalence, incidence, prevention, predisposing, safety, and cooling. Inclusion criteria included firefighters, exercise, intermittent exercise, protective clothing, heat stress, and heat strain. Exclusion criteria included abnormal populations, malignant hyperthermia, and animals.

\section{Environmental Exercise Physiology}

\section{Heat Acquisition}

Metabolic heat produced during exercise from the contraction and active use of muscles puts thermal stress on the body. Greater exercise intensities produce more metabolic heat within the body, thus increasing the amount of heat stored by the body as well as increasing $\mathrm{CBT}^{7,8,28}$ Core body temperature will rise in proportion to the increase in exercise intensity and can be compensated for in an appropriate environment. $^{28}$

However, when the ambient temperature rises above $25^{\circ} \mathrm{C}$, core temperature begins to increase as ambient temperature increases. ${ }^{28}$ Therefore, the environment in which one exercises can put additional stress on the body. The body acquires heat from many external factors such as ambient temperature, humidity, solar radiation, thermal radiation from the ground, and protective clothing. ${ }^{7}$ These factors are commonly present in the environment in which a firefighter works. During firefighting, Rossi et al. found temperatures to range from $50-130^{\circ} \mathrm{C}$ on the ground to $100-190^{\circ} \mathrm{C}$ at 1 meter above the ground with a maximum of $278^{\circ} \mathrm{C}$ experienced during a heat flux in a simulated domestic

fire. ${ }^{1}$ Sensors placed on the bottom and top of the firefighters jackets found temperatures in the range of $40-70^{\circ} \mathrm{C}$ and $50-120^{\circ} \mathrm{C}$, respectively. ${ }^{1}$ In this study, while they could not directly measure humidity, they observed that black smoke turned to a white mist while 
extinguishing the fire, indicating that partial pressure could be near saturation and therefore a high humidity was present. ${ }^{1}$

Protective clothing worn by firefighters to protect them from thermal injuries insulates the body and aids the increase in CBT beyond what is caused by the environmental temperature and physical work. ${ }^{29}$ The protective clothing worn by firefighters also reduces the surface area of the body exposed to the air, which reduces the body's means of dissipating heat. ${ }^{30}$ Kalyani et al. evaluated the physiological strain firefighters experienced while performing physical activity in their firefighting protective clothing versus typical work clothing while completing the Bruce exercise protocol in a thermoneutral environment. Physiological strain experienced by the participants in each set of clothing was evaluated with the Physiological Strain Index. The PSI in firefighting protective clothing was significantly greater compared to typical work clothing, indicating a greater level of strain on the body due to heat, especially with respect to increases in CBT and $\mathrm{HR}^{31}$

\section{Heat Dissipation}

While the body acquires this heat during exercise in a hot environment, it must find a way to dissipate the heat in order to maintain CBT within a safe range. Heat dissipation can occur via conduction, convection, radiation, and evaporation. Heat transfer by conduction is the movement of heat between two objects in direct contact with one another and is insignificant at most times. ${ }^{7}$ At lower ambient temperatures $\left(5-10^{\circ} \mathrm{C}\right)$, convection and radiation are the principal means of heat loss. ${ }^{28,30}$ However, as ambient temperature increases, heat dissipation via convection and radiation is reduced. ${ }^{7,28,30}$ Convection is the transfer of heat between one object and a moving medium, such as air 
or water, surrounding it, while radiation is the movement of heat by electromagnetic waves due to the temperature of the object. As ambient temperature increases, evaporation, the loss of heat via the process of changing the state of a liquid to a gas, becomes the principal method for removing heat from the body. ${ }^{7,28,30}$ However, evaporation can only be accomplished with the body's sweating mechanism, hydration status, and the environment's optimal humidity working together. If one becomes hypohydrated or otherwise compromises the body's sweating mechanism, heat dissipation also becomes compromised. ${ }^{7}$ Additionally, high humidity (greater than 50$70 \%)^{8}$ in the environment reduces the effect of evaporation on cooling the body. ${ }^{70}$ If the body becomes overwhelmed and unable to dissipate as much heat as it acquires, hyperthermia results. ${ }^{7,8,10,30}$ This increased CBT has many physiological and performance consequences. ${ }^{7,8}$ Hyperthermia reduces muscular endurance and shifts the body's metabolism from aerobic to anaerobic. ${ }^{8,28}$ This change in metabolism causes the body to use its limited store of carbohydrates much faster and provides less oxygen to working tissues. ${ }^{8}$ Hyperthermia also causes a change in blood flow throughout the body, increasing cardiovascular strain. ${ }^{8}$ The effects of these changes have been found to manifest as a perception of fatigue. ${ }^{8}$

Physiology of Exercise in the Heat

In an attempt to dissipate as much heat as the body acquires, physiological alterations will occur. Initially, blood begins to be shunted away from inactive tissues and the gut toward the skin and active muscles for heat dissipation and to continue exercise, respectively. This results in splanchnic vasoconstriction and peripheral vasodilation of the skin and muscles. Although blood flow has been shunted to help cool the body, the 
active muscles and cutaneous blood vessels are still competing for blood flow. ${ }^{28}$ By increasing cutaneous blood flow, heat is carried away from the body's core and heat dissipation via convection is enhanced. ${ }^{8,10}$ The heat brought to the skin's surface can transfer to the environment via the temperature gradient created between the blood and the environment. The dissipation of heat away from the body can only occur if the environmental temperature is lower than the temperature of the blood. As the environmental temperature increases to greater than $34-37^{\circ} \mathrm{C}$, heat dissipation due to peripheral vasodilation is reduced. ${ }^{8}$

As the body shunts blood to the periphery in attempt to dissipate heat, central blood volume is reduced. ${ }^{7,28}$ It is also reduced due to the decrease in plasma volume brought on by the loss of fluids via sweat. ${ }^{8}$ This decrease in central blood volume also causes a reduction in the heart's stroke volume. ${ }^{7,28}$ As stroke volume falls, HR increases in order to maintain cardiac output. ${ }^{7,28}$ Reductions in stroke volume, and thus cardiac output, result in hypoxia of working tissues. Furthermore, the reduction of cardiac output is augmented especially if a high environmental temperature requires blood to be shunted away from the core and toward the skin for cooling purposes. ${ }^{7}$ Cardiac output is maintained at submaximal exercise intensities as increases in HR compensate for the decreased stroke volume. However, due to the increased HR, maximum HR is reached at a lesser exercise intensity, thereby limiting cardiac output. ${ }^{7}$ Additionally, since maximal cardiac output is reached at a lesser exercise intensity, aerobic capacity, and thus the work that can be performed, are also reduced. ${ }^{7}$ The amount of time it takes to reach exhaustion also decreases as environmental temperature increases. ${ }^{7,10}$ 
Acute Physiological Responses to Heat in Firefighters

\section{Heart Rate}

Firefighters demonstrate HRs between 80 and 208 bpm during maximal physical work and operational work training with mean peak HRs as high as $197 \mathrm{bpm} .{ }^{3}$ Bugajoka et al. reported mean maximum HRs as high as $164.2 \pm 15.9 \mathrm{bpm}$ during a simulated victim rescue. ${ }^{4}$ Firefighters operated at up to $96.2 \pm 9.6$ percent of their maximum HR while climbing ladders or stairs and carrying a hose during a simulated victim rescue outdoors with an ambient temperature of approximately $12{ }^{\circ} \mathrm{C} .{ }^{4}$ In another study, Smith et al. had firefighters complete drills, such as dragging a dummy, hoisting a hose, and chopping, for approximately 14 minutes, followed by a ten-minute rest period, and then working for an additional seven minutes. Heart rates rose to $189.3 \pm 10.5$ bpm during the second work period. ${ }^{6}$ This research indicates that firefighters work at near maximal HRs during much of their training, thus increasing their physiological strain.

Not only does the physical work completed by firefighters increase HR, but also the sounding of the fire alarm to signal the firefighters to answer a call. On average, firefighters' HRs increased $47 \mathrm{bpm} 15$ to 30 seconds after the alarm, and remained, on average, 30 beats higher at one minute post-alarm. ${ }^{5}$ The physical activity of preparing to answer a call after the alarm sounds accounted for 36 beats of those additional 47 at 15 to 30 seconds post-alarm, but for only nine beats at one minute post-alarm. ${ }^{5}$ Upon arrival at a fire, firefighters averaged a HR of $150 \mathrm{bpm}^{5}$

\section{Body Temperature}

Rectal temperatures as high as $41.4^{\circ} \mathrm{C}$ were recorded by Ilmarinen et al. in firefighters during physical work training for 1.5 hours indoors and outdoors. ${ }^{3}$ 
Additionally, training in a flashover facility for 25 to 30 minutes produced rectal temperatures up to $39.3^{\circ} \mathrm{C}$ and as high as $39.9^{\circ} \mathrm{C}$ during wintertime training in small burning houses for 10 to 30 minutes. ${ }^{3}$ Espinoza et al. measured GI temperatures in firefighters during two, successive 15-minute drill sessions followed by a 20 -minute rest. Three percent of participants had peak GI temperatures above $40{ }^{\circ} \mathrm{C} .^{32}$ Another eight percent exhibited peak GI temperatures between 39.4 and $40^{\circ} \mathrm{C} .{ }^{32}$ Smith et al. measured rectal temperatures in firefighters during live-fire firefighting drills in a four-story building with fires on the second and fourth floors. Firefighters completed drills for approximately 18 minutes with a ten-minute rest period after about 12 minutes of drills. Rectal temperatures as high as $38.6^{\circ} \mathrm{C}$ were recorded. ${ }^{33}$ Similarly, Griefahn et al. found rectal temperatures of $38.4^{\circ} \mathrm{C}$ in firefighters completing firefighting drills for approximately 15 minutes. In this case, however, there was no live fire, and ambient temperatures ranged from $11-25^{\circ} \mathrm{C} .{ }^{34}$ Taken together, these studies show that firefighters often work at elevated CBTs, which may contribute to increasing a firefighter's risk of developing an EHI.

\section{Body Mass Loss}

Espinoza et al. demonstrated that 53 percent of firefighters lost two to three percent of their body weight after two 15-minute drill sessions and a 20-minute rehabilitation period using one of four cooling methods: peripheral cooling, KoreKooler

Rehab chairs, misting fans, or wet towels. ${ }^{32}$ Five percent of participants in the study lost more than three percent of their body weight. ${ }^{32}$ Those who lose more than three percent of their body weight during training will be at a greater risk of developing an EHI due to dehydration and may suffer a decrease in performance. 


\section{Urine Specific Gravity}

In the same report by Espinoza et al., firefighters were evaluated prior to training. Twenty-two percent of participants were dehydrated prior to training with urine specific gravities between 1.020 and $1.030 .^{32}$ Four percent demonstrated urine specific gravities greater than 1.030, indicating greater dehydration. ${ }^{32}$ Those with urine specific gravities greater than 1.020 may be at greater risk of developing an EHI due to dehydration.

\section{Ratings of Perceived Exertion}

Bugajoka et al. noted that firefighters reported RPE, on average, between 12.3 and 13.7, using Borg's 20 point RPE scale. ${ }^{4}$ Rating of perceived exertion increased from climbing a ladder, to climbing stairs with a hose, to rescuing a simulated victim. ${ }^{4}$ Smith et al. had firefighters complete drills for 14 minutes, followed immediately by a ten-minute rest period, another seven minutes of drills, and finally a 16-minute rest period. This set of work and rest was completed twice. Rating of perceived exertion increased both between and within sets, progressively increasing over each seven minutes of work. ${ }^{6}$

\section{Acclimatization to Exercise in Heat}

Although the body undergoes many acute responses to accommodate to exercise in the heat, chronic exposure results in acclimatization allowing the body to better perform in heat. ${ }^{7,8,10,28}$ Acclimatization results in the ability to improve heat transfer from the body's core to the skin and to improve cardiovascular function, thus increasing

one's ability to perform work. ${ }^{7,8,28}$ Approximately 10 to 14 days of successive exposure to continuous exercise for approximately 100 minutes $^{28}$ in heat is required for these changes to occur. ${ }^{8,10}$ The first adaptations to occur include increased plasma volume ${ }^{7}$, reduced $\mathrm{HR}^{7,28}$, and adaptations of the autonomic nervous system enhance heat 
dissipation. ${ }^{8}$ Core body and skin temperatures also are reduced. ${ }^{28}$ Most of these changes occur within two to six days. ${ }^{8}{ }^{28}$ Perceived exertion also is reduced within the same timeframe due to early autonomic nervous system changes. ${ }^{7,8}$ By the tenth day, most changes to support successful heat acclimatization have occurred, including a decrease in rectal temperature, as well as the renal and sweat concentrations of sodium and chloride. ${ }^{7}$, ${ }^{8,28}$ By day 14 , sweat rate also has increased to allow for greater heat dissipation via evaporation. ${ }^{7,8,28}$ Additionally, sweating begins at a lower CBT to help attenuate the rise with exercise in the heat. ${ }^{28}$ Currently, no literature is available regarding acclimatization specifically in firefighters.

\section{Heat Illness}

\section{Exertional Heat Stroke}

Exertional heat stroke occurs when the body's thermoregulatory system becomes overwhelmed by thermal stresses due to internal and external factors that exceed the body's ability to dissipate that heat. ${ }^{7,10,35}$ Exertional heat stroke can be triggered by intense exercise in a hot environment. ${ }^{35}$ Exertional heat stroke is divided into three phases: the acute phase, the blood and enzyme phase, and the late phase. ${ }^{35}$

The acute phase of exertional heat stroke occurs during the first hour after initial collapse, and is characterized by central nervous system dysfunction and hyperthermia (rectal temperature greater than $\left.40^{\circ} \mathrm{C}^{10}\right) .{ }^{11,35}$ Central nervous system dysfunction can be identified by any of the following symptoms: altered consciousness, convulsions, irrational behavior, stupor, irritability, delirium, agitation, coma, etc. ${ }^{11,35}$ Other signs and symptoms of exertional heat stroke may include hypotension, tachycardia, tachypnea, vomiting, diarrhea, and dehydration. ${ }^{8,11,35}$ Those suffering from exertional heat stroke 
may also be sweaty and pale. ${ }^{10}$ The second phase of exertional heat stroke is known as the blood and enzyme phase. This occurs between one and 48 hours after the initial collapse. ${ }^{35}$ During this phase, serum levels of various enzymes become elevated and blood disorders become recognizable. ${ }^{35}$ During the late phase of exertional heat stroke, approximately 12-72 hours after the initial collapse, the function of the liver and kidneys begins to deteriorate. ${ }^{35}$

With prompt recognition and treatment of exertional heat stroke, survival rate is 90-100 percent. $^{35,36}$ Treatment includes the prompt cooling of the individual via ice or cold water immersion, continued monitoring of CBT and vital signs, and transport to a hospital for definitive medical care once the patient is sufficiently cooled. ${ }^{8,10,11,35}$

\section{Exertional Heat Exhaustion}

Exertional heat exhaustion is characterized by the inability to continue exercising in the heat ${ }^{8,10,11}$ due to cardiac insufficiency. ${ }^{9}$ It is caused by a fluid-electrolyte imbalance during heat exposure. ${ }^{9}$ Individuals suffering from heat exhaustion may be distinguished from those suffering from exertional heat stroke by a moderately elevated $\mathrm{CBT}^{11}$, absence of central nervous system dysfunction, and normal serum enzyme levels. ${ }^{9}$ They also may exhibit some of the following signs and symptoms: headache, weakness, dizziness, vertigo, heat sensations on the head or neck, nausea, vomiting, increased pulse rate, profuse sweating, syncope, low blood pressure, and mild cognitive impairment. ${ }^{7,11}$ This usually occurs in unacclimatized individuals working at extremely high intensities who lose significant amounts of water and electrolytes via sweat. ${ }^{7}$

Cardiac insufficiency, the cause of exertional heat exhaustion, is due to water and/or salt depletion. Water depletion heat exhaustion is caused by water loss that is not 
adequately replaced. ${ }^{9}$ Initially, this may be recognized by dry mouth, thirst, decreased urine volume, vague discomfort, anorexia, rapid pulse, impatience, weariness, sleepiness, and dizziness followed by tingling, dyspnea, cyanosis, and physical exhaustion. ${ }^{9}$ If severe dehydration is present, cognitive function, coordination, and the ability to stand may become impaired. ${ }^{9}$ Symptoms of water depletion heat exhaustion may be apparent within a few hours of exercise. ${ }^{9}$ Salt depletion heat exhaustion, however, requires three to five days before symptoms become apparent. ${ }^{9}$ This is typically caused by a low intake of dietary sodium or a large loss of sodium. ${ }^{9}$ Three progressive stages of salt depletion heat exhaustion exist, characterized by fatigue, followed by pallor, nausea, muscle cramps, and vomiting, and finally collapse, hypotension, and possible shock. ${ }^{9}$

Appropriate treatment for exertional heat exhaustion includes rehydration ${ }^{11}$ by orally ingesting, if possible, a dilute electrolyte solution $(0.1 \% \mathrm{NaCl}){ }^{9}$ The patient also may be cooled for comfort by moving to the shade, lying supine with the feet elevated, and removing excessive or restrictive clothing, but rapid cooling is not necessary., ${ }^{9}, 11$ Incidence of Exertional Heat Illnesses in Firefighters

Firefighters are often exposed to extremely high temperatures while physically exerting themselves to perform different tasks essential to extinguishing fires. This puts them at risk of increasing their CBT due to physical exertion, the protective clothing worn, and extremely high ambient temperatures. With increased CBT during physical exertion, firefighters have an increased risk of developing an EHI.

The National Fire Protection Association's Fire Analysis and Research Division tracks the injuries, illnesses, and fatalities of firefighters while on the job. Between 2003 and 2006, 2330 injuries were reported due to exhaustion or fatigue, including heat 
exhaustion, as the primary symptom. ${ }^{12}$ Five hundred and fifty of those injuries were considered moderate to severe and potentially life-threatening. ${ }^{12}$ Symptoms of dizziness, fainting, weakness, dehydration, and nausea were also reported in over 1200 cases in the same report. ${ }^{12}$ These symptoms may be indicative of various EHIs, and a portion of these additional complaints may potentially represent undiagnosed heat illnesses. The lack of specific data regarding EHIs experienced by firefighters due to occupational thermal heat stress indicates that further research is necessary to determine the incidence of specific EHIs.

In 2008 , one fatality due to heat stroke was reported after a new volunteer firefighter died after participating in training exercises. ${ }^{13}$ This accounts for two percent of the deaths among volunteer firefighters. ${ }^{13}$ Forty-one deaths were reported due to overexertion/stress/related medical issues. ${ }^{13}$ Of those, four were due to stroke and one due to dehydration with an underlying hemoglobinopathy. ${ }^{13}$ The types of strokes suffered were not disclosed. Once again, the lack of detailed data may indicate a death due to an undiagnosed heat stroke. It also demonstrates the need for more data regarding the incidence of EHI in firefighters and perhaps for the education of firefighters and emergency medical services regarding prevention, recognition, and treatment of EHIs.

Prevention

\section{Predisposing Factors to Heat Illness}

The environment in which a firefighter works and the clothing required for protection contribute to the external factors predisposing one to the development of a heat illness. Firefighters are often exposed to extremely high environmental temperatures for prolonged periods of time while performing strenuous physical activity. Rossi et al. 
demonstrated that environmental temperatures typically range from $40-190^{\circ} \mathrm{C}$, with a maximum of $298^{\circ} \mathrm{C}$ during a heat flux, where the firefighters were training in a simulated live fire. ${ }^{1}$ These extreme temperatures put firefighters at an increased risk of developing an EHI as these temperatures exceed skin temperature. ${ }^{11,37}$ Once the environmental temperature exceeds the temperature of the skin, the body is unable to release heat via convection and radiation and is forced to rely mostly on evaporation. Humidity is often very high when extinguishing a fire since the black smoke turns to a white mist. ${ }^{1}$ Increased humidity reduces the body's ability to release heat via evaporation, increasing the amount of heat stored in the body and thus increasing the risk of developing an EHI.

Radiant heat from the fire and reduced air motion due to the firefighters' protective clothing also contributes to this risk. ${ }^{11,37}$ The protective clothing worn by firefighters also greatly reduces the amount of heat the body may lose by evaporation. ${ }^{11 \text {, }}$ ${ }^{30,37}$ With high environmental temperatures, high humidity, and protective clothing, the body's means of releasing heat are compromised, increasing the firefighters' risk of developing an EHI. Additionally, Armstrong et al. showed losses of sodium and calcium greater than the recommended daily intake in soldiers wearing uniforms for six hours. ${ }^{38}$ Firefighters may be wearing similar types of uniforms while fighting fires and may also be at risk for loss of electrolytes, increasing their risk of EHI.

In addition to environmental factors predisposing firefighters to heat illness, many internal, or inherent, factors have the potential to do the same. Dehydration is a major inherent factor that may predispose a firefighter to developing an EHI. ${ }^{11,37}$ The Orange County Fire Association assessed the hydration status via urine specific gravity of 101 of its firefighters in early August and reported that many were dehydrated before beginning 
drills. ${ }^{32}$ Urine specific gravities of 1.020 to 1.030 were found in $22 \%$ of the firefighters and specific gravities greater than 1.030 were found in $4 \% .{ }^{32}$ Considering that while firefighters are working, they may lose fluid via sweat, urine, and respiration and may not have the chance to replace the fluid, it can be dangerous for the firefighters to begin their work in an already dehydrated state. By not replacing those fluids appropriately, various levels of dehydration can occur. ${ }^{11,37}$

The same study noted that firefighters lost various amounts of body weight during firefighting activity. ${ }^{32}$ Drills during the study included 15 minutes of working in a live, simulated structural fire with persons trapped followed by another 15 minutes of workrelated movements such as stair climbing and overhaul without their self-contained breathing apparatus (SCBA). Following this activity, 53\% of firefighters lost 2-3\% of their body weight and $5 \%$ lost over $3 \%$ of their body weight. ${ }^{32}$ Once a firefighter becomes dehydrated, performance and normal abilities of the thermoregulatory system suffer $^{7,37}$, which increases heat storage and reduces time to exhaustion. ${ }^{10}$ Body weight water loss of $6-10 \%$ also can reduce one's tolerance of physical activity. ${ }^{10}$

Judelson et al. demonstrated that physical performance after completing six sets of back squats is reduced in 2.5 and $5 \%$ body water weight lost dehydrated individuals. ${ }^{39}$ This physical activity may relate to firefighters' tasks since they also regularly perform repeated, intermittent resistance exercise. Therefore, firefighters should always begin activity in a euhydrated state and replace lost fluids during rest periods. By failing to stay hydrated, firefighters may therefore increase their risk of developing an EHI. Given the health and performance consequences of dehydration, firefighters should give attention to their hydration status to help reduce the risk of EHI. 
Having a high body mass index, especially one above $22 \mathrm{~kg} / \mathrm{m}^{237}$, also increases the risk of developing an EHI. ${ }^{11,37}$ With a greater fat layer surrounding the body, less heat can be lost by the body, putting individuals at a greater risk of EHI. ${ }^{11,37}$ Additionally, those who are obese produce greater metabolic heat and are less efficient at dissipating heat. ${ }^{11,37}$ It is also important to be aware that despite the influence of body fat on predisposition to EHI, those who are muscular and carry a large lean body mass will produce greater metabolic heat. ${ }^{37}$ In addition, those with a lower surface area to body mass ratio will have a decreased ability to dissipate the heat generated. ${ }^{37}$ Increased metabolic heat production and decreased ability to dissipate heat cause one to developing an EHI.

Physical fitness plays a role in the prevention of EHIs as well. ${ }^{11,37}$ Those who have poor physical fitness ${ }^{10,11,37}$ or are untrained have a greater risk of EHI. ${ }^{37}$ Individuals practicing with a team can often overexert themselves to keep up, which may lead to higher CBTs, increasing the risk of EHI. ${ }^{37}$ Overzealousness also can predispose one to developing and EHI. ${ }^{11,37}$ One who is highly motivated to complete a task, keep up with teammates, or as in the case of a firefighter, rescue a victim from a burning building, may push his/her body beyond its physiological capabilities, increasing the risk of EHI. ${ }^{37}$

Acclimatization to the heat and performing in hot temperatures can reduce the risk of developing an EHI. ${ }^{10,37}$ Individuals who are less physically fit take longer to develop the adaptations to performing in a hot environment. ${ }^{37}$ Without these adaptations, physiological strain while working in a hot environment will be increased, performance will suffer, and the risk of developing an EHI will be increased. ${ }^{37}$ 
Many other factors such as recent illness, previous EHI, certain medicines (antihistamines and diuretics ${ }^{11,37}$ ), poor nutrition, electrolyte imbalance ${ }^{37}$, and poor sleep duration and quality ${ }^{7,37}$ also increase one's risk of developing a heat related illness. Safety Protocols

Firefighters are repeatedly exposed to extreme temperatures and heat fluxes while performing the physical demands required of their job. With safety of the emergency personnel a priority, many reports have evaluated the conditions under which firefighters work and from that, many standards and guidelines have been developed with the safety of the firefighters in mind. ${ }^{15-19,40,41}$ However, although these guidelines exist, fire departments are not required to follow the standards, and they serve as only a suggestion.

The International Association of Fire Fighters (IAFF), an entity of the United States Fire Administration (USFA) and the Federal Emergency Management Agency (FEMA), has created one such safety protocol to focus on prevention of EHI. The IAFF produces the Emergency Incident Rehabilitation manual to address the management of heat stress in firefighters while working. ${ }^{40}$ The recommendations found in this manual are based largely on the National Fire Protection Associations Standards 1582, 1583, and 1584. NFPA 1584 is the Standard on the Rehabilitation Process for Members During Emergency Operations and Training Exercises. ${ }^{16}$ Within this standard, the NFPA states that standard operating guidelines for firefighter rehabilitation during incidents and training activities should be developed by fire departments. Methods of firefighter rehabilitation should include at least the following: relief, rest, and recovery; active and/or passive cooling; rehydration; calorie and electrolyte replacement; medical monitoring; EMS treatment based on local protocol; member accountability; and release. 
The NFPA recommends that firefighters be educated on heat stress and follow the standards for fitness program. These standards also state that firefighters should maintain appropriate hydration, nutrition, and diet at all times to allow the body to function normally. If firefighters are aware of a scheduled event, such as a training session, they should drink 16 ounces of fluid two hours before the scheduled event.

When an emergency incident or training activity has the potential to become a health or safety risk to firefighters, the set-up of a rehabilitation area is indicated. It should be set up in the shade, provide a place to sit, and be distanced enough from the scene to allow for protective equipment to be removed safely. Fluids should always be available, as well as food and electrolyte solutions if indicated by the activity. An area for medical monitoring and treatments should be created as well as access to quick and convenient transport of an ill or injured firefighter to a hospital for definitive care. Emergency medical services retain the authority to oversee the rehabilitation, removal from activity, and transport of ill or injured firefighters. ${ }^{16}$

The NFPA suggests that firefighters undergo rehabilitation after the use of a second 30-minute SCBA cylinder, one 45-minute or 60-minute cylinder, or after 40 minutes of intense work without SCBA. The first rehabilitation period must be at least ten minutes but should be longer, if possible. ${ }^{16}$ The standards, however, represent the minimums for rehabilitation. Ideally, the NFPA recommends relief from duty or rehabilitation following the use of one 30-minute SCBA cylinder or 20 minutes of intense work without SCBA.

The IAFF's Thermal Heat Stress Protocol recommends that 30-minutes rest/rehabilitation periods should follow each 30 minutes of work. ${ }^{18}$ During rehabilitation, 
the NFPA suggests that firefighters remove protective gear, drink fluids to satisfy thirst, and use cooling when they feel warm or hot. During incidents longer than three hours or when working for more than one hour, firefighters should also replace calories and electrolytes. $^{16}$

Minimally, basic life support emergency medical services should be available and be cognizant of firefighters complaining of chest pain, dizziness, shortness of breath, weakness, nausea, headache, cramps, aches, pains, heat/cold stress, change in gain, speech, or behavior, are not alert and oriented to person, time, place, and thing, or abnormal vital signs as established by local protocol. ${ }^{16}$ Following rehabilitation, firefighters should not return to activity if they do not feel rested, display medical, psychological, or emotional distress, or display some other action indicating that their return to the incident would be unsafe. ${ }^{16}$

The IAFF also produces the Thermal Stress Protocol, which urges firefighters to maintain an appropriate hydration status and wear cotton garments underneath their protective clothing to aid cooling. It recommends that firefighters work in cycles of 30 minutes of work followed by 30 minutes of rest to recover for the next work cycle. Before re-entering the structure, firefighters should have their HR, blood pressure, and CBT evaluated; however, the protocol does not indicate that this temperature should be obtained rectally. If a firefighter's HR exceeds $75 \%$ of his or her age-adjusted maximum, he or she should reduce the next work cycle by one-third. During rest periods, firefighters should relax and rehydrate by drinking cool fluids, at least 8 ounces every 15 minutes. If the apparent temperature exceeds $32^{\circ} \mathrm{C}$, as indicated by the Steadman Apparent Temperature Index, training activities should be monitored closely. Activity should be 
modified or suspended when the apparent temperature exceeds $40^{\circ} \mathrm{C}$, taking into account an additional $2^{\circ} \mathrm{C}$ above the air temperature for exposure to direct sunlight or for wearing protective clothing. ${ }^{18}$

The Occupational Safety and Health Administration (OSHA) created the OSHA Technical Manual with a section on dealing with heat stress. This section educates on EHI and the various effects thermal stress can have on one's health as well as guidelines for work practices in the heat. ${ }^{19}$ OSHA suggests assessing work-load to use in combination with wet-bulb globe temperature adjusted by clothing type to determine work/rest ratios per hour. Assuming firefighter work would fall under moderate and heavy workload categories, continuous work can be performed below 26.7 and $25^{\circ} \mathrm{C}$, respectively. At higher temperatures, work/rest ratios evolve to $75 \%$ work to $25 \%$ rest, $50 \%$ work to $50 \%$ rest, and $25 \%$ work to $75 \%$ rest each hour. Additionally, the manual encourages proper heat acclimatization for those in warm climates by exposing the worker to hot temperatures for progressively longer periods of time beginning at $50 \%$ exposure and increasing daily by $10 \%$. Appropriate fluid replacement with cool liquids (except alcoholic beverages) at $50-60^{\circ} \mathrm{F}$ by drinking one cup every 20 minutes is suggested. Engineering controls such as general ventilation, air conditioning, local aircooling with blowers or fans, or shields also may alleviate some heat stress. Good work practices that include education of all workers on heat stress and its management with particular focus on warning signs, treatment, prevention, risk factors, use of protective equipment, and participation in medical surveillance programs.

OSHA also advocates the use of worker monitoring programs by encouraging workers to check their HR, recovery HR, oral temperature, and body mass loss. 
Unfortunately, oral temperature is not a valid means of assessing CBT in the heat, and should not be relied on as an accurate measure of CBT. Rectal or GI temperature should be used to determine CBT. However, their suggestion to reduce the next work cycle by one-third with a temperature greater than $37.6^{\circ} \mathrm{C}$ may be conservative enough to benefit a working firefighter. OSHA also suggests reducing the following work cycle by one-third if the HR exceeds $110 \mathrm{bpm}$ at the beginning of the rest period. Additionally, recovery HR should be monitored at 30 seconds and 2.5 minutes into the rest period. If the difference in HR between those times is ten or greater, satisfactory or better recovery is being achieved. Also, body mass loss should be monitored at the start and finish of the workday. Losses exceeding $1.5 \%$ total body weight indicate increased fluid intake. Administrative controls are also recommended for the health and safety of workers performing in the heat. OSHA suggests reducing physical demands of work, providing rehabilitation and recovery, working during the coolest parts of the day, allowing rest periods and water breaks, using relief workers and worker pacing, and increasing or decreasing the number of workers according to the space available on the job. Some of these controls, however, are difficult to apply to firefighters. The most beneficial to firefighters may be providing rest and recovery, water breaks, and using relief workers. The use of auxiliary body cooling devices may also relieve some heat stress in firefighters. OSHA specifically mentions the use of ice vests, wetted clothing, water-cooled garments, and circulating air. Many other cooling devices may be practical for use by firefighters, including fans, misting, forearm and hand immersion, and the focus of this study, head cooling. 
OSHA created National Institute for Occupational Safety and Health (NIOSH) located within the Centers for Disease Control and Prevention (CDC) under the United States Department of Health and Human Services. NIOSH is not a regulatory agency, but functions to provide research, education, and training to encourage safe working environments. NIOSH Publication No. 86-112 discusses working in hot environments, but does not address firefighting specifically. This publication focuses on education of the body's physiology when exposed to heat, potential health threats including heat illnesses, and how to prepare for the heat and prevent illness. In preparing for a job in the heat, they suggest acclimatizing over five to seven days. This may be a prominent factor for firefights extinguishing fires in hot environmental temperatures in addition to the heat produced by the fire. To reduce thermal stress, the NIOSH recommends reducing the number or durations of exposure to heat, using fans and ventilation when possible, and providing rest and fluids for rehydration. ${ }^{17}$

Beyond what government organizations have produced to address the safety of those working in hot environments, two researchers for the Toronto Fire Service produced a report and review article regarding the management of heat stress, specifically in firefighters. ${ }^{15,41}$ Studies they conducted led to the development of recommendations for establishing safe work limits and reducing heat stress. This compilation of research demonstrated that exercise tolerance time depended on workload and environmental conditions. ${ }^{15}$ This led to the development of the Heat Stress Wheel, which combines the environmental temperature with relative humidity to categorize heat stress and serve as a guide by which to modify activity appropriately. Their studies have also shown that passive cooling results in a continued rise in CBT during rest periods. ${ }^{15}$ Additionally, it 
was concluded that wearing shorts under protective equipment rather than pants increased exercise tolerance time when greater than 60 minutes and showed significantly reduced time loss due to heat exhaustion when shorts were worn. ${ }^{15}$ Appropriate hydration allowed tolerance of a higher rectal temperature during exercise, and forearm and hand submersion during rest periods provided the most efficient cooling, allowing increased exercise tolerance time, compared to passive cooling and the mister. ${ }^{15}$ Therefore, particular attention should be paid to the environmental temperature and relative humidity to modify work practices. Firefighters should also be encouraged to wear shorts under protective equipment and maintain an appropriate hydration status during and postincident. During rest periods, hand and forearm cooling is an effective means of active cooling to help rehabilitate firefighters.

\section{Cooling}

\section{Treatment Cooling}

Cold-water immersion is currently considered the standard treatment for exertional heat stroke. ${ }^{36,42,43}$ This treatment of exertional heat stroke is supported by both the National Athletic Trainers' Association ${ }^{11}$ and the American College of Sports Medicine. ${ }^{10}$ Research has suggested that the severity of exertional heat stroke is reduced if the amount of time the body's core temperature remains above $40^{\circ} \mathrm{C}$ is reduced. ${ }^{42}$ With the use of cold water immersion, $\mathrm{CBT}$ can be reduced below $40^{\circ} \mathrm{C}$ very quickly; therefore, the amount of organ damage sustained due to the elevated CBT is reduced. ${ }^{43}$

\section{Preventative Cooling}

Based on this treatment, many different methods of cooling have been developed and explored to help facilitate the attenuation of the rise of CBT in active individuals, 
especially during exercise in the heat. These cooling methods have been explored for the purpose of both performance and prevention of EHI by cooling the body or specific parts of the body before activity, during activity, during rest pauses between bouts of exercise, and as treatment for an existing EHI.

\section{Precooling}

Cooling the body prior to exercise for the purpose of enhancing performance has been explored. ${ }^{44-46}$ Arngrimsson et al. demonstrated that runners who wore ice vests during a 38 minute warm up attenuated the rise in body and skin temperature, $\mathrm{HR}$, and their perception of thermal discomfort at the beginning of a five kilometer race. ${ }^{44}$ Those who precooled with ice vests ran the race in a statistically significant lower time and at a faster pace, most evident in the last two-thirds of the race. ${ }^{44}$ Lee et al. pre-cooled participants by resting in thermoneutral or cold $\left(5^{\circ} \mathrm{C}\right)$ air. Both groups of participants then rested in room temperature air before running to exhaustion in thermoneutral conditions. Participants who were precooled demonstrated a greater time to exhaustion than those who were not. Rectal temperature in precooled subjects was significantly lower for 25 minutes of running. ${ }^{45}$ In a study by White et al, participants were cooled by either lower body or whole body immersion in $20^{\circ} \mathrm{C}$ water prior to cycling 30 minutes at $60 \% \mathrm{VO}_{2 \max }$. Those who underwent whole body immersion precooling had significantly lower rectal temperatures for the first 24 minutes of cycling. ${ }^{47}$

Although some studies have shown enhanced exercise performance with precooling, Bolster et al. explored the effects of precooling on attenuation of physiological variables and performance in swimming followed by biking, similar to the 
format of a triathlon. This study, however, found no significant effects on physiological or subjective variables, offering no performance advantage in this scenario. ${ }^{46}$

\section{Cooling between Bouts of Activity}

Cooling between bouts of physical activity has also been researched. ${ }^{48}$ Yeargin et al. had participants run for 90 minutes. Then, they were treated with cold water, ice water, and no water immersion over three separate trials. Following each immersion, they ran a two-mile race. Cold and ice water immersion of participants resulted in significantly lower rectal temperatures at the end of the two mile race and improved performance during the race. ${ }^{48}$ This decrease in rectal temperatures allows the body to maintain a lower rectal temperature for a longer period of time before reaching a critical level .

Cooling between bouts of exercise has also been explored in firefighters specifically. ${ }^{21}$ Firefighters completed two cycles of 10 minutes of work followed by ten minutes of rest. During rest, subjects either unbuckled their coat or removed it and rested in front of a fan. In those who rested with the fan, HR reached baseline in less time and was not as high as the control group in the second set. Rectal temperature and arm, chest, and thigh skin temperatures were also reduced in the fan group. Participants resting with a fan also lost significantly less fluid compared to the control group. ${ }^{21}$

\section{Cooling during Activity}

Vests fitted with ice packs or special cooling materials have been explored regarding attenuation of rise in CBT. Firefighters benefitted from the use of cool vests during activity for the attenuation of CBT and PTS. ${ }^{20,49}$ While wearing a phase change material cool vest and cycling for 30 minutes at 55\% VO2 max, the increase in rectal temperature was attenuated compared to control and ice vest participants. ${ }^{49}$ Additionally, 
the participants in the control condition felt significantly hotter than in the cool vest conditions. ${ }^{49}$ Firefighters also completed two live fire drills while wearing or not wearing cool vests. Those who wore the cool vest had a significantly lower rectal temperature of $38.6 \pm .3^{\circ} \mathrm{C}$, compared to $39.3 \pm .8^{\circ} \mathrm{C}$ in the control group, and significantly lower perceived thermal sensation of $4.4 \pm .9$, versus $5.5 \pm 1.3$ in the control group, after completing each drill. $^{20}$

Cooling of the hands and forearms between bouts of activity has also been successful in attenuating the rise of physiological variables in firefighters. ${ }^{22,23}$ Giesbrecht et al. instructed firefighters to complete 20 minutes of work (stepping) in full firefighter gear followed by 20 minutes of rest, three times. Aural canal temperature by thermal couple to the tympanic membrane was used to determine CBT. Cooling during rest periods consisted of immersing hands in 10 or $20^{\circ} \mathrm{C}$ water, immersing hands and forearms in 10 or $20^{\circ} \mathrm{C}$ water, and the control condition with no accessory cooling. Cooling the hands and forearms in $10^{\circ} \mathrm{C}$ water during rest periods resulted in significantly lower CBTs compared to all conditions after the second and third rest/cooling periods. ${ }^{22}$ Additionally, CBT at the completion of the protocol in this condition was not significantly higher than the baseline temperature, indicating that hand and forearm cooling at $10^{\circ} \mathrm{C}$ is a viable method of attenuating the rise in CBT in firefighters. $^{22}$

In another study by Selkirk et al., firefighters wore all typical firefighting gear and a breathing apparatus in a $35^{\circ} \mathrm{C}$ and $50 \%$ relative humidity environmental chamber while walking on a treadmill at $4.5 \mathrm{~km} / \mathrm{h}$ for 20 minutes. This was followed by walking at a slower pace and standing for 10 minutes to simulate a cylinder exchange, then another 20 
minutes of walking at $4.5 \mathrm{~km} / \mathrm{h}$, and finally a 30 minute rest phase. During the rest phase, firefighters submerged their forearms in approximately $17.4^{\circ} \mathrm{C}$ water. This resulted in significantly greater reductions in rectal temperature compared to passive cooling. ${ }^{23}$

Many studies have investigated the effects of different means of head cooling, some by cooling the head and neck with a "cap" or gel pack inside of a hat and others via a fan and mist with equivocal results. Most have found no significant reduction in rectal temperature. ${ }^{24-26,50}$ Fujii et al. explored the effects of pouring 2 liters of non-refrigerated water over the head and hands. Participants cycled for 20 minutes in a $35^{\circ} \mathrm{C} / 60 \%$ relative humidity environmental chamber then had 15 minutes of rest. At the beginning of the rest period, participants had the water poured over their head while they rubbed their head with both hands. This had no significant effect on reducing rectal temperature or HR. ${ }^{50}$ However, head wash cooling did significantly improve the partcipants' perception of alertness, concentration capacity, equilibrium, and tiredness. ${ }^{50}$

Simmons et al. investigated the effect of head and neck cooling on high core temperature. Subjects were passively heated in a $45^{\circ} \mathrm{C} / 50 \%$ relative humidity environmental chamber until their rectal temperature increased $1^{\circ} \mathrm{C}$. Two trials were performed, one with head cooling via a liquid conditioned balaclava perfused with $8^{\circ} \mathrm{C}$ water and one without cooling. Head cooling in this study significantly attenuated the time for rectal temperature to increase $1{ }^{\circ} \mathrm{C} .{ }^{25}$ During the head cooling condition, the increase of $1^{\circ} \mathrm{C}$ in rectal temperature took $101 \pm 4$ minutes, while no head cooling took only $94 \pm 5$ minutes. ${ }^{25}$ It also significantly improved the perception of thermal comfort. ${ }^{25}$

In another study, Choi et al. studied the effect of head cooling by gel pack inside of a hat during simulated red pepper harvesting in an environmental chamber (WBGT 
$33^{\circ} \mathrm{C}$ ) for two hours. Head cooling in this study showed no significant effect on the attenuation of rectal temperature, HR, or PSI. ${ }^{24}$

Wickwire et al. explore the effects of a gel pack worn inside of a ballistics helmet during light exercise in a $35^{\circ} \mathrm{C} / 38 \%$ relative humidity environmental chamber. Participants walked on a treadmill at $4.8 \mathrm{~km} / \mathrm{h}$ for two hours with 3 minute breaks every 12-15 minutes. During breaks, 10 bicep curls were performed. This study found no significant differences in rectal temperature, HR, RPE, or thermal strain rating. ${ }^{26}$ While many studies found rectal temperature to decrease due to accessory cooling, Ansley et al. found that rectal temperatures during head cooling, by means of a fan and mist of water, tended to be higher compared to no cooling. ${ }^{51}$ In this study, participants cycled at $75 \%$ of their $\mathrm{VO}_{2}$ max until volitional fatigue under conditions of head cooling and no head cooling. Head cooling resulted in a significantly greater time to fatigue and significantly lower RPE based on the Borg scale. ${ }^{51}$

\section{Conclusion}

In conclusion, firefighters store enough heat in their body to raise their CBTs. This, as well as many other factors, puts them at risk of developing an EHI. Due to this risk, studying ways to attenuate the rise in $\mathrm{CBT}$ is necessary to prevent $\mathrm{EHI}$ in firefighters. Therefore, the purpose of this study is to investigate the physiological and perceived effects of head cooling in firefighters during simulated firefighting activity. 


\section{CHAPTER 3}

\section{METHODS}

The study was a randomized, control group design. The independent variable was cooling with two levels: gel pack head cooling and no cooling. The experimental group wore the GelCool gel pack head cooling device while completing simulated firefighting tasks. The control group did not wear the head cooling device while completing simulated firefighting tasks. Dependent variables included physiological responses in HR, GI temperature, PSI score, body mass loss, sweat loss, sweat rate, urine specific gravity, and cognitive function determined by the Stroop Test interference score, and perceptual responses in RPE and PTS.

\section{Participants}

Forty-one career firefighters from the Terre Haute Fire Department in Terre Haute, Indiana volunteered to participate in the study after an informative presentation by the researchers. Twelve firefighters were randomly assigned to an experimental group outside of this study. Two firefighters voluntarily withdrew from the study before data collection. The remaining 26 firefighters $(40 \pm 8 \mathrm{y} ; 168 \pm 7 \mathrm{~cm} ; 91.8 \pm 14.2 \mathrm{~kg} ; 51.8 \pm 7.6$ $\mathrm{ml} / \mathrm{kg} / \mathrm{min}$ ) were randomly assigned to the control and experimental groups of this study. Two firefighters did not complete the second half of the protocol. Six firefighters had unusable data due to the failure of the ingestible thermistor to travel far enough into the 
intestine. Two participants were allowed to participate in the study but were excluded from inclusion in any variables related to heart rate as a result of taking medication for cardiovascular disease.

Participants completed their pre-participation physical required by the fire company for occupational duties and had it on file with the fire department. Participants were in good health; this was demonstrated by his ability to participate in any and all tasks related to the occupation without accommodation or restriction. Participants were excluded if they had work-related accommodations or restrictions. If participants had a cardiovascular disease and/or took beta- blocker medication, they were excluded from data analysis for heart rate related variables. All participants were informed of the experimental protocol, risks and benefits associated with participation, and how the researchers maintain each subject's privacy and confidentiality. The researchers also informed the participants of what was expected of their participation and provided them the opportunity to ask questions. Each participant signed an informed consent form.

$$
\text { Measurements and Instrumentation }
$$

\section{Gastrointestinal Temperature}

The CorTemp Ingestible Core Body Temperature Sensor (HT150002; HQ Inc., Palmetto, FL) measured GI temperature and was displayed on the CorTemp Data Recorder (HT150016; HQ Inc., Palmetto, FL) operated by the researchers. Participants swallowed the ingestible sensor with water approximately five hours before the beginning of data collection. The pill travels through the GI tract without disturbing normal body functions and typically passes within $12-48$ hours, although this time may vary between individuals. The ingestible sensor was activated once it was removed from 
its packaging. Once activated, it began to transmit a signal to the data recorder. GI temperature indicated a participant's core body temperature and was monitored throughout the training protocol for safety purposes.

\section{Heart Rate}

A heart rate strap (T31-non-coded; Polar Electro, New Hyde Park, NY) worn around the participant's chest inferior to the pectoral region measured HR and sent a signal to a watch worn by the researchers that displayed HR. HR indicated how fast the participant's heart was beating throughout the protocol and is useful in measurements of physiological strain due to heat. Additionally, HR was monitored for safety purposes throughout the training protocol.

\section{Physiological Strain Index}

The Physiological Strain Index (PSI) rates physiological strain due to heat on a zero to ten scale; it is calculated based on rectal temperature between 36.5 and $39.5^{\circ} \mathrm{C}$ and HR between 60 and $180 \mathrm{bpm}$. PSI was calculated with the following formula: PSI = $5\left(\mathrm{~T}_{\mathrm{re} t}-\mathrm{T}_{\mathrm{re} 0}\right) \cdot\left(39.5-\mathrm{T}_{\mathrm{re} 0}\right)^{-1}+5\left(\mathrm{HR}_{t}-\mathrm{HR}_{0}\right) \cdot\left(180-\mathrm{HR}_{0}\right)^{-1}$, where $\mathrm{T}_{\mathrm{re} t}$ and $\mathrm{HR}_{t}$ were simultaneous measurements taken at any time during the exposure for rectal temperature and $\mathrm{HR}$, respectively, and $\mathrm{T}_{\mathrm{re} 0}$ and $\mathrm{HR}_{0}$ were the initial measurements of rectal temperature and HR, respectively. A PSI score of 0 represents no/little heat strain, while 10 represents very high heat strain. ${ }^{52}$

\section{Body Mass Loss}

Body mass (BM) was measured by a scale (BWB-800; Tanita, Arlington Heights, IL) before and after the experimental protocol. Body mass loss (BML) due to the training protocol was calculated with the following formula: $\operatorname{BML}(\%)=\left[\left(\mathrm{BM}_{0}-\mathrm{BM}_{f}\right) \cdot \mathrm{BM}_{0}^{-1}\right] \bullet$ 
100, where $\mathrm{BM}_{0}$ was the initial body mass and $\mathrm{BM}_{f}$ was the final body mass following the experimental protocol. ${ }^{53}$ To measure BM, participants stepped on the scale wearing only shorts. The researchers recorded the BM in kilograms. Body mass loss was calculated to determine hydration status and for safety purposes. Losses of even one to two percent can negatively impact physiological function and performance, while a loss of more than three percent of body mass also increases the risk of developing an EHI. ${ }^{53}$ Sweat Loss

The researchers calculated sweat loss for each participant to determine the amount of sweat lost due to the experimental protocol by considering the pre- and post-exercise body mass, the amount of fluid consumed in milliliters, and the amount of urine output in milliliters. It was calculated with the following formula: $\mathrm{SL}=\left(\mathrm{BM}_{0}-\mathrm{BM}_{t}\right)+$ fluid intake - urine output. Sweat loss was calculated to determine hydration status.

\section{Sweat Rate}

The researchers calculated sweat rate for each participant to determine the rate at which they lost sweat during the experimental protocol based on the same formula as sweat loss with a time component in hours. It was calculated with the following formula: $\mathrm{SR}=\left[\left(\mathrm{BM}_{0}-\mathrm{BM}_{t}\right)+\right.$ fluid intake - urine output $] /$ time. ${ }^{53}$ Sweat rate was calculated for descriptive purposes and to provide personal data to each participant.

\section{Urine Specific Gravity}

A refractometer (Model A300CL; ATAGO Inc., Bellevue, WA) measured the density of the particles in the urine compared to pure water; this is an indication of hydration status and was measured for safety purposes. ${ }^{53}$ A refractometer was chosen to assess hydration status because it is less subjective than referring to a urine color chart. 
Urine specific gravity (USG) greater than 1.020 were considered dehydrated, while those equal to or less than 1.020 were considered hydrated. ${ }^{11,53}$

\section{Rating of Perceived Exertion}

A numbered scale from six to 20 served as an index of how easy or difficult one

perceived their work. ${ }^{54}$ The researchers showed the participants a visual representation of this numbered scale with descriptions and asked participants to rate their level of perceived exertion based on how hard they felt they were working; the researchers recorded this number.

\section{Perceived Thermal Strain}

Perceived thermal strain was measured on a scale of zero to eight, ranging from unbearably cold to unbearably hot, respectively. ${ }^{55}$ The researchers showed the participants a visual representation of the numbered scale with descriptions and asked the participants to describe their thermal perception in number based on the corresponding written descriptions. The researchers recorded this number.

\section{Cognitive Function- Stroop Test}

The Stroop test is a paper test in which cognitive flexibility is assessed. This test was chosen to evaluate how well a firefighter can concentrate on a given task with interference. In this test, there were three parts, each lasting 45 seconds. Participants saw a series of color words written in black ink. They read the name of the color aloud, and the researchers recorded the number of words read. They then saw a series of XXXX's printed in different colors. Participants named the color in which the symbol was printed aloud, and the researchers recorded the number of colors stated in 45 seconds. These first two sections of the test served as baseline measurements. Then, the participants were saw 
a series of words written in a conflicting ink color and were asked to say aloud the color ink in which the word was printed and instructed not to read the word written. The researchers recorded the number of colors stated in 45 seconds. This demonstrated the participants' ability to overcome the interference of the desire to read the written word and say only the color in which the word is printed. The number of words read in the incongruent color condition (conflicting colors) was subtracted from the congruent color condition (colored XXXX's). A lower score represents better performance and thus greater ability to resist the interference, whereas a higher score indicates a lesser ability to resist the interference. ${ }^{56}$ This score was recorded to describe cognitive flexibility and demonstrate how well the firefighters' brain functioned with respect to an interference task throughout the training protocol.

\section{Procedures}

\section{Day One}

Participants arrived at the firehouse. The researchers briefed the participants on the schedule for the day and the study. The researchers informed the participants that the purpose of this study was to assess the effectiveness of an auxiliary head cooling device worn inside the helmet, intended for use by firefighters during activity. Researchers informed the participants of the measures and means of instrumentation and the experimental protocol they were expected to complete as a participant of the study. Researchers also informed participants that they may withdraw from the study at any time and that their participation in the study is completely voluntary. The researchers allowed the participants to ask any questions they had about the study or their participation in the study. After all of their questions were answered, those who chose to 
participate completed a health history questionnaire, a current health questionnaire, and the informed consent document. After the appropriate paperwork was completed, the participants completed the Queens College Step test to estimate oxygen consumption. ${ }^{57}$ Day Two

The researchers arrived at the fire stations five hours prior to the training session to meet the participants. At this time, the participants completed a current health questionnaire, which was reviewed by the researchers. If the participant was found to be in good current health, the researchers activated the ingestible temperature sensor, and the participants swallowed the capsule. At their scheduled time, participants arrived at the testing facility. Upon arrival, the researchers made sure the pill was functional by taking a baseline reading. Participants picked whether they would be in the experimental or control group by blindly picking a marked ping-pong ball out of a box as well as a marked ping-pong ball to determine at which drill they would begin the training protocol. Participants then provided a urine sample in order to assess urine specific gravity. Participants stepped on a scale wearing only shorts, and the researchers recorded pretraining session body mass. Participants adorned the HR monitor with help from the researchers. Researchers made sure the HR strap was functional and reporting data to the watch and recorded the heart rate.

After obtaining these baseline measurements, participants adorned their trousers and jackets. The baseline Stroop test was administered by the researchers and baseline RPE and PTS were recorded. Following this, the firefighters adorned their remaining gear including hoods, gloves, helmets, and self-contained breathing apparatus $(23.3 \pm 1.4 \mathrm{~kg})$ Those in the experimental group also adorned the head cooling gel pack by removing it 
from the freezer and securing it in the top of the helmet. The researchers recorded GI temperature and HR, and the participants began the experimental protocol. Participants completed four drills determined by the Training Officer for 15 minutes. The participants' starting points in the drill sequence was chosen at random. The drills included an obstacle course, a high-rise drill, a search and rescue drill, and vehicle extrication. During the obstacle course, the firefighters crawled by following a hose on the ground over and through props and by carrying Rescue Randy. During the high-rise drill, the firefighters carried an appliance kit or a hose up four flights of stairs to the top of the training structure. They touched the pipe on that floor and then returned to the bottom floor. The tower was filled with smoke during this drill. The search and rescue consisted of the firefighters following a hose through a smoke-filled 2-story residence and crawling through props and up and down steps. During the vehicle extrication drill, the firefighters cut apart vehicles as they would in an emergency to extricate a victim.

During the 15-minute drills, the researchers recorded GI temperature and HR every three minutes. Following the drill, the participants exited the training facility or drill area, and the researchers recorded the GI temperature, HR, RPE, PTS, and Stroop test (part three) score for each participant. Participants replaced their air cylinder, and in the case of the experimental group, also replaced the head cooling gel pack. This exchange lasted 8:31 $\pm 1: 30$. The researchers recorded the GI temperature and HR before the participants re-entered the structure or drill area to complete drills for another 15 minutes. During this time, the researchers recorded each participant's GI temperature and HR at three-minute intervals. Following the 15 minutes of work, the participants exited the training structure and drill areas. Researchers recorded GI temperature, HR, RPE, 
PTS, and Stroop test score. The participants removed their helmet, hood, SCBA, gloves, and jacket and lowered their trousers to rest in the rehab facility (a shaded area with picnic benches) for 15 minutes while drinking water ad libitum. Researchers continued to record GI temperature and $\mathrm{HR}$ at three-minute intervals during the rest period. Each participant had his own water bottle to drink from so that the volume of fluid consumed could be recorded. Nearing the end of the 15-minute rest, the researchers recorded the participants' GI temperature, HR, RPE, PTS, and Stroop test score. The participants redressed and re-entered the structure and drill areas to complete a second cycle of working for 15 minutes, exchanging cylinders, working for another 15 minutes, and resting for 15 minutes. At the end of the second rest period, the researchers recorded the participants' GI temperature, HR, RPE, PTS, and Stroop test score. The entire training protocol lasted 1:57:47 $\pm 0: 19$. Participants then provided a second urine sample and stepped on a scale wearing only shorts for the researchers to record post-training body mass.

Statistical Analysis

Descriptive statistics were calculated for each variable. Independent samples $\mathrm{t}$ tests compared groups by demographics and hydration status. A repeated measures oneway analysis of variance (ANOVA) analyzed group (HC vs. CON) by time (baseline [BSLN], end drill one [D1], end drill two [D2], end rehab one [R1], end drill three [D3], end drill four [D4], end rehab two [R2]) for $\mathrm{T}_{\mathrm{GI}}, \mathrm{HR}$, SIS, RPE, and PTS. When sphericity was not assumed, a Huynh-Feldt adjustment was used. If interactions were deemed significant by the ANOVA, paired t-tests were used for post-hoc analyses. A correlation analyzed the relationship between $\mathrm{T}_{\mathrm{GI}}$ and PTS. Significance was set a priori at $\mathrm{p}<0.05$. 


\section{CHAPTER 4}

\section{MANUSCRIPT}

Physiological and perceived effects of head cooling during simulated firefighting activity Introduction

Firefighters must tolerate a variety of physiological stressors while on the job. They must repeatedly enter burning buildings with temperatures as high as $278^{\circ} \mathrm{C}^{1}$ and sustain long periods of physical exertion ${ }^{2,3}$. Further, they must complete this task while wearing heavy protective clothing and a self-contained breathing apparatus (SCBA). The combination of reduced body surface area for dissipating heat due to protective clothing ${ }^{4}$, increased ambient temperature, and physical exertion forces firefighters' core body temperatures (CBT) to increase. ${ }^{5-8}$ As firefighters work to extinguish a fire, heart rate (HR) also increases ${ }^{2,3,5,9}$ resulting in increased physiological strain. ${ }^{10}$ As physiological strain rises, firefighters also perceive that they feel hotter and as though they are working $\operatorname{harder}^{3}$

As the body stores heat, CBT continues to rise, which increases the risk of developing an exertional heat illness (EHI). ${ }^{11-15}$ In addition to elevated CBT, the ambient temperature, humidity, intensity of work, length of exposure, protective equipment, hydration status, illness, and lack of sleep may also contribute to the development of an EHI. ${ }^{12-15}$ Exertional heat illnesses ${ }^{16-18}$ and fatalities resulting from EHI ${ }^{17,18}$ are often 
reported in firefighters on the job. In order to protect firefighters from adverse events, including EHI, several safety procedures exist. ${ }^{19-23}$ Accessory cooling devices and

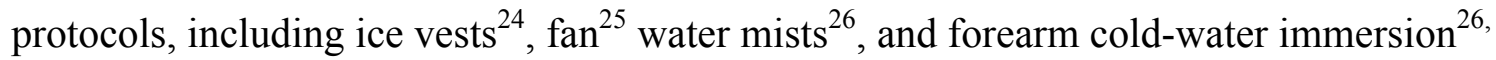

${ }^{27}$ have also been investigated as a means of protecting firefighters from a dangerous rise in CBT.

Head cooling is one method that has been studied in various settings and at different levels of activity ${ }^{28-31}$, but never in firefighters with their unique physical demands. It is unknown whether head cooling in firefighters attenuates the rise in core body temperature. Therefore, the purpose of this study was to investigate the physiological and perceived effects of head cooling in firefighters during simulated firefighting activity.

\section{Methods}

The study was a randomized control group design exploring the effects of head cooling $(\mathrm{HC})$ versus no head cooling $(\mathrm{CON})$ in firefighters during drills. Physiological variables included gastrointestinal temperature $\left(\mathrm{T}_{\mathrm{GI}}\right), \mathrm{HR}$, Physiological Strain Index score (PSI), hydration status, and Stroop test interference score (SIS). Perceptual measures were also recorded and analyzed and included rating of perceived exertion (RPE) and perceived thermal sensation (PTS).

\section{Participants}

Twenty-six career firefighters (male, $40 \pm 8 \mathrm{y}, 168 \pm 7 \mathrm{~cm}, 91.8 \pm 14.2 \mathrm{~kg}$, $51.81 \pm 7.61 \mathrm{ml} / \mathrm{kg} / \mathrm{min}$ ) volunteered to participate in the study. At times throughout the protocol, not all participants were included in data analyses $(n=10)$ as two were unable to complete the entire training protocol, six had unusable temperature data due to failure of 
the ingestible thermistor to travel far enough into the intestine, and two took a medicine that altered HR. All participants had a medical physical on file with the fire department indicating that they were fit for work and medically cleared to use a SCBA without accommodation or restriction. Having a scheduled MRI, a gastrointestinal illness or pathology, and/or trouble swallowing large pills were considered contraindications to ingesting the thermistors; those with contraindications to the ingestible thermistor were excluded from participation. All participants were informed of the experimental protocol and expectations of participants, risks and benefits associated with participation, and how the researchers maintain participant privacy and confidentiality. After the participants had all of their questions answered, each participant signed an informed consent form. The university's Institutional Review Board approved the experimental protocol.

\section{Instrumentation}

\section{Environmental Conditions and Demographics}

The wet bulb globe temperature (Metrosonics HS-32 area heat stress monitor; Quest Technologies, Oconomowoc, WI) was measured at least once each hour so that any differences between shifts and days could be detected. Self-reported age was recorded; height was measured using a standard tape measure fixed to a wall. Aerobic capacity was estimated using the Queen's College Step Test. ${ }^{32}$

\section{Hydration Status}

Hydration status was represented by urine specific gravity (USG), percent dehydration, and sweat loss. Each firefighter's pre-training and post-training USG was read using a handheld clinical refractometer (A300CL; ATAGO Inc., Bellevue, WA) to determine hydration status. Also, pre-training and post-training body masses of each 
firefighter were measured using a scale (BWB-800; Tanita, Arlington Heights, IL) to calculate percent dehydration by body mass loss using the following formula: ((pretraining body mass - post-training body mass) $* 100) .{ }^{33}$ Firefighters were measured wearing only the shorts or pants they would be wearing under their personal protective equipment during the training protocol. Sweat loss was calculated with the following formula: [(pre-training body mass - post-training body mass) + fluid consumed - urine output]. ${ }^{33}$ The volumes of fluid consumed and urine void were also recorded.

\section{Gastrointestinal Temperature and Heart Rate}

Gastrointestinal temperature was measured by the CorTemp ingestible thermistor(HT150002; HQ Inc., Palmetto, FL), which transmitted a signal to a handheld data receiver (HT150016; HQ Inc., Palmetto, FL) that displayed the temperature. Ingestible thermistors were distributed to firefighters after arrival at their station for their shift and were ingested five hours prior to their arrival time at the training facility. Heart rate straps (T31-noncoded; Polar Electro, New Hyde Park, NY) worn by firefighters sent a signal to the watch worn by the researchers and to the handheld data receiver. From the data displayed on the handheld data receiver and watch, researchers recorded $\mathrm{T}_{\mathrm{GI}}$ and $\mathrm{HR}$ at three-minute intervals during the training protocol. Following data collection, PSI scores were calculated with the following formula: $\mathrm{PSI}=5\left(\mathrm{~T}_{\mathrm{GI} t}-\mathrm{T}_{\mathrm{GI} \theta}\right) \cdot\left(39.5-\mathrm{T}_{\mathrm{GI} 0}\right)^{-1}+$ $5\left(\mathrm{HR}_{t}-\mathrm{HR}_{0}\right) \cdot\left(180-\mathrm{HR}_{0}\right)^{-1}$, where $\mathrm{T}_{\mathrm{GI} t}$ and $\mathrm{HR}_{t}$ were simultaneous measurements taken at any time during the exposure for $\mathrm{T}_{\mathrm{GI}}$ and $\mathrm{HR}$, respectively, and $\mathrm{T}_{\mathrm{GI} 0}$ and $\mathrm{HR}_{0}$ were the initial measurements of $\mathrm{T}_{\mathrm{GI}}$ and $\mathrm{HR}$, respectively. A PSI score can range from zero to ten; a score of one represents no/little heat strain, five represents moderate strain, and nine represents very high heat strain. ${ }^{34}$ 


\section{Cognitive Function}

A modified version of the Stroop Color Word Test was administered to firefighters to assess cognitive flexibility. ${ }^{35}$ The test consisted of three sections, each lasting 45 seconds. During the first section, firefighters were shown color words printed in black ink and instructed to read the word they saw. The second section consisted of a series of "XXXX XXXX" printed in various colors. The firefighters were instructed to say aloud the color they saw. During the third section, the firefighters were shown color words printed in a conflicting ink color and were instructed to say aloud the color in which the word was printed and not the word they read. The researchers recorded the number of colors correctly stated in each section. The interference score was calculated by subtracting the number of conflicting colors (section 3) stated from the number of visual colors (section 2) stated. A higher score indicated decreased test performance by stating fewer conflicting colors compared to visual colors, while a lower score indicated improved test performance by stating more conflicting colors.

\section{Perceptual Measures}

Firefighters were shown a visual scale numbered from 6 to 20 with descriptions and indicated the number that represented their rating of perceived exertion ${ }^{36}$ at the conclusion of the station. For PTS, a visual scale numbered from 0 to 8 with descriptions was shown to firefighters, who indicated how hot or cold they felt at the time based on the scale descriptions. ${ }^{37}$

\section{Training Protocol}

The training protocol included four 15-minute firefighting drills, including an obstacle course, high-rise drill, two-story search and rescue drill, and car extrication. 
Firefighters randomly picked their starting point within the drill sequence by choosing a letter out of a box; the letter corresponded to the drill at which they would begin the training protocol. During the outdoor obstacle course, firefighters crawled on their hands and knees while following along a hose on the ground over and through various props and then used an armpit drag to move I.A.F.F. Rescue Randy (Simulaids, Inc., Saugerties, NY). The high-rise drill consisted of the firefighter carrying either a hose or an appliance kit up four flights of stairs to the top of the smoke-filled tower, reaching the pipe where the hose would be attached, and then descending the stairs to the bottom of the tower. At the search and rescue drill, firefighters crawled on their hands and knees through a smoke-filled two-story residence while following a hose, crawling through props, and making their way up and down stairs to simulate a search and rescue. The fourth drill consisted of practicing car extrication skills outdoors in the sun. The firefighters were allowed to self-pace their completion of the drills. If any of the tasks were completed before the 15 minutes, the firefighters repeated the task for the remainder of the time.

Firefighters were randomly assigned to either the control group $(\mathrm{CON})(\mathrm{n}=14)$ or the head cooling group $(\mathrm{HC})(\mathrm{n}=12)$ when they arrived at the training facility. The researchers recorded baseline $\mathrm{T}_{\mathrm{GI}}$ to ensure the ingestible thermistor was functional. Firefighters provided a urine sample and then were weighed; researchers recorded pretraining USG and body mass. With the help of the researchers, firefighters adorned a HR monitor. The researchers ensured the HR strap was functional and recorded the firefighter's HR. Firefighters adorned their steel-toe boots, bunker pants with suspenders, 
and bunker coats. The researchers administered the Stroop Color-Word Test to the firefighters $^{35}$. The researchers also recorded each firefighter's baseline RPE and PTS.

Following this, the firefighters adorned their remaining gear including Nomex hoods, gloves, helmets, Dregar SCBA with mask and a 20-minute 450 psi air bottle $(23.3 \pm 1.4 \mathrm{~kg})$. Those assigned to the HC group inserted a head cooling gel pack (GelCool Model GX gel packs; GelCool Systems, Inc., Nashville, TN) just removed from the freezer into the top of their helmet (Figure 1). The gel pack was circular with various compartments of gel intended to conform to the shape of the head and helmet. One side was microfiber, which was placed against the participant's head per manufacturer instructions. Some firefighters adjusted the straps inside the helmet to accommodate the size of the gel pack, while others placed it directly behind the straps in the dead space of the helmet. Many of the firefighters mentioned that the gel pack made their helmets feel heavier and/or sit higher on their head, decreasing their personal comfort.

The firefighters reported to the station they picked out of a box at random and completed that drill for 15 minutes, during which $\mathrm{HR}$ and $\mathrm{T}_{\mathrm{GI}}$ were recorded every three minutes for a total of six times per drill. Then, the firefighters reported to the "exchange" area where the researchers recorded only the firefighter's RPE, PTS, and conflicting color Stroop test score (section 3). Following data collection, the firefighters exchanged their air tanks for a new, full tank. Firefighters assigned to the HC group also replaced their head cooling gel pack with a fresh one from the freezer. Following the exchange $(8: 31 \pm 1: 30)$, the firefighters completed the next drill in the sequence of drills for 15 minutes. Then they reported to the rehabilitation (rehab) area where firefighters rested for 15 minutes by sitting in the shade, removing their SCBA, helmet, hood, gloves, and 
jacket and lowering their trousers. Firefighters drank water ad libitum. At the beginning and end of rehab, the researchers recorded the firefighter's RPE, PTS, and conflicting color Stroop test score. After rehab, the firefighters redressed and completed the drillexchange-drill-rehab sequence a second time (Figure 2).

\section{Statistical Analysis}

Descriptive statistics were calculated for each variable. Independent samples t tests compared groups by demographics and hydration status. A repeated measures oneway analysis of variance (ANOVA) analyzed group (HC vs. CON) by time (baseline [BSLN], end drill one [D1], end drill two [D2], end rehab one [R1], end drill three [D3], end drill four [D4], end rehab two [R2]) for $\mathrm{T}_{\mathrm{GI}}, \mathrm{HR}$, SIS, RPE, and PTS. When sphericity was not assumed, a Huynh-Feldt adjustment was used. If interactions were deemed significant by the ANOVA, paired t-tests were used for post-hoc analyses. A correlation analyzed the relationship between $\mathrm{T}_{\mathrm{GI}}$ and PTS. Significance was set a priori at $\mathrm{p}<0.05$.

\section{Results}

\section{Participant and Environmental Characteristics}

There were no demographic differences between the $\mathrm{HC}$ and the $\mathrm{CON}$ groups ( $>0.05$ [Table 1]). The wet bulb globe temperatures were $27.7 \pm 1.7^{\circ} \mathrm{C}$ on average. Environmental conditions were hot with an average ambient temperature of $33.1 \pm 1.4^{\circ} \mathrm{C}$ and a relative humidity of $27 \pm 3 \%$. Two training sessions were held each day for three days. The second session on day one was significantly cooler than the second session on day three $\left(\mathrm{F}_{5,13}=3.748, \mathrm{p}<0.05, \mathrm{ES}=.618\right)$. There were no significant differences between 
all other sessions. Average and maximum wet bulb globe temperatures for each day are found in Table 2.

\section{Training Protocol Time}

The entire training protocol took 1:57:47 $\pm 0: 3: 21$. Exchanges between drills lasted 8:40 $\pm 1: 35$. The time to redress after the first rehab and begin the third drill was $7: 15 \pm 1: 33$

\section{Gastrointestinal Temperature}

Firefighters arrived at the training facility with $\mathrm{T}_{\mathrm{GI}}$ of $37.70 \pm .3^{\circ} \mathrm{C}$, ranging from $37.19^{\circ} \mathrm{C}$ to $38.35^{\circ} \mathrm{C}$. There was a significant interaction between group and time for gastrointestinal temperature $\left(\mathrm{F}_{1,6}=2.493, \mathrm{p}<0.05, \mathrm{ES}=.128\right)$. There was a significant main effect for time $\left(\mathrm{F}_{1,6}=39.029, \mathrm{p}<0.05, \mathrm{ES}=.697\right)$ and no main effect for group $\left(\mathrm{F}_{1,6}=0.510\right.$, $\mathrm{p}>0.05,1-\beta=0.104)$. There was a significant increase in $\mathrm{T}_{\mathrm{GI}}$ between baseline and all drills and rehabs $(\mathrm{p}<.05)$ (Figure 3). During the training protocol, firefighters experienced an overall rise in $\mathrm{T}_{\mathrm{GI}}$ of $1.75 \pm .40^{\circ} \mathrm{C}$, ranging from $1.05^{\circ} \mathrm{C}$ to $2.49^{\circ} \mathrm{C}$. Maximum $\mathrm{T}_{\mathrm{GI}}$ ranged from $38.93^{\circ} \mathrm{C}$ to $40.27^{\circ} \mathrm{C}$. Gastrointestinal temperatures rose during drills and declined during rehab. Although $\mathrm{T}_{\mathrm{GI}}$ declined during rehab, it never returned to baseline in the 15 -minute rehab. Gastrointestinal temperature remained $0.93 \pm 0.69^{\circ} \mathrm{C}$ higher than baseline at the end of $\mathrm{R} 1$ and $0.82 \pm 0.46^{\circ} \mathrm{C}$ higher after $\mathrm{R} 2$.

\section{Heart Rate}

There was no significant interaction between group and time for $\operatorname{HR}\left(\mathrm{F}_{1,6}=0.596\right.$, $\mathrm{p}>0.05,1-\beta=0.228)$. However, there was a main effect of time $\left(\mathrm{F}_{1,6}=44.559, \mathrm{p}<0.05\right.$, $\mathrm{ES}=.736)$ At the end of each drill, firefighters had a significantly higher HR compared to 
baseline and rehabs (Figure 4). There was no main effect for group $\left(F_{1,6}=.165, p>0.05,1\right.$ $\beta=.067)$.

Each firefighter's age-adjusted maximal heart rate (MHR) was calculated by subtracting his age from 220 . The firefighters' MHR were $180 \pm 8$ beats per minute (bpm). Maximal HR reached $186 \pm 7 \mathrm{bpm}$ with a range of 172 to $198 \mathrm{bpm}$. Each firefighter reached his MHR at some point during the training protocol. Fifty percent of firefighters worked at a HR greater than their MHR $16 \pm 23 \%$ of the time spent working during the protocol. All firefighters worked at more than $90 \%$ of their MHR $50 \pm 30 \%$ of the time. Physiological Strain Index

Physiological strain index score was calculated for each firefighter at the end of each drill and rehab (Figure 5). There was no interaction between group and time for PSI score $\left(F_{1,5}=1.691, p>0.05,1-\beta=.533\right)$ There was a main effect for time $\left(F_{1,5}=26.699\right.$, $\mathrm{p}<0.05, \mathrm{ES}=.708)$ but not group $\left(\mathrm{F}_{1,5}=.105, \mathrm{p}>0.05,1-\beta=.060\right)$. On average, PSI score increased over consecutive drills and then decreased during rehabs. After D1 and D2, PSI rose from $6.2 \pm 1.4$ to $8.0 \pm 1.2$, then PSI decreased to $4.6 \pm 2.2$ after R1. Following D3 and D4, PSI increased from $6.0 \pm 1.6$ to $7.3 \pm 1.2$. During R2, PSI fell to $3.7 \pm 1.6$. Both rehabs and D2 and D4 were significantly different from all other time points and each other $(\mathrm{p}<0.05)$.

\section{Hydration Status}

There were no differences between groups for hydration status and fluid needs including percent dehydration $\left(\mathrm{t}_{1,24}=-.110, \mathrm{p}>.05\right)$, sweat loss $\left(\mathrm{t}_{1,24}=-1.096, \mathrm{p}>0.05\right)$, sweat rate $\left(\mathrm{t}_{1,24}=-1.096, \mathrm{p}>0.05\right)$, USG pre-training $\left(\mathrm{t}_{1,24}=-.524, \mathrm{p}>0.05\right)$ and posttraining $\left(\mathrm{t}_{1,24}=-1.629, \mathrm{p}>0.05\right)$, and fluid consumed $\left(\mathrm{t}_{1,24}=-.831, \mathrm{p}>0.05\right)$. Firefighters 
weighed $91.2 \pm 13.8 \mathrm{~kg}$ with a USG of $1.015 \pm .006$ (Figure 6) at the beginning of the training protocol. During the protocol, firefighters consumed $1.7 \pm .8 \mathrm{~L}$ of fluid and had a sweat loss of $2.5 \pm .8 \mathrm{~L}$ (Figure 7). At the conclusion of the training protocol, firefighters lost $0.7 \pm .7 \%$ of their body weight (Figure 8) and USG increased to $1.020 \pm .007$.

\section{Cognition}

Three firefighters were color blind and therefore unable to participate in the Stroop Test. There was no interaction between group and time for Stroop test interference scores $\left(\mathrm{F}_{1,6}=1.286, \mathrm{p}>0.05,1-\beta=.481\right)$. There was a main effect for time $\left(\mathrm{F}_{1,6}=6.681\right.$, $\mathrm{p}<.05, \mathrm{ES}=.308)$, but not group $\left(\mathrm{F}_{1,6}=1.193, \mathrm{p}>.05,1-\beta=.176\right)$. Baseline and scores at the end of drill one were significantly different from all others (Figure 9). Firefighters scored $29 \pm 10$ on the baseline interference score. During the training protocol, scores generally decreased, indicating improved cognitive flexibility with an increased number of colors stated. As the training protocol progressed, those in the HC group had higher interference scores than those in the CON group, indicating more interference and fewer colors stated. However, this difference was not statistically significant $(\mathrm{p}>0.05)$.

\section{Perceptual Measures}

There was no interaction between group and time for $\operatorname{RPE}\left(\mathrm{F}_{1,6}=.089, \mathrm{p}>0.05,1\right.$ $\beta=.064)$. There was a main effect for time $\left(\mathrm{F}_{1,6}=48.556, \mathrm{p}<.05, \mathrm{ES}=.719\right)$; there was no main effect for group $\left(\mathrm{F}_{1,6}=.313, \mathrm{p}>0.05,1-\beta=.083\right)$. At the conclusion of each 15 -minute drill, both groups felt they were working somewhat hard to very hard. They also perceived they were working harder after D2 and D4 compared to D1 and D3, respectively (Figure 10). Near the end of the training protocol, the CON group perceived to be working harder than the HC group but this difference was not significant $(\mathrm{p}>0.05)$. 
There was no interaction between groups over time for PTS after each drill and $\operatorname{rehab}\left(\mathrm{F}_{1,6}=1.436, \mathrm{p}>0.05,1-\beta=.531\right)$. There was a main effect of time $\left(\mathrm{F}_{1,6}=37.733\right.$, $\mathrm{p}<0.05, \mathrm{ES}=.729)$ but not group $\left(\mathrm{F}_{1,6}=2.051, \mathrm{p}>0.05,1-\beta=.266\right)$. Throughout the training protocol, the HC group felt cooler than the CON group; however, this difference was not statistically significant $(\mathrm{p}>0.05)$ (Figure 11$)$.

Perceived thermal sensation and gastrointestinal temperature

Only weak to moderate relationships were present between PTS and $\mathrm{T}_{\mathrm{GI}}$ measured at the same time point $(\mathrm{r}=.248, \mathrm{p}>0.05)$. The relationship between PTS and $\mathrm{T}_{\mathrm{GI}}$ was only significant at the end of the third drill, but was only moderately correlated $(\mathrm{r}=.581$, $\mathrm{p}<0.05)$.

\section{Discussion}

While there have been studies that have examined head cooling devices, this was the first study to investigate head cooling during firefighting. The purpose of the study was to determine the physiological and perceived effects of head cooling on firefighters performing simulated firefighting drills. Head cooling was found to be ineffective in reducing $\mathrm{T}_{\mathrm{GI}}, \mathrm{HR}$, PSI, RPE, and PTS. Additionally, USG, percent dehydration, sweat loss, and sweat rate were not affected by the head cooling device.

\section{Gastrointestinal Temperature}

For all firefighters, $\mathrm{T}_{\mathrm{GI}}$ increased between consecutive drills (D1 to $\mathrm{D} 2$, and $\mathrm{D} 3$ to D4) and decreased during rehabs. Firefighter's maximum $\mathrm{T}_{\mathrm{GI}}$ ranged from $38.9-40.3^{\circ} \mathrm{C}$ throughout the training protocol, similar to other studies reporting maximum $\mathrm{T}_{\mathrm{GI}}$ during drill and rehab sequences ranging from 38.4 to $41.1^{\circ} \mathrm{C} .^{5,7,8}$ The head cooling gel pack had no significant effect on $\mathrm{T}_{\mathrm{GI}}$ in firefighters in the current study, while other means of 
cooling, such as torso cooling via ice and phase change material vests and cooling of the hands and forearms via immersion in cold water, have been successful at significantly and practically reducing $\mathrm{T}_{\mathrm{GI}}$ in firefighters using accessory cooling means compared to those who did not. $24,26,27,38$

The inadequate performance of the head cooling device may be explained by the head cooling device's limited ability to stay cool and allow the head to effectively transfer heat. Data in the present study are similar to Wickwire et al, who found that forehead skin temperature and the temperature of a cooling pad inside a helmet equalized within 30 minutes. ${ }^{31}$ Increased temperature gradients between two objects allow for improved heat dissipation. However, the quick temperature equalization of the cooling device and the skin reduced the temperature gradient between the gel pack and the skin, diminishing the ability to dissipate heat. Although the gel pack was replaced with a new one from the freezer before each drill (15 minutes) in the present study, it still had no effect on $\mathrm{T}_{\mathrm{GI}}$. The ability to effectively transfer heat away from the head may also have been limited by the awkward fit inside the helmet reported by many of the firefighters, yielding a decreased surface area of contact between the gel pack and the head. Since the gel pack sat directly on the superior portion of the head, the amount of hair a firefighter possessed may also have limited contact.

Accessory cooling methods, such as ice vests and hand/forearm immersion, which are successful at reducing $\mathrm{T}_{\mathrm{GI}}$, have a greater surface area of contact between the skin and the cooling means compared to the gel pack and the head Additionally, assuming there is some movement of the hands and forearms during submersion in cold water, it allows 
heat transfer via the more efficient means of convection ${ }^{39}$ as opposed to conduction found in the direct contact between the head and the gel pack in the current study.

Both groups reached their peak temperatures in the first half of the training protocol and exhibited greater $\mathrm{T}_{\mathrm{GI}}$ in $\mathrm{D} 1$ and $\mathrm{D} 2$ compared to $\mathrm{D} 3$ and $\mathrm{D} 4$. This may be evidence of reduced self-pacing on the part of the firefighters to lower physiological stress $^{40,41}$ and protect themselves from injury or illness, ${ }^{42}$ since the intensity at which the drills were performed was not specified as part of the training protocol. However, there are situations in which firefighters may not be able to self-pace (i.e. an actual fire call or live-fire drill). In these situations, we may see $\mathrm{T}_{\mathrm{GI}}$ rise to a greater extent than it did in this protocol since the firefighters will not have the option to voluntarily decrease their intensity of work. In this case, the firefighters' lack of effective cooling means while being motivated to work beyond physiological constraints may put firefighters at risk for injury or illness.

\section{Heart Rate}

For all firefighters, HR increased during drills and decreased during rehabs. Throughout the protocol, firefighters worked at up to $104 \pm 5$ percent of their MHR, with HR reaching $183 \pm 10 \mathrm{bpm}$, similar to other drill and rehab sequenced studies. ${ }^{2,3,5}$ Head cooling did not significantly reduce HR. The present study demonstrated that head cooling had no effect on $\mathrm{T}_{\mathrm{GI}}$ and another study reported it to have no influence on plasma volume $^{31}$. Therefore, it is likely the body shunted blood to the periphery in order to allow for a heat transfer to the environment as a means of cooling. This shift in blood flow explains the increase in HR in order to maintain cardiac output. Additionally, with no vasomotor control in the head, the gel pack would not have been able to cause the blood 
vessels in the head to constrict to promote an increase central blood volume and reduce cardiovascular strain. High ambient temperatures may have contributed to the cardiovascular drift observed in these firefighters. ${ }^{43}$ Physical effort and the intensity at which they performed the drills may have also been factors in the increased $\mathrm{HR}$ and $\mathrm{T}_{\mathrm{GI}}$ observed. Slightly higher HR were reached and maintained during D1 and D2 compared to D3 and D4 for both groups. This may be evidence of fatigue and self-pacing on the part of the firefighters in order to protect themselves. As discussed earlier, firefighters are often in situations where they are unable to control the intensity at which their physical work is performed due to a live fire. In this situation, firefighters will be at risk of working beyond physiological limitations without an effective means of reducing HR. Physiological Strain Index

A study by Kalyani et al. investigated the PSI of firefighters wearing firefighting protective clothing and usual work clothing while performing the Bruce exercise protocol. Physiological strain index scores recorded were $6.15 \pm 1.12 .{ }^{44}$ During the drills performed in the present study, PSI scores were $7 \pm 1$ among firefighters, indicating moderate to high physiological strain, representing increased $\mathrm{HR}$ and $\mathrm{T}_{\mathrm{GI}}$.

Reliable data regarding PSI among firefighters are limited in the literature. Physiological strain index scores in the study by Kalyani et al. were calculated using core body temperatures obtained with a tympanic membrane measuring method, which has been found to be unreliable. ${ }^{45}$ Using the ingestible thermistors to measure $\mathrm{T}_{\mathrm{GI}}$ was found to be a more reliable method of assessing core body temperature when compared to rectal temperature, the gold standard. ${ }^{46}$ 
In the present study, PSI score of firefighters increased over consecutive drills. Physiological strain index score was lower in D4 compared to D2 on average for all firefighters. Since the firefighters were not required to complete the drill stations at a certain pace, reduced PSI score in D4 compared to D2 may be explained by reduced selfpacing by the firefighters due to fatigue and/or to protect themselves from working beyond their physiological capabilities and the critical $\mathrm{T}_{\mathrm{GI}} \cdot{ }^{42}$ Head cooling did not have a significant effect on physiological strain, likely due to its inability to reduce $\mathrm{T}_{\mathrm{GI}}$ and $\mathrm{HR}$ as discussed earlier.

The PSI was developed as an index of quantifiable heat stress during occupational exposure resulting from reactions of the thermoregulatory and cardiovascular systems. Those displaying high PSI scores possibly exhibit greater body heat storage and cardiovascular strain to the metabolic and environmental conditions. Additionally, the PSI assumes that heart rates will remain between 60 and 180 and that $\mathrm{T}_{\mathrm{GI}}$ will remain between 36.5 and $39.5^{\circ} \mathrm{C}$ in order to meet the 0 to 10 scale criteria. In actual occupational exposure, however, $\mathrm{T}_{\mathrm{GI}}$ or HR higher than accounted for by the scale is possible. Firefighters with high PSI (score greater than 7) as well as those who display physiological characteristics greater than the index can accommodate, are thus at a greater risk of developing an EHI.

\section{Hydration Status}

During the training protocol, $10.5 \%$ of firefighters lost a maximum of $1.9 \%$ of their body weight; all others lost less fluid or gained weight. These results vary from a report by the Orange County Fire Association (OCFA) stating that 53\% of firefighters lost $2-3 \%$ of their body weight, and $5 \%$ lost more than $3 \%$ of their body weight in a 
training exercise similar to the first half of the protocol in this study. ${ }^{47}$ Firefighters in the current study may have appeared to lose less of their body weight if the fluid lost collected in the shorts in which they were weighed. In addition, the firefighters had two breaks, 15 minutes for each set of 30 minutes worked, during the training protocol. This may have allowed the firefighters time to recover and replenish fluid lost during the drills. However, losing even 1-2\%of your body weight can lead to detriments in both physiological function and performance, while losing more than three percent may also increase one's risk of developing an EHI. ${ }^{33}$

Additionally, head cooling had no effect on sweat loss or sweat rate. Sweat rates observed in firefighters were within normal values. ${ }^{15,33}$ While $\mathrm{T}_{\mathrm{GI}}$ rose similarly between groups, the need for sweating to promote heat loss via evaporation may also be similar. Sweat rate and sweat loss are typically reduced in more extreme conditions of hypohydration (more than $3 \%$ dehydration). ${ }^{48}$ Significant hypohydration was not observed in the firefighters in this study, which may have prevented reductions in sweat rate and sweat loss. It is possible, however, that sweat rates and losses were actually slightly higher than measured since the calculation was based on body weight loss; since the firefighters may have retained sweat in the shorts or pants they wore while being weighed. If so, their post-exercise body weight would be greater than reality, masking dehydration and sweat loss results.

Twenty-six percent of firefighters in the present study arrived dehydrated (USG between 1.020 and 1.030). Following training, 58 percent of firefighters were dehydrated to some degree. A report by the OCFA found similar results pre-training but did not assess USG after training in their study. ${ }^{47}$ In the present study, those who were 
dehydrated prior to training did not improve their hydration level with fluid consumed during training and had sweat rates within normal values. Beginning the training protocol in an already dehydrated state may have influenced physiological characteristics, such as $\mathrm{T}_{\mathrm{GI}}$ and HR. ${ }^{49}$ Although performance deficits are often associated with dehydration greater than $3 \%$, it is possible that performance may be affected at lesser degrees of dehydration. ${ }^{33}$ This may have played a role in the degree to which firefighters paced themselves during the training protocol.

Head cooling did not have an effect on hydration status of firefighters. During data collection, firefighters were observed encouraging and reminding each other to drink fluids during the rehab, indicating the practice of good hydration habits. This behavior may explain why loss of fluids was limited, no firefighter was seriously dehydrated, and no differences were found between groups. Knowing the purpose of the study and recording the amount of fluid consumed may also have influenced their behavior.

\section{Cognition}

Stroop test interference scores decreased in both groups as the training protocol progressed, indicating improved test performance. The CON group had a greater decrease in score, and thus a larger improvement in test performance, but this difference was not significant. Therefore, head cooling did not have a significant effect on cognitive performance. The improvement in scores may be due to a learning effect since no familiarization session was used and improvements in scores were seen over the first three test performances. The observed competitiveness that developed between firefighters may also contribute to improved test performance. One study showed improved processing speed in the Headminders Cognitive Stability Index (CSI) test in 
participants who were $3.27 \%$ dehydrated on average. ${ }^{50}$ The improved processing speed found in that study may be similar to the reduced interference score (increased number of conflicting colors stated) of the firefighters in the current study; however, the firefighters in the current study were dehydrated to a lesser degree, demonstrating less than one percent dehydration on average.

Additionally, firefighters' $\mathrm{T}_{\mathrm{GI}}$ remained within a reasonable range, rarely exceeding $40^{\circ} \mathrm{C}$ during the training protocol. This may also explain the lack of change in interference scores between groups. Core body temperatures above $40^{\circ} \mathrm{C}$ have been associated with central nervous system dysfunction, namely as a symptom of exertional heat stroke. ${ }^{14,15}$ Hyperthermia has been shown to have an effect on cognitive function, namely memory as opposed to processing speed, response speed, and attention, as measured by Headminder CSI test. ${ }^{51}$ This finding may support the lack of change in cognitive function as measured by the Stroop test interference score.

\section{Perceptual Measures}

Firefighters reported feeling as though they were working hard to very hard $(16 \pm 3)$ during drills, and felt as though they were working harder the more they worked. Other studies regarding firefighters' RPE found similar results, ranging from 13 to 16 during similar drills. ${ }^{2}$ In the present study, head cooling did not have an effect on how hard the firefighters felt they were working. The lack of change in the firefighter's perception of exertion may be explained by the fact that head cooling also had no effect on HR, therefore not relieving any cardiovascular strain. While maintaining maximal or near maximal HR and feeling as though they must work harder in order to complete a task, firefighters may not be able to complete tasks as easily or quickly later in a training 
session or extended call. When an actual fire is involved, firefighters may also be motivated to work beyond what they can physiologically tolerate, putting them at risk of suffering an injury or illness.

The firefighters' PTS increased over consecutive drills and decreased during rehabs. Head cooling had no effect on PTS. Although the firefighters in the head cooling group may have generally felt cooler, the difference was not statistically nor practically significant. In actuality, the $\mathrm{T}_{\mathrm{GI}}$ of the $\mathrm{HC}$ group was higher than the $\mathrm{CON}$ group, but the difference was not statistically significant. The inability of the head cooling device to change the user's PTS may be due to a poor and uncomfortable fit within the helmet noted by the firefighters, as well as the barrier of their hair between the gel pack and their skin. This decreased surface area of contact between the gel pack to skin may have inhibited the device from having an effect on the firefighters' perceptions. The firefighters also stated that any cooling sensation they felt diminished very quickly once they started working, similar to Wickwire et al.'s findings. ${ }^{31}$

\section{Gastrointestinal Temperature and Perceived Thermal Sensation}

No relationship was found between the firefighters' PTS and $\mathrm{T}_{\mathrm{GI}}$. Perceived thermal sensation may be influenced more so by skin temperature as compared to $\mathrm{T}_{\mathrm{GI}}$. Wickwire et al. found that those using a head cooling device perceived themselves to be cooler than those in the control group without any significant difference in $\mathrm{T}_{\mathrm{GI}}$ between groups. ${ }^{31}$ That study also found that forehead skin temperature of those in the head cooling group remained lower than those in the control group for approximately 50 minutes. ${ }^{31}$ This may indicate that PTS is determined, to a greater extent, by perception of skin temperature as opposed to $\mathrm{T}_{\mathrm{GI}}$. The difference in sensation versus actual temperature 
can be dangerous for firefighters, either in training or fighting a live fire. Firefighters will be motivated to perform their job to the best of their ability, and the lack of correlation between thermal sensation and gastrointestinal temperature can put them at risk of reentering a fire when their CBT is dangerously high. During training sessions and extended fire calls, particular attention should be given to recognize the outward signs of fatigue and EHI in firefighters on the job. Recognizing early signs of an EHI can prevent a firefighter who is unfit to continue working from re-entering the fire and working beyond his or her physiological capability. In extended drills or fires, emergency services personnel should be on site to measure each firefighter's CBT with an effective means before allowing them to continue working if an EHI is suspected.

\section{Conclusion}

This study has demonstrated that among career firefighters performing simulated firefighting activity, head cooling did not affect physiological function, including $\mathrm{T}_{\mathrm{GI}}$, HR, physiological strain, cognition, or hydration status. Additionally, it did not affect how hard a firefighter felt he was working or the firefighters' thermal perception. No relationship was found between thermal sensation and $\mathrm{T}_{\mathrm{GI}}$; therefore, a firefighter should not rely solely on how hot or cold they feel in determining whether they should continue working. Ultimately, head cooling via a frozen gel pack provided no physiological or perceptual benefit to career firefighters while performing firefighting drills, and therefore, it should not be used. 


\section{References}

1. Rossi R. Fire fighting and its influence on the body. Ergonomics. 2003;46(10):10171033.

2. Bugajoka J, Zuzewica K, Szmauz-Bybko M, Konarska M. Cardiovascular stress, energy expenditure and subjective perceived ratings of fire fighters during typical fire suppression and rescue tasks. Intl J Occup Saf Ergon. 2007;13(3):323-331.

3. Smith DL, Manning TS, Petruzzello SJ. Effect of strenuous live-fire drills on cardiovascular and psychological responses of recruit firefighters. Ergonomics. $2001 ; 44(3): 244-254$.

4. Pascoe DD, Shanley LA, Smith EW. Clothing and exercise: biophysics of heat transfer between the individual, clothing, and environment. Sports Med. 1994;18(1):38-52.

5. Ilmarinen R, Mäkinen H. Heat strain in fire-fighting drills. Paper presented at: The Fifth Int. Conf. on Environmental Ergonomics1992; Maastricht, The Netherlands.

6. Guidotti TL, Clough VM. Occupational health concerns of firefighting. Annu Rev Public Health. 1992;13:151-171.

7. Smith DL, Petruzzello SJ, Chludzinski MA, Reed JJ, Woods JA. Effect of strenuous live-fire fire fighting drills on hematological, blood chemistry and psychological measures. J Thermal Biol. 2001;26:375-379.

8. Griefahn B, Kunemund C, Brode P. Evaluation of performance and load in simulated rescue tasks for a novel design SCBA: effect of weight, volume and weight distribution. Appl Ergon. 2003;34:157-165. 
9. Barnard RJ, Duncan HW. Heart rate and ECG responses of fire fighters. J Occup Med. 1975;17(4):247-250.

10. Kalyani MN, Ebadi A, Mehri SJ, Jamshidi N. Comparing the effect of firefighting protective clothes and usual work clothes during physical activity on heat strain. Pak J Med Sci. 2009;25(3):375-379.

11. Casa DJ. Exercise in the heat. I. Fundamentals of thermal physiology, performance implications, and dehydration. J Athl Train. 1999;34(3):246-252.

12. Armstrong LE. Heat and Humidity. Performing in Extreme Environemnts. Champaign: Human Kinetics; 2000.

13. Armstrong LE, Anderson JM. Heat exhaustion, exercise-associated collapse, and heat syncope. In: Armstrong LE, ed. Exertional Heat Illnesses. Champaign: Human Kinetics; 2003.

14. Armstrong LE, Casa DJ, Millard-Stafford M, Moran DS, Pyne SW, Roberts WO. Exertional heat illness during training and competition. Med Sci Sports Exerc. 2007:556-572.

15. Binkley HM, Beckett J, Casa DJ, Kleiner DM, Plummer PE. National Athletic Trainers' Association Position Statement: Exertional Heat Illnesses. J Athl Train. 2002;37(3):329-343.

16. Karter Jr. M. Patterns of firefighter fireground injuries: National Fire Protection Association; 2009.

17. Fahy RF, LeBlanc PR, Molis JL. Firefighter fatalities in the United States - 2008: National Fire Protection Association; 2009.

18. United States Fire Association. 2009 Fatality Summary; 2009. 
19. McLellan TM, Selkirk GA. The management of heat stress for the firefighter: a review of work conducted on behalf of the Toronto Fire Service. Ind Health. 2006;44:414-426.

20. Technical Committee on Fire Service and Occupational Safety and Health . Standard on the Rehabilitation Processes of Members During Emergency Operations and Training Exercises. Vol 1584: National Fire Protection Association; 2008.

21. National Institute for Occupational Safety and Health. Heat Stress: Centers for Disease Control and Prevention; 2009.

22. International Association of Fire Fighters. Thermal Stress Protocol: International Association of Fire Fighters.

23. Occupational Safety and Health Administration. OSHA Technical Manual. Heat Stress; 1999.

24. Bennett BL, Hagan RD, Huey KA, Williams F. Use of a cool vest to reduce heat strain during shipboard firefighting: Naval Health Research Center;1994.

25. Carter JB, Banister EW, Morrison JB. Effectiveness of rest pauses and cooling in alleviationof heat stress during simulated fire-fighting activity. Ergonomics. 1999;42(2):299-313.

26. Selkirk GA, McLellan TM, Wong J. Active versus passive cooling during work in warm environments while wearing firefighting protective clothing. J Occup Environ Hyg. 2004;1:521-531.

27. Giesbrecht GG, CJamieson C, Cahilll F. Cooling hyperthermic firefighters by immersing forearms and hands in 10 degree Celsius and 20 degree Celsius water. Aviat Space Environ Med. 2007;78(6):561-567. 
28. Fujii RK, Horie S, Tsutsui T, Nagano C. Effectiveness of a head wash cooling protocol using non-refridgerated water in reducing heat stress. J Occup Health. 2008;50:251-261.

29. Choi J, Kim M, Lee J. Alleviation of heat strain by cooling different body areas during red pepper harvest work at WBGT 33 degrees C. Ind Health. 2008;46:620628.

30. Simmons SE, Saxby BK, McGlone FP, Jones DA. The effect of passive heating and head cooling on perception, cardiovascular function and cognitive performance in the heat. Eur J Appl Physiol. 2008;104:271-280.

31. Wickwire PJ, Bishop PA, Green JM, et al. Physiological and comfort effects of a commercial "cooling cap" worn under protective helmets. J Occup Environ Hyg. $2009 ; 6: 455-459$.

32. ACSM's Guidelines for Exercise Testing and Prescription. Philadelphia, PA: Wolters Kluwer; 2010.

33. Casa DJ, Armstrong LE, Hillman SK, et al. National Athletic Trainers' Association Position Statement: Fluid Replacement for Athletes. J Athl Train. 2000;35(2):212224.

34. Moran DS, Shitzer A, Pandolf KB. A physiological strain index to evaluate heat stress. Am J Physiol. 1998;275(44):R129-R134.

35. Buck SM, Hillman CH, Castelli DM. The relation of aerobic fitness to Stroop task performance in preadolescent children. Med Sci Sports Exerc. 2008;40(1):166-172.

36. Borg G. Psychophysical bases of perceived exertion. Med Sci Sports Exerc. 1982;14(5):377-381. 
37. Toner MM, Drolet LL, Pandolf KB. Perceptual and physiological responses during exercise in cool and cold water. Percept Mot Skills. 1986;62(1):211-220.

38. Chou C, Tochihara Y, Kim T. Physiological and subjective responses to cooling devices on firefighting protetive clothing. Eur J Appl Physiol. 2008;104:369-374.

39. Proulx CI, Durcharme MB, Kenny GP. Effect of water temperature on cooling efficiency during hyperthermia in humans. J Appl Physiol. 2003;94:1317-1323.

40. Lander PJ, Butterly RJ, Edwards AM. Self-paced exercise is less physically challenging than enforced constant pace exercise of the same intensity: influence of complex central metabolic control. Br J Sports Med. 2009;43:789-795.

41. Brake DJ, Bates GP. Fatigue in industrial workers under thermal stress on extended shift lengths. Occup Med. 2001;51(7):456-463.

42. Nielsen B. Heat stress causes fatigue! Exercise performance during acute and repeated exposures to hot, dry environments. Med Sport Sci. 1992;34:207-217.

43. Lafrenz AJ, Wingo JE, Ganio MS, Cureton KJ. Effect of ambient temperature on cardiovascular drift and maximal oxygen uptake. Med Sci Sports Exerc. 2008;40(6):1065-1071.

44. Kalyani MN, Jamshidi N. Comparing the effect of firefighting protective clothes and work clothes during physical activity on heat strain. Pak J Med Sci. 2009;25(3):375379.

45. Ganio MS, Brown CM, Casa DJ, et al. Validity and reliability of devices that assess body temperature during indoor exercise in the heat. J Athl Train. 2009;44(2):124135. 
46. Casa DJ, Becker SM, Ganio MS, et al. Validity of devices that assess body temperature during outdoor exercise in the heat. J Athl Train. 2007;42(3):333-342.

47. Espinoza N, Contreras M. Safety and performance implications of hydration, core body temperature, and post-incident rehabilitation: Orange County Fire Authority; December 2007.

48. Armstrong LE, Maresh CM, Gabaree CV, et al. Thermal and circulatory responses during exercise: effects of hypohydration, dehydration, and water intake. $J$ Appl Physiol. 1997;82:2028-2035.

49. Montain SJ, Coyle EF. Influence of graded dehydration on hyperthermia and cardiovascular drift during exercise. J Appl Physiol. 1992;73(4):1340-1350.

50. Zuri RE, Cleary MA, Lopez RM, Jones L, Moseley B. Cognitive performance may be impaired by exercise in a hot, humid environment: a preliminary investigation. Paper presented at: The Third Annual College of Education Research Conference 2004; Florida International University.

51. Stubblefield ZM, Cleary MA, Garvey SE, Eberman LE. Effects of active hyperthermia on cognitive performance. Paper presented at: The Fifth Annual College of Education Research Conference 2006; Florida International University. 
Table 1. Demographics by group (mean $\pm \mathrm{SD})$.

\begin{tabular}{|c|c|c|}
\hline & HC & CON \\
\hline Age (years) & $40 \pm 6$ & $41 \pm 9$ \\
\hline Height (cm) & $170 \pm 7$ & $166 \pm 8$ \\
\hline Weight (kg) & $97 \pm 17$ & $89 \pm 12$ \\
\hline $\begin{array}{c}\text { Estimated oxygen consumption } \\
(\mathrm{ml} / \mathrm{kg} / \mathrm{min})\end{array}$ & $52.2 \pm 7.6$ & $50.2 \pm 7.3$ \\
\hline
\end{tabular}

Table 2. Average and maximum WBGT outdoors over days and inside the training facility.

\begin{tabular}{|l|c|c|c|c|}
\hline & DAY ONE & DAY TWO & DAY THREE & TOWER \\
\hline Mean \pm SD & $26.2 \pm .5$ & $27.5 \pm 1.6$ & $28.9 \pm 1.5$ & $30.7 \pm 2.1$ \\
\hline Max WBGT & 27.1 & 29.6 & 32.6 & 32.1 \\
\hline
\end{tabular}

Note: Day one was significantly cooler than day three. 
Figure 1. Head cooling gel pack and firefighting helmet.

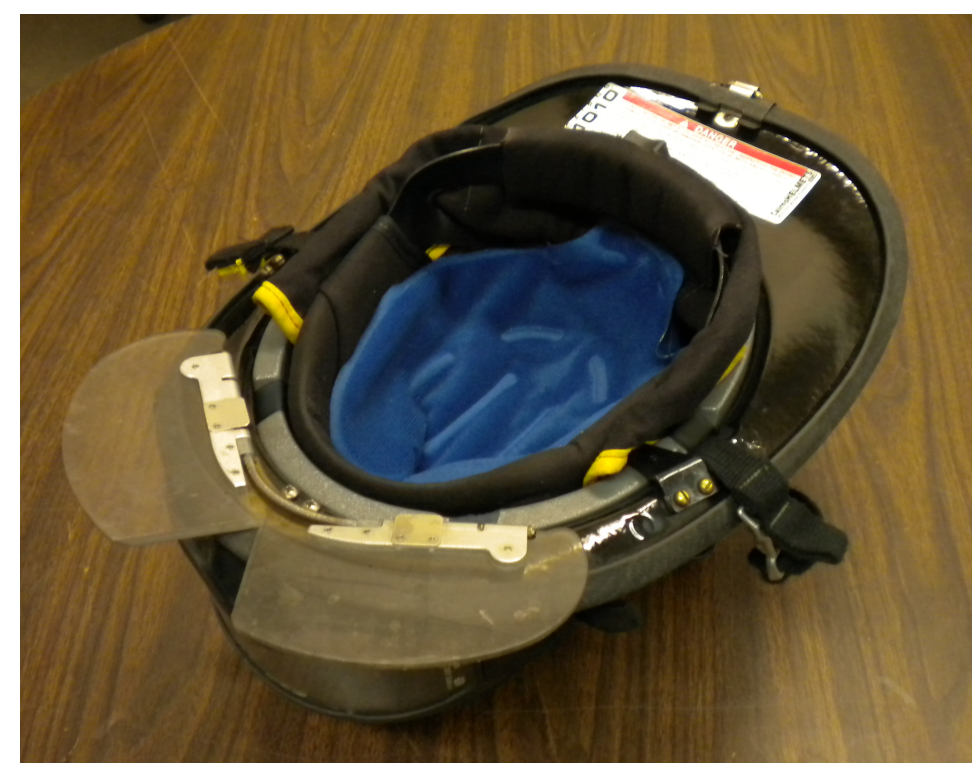

Gel pack fitted inside of firefighting helmet.

Figure 2. Training protocol order of events.

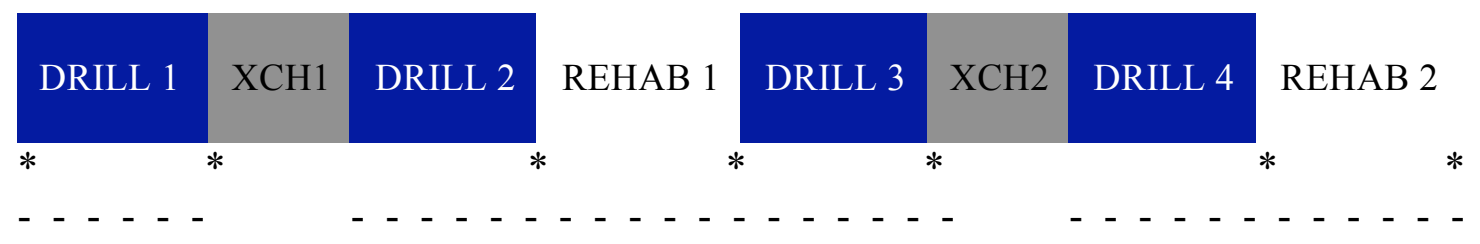

Note: *RPE, PTS, Stroop test recorded; - HR and $\mathrm{T}_{\mathrm{GI}}$ recorded; drill: firefighters completed firefighting drills; xch: firefighters exchanged air cylinders and measurements were recorded; rehab: firefighters rested in the shade. 
Figure 3. Gastrointestinal temperatures by group at the end of each station.

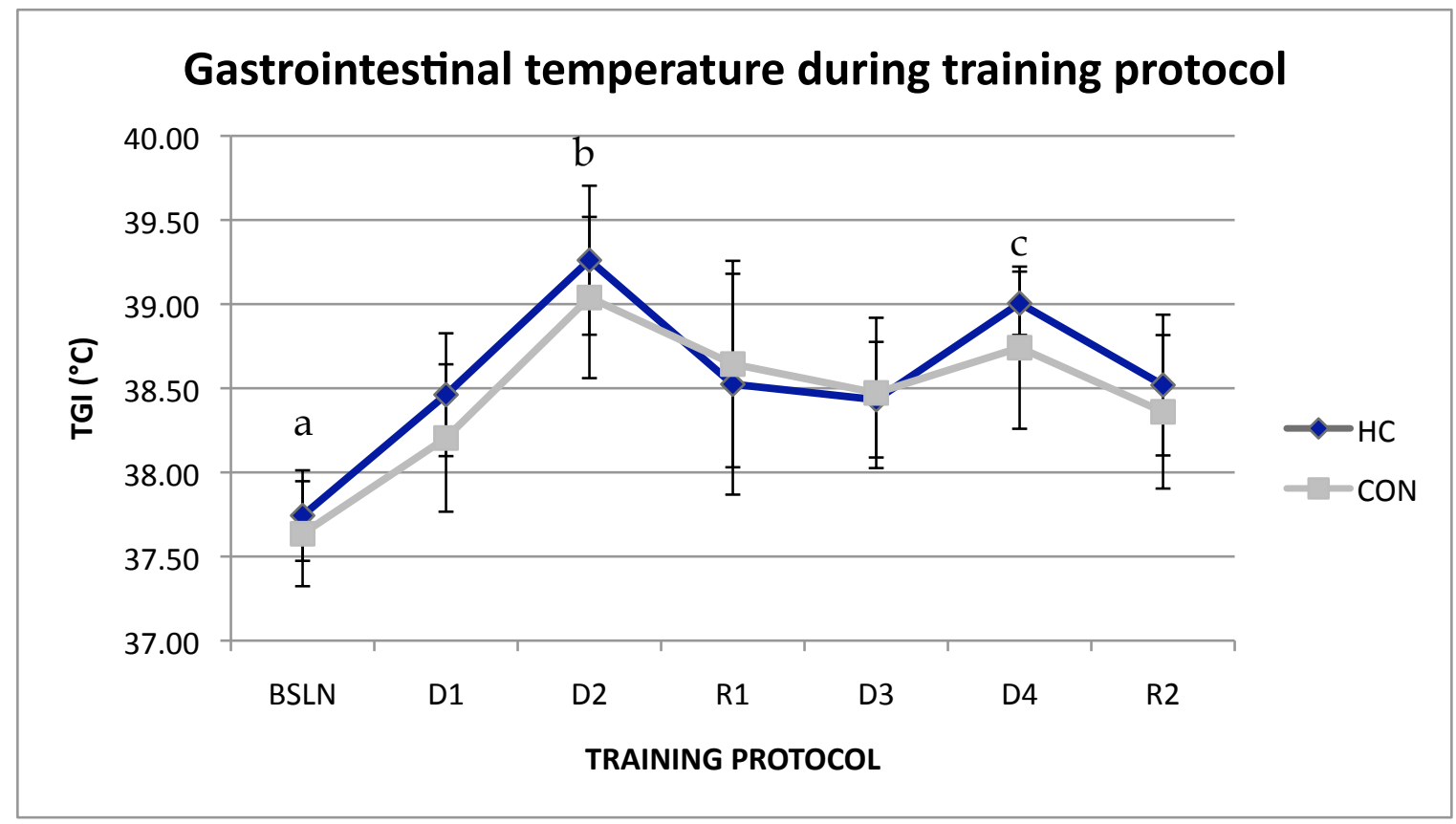

Note: $\mathrm{HC}=$ head cooling group; $\mathrm{CON}=$ control group

$\mathrm{a}=\mathrm{BSLN}<$ all

$\mathrm{b}=\mathrm{D} 2>$ all

$\mathrm{c}=\mathrm{D} 4>\mathrm{BSLN}, \mathrm{D} 1, \mathrm{D} 3, \mathrm{R} 2$ 
Figure 4. Heart rate by group at the end of each drill and rehab.

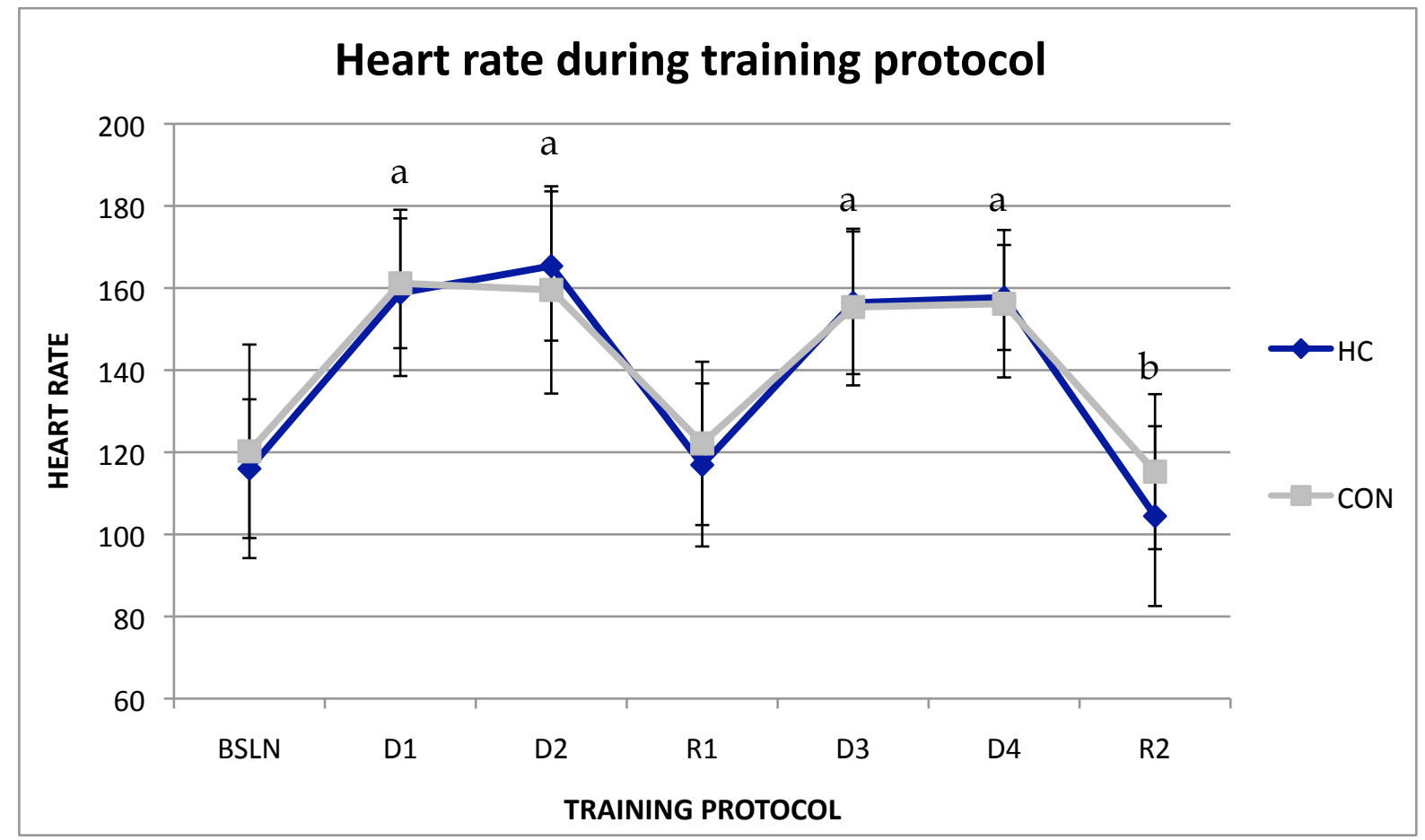

Note: $\mathrm{HC}=$ head cooling group; $\mathrm{CON}=$ control group

$\mathrm{a}=\mathrm{D} 1, \mathrm{D} 2, \mathrm{D} 3, \mathrm{D} 4>\mathrm{BSLN}, \mathrm{R} 1, \mathrm{R} 2$

$\mathrm{b}=\mathrm{R} 2<\mathrm{BSLN}, \mathrm{R} 1$ 
Figure 5. Average Physiological Strain Index score at the end of each drill and rehab.

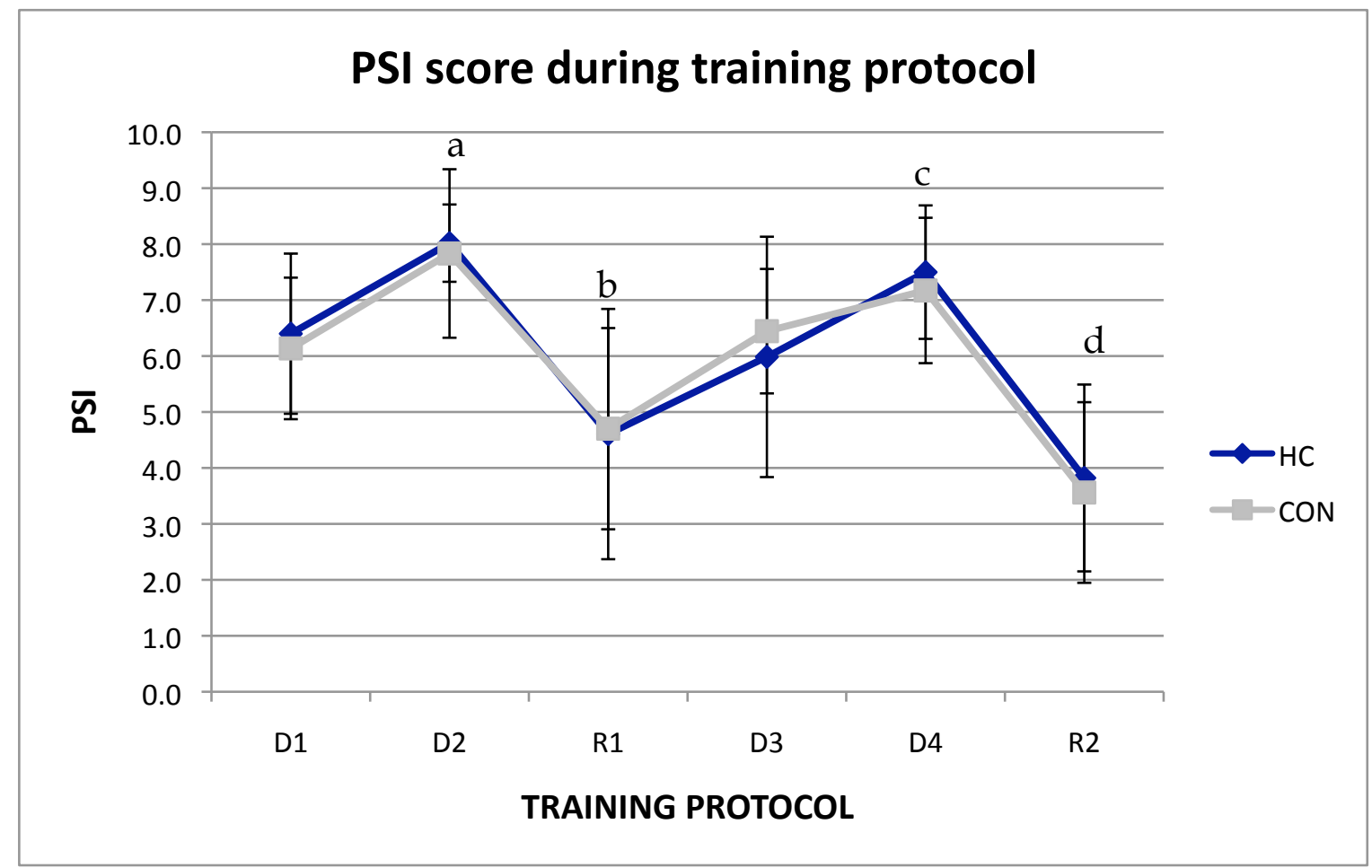

Note: $\mathrm{HC}=$ head cooling group; $\mathrm{CON}=$ control group

$\mathrm{a}=\mathrm{D} 2>$ all

$\mathrm{b}=\mathrm{R} 1<\mathrm{D} 1, \mathrm{D} 2, \mathrm{D} 3, \mathrm{D} 4$

$\mathrm{c}=\mathrm{D} 4>\mathrm{D} 1, \mathrm{R} 1, \mathrm{D} 3, \mathrm{R} 2$

$\mathrm{d}=\mathrm{R} 2<$ all 
Figure 6. Urine specific gravity before and after training by group.

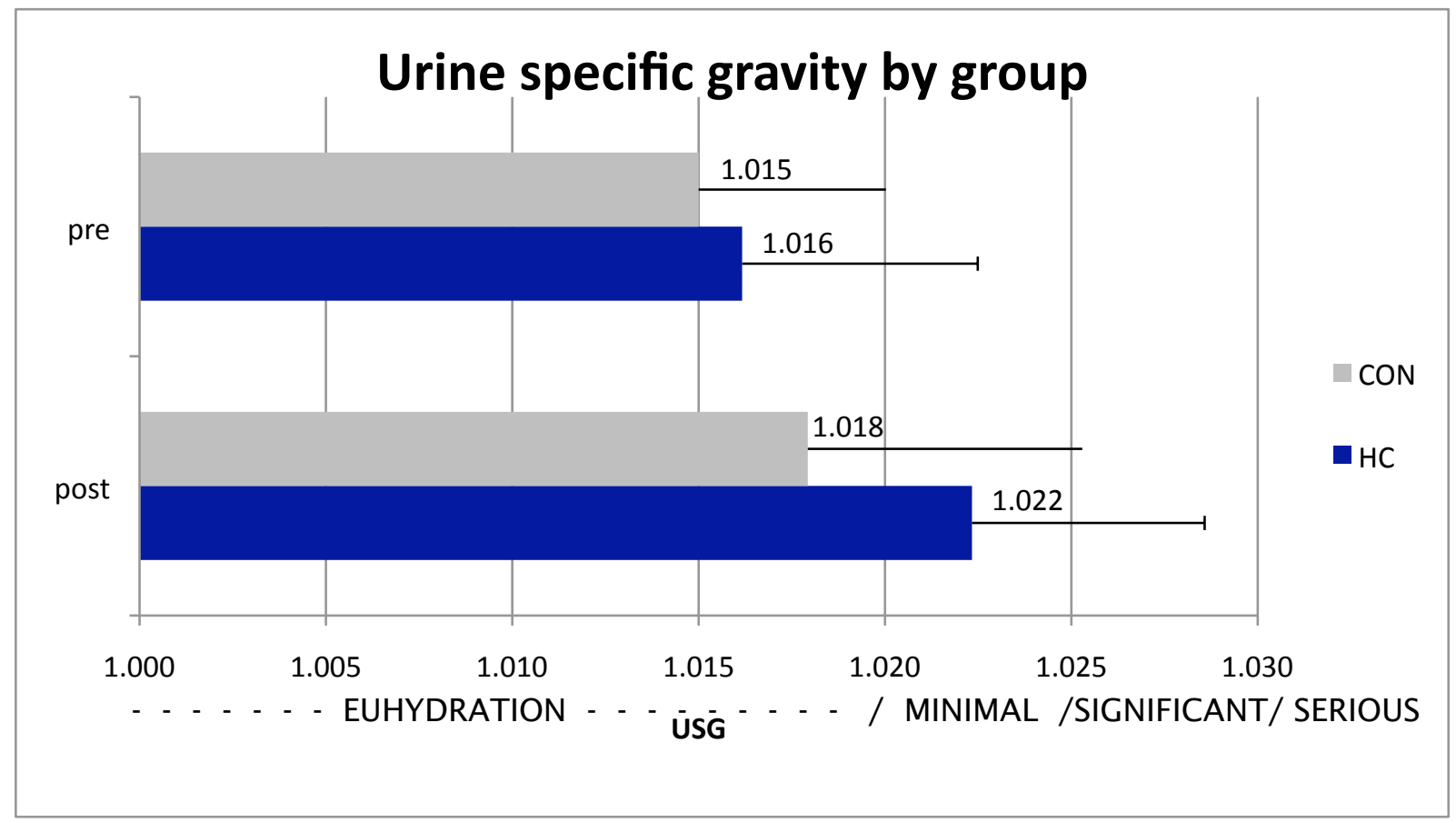

Note: $\mathrm{PRE}=\mathrm{USG}$ before training protocol; $\mathrm{POST}=\mathrm{USG}$ after training protocol; $\mathrm{HC}=$ head cooling group; $\mathrm{CON}=$ control group

-No differences between groups for USG pre-training $\left(\mathrm{t}_{1,24}=-.524, \mathrm{p}>0.05\right)$ and posttraining $\left(\mathrm{t}_{1,24}=-1.629, \mathrm{p}>0.05\right)$ 
Figure 7. Sweat loss, sweat rate, and fluid consumed during training protocol.
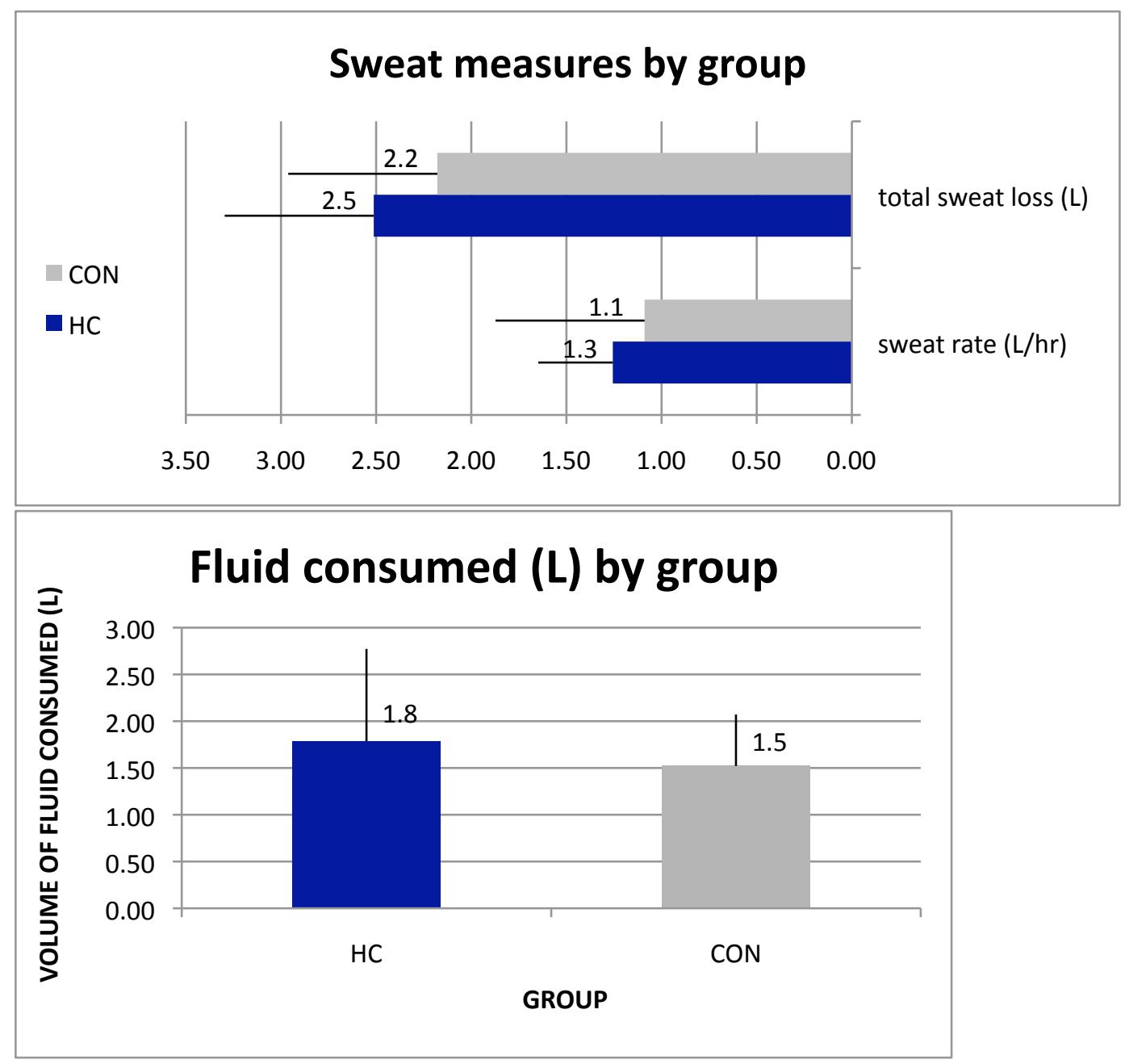

Note: $\mathrm{CON}=$ control group; $\mathrm{HC}=$ head cooling group

-No differences between groups for total sweat loss $\left(\mathrm{t}_{1,24}=-1.096, \mathrm{p}>0.05\right)$, sweat rate $\left(\mathrm{t}_{1,24}=-1.096, \mathrm{p}>0.05\right)$

-No difference between groups for fluid consumed $\left(\mathrm{t}_{1,24}=-.831, \mathrm{p}>0.05\right)$ 
Figure 8. Percent dehydration after training protocol.

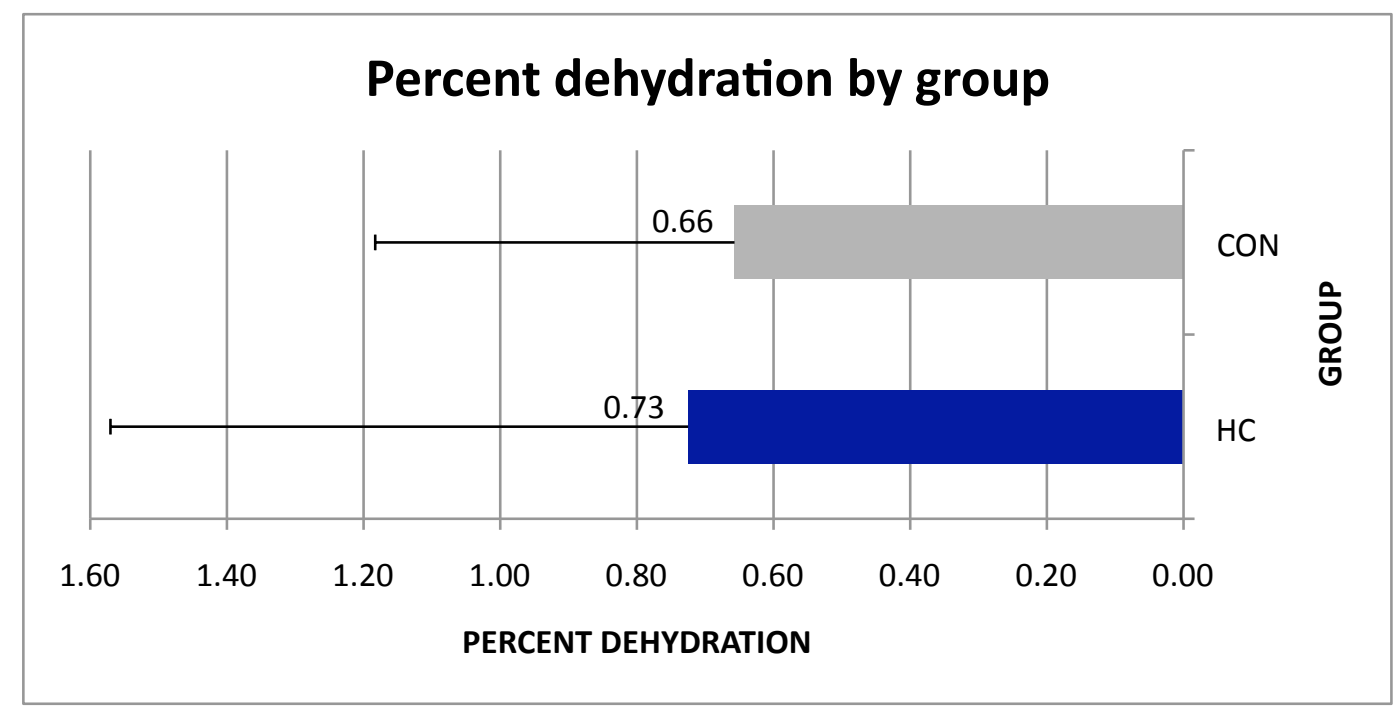

Note: $\mathrm{CON}=$ control group; $\mathrm{HC}=$ head cooling group

-No differences between groups for percent dehydration $\left(\mathrm{t}_{1,24}=-.110, \mathrm{p}>.05\right)$ 
Figure 9. Stroop test interference scores throughout training protocol.

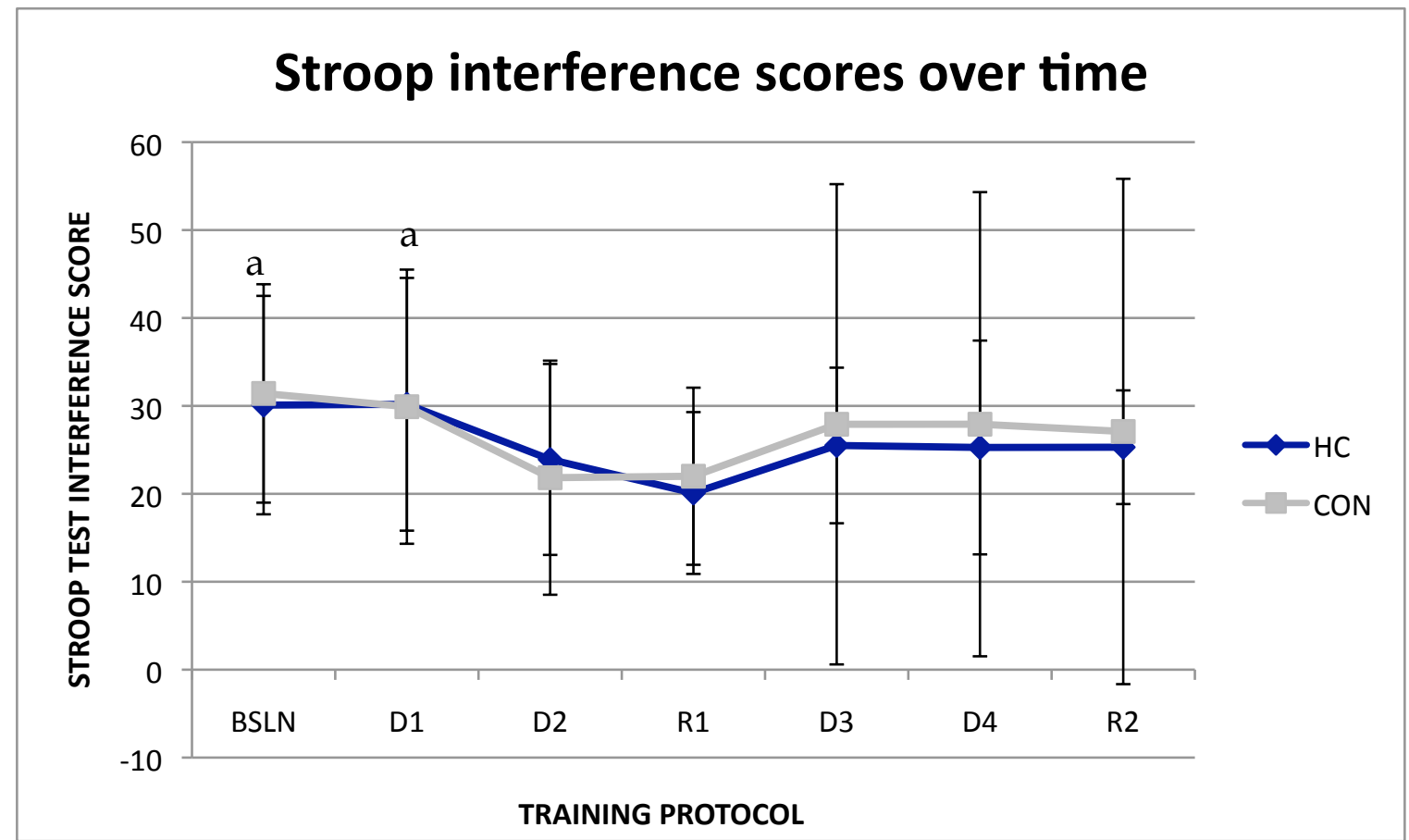

Note: $\mathrm{HC}=$ head cooling group; $\mathrm{CON}=$ control group

A higher score indicates decreased performance, i.e. less correct colors stated; a lower score indicates increased performance, i.e. more correct colors stated.

$\mathrm{a}=\mathrm{BSLN}, \mathrm{D} 1>\mathrm{D} 2, \mathrm{R} 1, \mathrm{D} 3, \mathrm{D} 4, \mathrm{R} 2$ 
Figure 10. Rating of perceived exertion during training protocol.

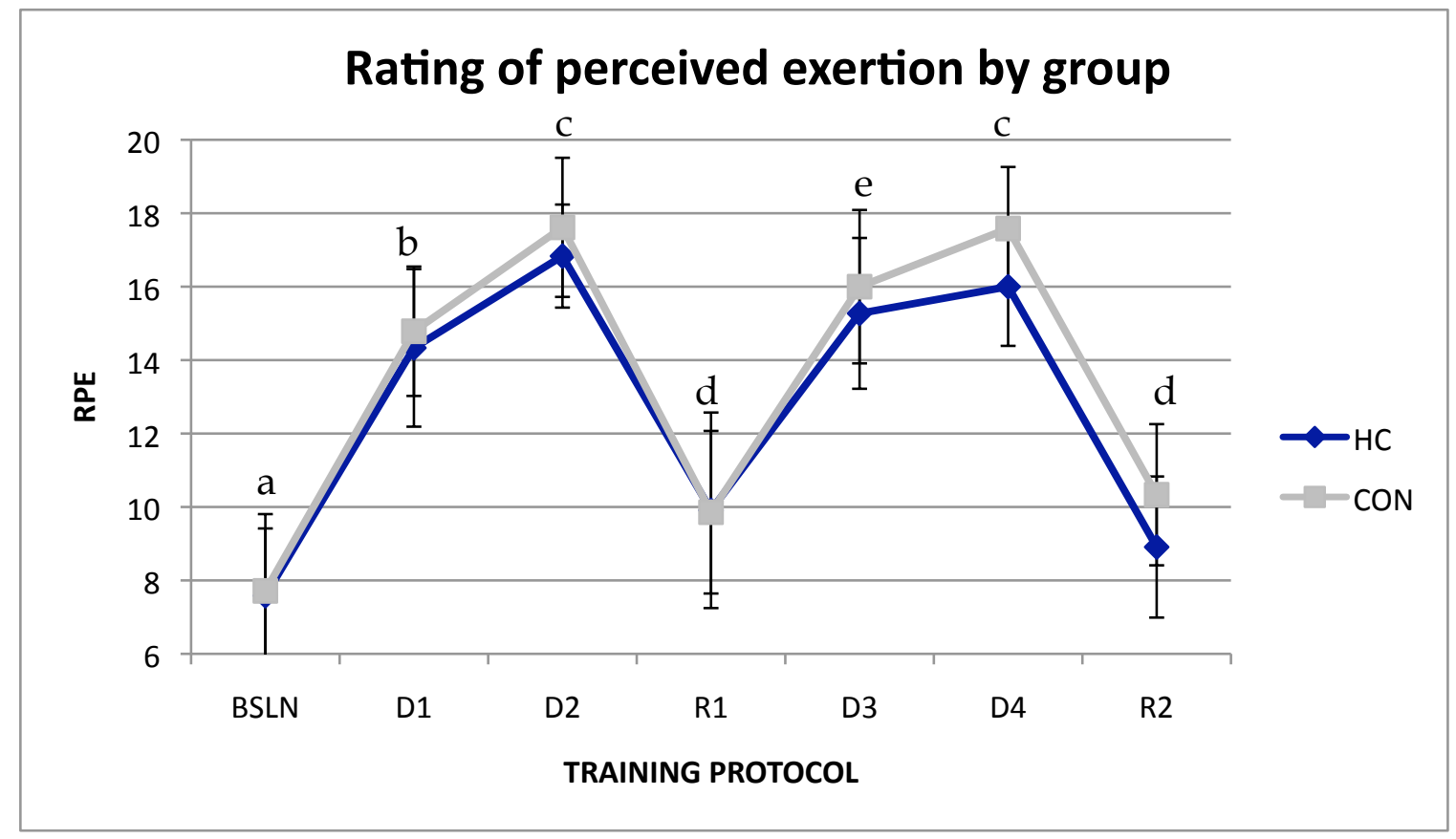

Note: $\mathrm{HC}=$ head cooling group; $\mathrm{CON}=$ control group

$\mathrm{a}=\mathrm{BSLN}<$ all other time points

$\mathrm{b}=\mathrm{D} 1<\mathrm{D} 2, \mathrm{D} 4 ; \mathrm{D} 1>\mathrm{BSLN}, \mathrm{R} 1, \mathrm{R} 2$

$\mathrm{c}=\mathrm{D} 2, \mathrm{D} 4>\mathrm{BSLN}, \mathrm{D} 1, \mathrm{R} 1, \mathrm{D} 3, \mathrm{R} 2$

$\mathrm{d}=\mathrm{R} 1, \mathrm{R} 2<\mathrm{D} 1, \mathrm{D} 2, \mathrm{D} 3, \mathrm{D} 4$

$\mathrm{e}=\mathrm{D} 3>\mathrm{BSLN}, \mathrm{W} 2, \mathrm{R} 1, \mathrm{R} 2 ; \mathrm{D} 3<\mathrm{D} 2, \mathrm{D} 4$ 
Figure 11. Perceived thermal sensation during training protocol.

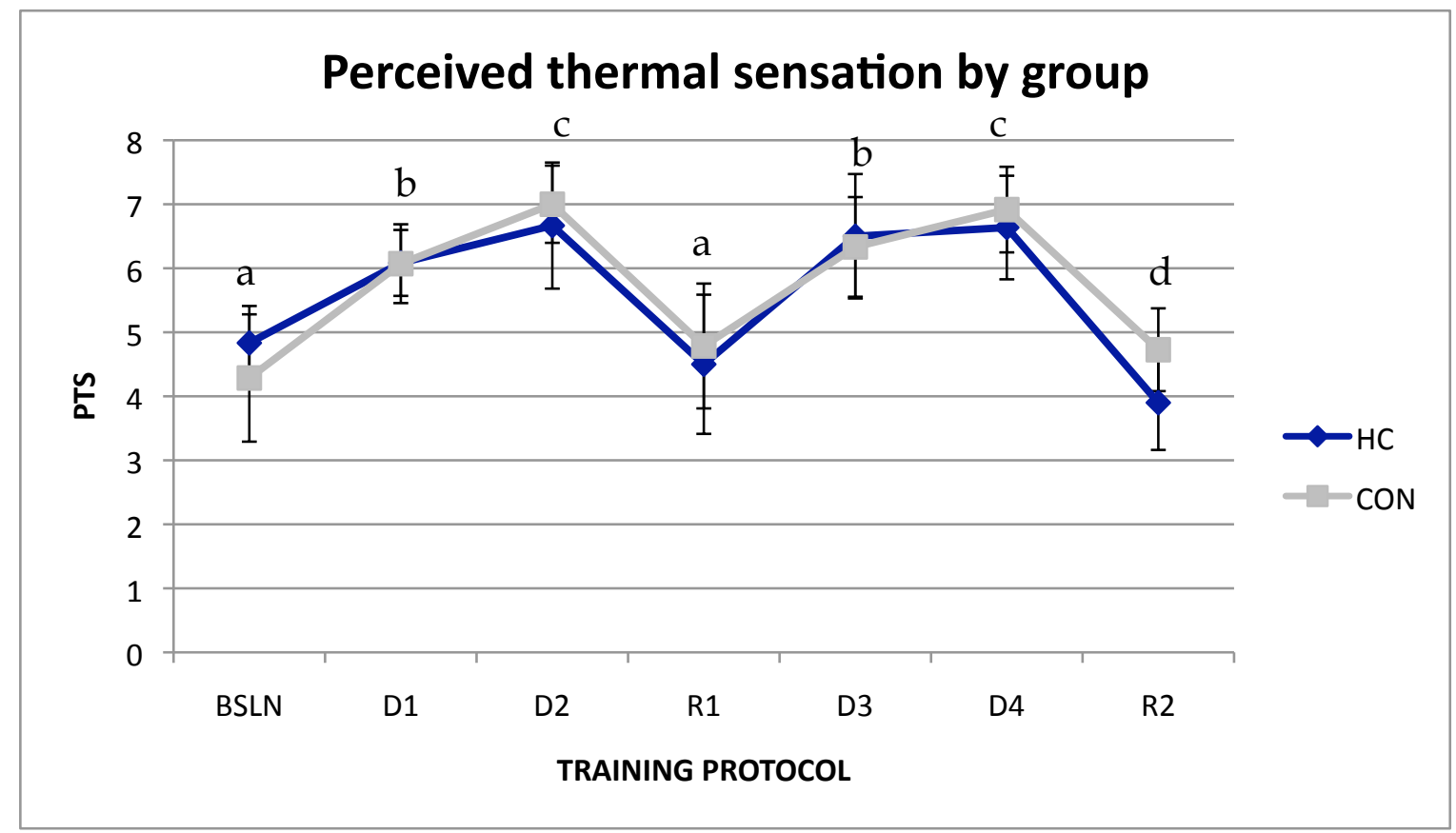

Note: $\mathrm{HC}=$ head cooling group; $\mathrm{CON}=$ control group

$\mathrm{a}=\mathrm{BSLN}, \mathrm{R} 1<\mathrm{D} 1, \mathrm{D} 2, \mathrm{D} 3, \mathrm{D} 4, \mathrm{R} 2$

$\mathrm{b}=\mathrm{D} 1, \mathrm{D} 3>\mathrm{BSLN}, \mathrm{R} 1, \mathrm{R} 2 ; \mathrm{D} 1, \mathrm{D} 3<\mathrm{D} 2, \mathrm{D} 4$

$\mathrm{c}=\mathrm{D} 2, \mathrm{D} 4>\mathrm{BSLN}, \mathrm{D} 1, \mathrm{R} 1, \mathrm{D} 3, \mathrm{R} 2$

$\mathrm{d}=\mathrm{R} 2<$ all 


\section{REFERENCES}

1. Rossi R. Fire fighting and its influence on the body. Ergonomics. 2003;46(10):1017-1033.

2. Kalyani MN, Ebadi A, Mehri SJ, Jamshidi N. Comparing the effect of firefighting protective clothes and usual work clothes during physical activity on heat strain. Pak J Med Sci. $2009 ; 25(3): 375-379$.

3. Ilmarinen R, Mäkinen H. Heat strain in fire-fighting drills. Paper presented at: The Fifth Int. Conf. on Environmental Ergonomics1992; Maastricht, The Netherlands.

4. Bugajoka J, Zuzewica K, Szmauz-Bybko M, Konarska M. Cardiovascular stress, energy expenditure and subjective perceived ratings of fire fighters during typical fire suppression and rescue tasks. Intl J Occup Saf Ergon. 2007;13(3):323-331.

5. Barnard RJ, Duncan HW. Heart rate and ECG responses of fire fighters. J Occup Med. $1975 ; 17(4): 247-250$.

6. Smith DL, Manning TS, Petruzzello SJ. Effect of strenuous live-fire drills on cardiovascular and psychological responses of recruit firefighters. Ergonomics. 2001;44(3):244-254.

7. Casa DJ. Exercise in the heat. I. Fundamentals of thermal physiology, performance implications, and dehydration. J Athl Train. 1999;34(3):246-252.

8. Armstrong LE. Heat and Humidity. Performing in Extreme Environemnts. Champaign: Human Kinetics; 2000. 
9. Armstrong LE, Anderson JM. Heat exhaustion, exercise-associated collapse, and heat syncope. In: Armstrong LE, ed. Exertional Heat Illnesses. Champaign: Human Kinetics; 2003.

10. Armstrong LE, Casa DJ, Millard-Stafford M, Moran DS, Pyne SW, Roberts WO. Exertional heat illness during training and competition. Med Sci Sports Exerc. 2007:556-572.

11. Binkley HM, Beckett J, Casa DJ, Kleiner DM, Plummer PE. National Athletic Trainers' Association Position Statement: Exertional Heat Illnesses. J Athl Train. 2002;37(3):329-343.

12. Karter Jr. M. Patterns of firefighter fireground injuries: National Fire Protection Association; 2009.

13. Fahy RF, LeBlanc PR, Molis JL. Firefighter fatalities in the United States - 2008: National Fire Protection Association; 2009.

14. United State Fire Association. 2009 Fatality Summary; 2009.

15. McLellan TM, Selkirk GA. The management of heat stress for the firefighter: a review of work conducted on behalf of the Toronto Fire Service. Ind Health. 2006;44:414-426.

16. Technical Committee on Fire Service and Occupational Safety and Health. Standard on the Rehabilitation Processes of Members During Emergency Operations and Training Exercises. Vol 1584: National Fire Protection Association; 2008.

17. National Institute of Occupational Safety and Health. Heat Stress: Centers for Disease Control and Prevention; 2009.

18. International Association of Fire Fighters. Thermal Stress Protocol: International Association of Fire Fighters.

19. Occupational Safety and Health Administration. OSHA Technical Manual. Heat Stress 1999. 
20. Bennett BL, Hagan RD, Huey KA, Williams F. Use of a cool vest to reduce heat strain during shipboard firefighting: Naval Health Research Center;1994.

21. Carter JB, Banister EW, Morrison JB. Effectiveness of rest pauses and cooling in alleviationof heat stress during simulated fire-fighting activity. Ergonomics. 1999;42(2):299313.

22. Giesbrecht GG, CJamieson C, Cahilll F. Cooling hyperthermic firefighters by immersing forearms and hands in 10 degree Celsius and 20 degree Celsius water. Aviat Space Environ Med. 2007;78(6):561-567.

23. Selkirk GA, McLellan TM, Wong J. Active versus passive cooling during work in warm environments while wearing firefighting protective clothing. J Occup Environ Hyg. 2004; $1: 521-531$.

24. Choi J, Kim M, Lee J. Alleviation of heat strain by cooling different body areas during red pepper harvest work at WBGT 33 degrees C. Ind Health. 2008;46:620-628.

25. Simmons SE, Saxby BK, McGlone FP, Jones DA. The effect of passive heating and head cooling on perception, cardiovascular function and cognitive performance in the heat. Eur $J$ Appl Physiol. 2008;104:271-280.

26. Wickwire PJ, Bishop PA, Green JM, et al. Physiological and comfort effects of a commercial "cooling cap" worn under protective helmets. J Occup Environ Hyg. 2009;6:455-459.

27. GelCool. GelCool gel packs. 2010; http://www.gelcool.com/firefighting.html, 2010.

28. Castellani JW. Physiology of Heat Stress. In: Armstrong LE, ed. Exertional Heat Illnesses. Champaign: Human Kinetics; 2003.

29. Guidotti TL, Clough VM. Occupational health concerns of firefighting. Annu Rev Public Health. 1992;13:151-171. 
30. Pascoe DD, Shanley LA, Smith EW. Clothing and exercise: biophysics of heat transfer between the individual, clothing, and environment. Sports Med. 1994;18(1):38-52.

31. Kalyani MN, Jamshidi N. Comparing the effect of firefighting protective clothes and work clothes during physical activity on heat strain. Pak J Med Sci. 2009;25(3):375-379.

32. Espinoza N, Contreras M. Safety and performance implications of hydration, core body temperature, and post-incident rehabilitation: Orange County Fire Authority; December 20072007.

33. Smith DL, Petruzzello SJ, Chludzinski MA, Reed JJ, Woods JA. Effect of strenuous live-fire fire fighting drills on hematological, blood chemistry and psychological measures. $J$ Thermal Biol. 2001;26:375-379.

34. Griefahn B, Kunemund C, Brode P. Evaluation of performance and load in simulated rescue tasks for a novel design SCBA: effect of weight, volume and weight distribution. Appl Ergon. 2003;34:157-165.

35. Casa DJ, Armstrong LE. Exertional Heatstroke: A Medical Emergency. In: Armstrong LE, ed. Exertional Heat Illnesses. Champaign: Human Kinetics; 2003.

36. Costrini A. Emergency treatment of exertional heatstroke and comparison of whole body cooling techniques. Med Sci Sports Exerc. 1990;22(1):15-18.

37. Cleary M. Predisoposing risk factors on susceptibility to exertional heat illness: clinical decision-making considerations. J Sport Rehabil. 2007;16:204-214.

38. Armstrong LE, Szlyk PC, De Luca JP, Sils IV, Hubbard RW. Fluid-electrolyte losses in uniforms during prolonged exercise at $30^{\circ}$ C. Aviat Space Environ Med. 1992;63(5):351-355.

39. Judelson DA, Maresh CM, Farrell MJ, et al. Effect of hydration state on strength, power and resistance exercise performance. Med Sci Sports Exerc. 2007;39(10):1817-1824. 
40. International Association of Fire Fighters. Emergency Incident Rehabilitation: U.S. Fire Administration; 2008.

41. McLellan TM, Selkirk GA. The management of heat stress for the firefighter. Toronto, Canada: Defence R\&D Canada;2005.

42. Casa DJ, McDermott BP, Lee EC, Yeargin SW, Armstrong LE, Maresh CM. Cold water immersion: the gold standard for exertional heatstroke treatment. Exerc Sport Sci Rev. 2007;35(3):141-149.

43. McDermott BP, Casa DJ, Ganio MS, et al. Acute whole-body cooling for exercise-induced hyperthermia: a systematic review. J Athl Train. 2009;44(1):84-93.

44. Arngrimsson SA, Petitt DS, Stueck MG, Jorgensen DK, Cureton KJ. Cooling vest work during active warm-up improves 5-km run performance in the heat. J Appl Physiol. 2004;96:1867-1874.

45. Lee DT, Haymes EM. Exercise duration and thermoregulatory responses after whole body precooling. J Appl Physiol. 1995;79(6):1971-1976.

46. Bolster DR, Trappe SW, Short KR, et al. Effects of precooling on thermoregulation during subsequent exercise. Med Sci Sports Exerc. 1999;31(2):251-257.

47. White AT, Davis SL, Wilson TE. Metabolic, thermoregulatory, and perceptual responses after lower vs. whole body precooling. J Appl Physiol. 2003;94(3):1039-1044.

48. Yeargin SW, Casa DJ, McClung JM, et al. Body cooling between two bouts of exercise in the heat enhances subsequent performance. J Strength Cond Res. 2006;20(2):383-389.

49. Chou C, Tochihara Y, Kim T. Physiological and subjective responses to cooling devices on firefighting protetive clothing. Eur J Appl Physiol. 2008;104:369-374. 
50. Fujii RK, Horie S, Tsutsui T, Nagano C. Effectiveness of a head wash cooling protocol using non-refridgerated water in reducing heat stress. J Occup Health. 2008;50:251-261.

51. Ansley L, Marvin G, Sharma A, Kendall MJ, Jones DA, Bridge MW. The effects of head cooling on endurance and neuroendocrine responses to exercise in warm conditions. Physiol Res. 2008;57:863-872.

52. Moran DS, Shitzer A, Pandolf KB. A physiological strain index to evaluate heat stress. Am J Physiol. 1998;275(44):R129-R134.

53. Casa DJ, Armstrong LE, Hillman SK, et al. National Athletic Trainers' Association Position Statement: Fluid Replacement for Athletes. J Athl Train. 2000;35(2):212-224.

54. Borg G. Psychophysical bases of perceived exertion. Med Sci Sports Exerc. 1982;14(5):377381.

55. Toner MM, Drolet LL, Pandolf KB. Perceptual and physiological responses during exercise in cool and cold water. Percept Mot Skills. 1986;62(1):211-220.

56. Buck SM, Hillman CH, Castelli DM. The relation of aerobic fitness to Stroop task performance in preadolescent children. Med Sci Sports Exerc. 2008;40(1):166-172.

57. ACSM's Guidelines for Exercise Testing and Prescription. Philadelphia, PA: Wolters Kluwer; 2010. 


\section{APPENDIX A: STUDY PARAMETERS}

\section{Operational definitions}

Physiological effects: changes in variables including gastrointestinal temperature, heart rate, Stroop Test interference score, and hydration measures (percent dehydration, urine specific gravity, sweat loss, sweat rate, fluid consumed)

Perceived effects: changes in variables including perceived thermal strain and rating of perceived exertion

Head cooling: a means of accessory cooling; in this study, a frozen gel pack placed inside in the upper portion of a firefighting helmet worn during firefighting activity Simulated firefighting activity: typical drills performed by firefighters during training that mimic actual events that would happen during an actual firefighting call. These drills included a search and rescue obstacle course, a high-rise drill, a two-story smoked search and rescue drill, and car extrication.

Career firefighter: a firefighter who is employed full-time by a fire department Good health: a firefighter who does not take medication for cardiovascular disease and has no work related restrictions requiring any type of accommodation.

Training protocol: the work/rest cycle of drills and recovery completed by participants. 


\section{$\underline{\text { Assumptions }}$}

- The fire department regulated the personal protective equipment and undergarments worn by the firefighters, so we assume there was no difference between participants in clothing and gear.

- We assume the firefighters' physical ability is similar with respect to simulated firefighting drills since all firefighters are required to be able to complete the same work related tasks.

- The firefighters were assigned to groups randomly, so we assume it was unnecessary to match groups by physical characteristics.

\section{$\underline{\text { Delimitations }}$}

- The applicability of the results of this study was limited to career firefighters, specifically those who work under the guidelines imposed by the Terre Haute Fire Department, Terre Haute, Indiana.

- The applicability of the results of this study was limited to simulated firefighting tasks, such as training drills and car extrication, rather than a live-fire scenario. In addition, it was limited to a training setting where firefighters typically allow themselves to self-pace.

- The applicability of the results of this study was limited to the effects of the GelCool gel pack (model GX) manufactured by GelCool Systems, Inc. of Nashville, Tennessee.

\section{$\underline{\text { Limitations }}$}

- As researchers, we were unable to control the weather and environmental conditions in which the firefighters performed the training protocol. 
- Due to the nature of their profession and the fact that the firefighters were taken out of service while on the job to complete the training protocol, we were unable to control for activity completed prior to participation in the study.

- Not all firefighters who participated in the study were able to complete the training protocol in the same day. Given this limitation and the fact that firefighters naturally communicate between shifts, those who completed the training protocol on the first day communicated to those testing the second day and so on regarding specifics of the training protocol and how to better prepare for it with simple behavior modifications, such as improving hydration.

- Since the design of the firefighting drills was referred to the expertise of the fire department training chief, we could not control the types of drills performed nor the personal motivation or intensity at which the firefighters completed the activities.

- Firefighters were weighed wearing the shorts or pants they wore under their protective equipment before and after the training protocol. After the training protocol, sweat had collected in the firefighters' shorts and pants, thus affecting their post-training weight, and potentially their percent dehydration, sweat loss, and sweat rate calculations. 


\section{APPENDIX B: PILOT RESEARCH}

Methods

Members of the department could not complete the exact protocol in order to truly pilot the methods due to our lack of training in firefighting skills. In place of a true pilot, we completed many walk-throughs to adjust the logistics of the methods, culminating in a dry run of the training protocol with the research assistants practicing their role in data collection by following a "subject" through their assigned drill to familiarize themselves with protocol and the equipment. The training protocol script was tested and modified during this walk-through.

Data by Subject and Results

No data was analyzed since it was not a true pilot regarding the effects of the independent variables. 
APPENDIX C: RELEVANT STUDY FORMS 


\section{Data collection forms}

\begin{tabular}{|c|c|c|c|c|c|}
\hline \multicolumn{6}{|c|}{$\begin{array}{c}\text { Health History Questionnaire } \\
\text { Indiana State University } \\
\text { Applied Medicine and Rehabilitation Department }\end{array}$} \\
\hline Subject No. & Height: (in cm) & Weight: (in kg.) & Age: & & \\
\hline \multicolumn{6}{|c|}{ Please answer the following questions to the best of your knowledge: } \\
\hline 1. & Do you regularly exercise $20-3$ & nutes at least twi & week? & Yes & No \\
\hline 2. & Are you currently under a doc & care? & & Yes & No \\
\hline 3. & Women only: Are you pregna & do you think you & th be? & Yes & No \\
\hline 4. & Do you have a pacemaker or a & natic implanted c & c defibrillator (AICD)? & Yes & No \\
\hline 5. & $\begin{array}{l}\text { Have you ever donate blood? } \\
\text { If YES, have you ever been scre } \\
\text { have a low blood count? }\end{array}$ & out of blood don & n due to being told you & Yes & No \\
\hline 6. & $\begin{array}{l}\text { Do you have, or suspect you h } \\
\text { hemophilia? }\end{array}$ & a blood clotting d & der such as & Yes & No \\
\hline 7. & $\begin{array}{l}\text { Do you have, or suspect that y } \\
\text { (hepatitis, HIV, AIDS)? }\end{array}$ & ave, any form of & $\mathrm{d}$ borne disease & Yes & No \\
\hline 8. & $\begin{array}{l}\text { Do you have, or suspect that y } \\
\text { (problems with your veins or a } \\
\text { diseases? }\end{array}$ & $\begin{array}{l}\text { ave, any circulato } \\
\text { es) disorders, con }\end{array}$ & $\begin{array}{l}\text { roblems or vascular } \\
\text { ons, disorders, or }\end{array}$ & Yes & No \\
\hline 9. & $\begin{array}{l}\text { Do you have, or suspect that y } \\
\text { conditions, disorders or diseas }\end{array}$ & ave, any rheumat & (joint) or muscular & Yes & No \\
\hline 10. & $\begin{array}{l}\text { Do you have, or suspect that y } \\
\text { disease, condition, or disorder } \\
\text { study (see attachment for clar }\end{array}$ & $\begin{array}{l}\text { ave, a mitral valve } \\
\text { may be aggravat } \\
\text { (ion)? }\end{array}$ & $\begin{array}{l}\text { lapse, or any other } \\
\text { y participating in this }\end{array}$ & Yes & No \\
\hline 11. & $\begin{array}{l}\text { Do you experience numbness, } \\
\text { or have other neurological pro }\end{array}$ & $\begin{array}{l}\text { ling, or decreased } \\
\text { ns, conditions, dis }\end{array}$ & $\begin{array}{l}\text { sation in extremities, } \\
\text { rs, or diseases? }\end{array}$ & Yes & No \\
\hline 12. & $\begin{array}{l}\text { Do you have any problems, co } \\
\text { ability to keep your balance? }\end{array}$ & ons, disorders or & ases that affect your & Yes & No \\
\hline 13. & $\begin{array}{l}\text { Are you currently taking any } p \\
\text { If } Y E S \text {, please list all prescriptic }\end{array}$ & $\begin{array}{l}\text { iption medicatior } \\
\text { edications. }\end{array}$ & & Yes & No \\
\hline 14. & $\begin{array}{l}\text { Are you taking any over-the-ce } \\
\text { If YES, please list below. }\end{array}$ & er medications or & plements? & Yes & No \\
\hline 15. & Do you have any other type of & lanted magnetic $\mathrm{c}$ & & Yes & No \\
\hline 16. & $\begin{array}{l}\text { Have you suffered from an up } \\
\text { months? }\end{array}$ & r a lower extremi & jury in the past 6 & Yes & No \\
\hline 17. & $\begin{array}{l}\text { Have you ever been diagnosec } \\
\text { disorder of the gastrointestina }\end{array}$ & $\begin{array}{l}\mathrm{h} \text { any obstruction } \\
\text { ) tract (see attach }\end{array}$ & $\begin{array}{l}\text { ease or inflammatory } \\
\text { t for clarification)? }\end{array}$ & Yes & No \\
\hline 18. & Do you have, or have you bee & gnosed with, an ir & ired gag reflex? & Yes & No \\
\hline 19. & $\begin{array}{l}\text { Have you been diagnosed witl } \\
\text { the esophagus? }\end{array}$ & nization (see atta & ent for clarification) of & Yes & No \\
\hline
\end{tabular}




\begin{tabular}{|l|l|l|l|}
\hline 20. & $\begin{array}{l}\text { Will you be undergoing Nuclear Magnetic Resonance/Magnetic Resonance } \\
\text { Imaging scanning anytime throughout this study? }\end{array}$ & Yes & No \\
\hline 21. & $\begin{array}{l}\text { Have you ever had any gastrointestinal (GI) surgery (this includes surgery of } \\
\text { stomach or intestines)? }\end{array}$ & Yes & No \\
\hline 22. & $\begin{array}{l}\text { Have you been diagnosed with any hypomotility disorder of the gastrointestinal } \\
\text { (GI) tract (please see attachment for clarification)? }\end{array}$ & Yes & No \\
\hline
\end{tabular}

If you answered "YES" to any question or you are unsure about your answers, you will be asked for more detail to help the investigators better assess whether your condition increases your risk for participation.

The questions and responses will be recorded on below. Your responses will be kept confidential and only reviewed by the research investigators and the Medical Director.

Is your annual medical physical on file with the fire department?

I certify that all the information provided is correct.
YES / NO

Date 


\section{Indiana State University \\ Department of Applied Medicine and Rehabilitation CURRENT HEALTH QUESTIONNAIRE}

\begin{tabular}{|l|l|l|l|}
\hline 1. & Have you experienced any vomiting or diarrhea in the last 48 hours? & Yes & No \\
\hline 2. & Have you consumed an excessive amount of alcohol in the last 48 hours? & Yes & No \\
\hline 3. & Have you had the cold or the flu within the last week? & Yes & No \\
\hline 4. & Have you had a gastrointestinal illness within the last week? & Yes & No \\
\hline 5. & $\begin{array}{l}\text { Have you had any other general illness the investigator should know about } \\
\text { in the last week? }\end{array}$ & Yes & No \\
\hline 6. & $\begin{array}{l}\text { Have you being following habits of good health within the last week such as } \\
\text { eating well, drinking fluids, and getting sufficient sleep? }\end{array}$ & Yes & No \\
\hline 7. & $\begin{array}{l}\text { Do you feel dizzy or "unwell" in other ways that the primary investigators } \\
\text { should be aware of? }\end{array}$ & Yes & No \\
\hline
\end{tabular}

Did you work yesterday? YES / NO

** If you answered yes to some of the questions above, the investigator may ask to delay you participation. Data collection will be delayed until all symptoms have resolved to ensure your safety during the study. 
2010 Firefighter Study - Indiana State University - Dept of Applied Medicine and Rehabilitation

Day One - date

Participant \#

Informed Consent Form

Completed? Yes / No

Health History Questionnaire

Completed? Yes / No

Current Health Questionnaire

Completed? Yes / No

Demographics

Age

Step Test Results

HR 15 seconds after completion of 3 minute step test ___ bpm

HR 60 seconds after completion of 3 minute step test___ bpm

Day One - date

Participant \#

Informed Consent Form

Completed? Yes / No

\section{Health History Questionnaire}

Completed? Yes / No

Current Health Questionnaire

Completed? Yes / No

\section{Demographics}

Age

Step Test Results

HR 15 seconds after completion of 3 minute step test bpm

HR 60 seconds after completion of 3 minute step test bpm 
2010 Firefighter Study - Indiana State University - Dept of Applied Medicine and Rehabilitation

\section{Pre / Post Data}

\section{Date} Firefighter \#

\begin{tabular}{|l|c|}
\hline Age & \\
\hline Height & \\
\hline BWinitial $(\mathrm{kg})$ & \\
\hline USGinitial & \\
\hline BWgear $(\mathrm{kg})$ & \\
\hline HR & \\
\hline Gltemp $\left({ }^{\circ} \mathrm{C}\right)$ & \\
\hline RPEpre & \\
\hline PTSpre & \\
\hline Strooppre & $/$ \\
\hline BWfinal $(\mathrm{kg})$ & \\
\hline Fluid consumed & \\
\hline USGfinal & \\
\hline
\end{tabular}

\section{Date}

\section{Pre / Post Data} Firefighter \#

\begin{tabular}{|l|c|}
\hline Age & \\
\hline Height & \\
\hline BWinitial $(\mathrm{kg})$ & \\
\hline USGinitial & \\
\hline BWgear $(\mathrm{kg})$ & \\
\hline HR & \\
\hline Gltemp $\left({ }^{\circ} \mathrm{C}\right)$ & \\
\hline RPEpre & \\
\hline PTSpre & \\
\hline Strooppre & $/$ \\
\hline BWfinal $(\mathrm{kg})$ & \\
\hline Fluid consumed & \\
\hline USGfinal & \\
\hline
\end{tabular}




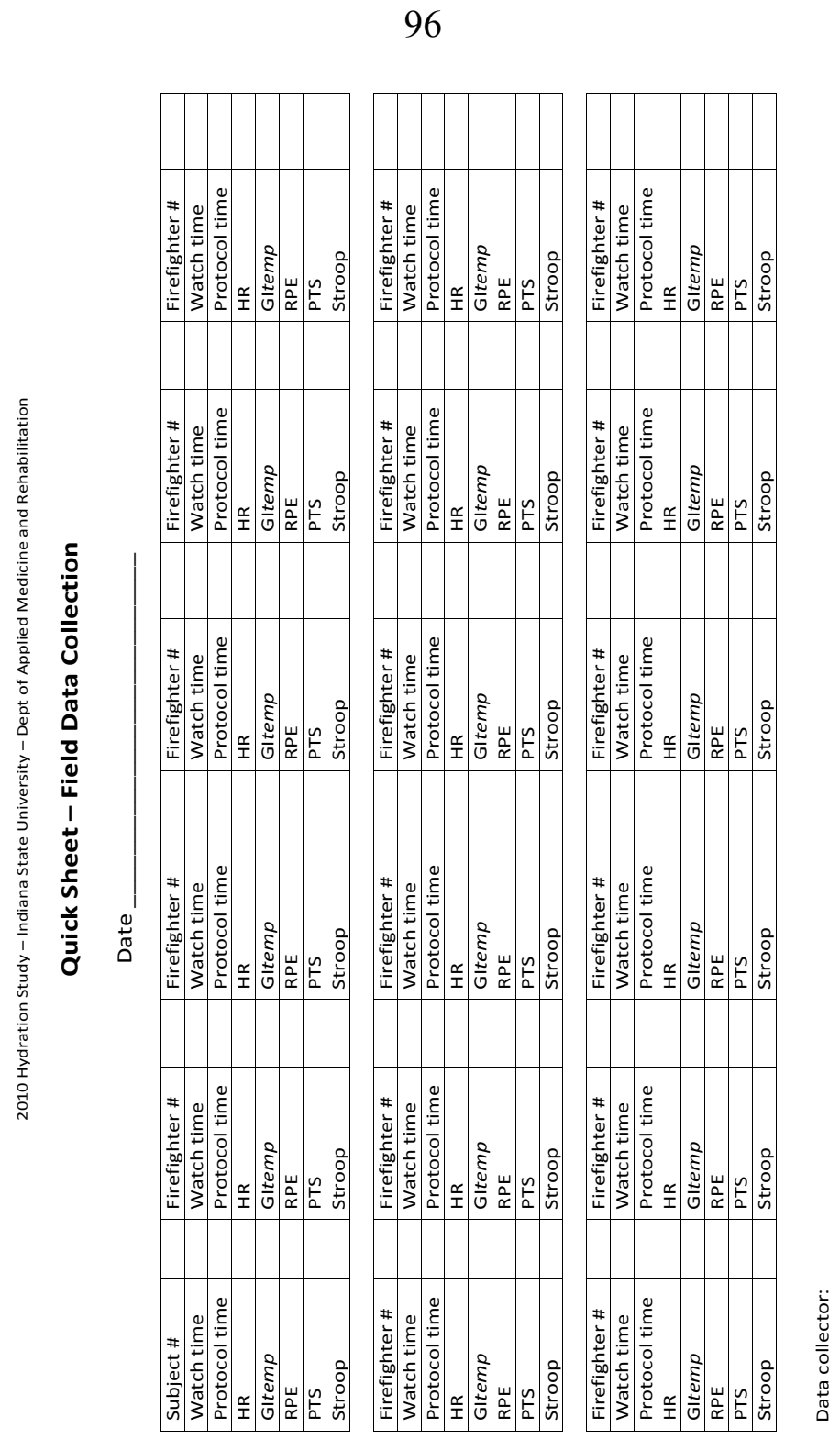


Training Protocol Script

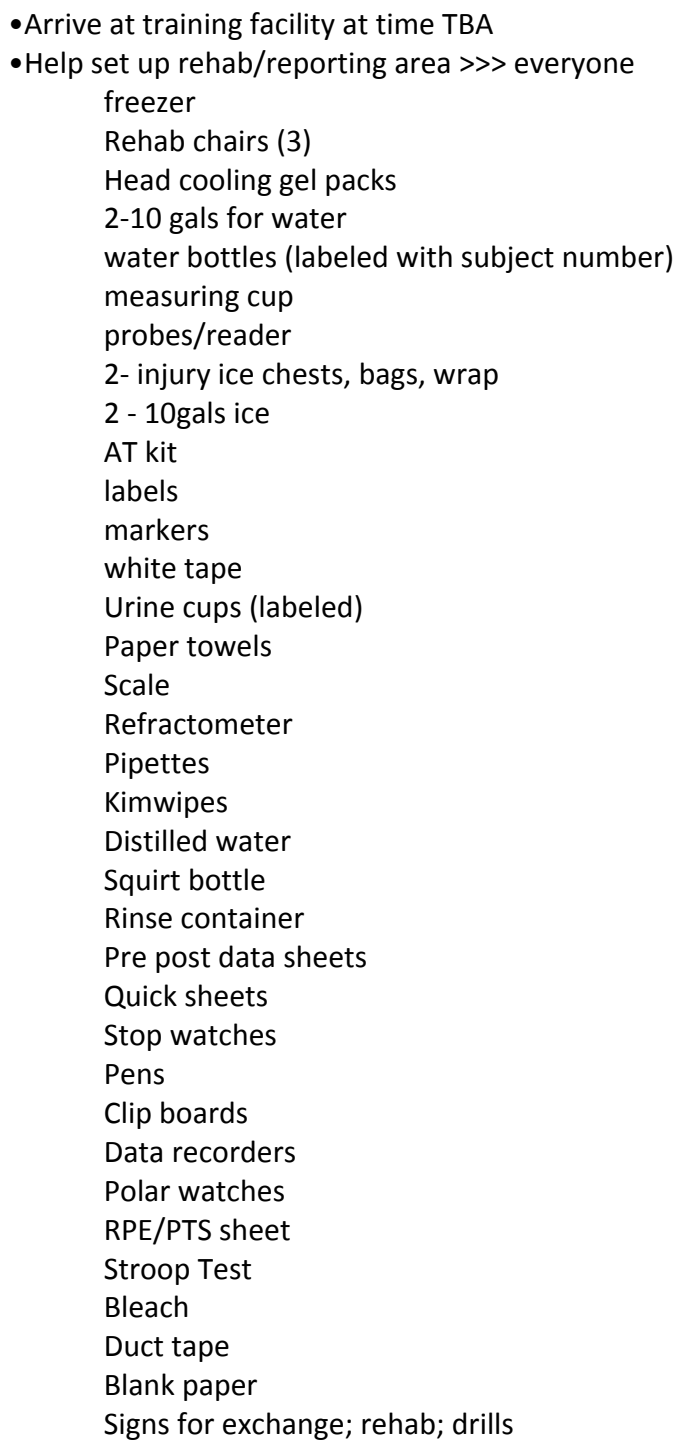


- Set up rehab/reporting area >>> everyone

- Set up drills/protocol signs $>>>$ everyone

Signs with A, B, C, D

Duct tape

Sign for exchange

Sign for rehab

- Greeter for trucks that arrive $\gg>>$ Janie, Tiffani

-FF arrive - Escort to reporting/rehab tent >> Janie, TIffani

-FF pull group out of hat $\gg>$ Amy or Susan

-FF pull starting drill station out of hat $\gg \gg$ Amy or Susan

- Label with FF\# >> Amy or Susan

blue=arm chair

green=head

red=control

-FF assigned to researchers based on drill station starting point $\gg>$ Amy or Susan

Group at drill $A=$ Meg

Group at drill $B=$ Dave

Group at drill $C=$ Andy

Group at drill D = Meghan

$5^{\text {th }}$ receiver $=$ Susan or Amy

official time $=$ Amy

-Record baseline HR/temp on pre/post sheet $\gg>>$ receivers

- Orientation for FF, special instructions $\gg \gg$ Amy or Susan

-1. FF provide urine sample in labeled cup, return to rehab tent $\gg \gg$ Dana, Tiffani

-FF get height measured in $\mathrm{cm}$ on pre/post sheet $\gg>>$ Jennifer, Janie

-2. FF get initial body weight in kg (shorts only- tshirt if they are strongly opposed) on pre/post sheet $\gg>$ Jennifer, Janie

-FF adorn heart rate strap $\gg>$ Dr. Kingsley, Yoder, Andy, Meghan, Dave

-FF adorn gear

-FF get gear body weight on pre/post sheet >>> Jennifer, Janie

Baseline RPE, PTS, Stroop on pre/post sheet >>> Amy, Jennifer, Janie, Dana, Tiffani, Yoder, DK, Susan

HR, temp on quick sheet $\gg>$ receivers

-DRILLone (15 mins)•Send to drill one $\gg>$ Amy

Check time on your watch! >>> everyone

Collect HR/temp every 3-5 mins (protocol time: 1-letter of drill station) > > receivers

2 minute warning, FF begin to exit $\gg>$ Amy

Encourage FF to keep moving if they exit before 15 mins > > everyone

$\bullet$ EXCH•Announce FF to exchange tent $\gg>$ Amy

Collect HR, temp at beginning of exchange (final data point drill 1) $\gg>>$ receivers

Collect PTS, RPE, Stroop (protocol time: 1) > > Amy, Janie, Tiffani, Yoder, DK, Susan

Instruct FF to exchange (cylinders, head cooling) if applicable 
-DRILLtwo (15 mins)•Send to drill two >> Amy

Check time on your watch!

Collect HR/temp every 3-5 mins (protocol time: 2-letter of drill station) > > receivers

2 minute warning, FF begin to exit $\gg>$ Amy

Encourage FF to keep moving if they exit before 15 mins $\gg>>$ everyone

-REHABone (15 mins)•Announce FF back to rehab tent for rehab $\gg>$ Amy

Collect RPE, PTS, Stroop (protocol time: 2) >> Amy, Janie, Tiffani, Yoder, DK, Susan

Collect HR, temp every 3 mins (protocol time: $R 1$ ) $\gg>>$ receivers

2 minute warning $\gg>$ Amy

Collect RPE, PTS, Stroop (protocol time: 3) >> Amy, Janie, Tiffani, Yoder, DK, Susan

Collect HR,temp (protocol time: R1) $\gg>$ receivers

Announce end of rehab > > Amy

FF get dressed

-DRILLthree (15 mins)•Send to drill three $\gg>$ Amy

Check time on your watch!

Collect HR/temp every 3-5 mins (protocol time: 3-letter of drill station >> receivers

2 min warning, FF begin to exit $\gg>$ Amy

Encourage to keep moving >>> everyone

'•EXCH•Announce FF back to rehab tent to exchange (cylinders, head cooling) $\gg>$ Amy Collect HR, temp at beginning of exchange (last data point of drill 3 ) $\gg>>$ receivers Collect PTS, RPE, Stroop (protocol time: 4) >> Amy, Janie, Tiffani, Yoder, DK, Susan Instruct FF to exchange (cylinders, head cooling) if applicable

-DRILLfour (15 mins)•Send to drill four $\gg>$ Amy

Check time on your watch!

Collect HR/temp every 3-5 mins (protocol time: 4-letter of drill station) >> receivers

2 minute warning, FF begin to exit $\gg>$ Amy

Encourage FF to keep moving if they exit before 15 mins $\gg>$ everyone

-REHABtwo (15 mins)•Announce FF back to rehab tent for rehab $\gg>$ Amy

Collect RPE, PTS, Stroop (protocol time: 5) >> Amy, Janie, Tiffani, Yoder, DK, Susan

Collect HR, temp every $\mathbf{3}$ mins (protocol time: R2) $\gg>$ receivers

-END•Announce end of rehab $\gg>$ Amy

Collect final PTS, RPE, Stroop (protocol time: 6) >> Amy, Janie, Tiffani, Yoder, DK, Susan

Collect final HR, temp (protocol time: R2) $\gg>$ receivers

Instruct FF to remove gear

1.Collect BW final $\gg>$ Janie

2.Collect urine sample $\gg>>$ Tiffani

Collect fluid consumed $\gg>$ Amy, any available RAs

Thank FF for participating $\gg>$ Amy/Susan 
Stroop Test - Section 1

RED BLUE YELLOW GREEN YELLOW RED BLUE GREEN BLUE RED GREEN YELLOW BLUE YELLOW RED GREEN BLUE RED YELLOW GREEN RED GREEN BLUE YELLOW GREEN RED YELLOW BLUE YELLOW BLUE RED GREEN RED GREEN YELLOW BLUE RED GREEN YELLOW BLUE GREEN RED BLUE YELLOW BLUE YELLOW GREEN RED GREEN YELLOW BLUE RED GREEN BLUE RED YELLOW RED BLUE GREEN YELLOW BLUE GREEN RED YELLOW RED YELLOW BLUE GREEN RED YELLOW GREEN BLUE YELLOW BLUE GREEN RED YELLOW RED GREEN BLUE GREEN YELLOW RED BLUE GREEN BLUE YELLOW RED BLUE GREEN YELLOW RED YELLOW GREEN BLUE RED GREEN BLUE RED YELLOW RED BLUE YELLOW GREEN YELLOW BLUE GREEN RED BLUE RED GREEN YELLOW RED GREEN BLUE YELLOW GREEN RED YELLOW BLUE GREEN BLUE YELLOW RED BLUE GREEN RED YELLOW BLUE RED YELLOW GREEN RED GREEN YELLOW BLUE GREEN RED BLUE YELLOW BLUE YELLOW RED GREEN YELLOW GREEN 
BLUE RED BLUE GREEN YELLOW RED YELLOW RED GREEN BLUE YELLOW BLUE RED GREEN RED YELLOW BLUE GREEN YELLOW RED BLUE GREEN RED GREEN YELLOW BLUE GREEN YELLOW RED BLUE RED BLUE GREEN YELLOW RED YELLOW GREEN BLUE GREEN YELLOW BLUE RED BLUE YELLOW GREEN RED GREEN BLUE RED YELLOW BLUE YELLOW GREEN RED YELLOW RED GREEN BLUE GREEN BLUE YELLOW RED BLUE GREEN RED YELLOW GREEN YELLOW RED BLUE YELLOW BLUE RED GREEN YELLOW BLUE GREEN RED BLUE RED YELLOW GREEN RED YELLOW GREEN BLUE YELLOW GREEN BLUE RED GREEN RED YELLOW BLUE GREEN YELLOW BLUE RED GREEN RED BLUE YELLOW BLUE YELLOW RED GREEN YELLOW GREEN RED BLUE RED BLUE GREEN YELLOW BLUE RED GREEN YELLOW RED GREEN YELLOW BLUE RED BLUE YELLOW GREEN RED YELLOW BLUE GREEN BLUE YELLOW RED GREEN YELLOW RED BLUE GREEN RED GREEN BLUE YELLOW RED GREEN BLUE YELLOW 
Stroop Test - Section 2

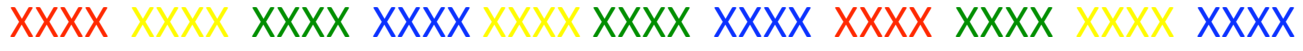

$$
\begin{aligned}
& \text { XXXX XXXX } \quad X X X X \quad X X X X \quad X X X X \quad X X X X \quad X X X X X X X X X \quad X X X X \\
& \begin{array}{lllllllllll}
X X X X & X X X X & X X X X & X X X X & X X X X & X X X X & X X X X & X X X X & X X X X
\end{array} \\
& \begin{array}{lllllllllllllll}
X X X X & X X X X & X X X X & X X X X & X X X X & X X X X & X X X X & X X X X & X X X X & X X X X
\end{array} \\
& \begin{array}{llllllllllllllllllllll} 
& X X X X & X X X X & X X X X & X X X X & X X X X & X X X X & X X X X & X X X X & X X X X & X X X X
\end{array} \\
& \begin{array}{lllllllllllllllll}
X X X X & X X X X & X X X X & X X X X & X X X X & X X X X & X X X X & X X X X & X X X X
\end{array} \\
& \begin{array}{llllllllllllllllllllllllll}
X X X X & X X X X & X X X X & X X X X & X X X X & X X X X & X X X X & X X X X & X X X X & X X X X & X X X X
\end{array}
\end{aligned}
$$

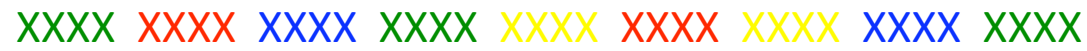

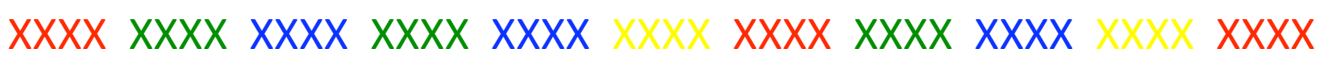

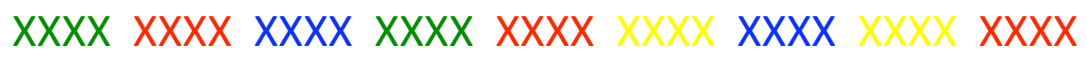

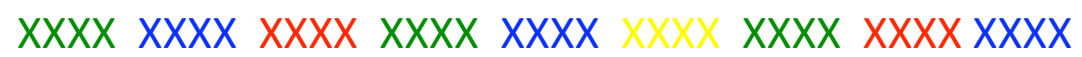

$$
\begin{aligned}
& \begin{array}{llllllllllllllllllll}
X X X X & X X X X & X X X X & X X X X & X X X X & X X X X & X X X X & X X X X & X X X X & X X X X
\end{array} \\
& \begin{array}{llllllllllllllllll} 
& X X X X & X X X X & X X X X & X X X X & X X X X & X X X X & X X X X & X X X X & X X X X
\end{array} \\
& \begin{array}{lllllllllllllllll}
X X X X & X X X X & X X X X & X X X X & X X X X & X X X X & X X X X X & X X X X & X X X X & X X X X & X X X X
\end{array} \\
& \begin{array}{llllllllllllllllllllll}
X X X X & X X X X & X X X X & X X X X & X X X X & X X X X & X X X X & X X X X & X X X X & X X X X
\end{array}
\end{aligned}
$$

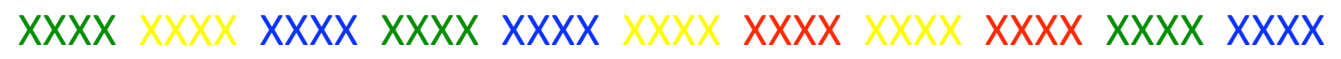

$$
\begin{aligned}
& \begin{array}{llllllllllll} 
& X X X X & X X X X & X X X X & X X X X & X X X X & X X X X & X X X X & X X X X & X X X X
\end{array}
\end{aligned}
$$

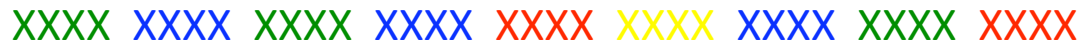

$$
\begin{aligned}
& \begin{array}{llllllllll} 
& X X X X & X X X X & X X X X & X X X X & X X X X & X X X X & X X X X & X X X X & X X X X
\end{array} \\
& \begin{array}{lllllllllllllllllll} 
& X X X X & X X X X & X X X X & X X X X & X X X X & X X X X & X X X X & X X X X & X X X X & X X X X
\end{array} \\
& X X X X \quad X X X X \quad X X X X \quad X X X X \quad X X X X \quad X X X X
\end{aligned}
$$


Stroop Test - Section Three

\author{
YELLOW BLUE RED YELLOW RED GREEN \\ RED YELLOW BLUE GREEN RED GREEN YELLOW \\ BLUE GREEN RED BLUE YELLOW RED YELLOW \\ BLUE GREEN RED YELLOW BLUE YELLOW \\ BLUE RED GREEN BLUE YELLOW RED BLUE GREEN RED \\ YELLOW RED GREEN BLUE YELLOW RED \\ YELLOW GREEN BLUE YELLOW GREEN RED BLUE \\ YELLOW RED YELLOW BLUE GREEN \\ YELLOW BLUE RED GREEN YELLOW GREEN RED BLUE \\ GREEN YELLOW RED BLUE YELLOW RED BLUE \\ GREEN RED BLUE GREEN YELLOW GREEN BLUE RED \\ YELLOW BLUERED YELLOW GREEN BLUE YELLOW \\ GREEN BLUE RED GREEN YELLOW GREEN BLUE RED \\ YELLOW GREEN YELLOW RED BLUE RED YELLOW \\ GREEN BLUE RED GREEN YELLOW BLUE GREEN BLUE \\ YELLOW RED GREEN RED BLUE YELLOW BLUE YELLOW \\ GREEN RED BLUE GREEN YELLOW RED GREEN \\ YELLOW BLUE RED BLUE YELLOW GREEN YELLOW
}


GREEN BLUE RED BLUE RED YELLOW GREEN RED

GREEN BLUE YELLOW GREEN YELLOW BLUE RED BLUE

GREEN RED YELLOW BLUE YELLOW RED GREEN

YELLOW RED BLUE GREEN YELLOW BLUE RED GREEN

YELLOW GREEN RED BLUE YELLOW RED GREEN

BLUE YELLOW BLUE GREEN RED 
Rating of Perceived Exertion

\section{$\underline{\text { Rating of Perceived Exertion }}$}

6

7 Very, Very Light

8

9 Very Light

10

11 Fairly Light

12

13 Somewhat Hard

14

15 Hard

16

17 Very Hard

18

19 Very, Very Hard

20 
Perceived Thermal Sensation

\section{Thermal Scale}

0 Unbearably Cold

1 Very Cold

2 Cold

3 Cool

4 Comfortable

5 Warm

6 Hot

7 Very Hot

8 Unbearably Hot 


\title{
Institutional Review Board Informed Consent Form
}

\section{CONSENT TO PARTICIPATE IN RESEARCH}

\author{
Physiological and perceived effects of field cooling during simulated firefighting activity
}

You are asked to participate in a research study during a normal department training session conducted by Dr. Susan Yeargin, Amy McKenzie, Dr. Lindsey Eberman, and Dr. Derek Kingsley, from the Department of Applied Medicine and Rehabilitation at Indiana State University. A portion of this study will be used for Amy McKenzie to complete her Master's Thesis. Your participation in this study is entirely voluntary. Please read the information below and ask questions about anything you do not understand, before deciding whether or not to participate.

You have been asked to participate in this study because you are a firefighter and the devices being tested in this study are marketed specifically for you and your occupation. To be eligible in this study, you must be a male/female firefighter between the ages of 18 and 60 and have successfully completed and filed your annual physical examination with the fire department. You should not participate if you cannot perform all job activities without restrictions or accommodations. You should also not participate if you have any form of cardiovascular disease, are taking any medication that alters heart rate, or have a condition that would prevent you from taking the temperature capsule.

\section{PURPOSE OF THE STUDY}

The purpose of this study is to determine how your body responds, physically and mentally, to two cooling devices during firefighter department training session. This study will determine if the cooling devices are beneficial to firefighters by reducing the rise in body temperature.

\section{PROCEDURES}

If you volunteer to participate in this study, you will be asked to do the following things:

- Volunteer approximately 4 to 5 hours of your time over two separate days:

Day One:

- Complete a health history questionnaire, informed consent form, and a current health questionnaire.

- Complete a step test. This requires you to step up for three minutes at a fast pace and have your heart rate recorded by wearing a heart rate strap for 15 seconds after completing the test.

- This will require about one hour of your time.

Day Two:

- You will swallow a capsule at your station in order to measure internal body temperature 5-8 hours before arriving at the facility and complete a current heath questionnaire asking how you currently feel.

- You will arrive to the District 7 Training Facility for a training session.

- You will stand on a scale wearing only shorts and a sports bra(if female) in order to measure your body weight before and after the training session.

- You will provide a urine sample before and after the training session in order to measure hydration status.

-We will help you secure a strap around your chest to measure heart rate during the training session.

- You will be asked to provide your opinion about how hard or easy you feel you are working and how hot or cold you feel at different times throughout the training session.

- You will be asked to take a verbal test which asks you to say out loud the word or the color in which a word is written at different times throughout the training session to measure brain function.

IRB Number: $10-157$

Date of IRB Approval: July 20, 2010

Page 1 of 4

Project Expiration Date: July 14, 2011 
- You will complete a departmental training session designed by the training officer while wearing all the appropriate gear, including a self-contained breathing apparatus.. You will do this for 15-minutes, then "exchange" air cylinders and do it again. Then you will "rest" for 15 minutes. and the training session will take approximately one hour and 40 minutes.

-You will be allowed to drink fluids any time you want during the training session.

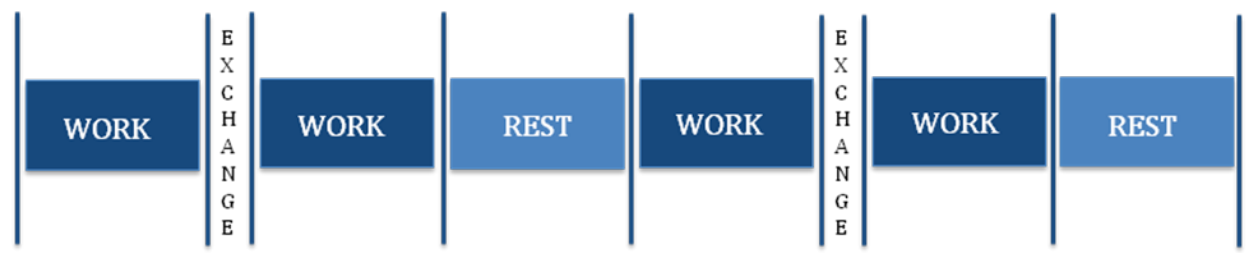

-You will be randomly placed in one of three groups by pulling a piece of paper out of a hat:

1. Head cooling group- you will wear a cold gel pack inside your helmet during "work"

2. Arm chair group- you will "rest" while sitting in a chair with your hands and forearms in cold water

3. Control group- you will do "work" and "rest" without using a cooling method

\section{POTENTIAL RISKS AND DISCOMFORTS}

There are no known discomforts to use of the temperature capsule as it moves through your body. The materials used to make the capsule will not harmyou. The known symptoms of capsule rupture are nausea, vomiting, or diarrhea. In 22 years of conducting research using this capsule, there have been no known adverse effects associated with its use. The risk of not passing the capsule is possible, but has never occurred. Passage of the capsule is similar to passing a small marble.You are encouraged to immediately report to any of the researchers if any of the above mentioned symptoms arise.

You may also be at risk of developing a heat illness during this study (heat cramps, heat exhaustion, and heat stroke). However, this risk is no greater than during any other training session. Additionally, your body temperature will be monitored throughout the study. You will have the opportunity to stop participating in the training sessions at any time for any reason. Also, if you experience symptoms of a heat illness (nausea, dizziness, muscle spasms, confusion, disorientation, or personality changes), your training officer will be made aware of the situation and you will be asked to stop exercising. Should you require treatment, at least one certified professional will be present to provide you the appropriate treatment, which typically involves drinking water, resting, and cooling the body with cold water tubs. You are responsible for any cost associated with further evaluation and treatment of any injury you sustain while participating in this study.

There are no known risks with using the head cooling device or arm chair cooling device. The only discomfort you may experience is a sensation of cold on your head or arms and possibly shivering.

You may be at risk of embarrassment during this study since you will be asked to step on a scale wearing only shorts and a sports bra, expose your chest to apply a strap to measure heart rate, and provide a urine sample. This risk is minimal, as the researchers will do their best to make these processes as quick as possible. Additionally, you may be allowed to keep your shirt on and you will provide your urine sample in a private bathroom and return it to the researchers wrapped in a paper towel. 


\section{POTENTIAL BENEFITS TO SUBJECTS AND/OR TO SOCIETY}

By participating in this study, you will benefit by learning about your hydration status, heart rate, body temperature, and sweat rate. With this information, you can better adjust your training and water drinking habits to enhance your safety while on the job. There are no other direct benefits to you.

Additionally, based on the outcomes of this study, fire departments can make more educated choices on the use of various cooling methods during extended fire emergencies and during training sessions. Choosing good cooling methods will keep firefighters safer and possibly avoid heat illnesses.

\section{INCENTIVE FOR PARTICIPATION}

There will be a drawing, for two people to win a free dinner at Stables Restaurant. At the completion of the study, your study number will be placed in a hat and two people will be randomly chosen to win the dinner. If you choose to withdrawal from the study during the training session, you will still be included in the drawing.

\section{CONFIDENTIALITY}

Any information that is obtained in connection with this study will remain confidential and will be disclosed only with your permission or as required by law. Confidentiality will be maintained by means of assigning you a number. This number will be recorded on a master list that will be seen only by the researchers. The master list and all data sheets will be kept in a locked file cabinet by the primary investigator and then stored in a password-protected folder on a computer. It is not possible to hide your participation in the study from peers or administrations that are training at the facility with you since you will be wearing a subject number on your uniform sleeve. However, the Chief and Training Officer are supportive of the study.

\section{PARTICIPATION AND WITHDRAWAL}

You can choose whether or not to be in this study. If you volunteer to be in this study, you may withdraw at any time without consequences of any kind or loss of benefits to which you are otherwise entitled. You may also refuse to answer any questions you do not want to answer. There is no penalty if you withdraw from the study and you will not lose any benefits to which you are otherwise entitled.

The investigator may withdraw you from this research if circumstances arise which warrant removal. If you display signs or symptoms of a heat illness, you will be asked to discontinue the training for your own safety.

\section{IDENTIFICATION OF INVESTIGATORS}

If you have any questions or concerns about this research, please contact the following researchers:

Susan Walker Yeargin, PhD, ATC

susan.yeargin@indstate.edu

812-237-3962

\author{
Amy L. McKenzie, ATC, PES \\ amckenzi@indstate.edu \\ 610-551-5487
}




\section{RIGHTS OF RESEARCH SUBJECTS}

If you have any questions about your rights as a research subject, you may contact the Indiana State University Institutional Review Board (IRB) by mail at Indiana State University, Office of Sponsored Programs, Terre Haute, IN 47809, by phone at (812) 237-8217, or e-mail the IRB at irb@indstate.edu. You will be given the opportunity to discuss any questions about your rights as a research subject with a member of the IRB. The IRB is an independent committee composed of members of the University community, as well as lay members of the community not connected with ISU. The IRB has reviewed and approved this study.

I understand the procedures described above. My questions have been answered to my satisfaction, and I agree to participate in this study. I have been given a copy of this form.

Printed Name of Subject

Signature of Subject

Date

IRB Number: 10-157

Page 4 of 4

Date of IRB Approval: July 20, 2010

Project Expiration Date: July 14, 2011 
APPENDIX D: RAW DATA 
Subject Demographics and Hydration

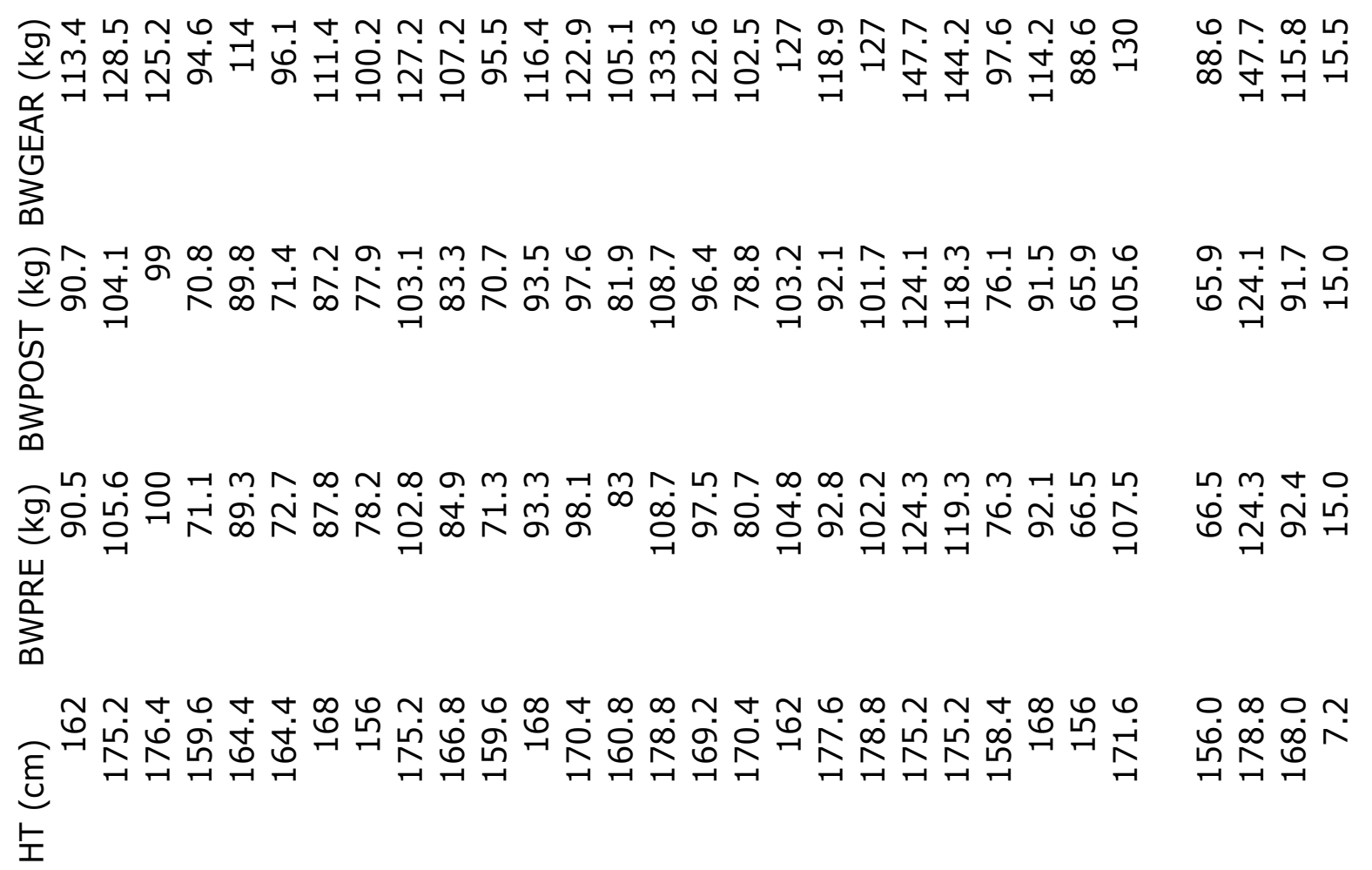

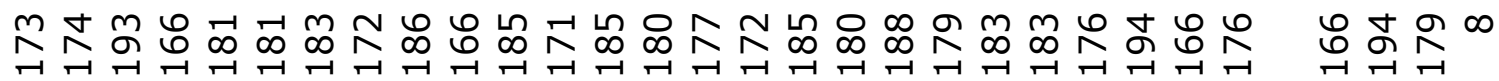

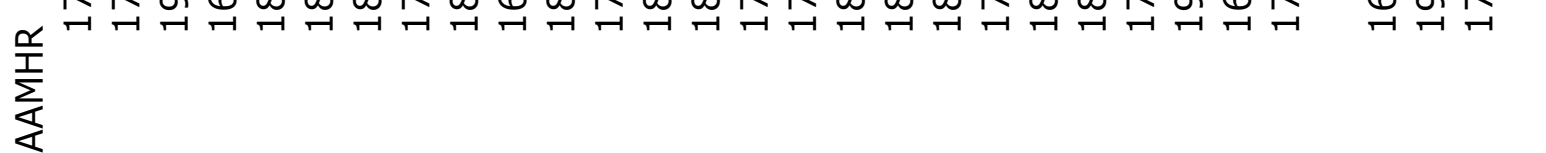

암 岕

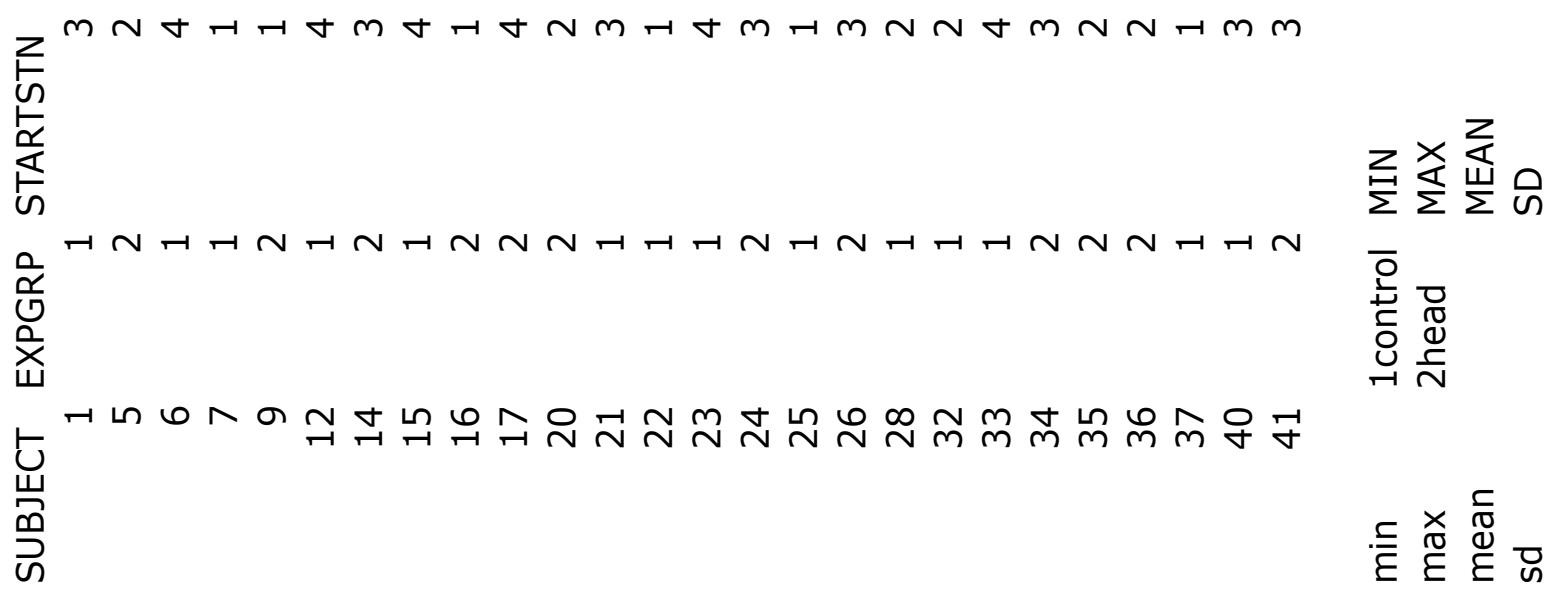




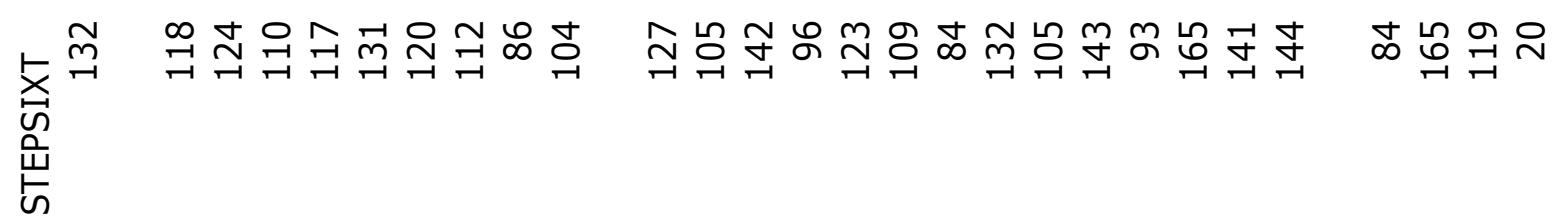

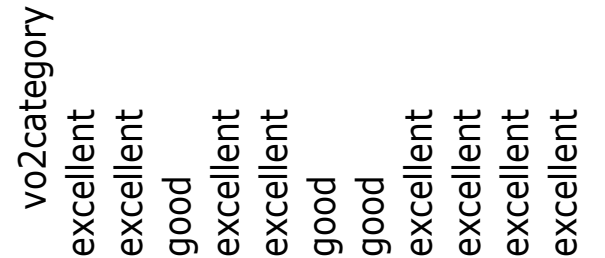
n m m m n n ने

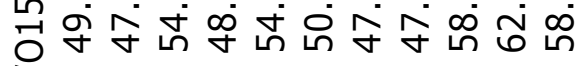
点

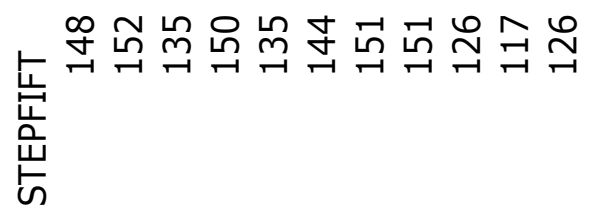

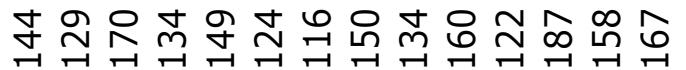

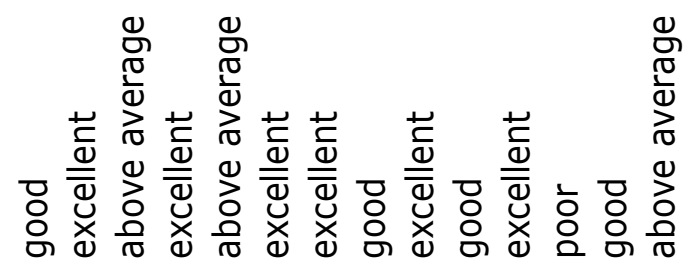
ம 다 ம் กิ m 苞

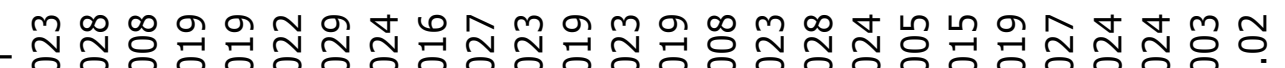
ص

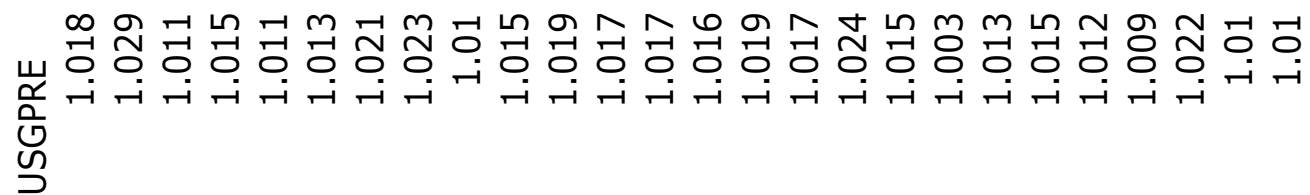

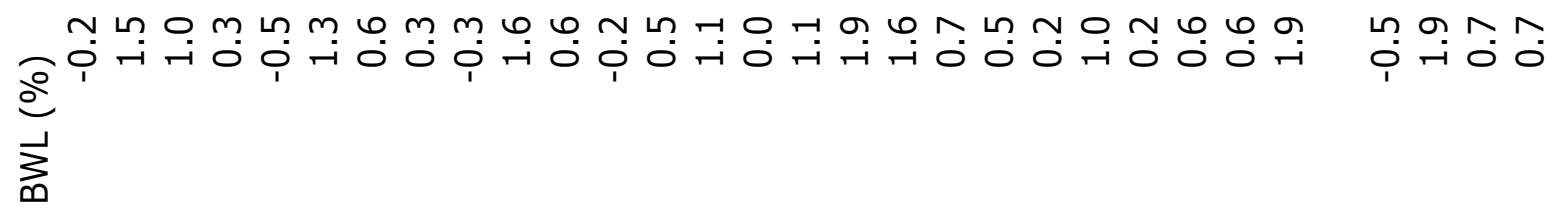

ดิด ด ำ ָN N

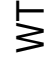

孚

比

न

ㅇํำ ס

m ㄷ․ ำ $m$ ㅁํํ

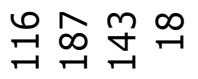

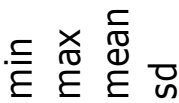



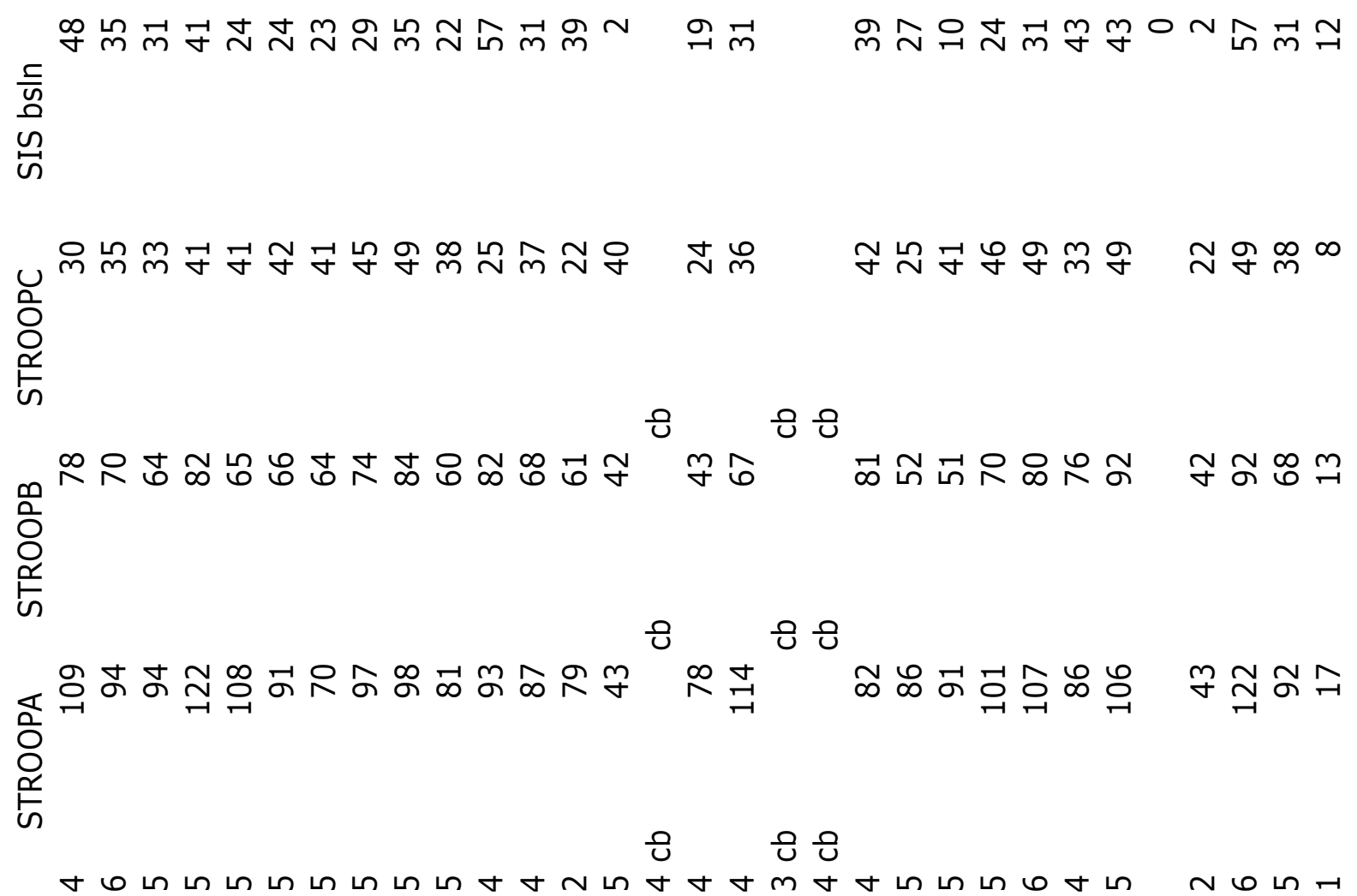

$\stackrel{n}{\llcorner}$

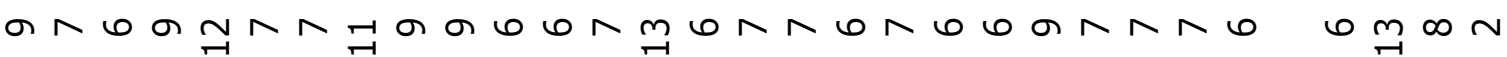
$\frac{w}{\alpha}$

공

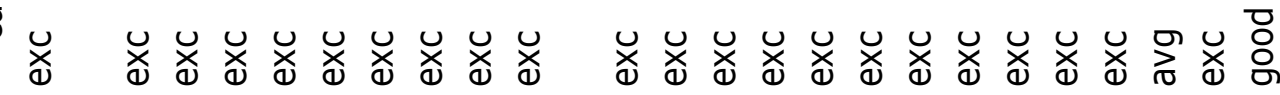

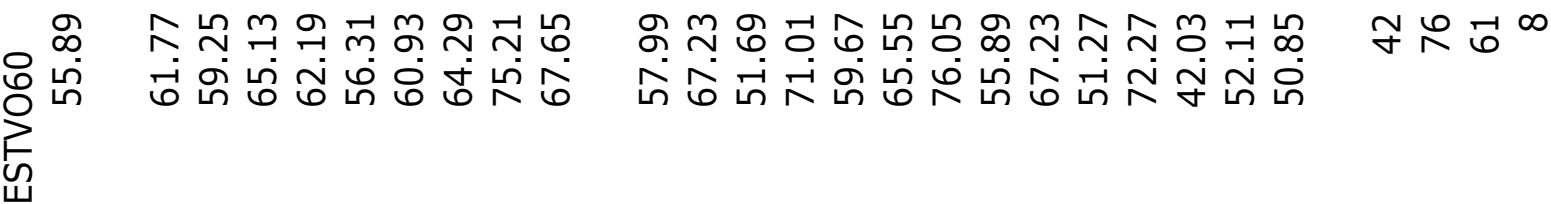

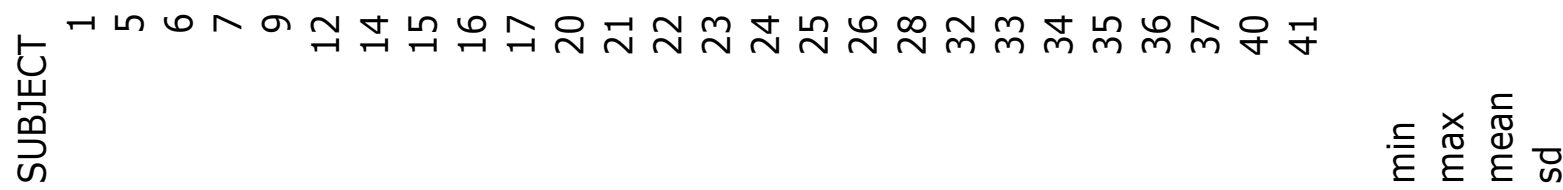




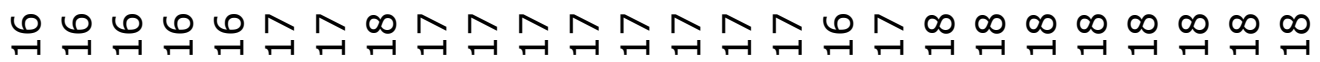

岩

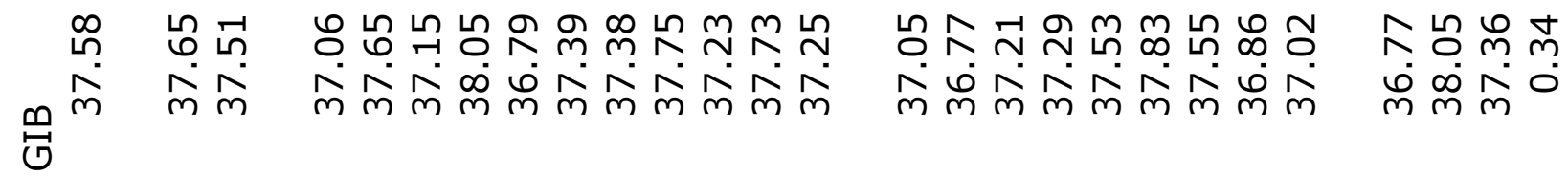

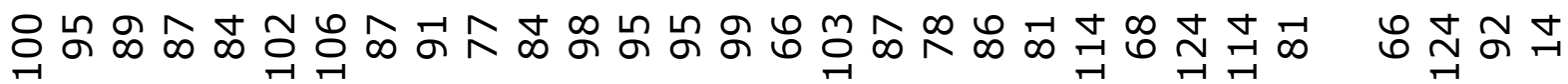
$\stackrel{\oplus}{\underline{I}}$

Nㅇำ 主 岂

$\infty$ i

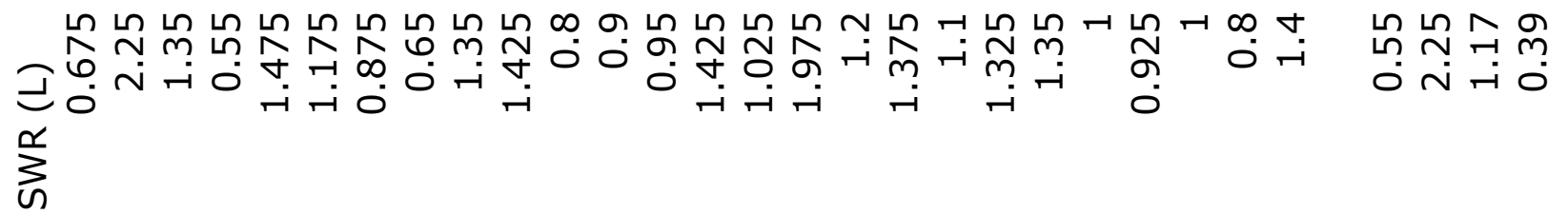

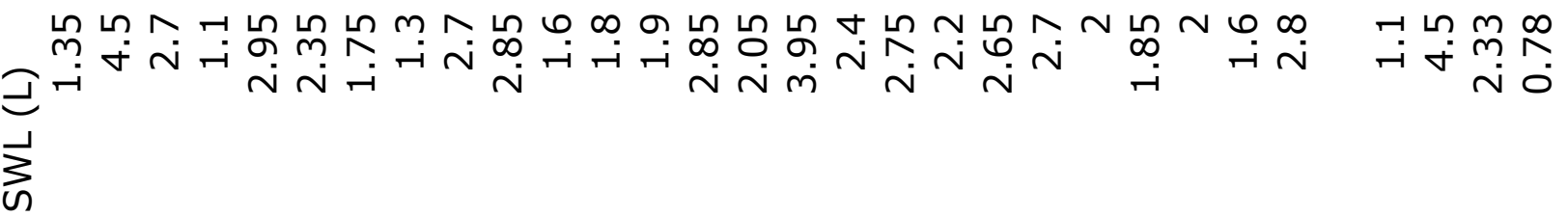

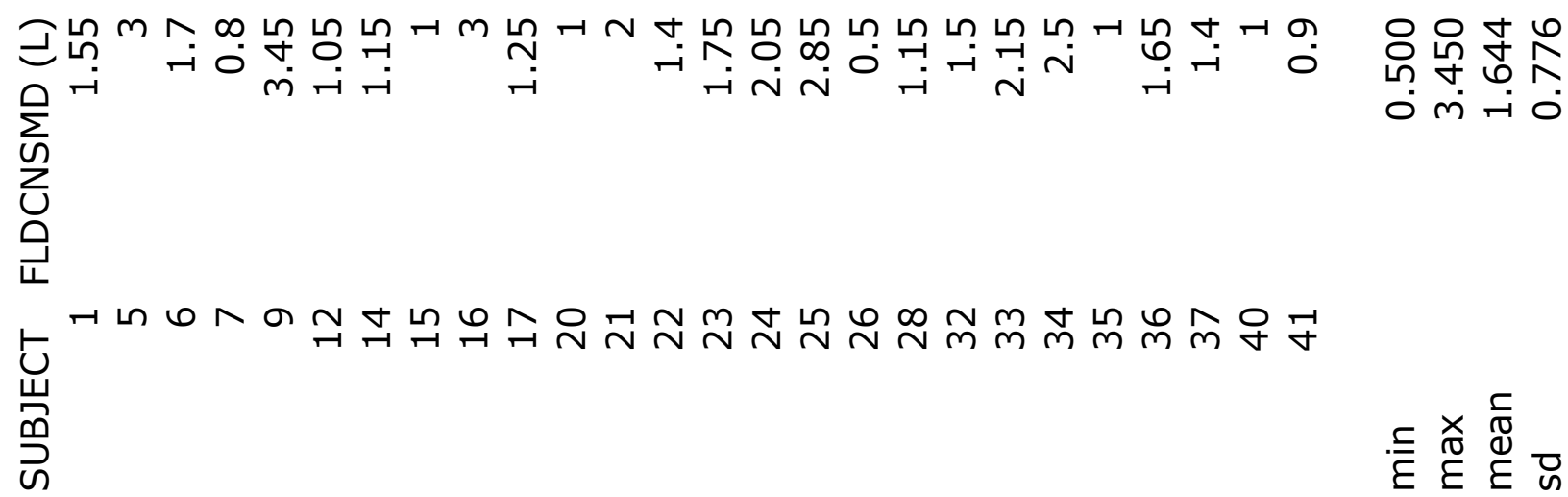




\section{Elapsed Time during Training Protocol}

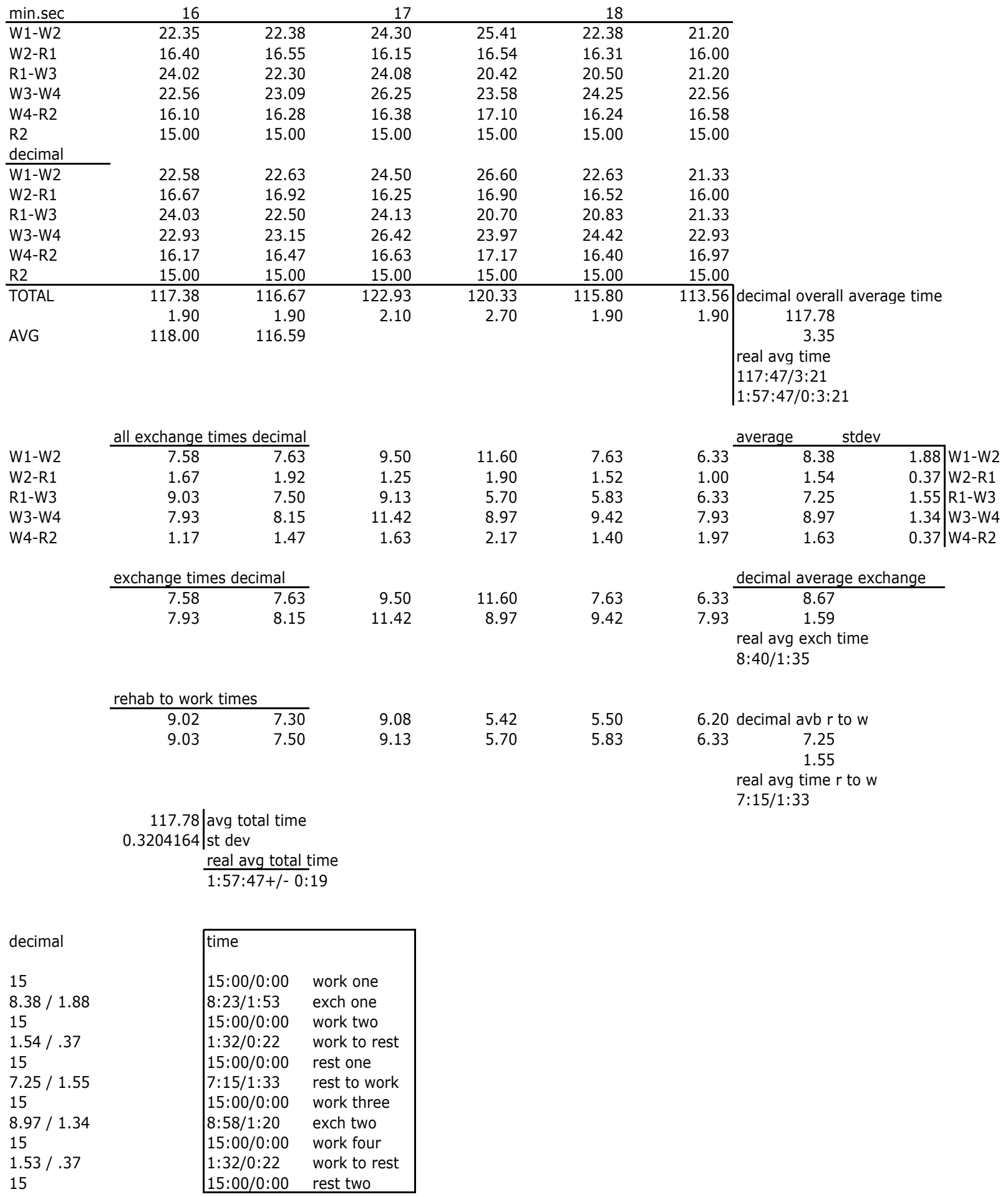


Environmental Conditions

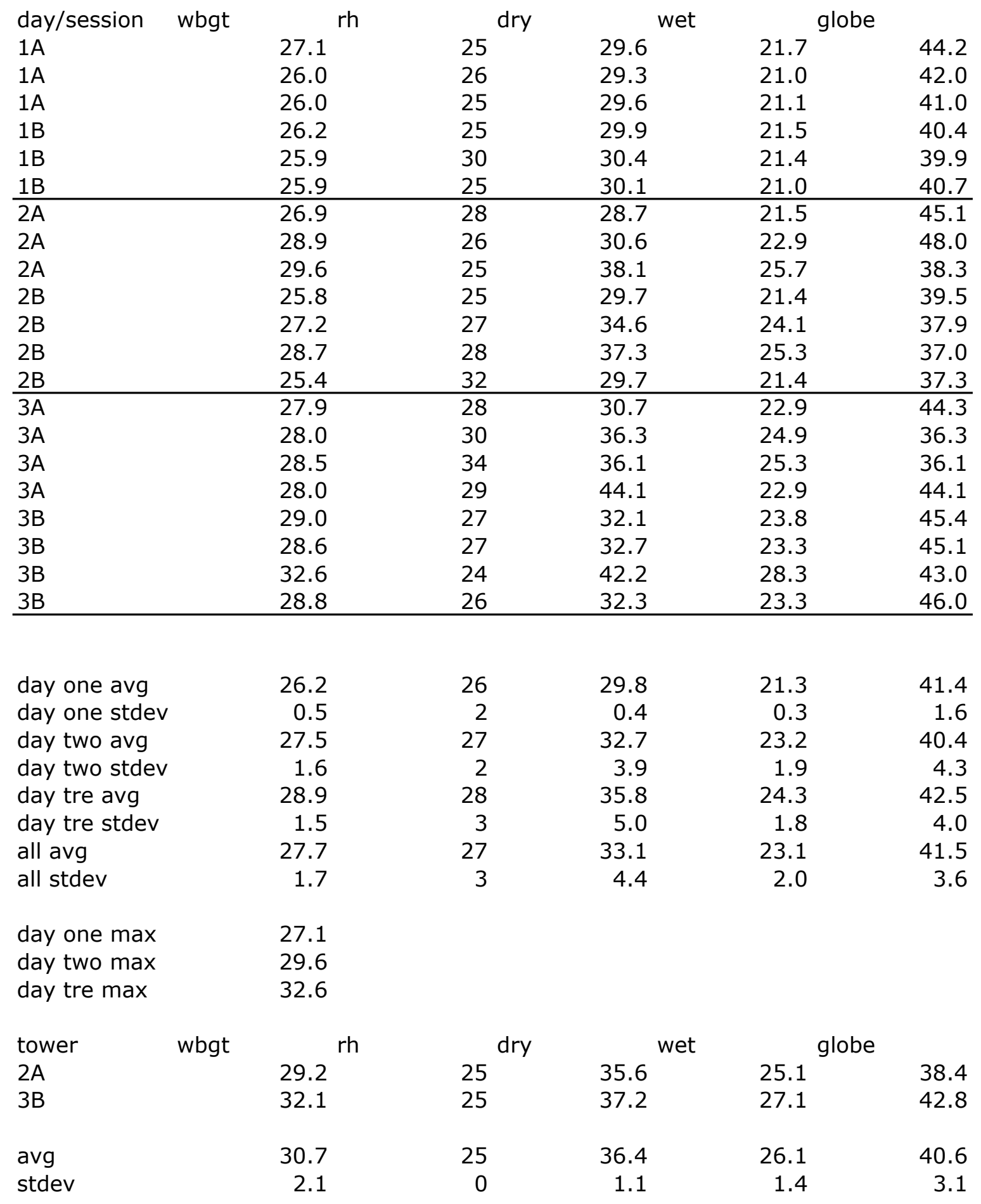


Heart Rate

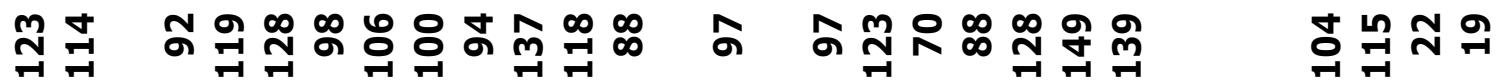

$\stackrel{n}{\underset{1}{2}}$

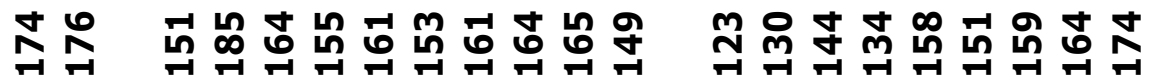

N
$\frac{0}{0}$
$\frac{0}{0}$

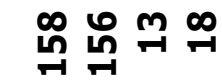

$\stackrel{n}{\stackrel{1}{5}}$

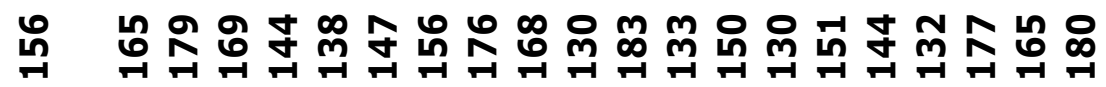

$\stackrel{+}{\text { 突 }}$

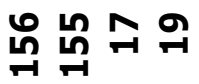

$\stackrel{n}{\stackrel{n}{m}}$

$\stackrel{m}{\equiv}$

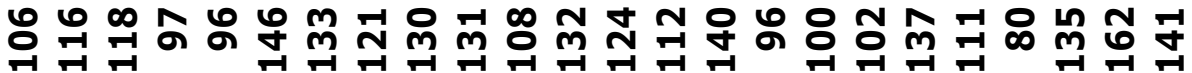

$\underset{2}{\stackrel{1}{2}}$

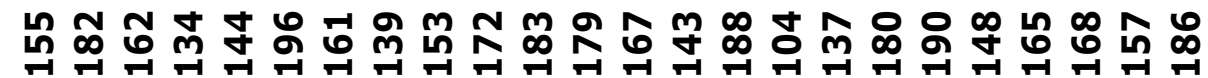

$\stackrel{\text { Ln }}{\stackrel{\text { I }}{\mathbf{S}}}$

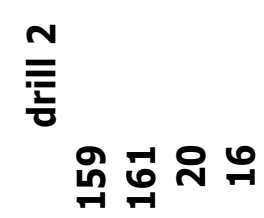

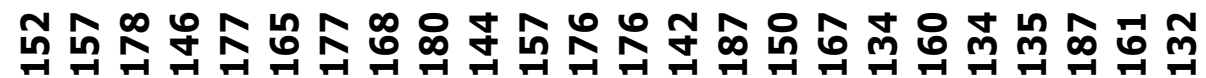

$\stackrel{n}{\underset{1}{3}}$

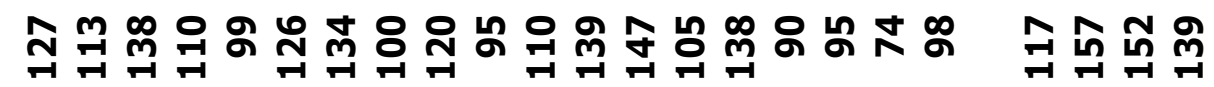

$\stackrel{0}{\mathrm{E}}$

m

$\underset{\sum}{\frac{1}{X}}$

$\stackrel{-1}{\overline{2}}$

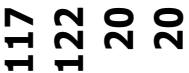

몬

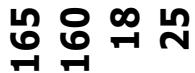

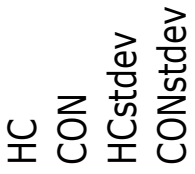

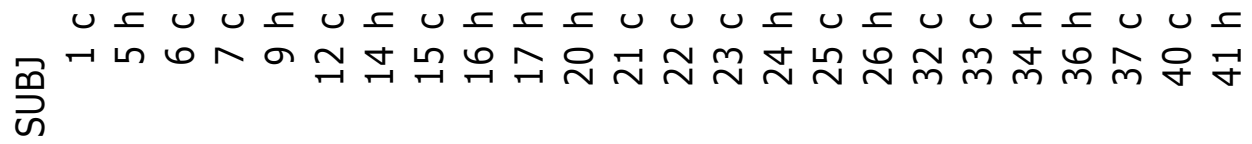




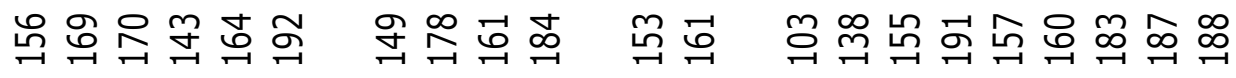

$\stackrel{6}{\frac{1}{3}}$

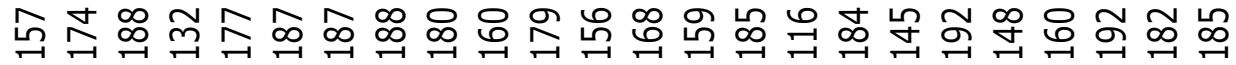

$\stackrel{m}{\stackrel{m}{\lessgtr}}$

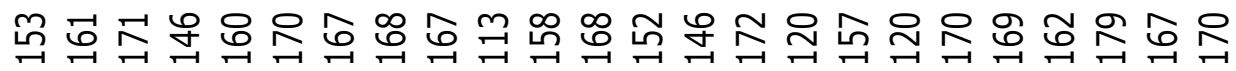

$\stackrel{ }{\frac{9}{3}}$

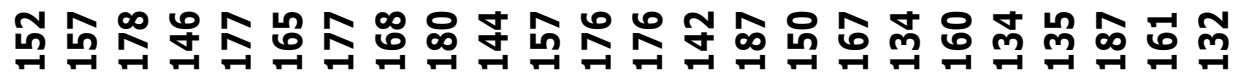

믈

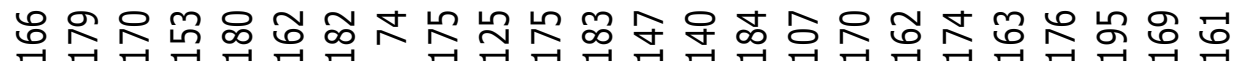

$\stackrel{\sim}{\rightleftharpoons}$

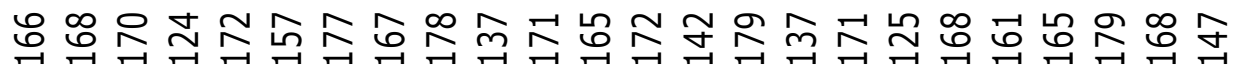

$\stackrel{\circ}{\risingdotseq}$

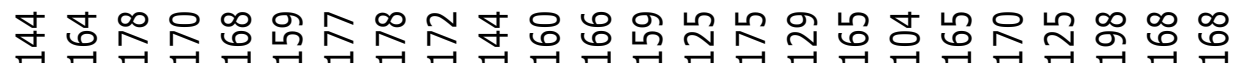

$\stackrel{6}{5}$

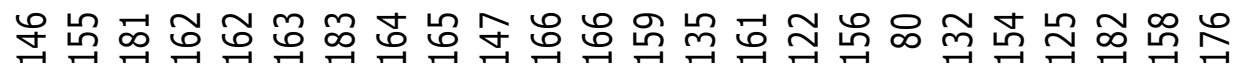

$\stackrel{m}{E}$

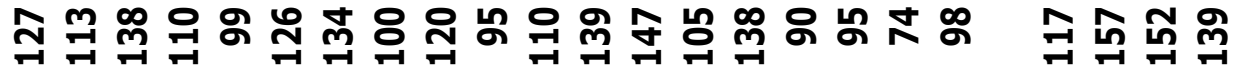

은

نᄃ 䍃 


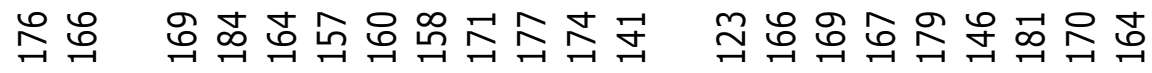

$\stackrel{0}{\stackrel{5}{3}}$

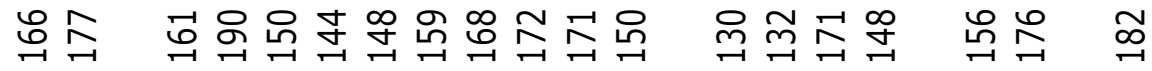

$\stackrel{m}{\stackrel{5}{3}}$

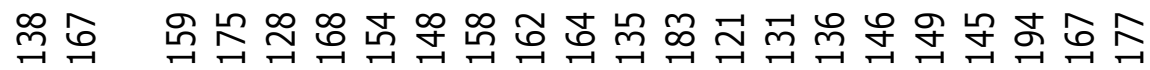

$\stackrel{0}{\stackrel{5}{3}}$

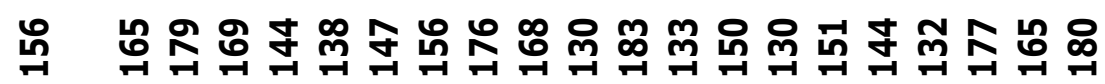

$\stackrel{n}{\text { 둔 }}$

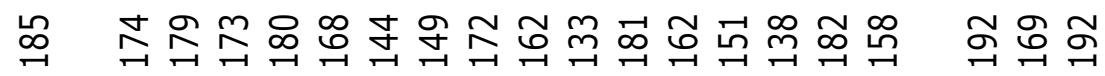

$\stackrel{\sim}{\stackrel{一}{m}}$

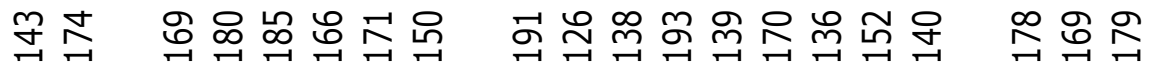

$\stackrel{a}{m}$

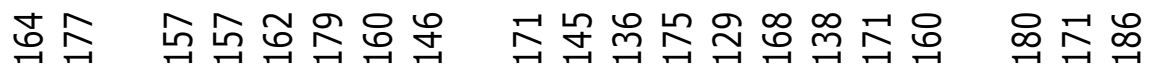

$\stackrel{\circ}{m}$

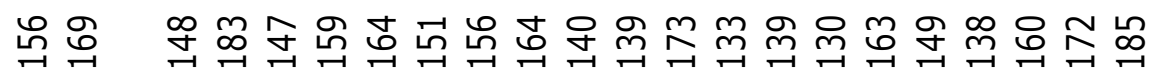

$\frac{m}{m}$

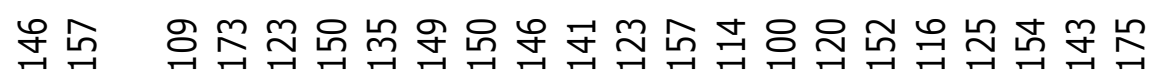

$\stackrel{\circ}{m}$

Uᄃ

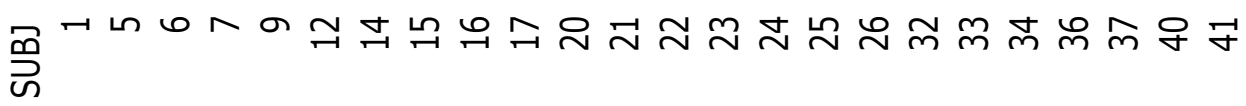




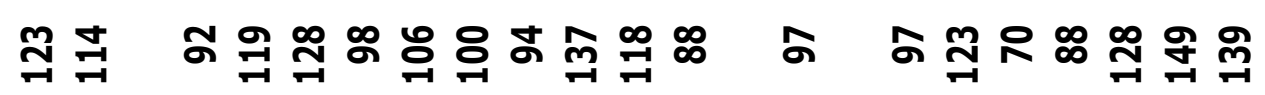

$\stackrel{\text { n) }}{\stackrel{1}{2}}$

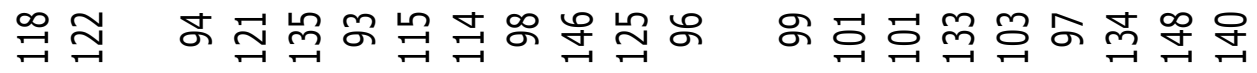

$\stackrel{\sim}{\rightleftharpoons}$

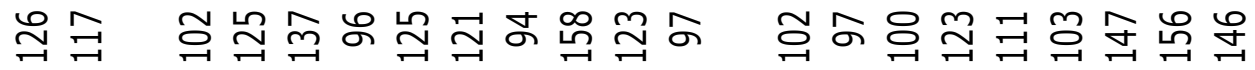

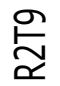

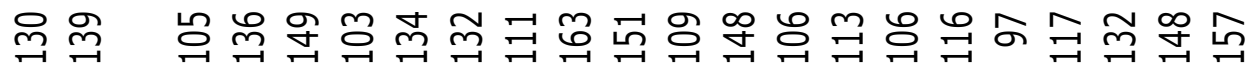

$\stackrel{\circ}{\check{2}}$

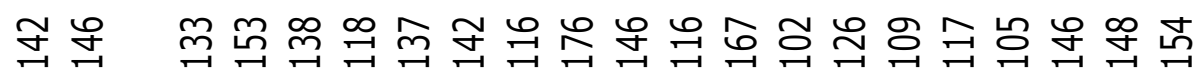

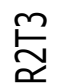

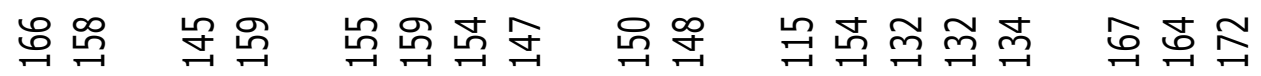

$\stackrel{\varrho}{\stackrel{2}{ }}$

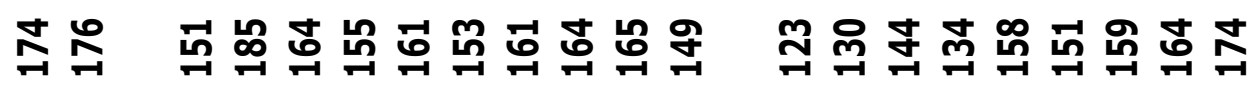

$\stackrel{\text { L }}{\stackrel{1}{\mathbf{Z}}}$

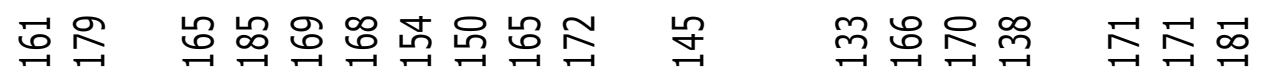

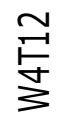

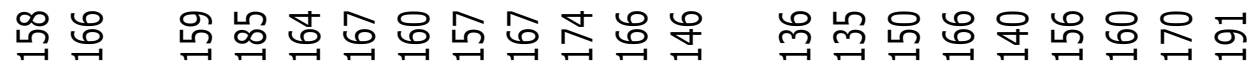

$\stackrel{\text { g }}{\stackrel{9}{8}}$

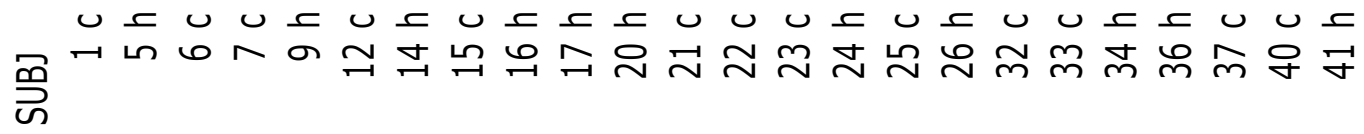




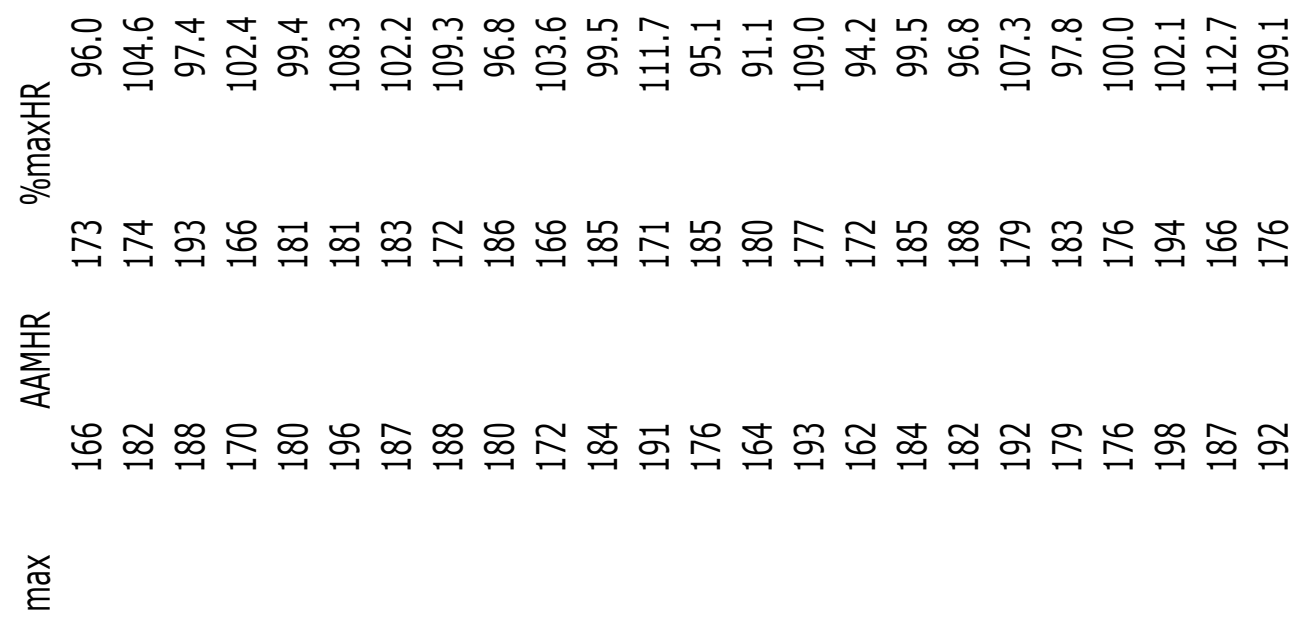

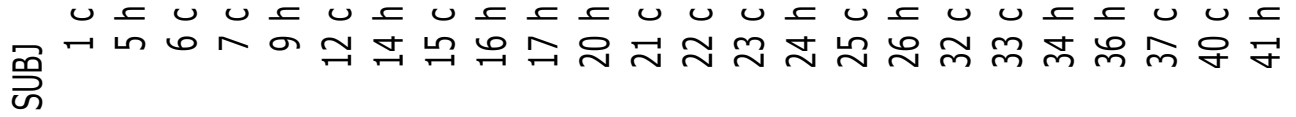




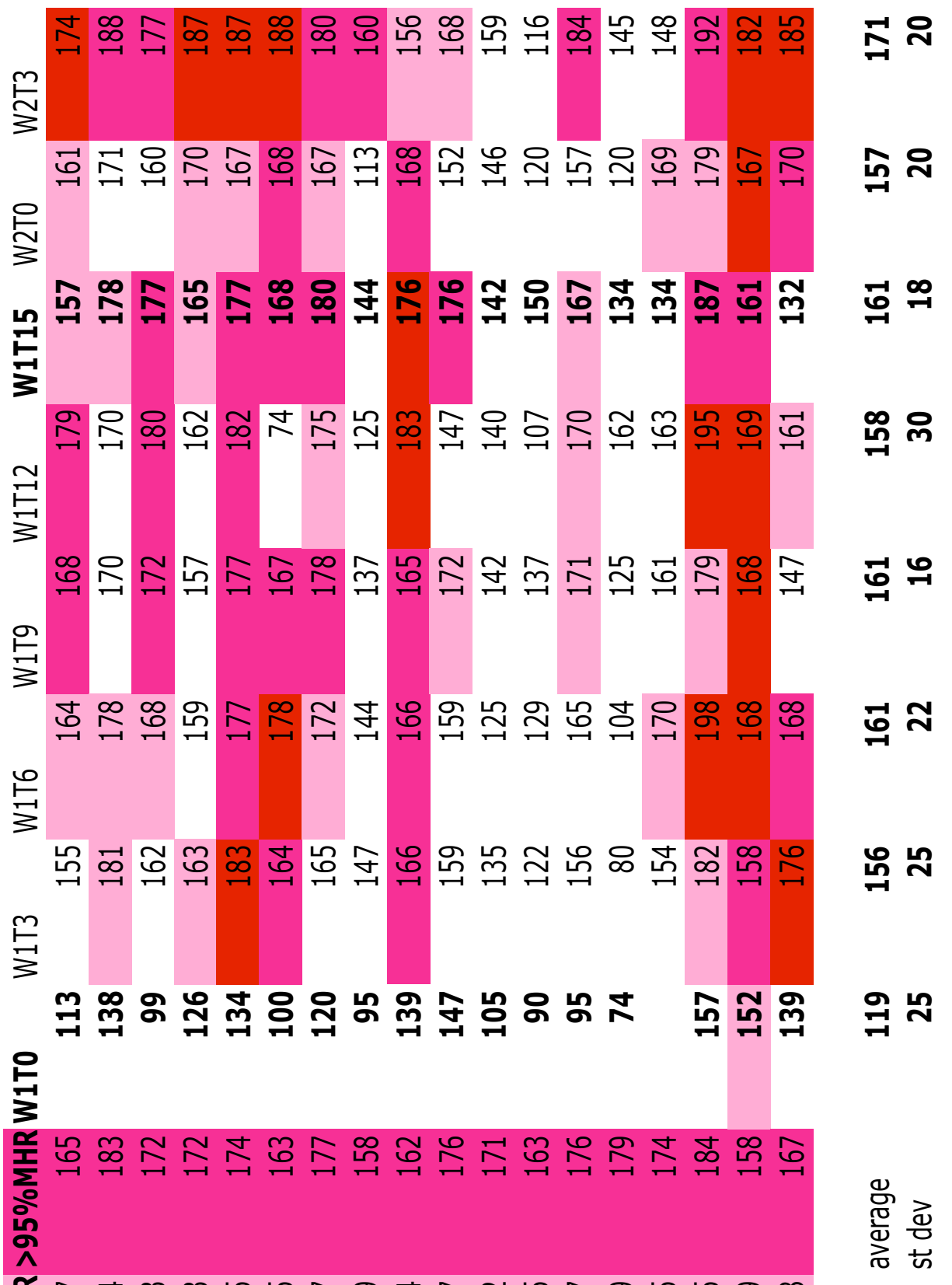

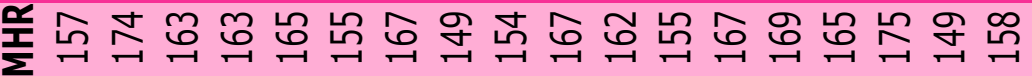

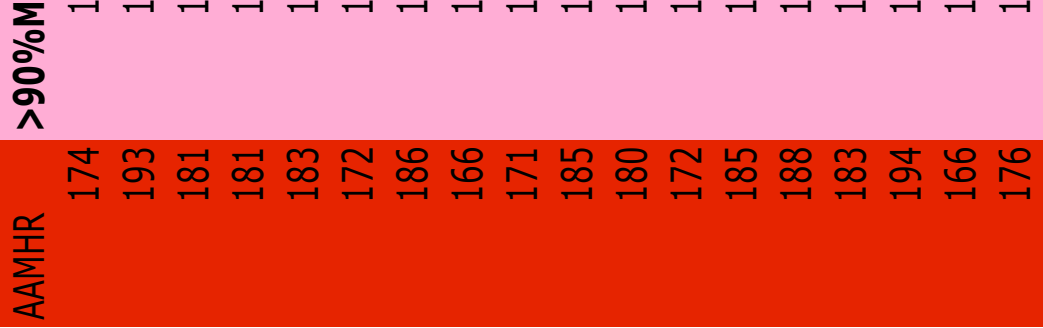

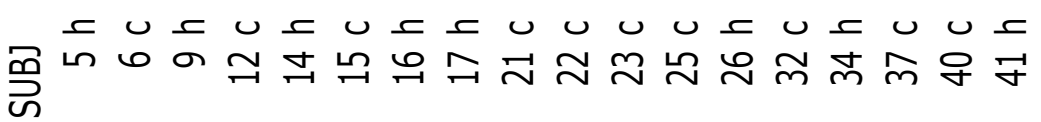




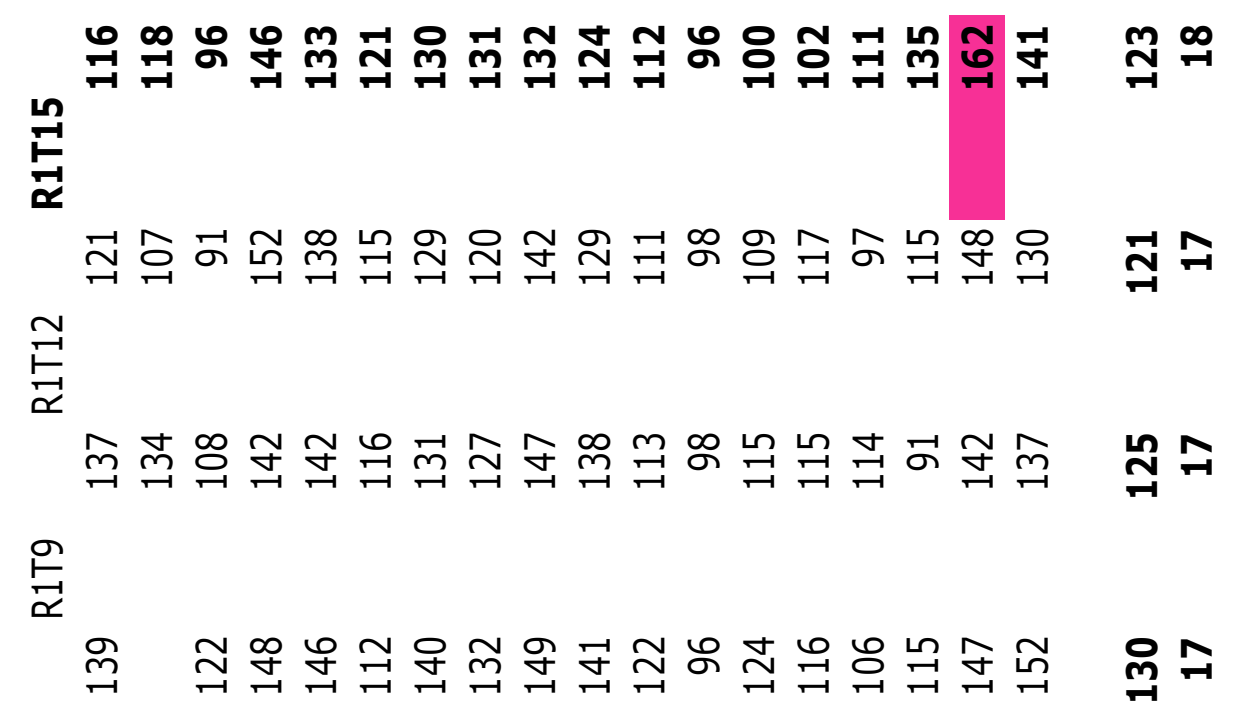

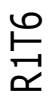

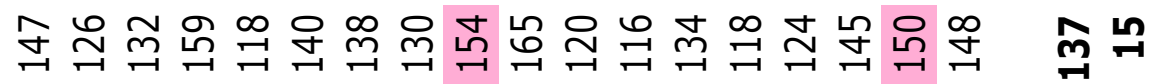

$\stackrel{m}{\rightleftharpoons}$

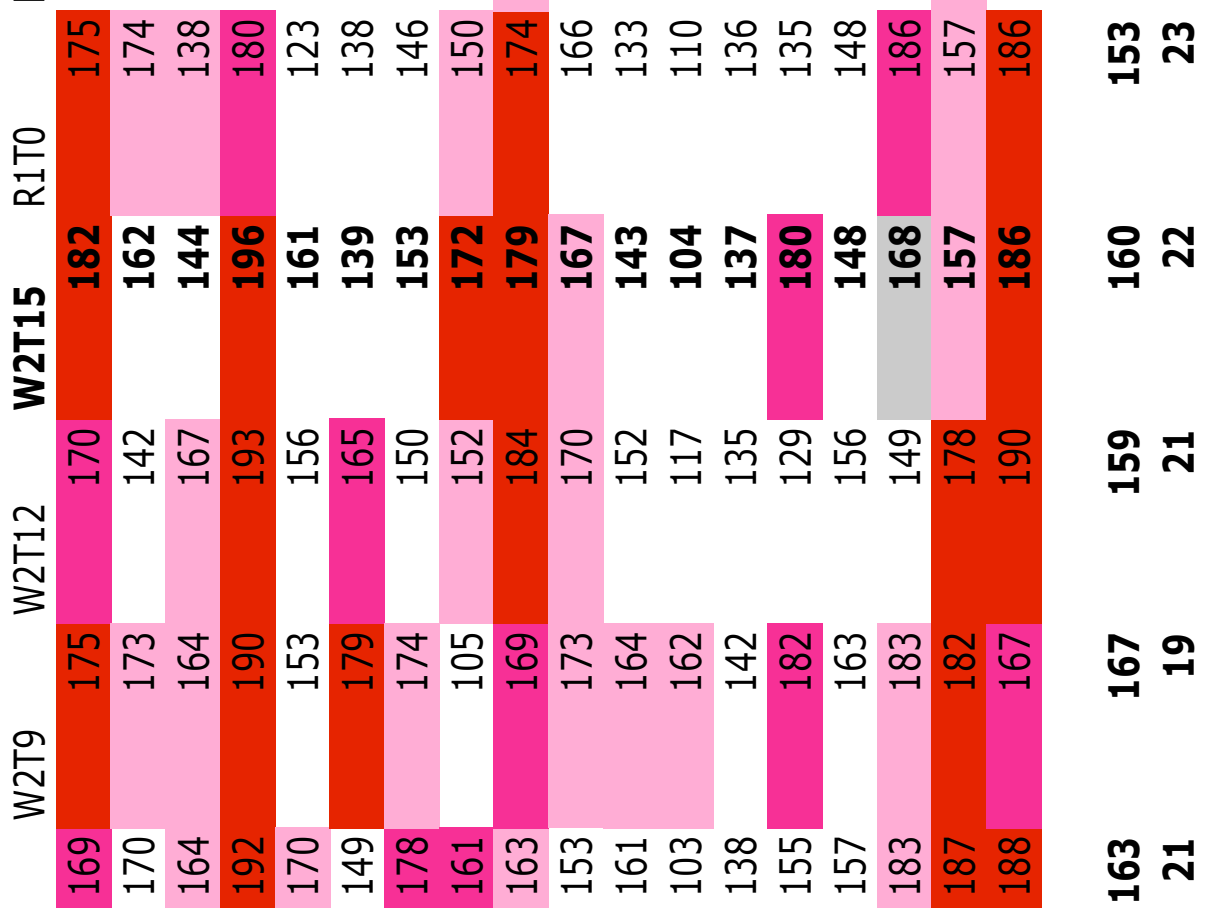

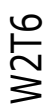

ᄃ 哥 ம 


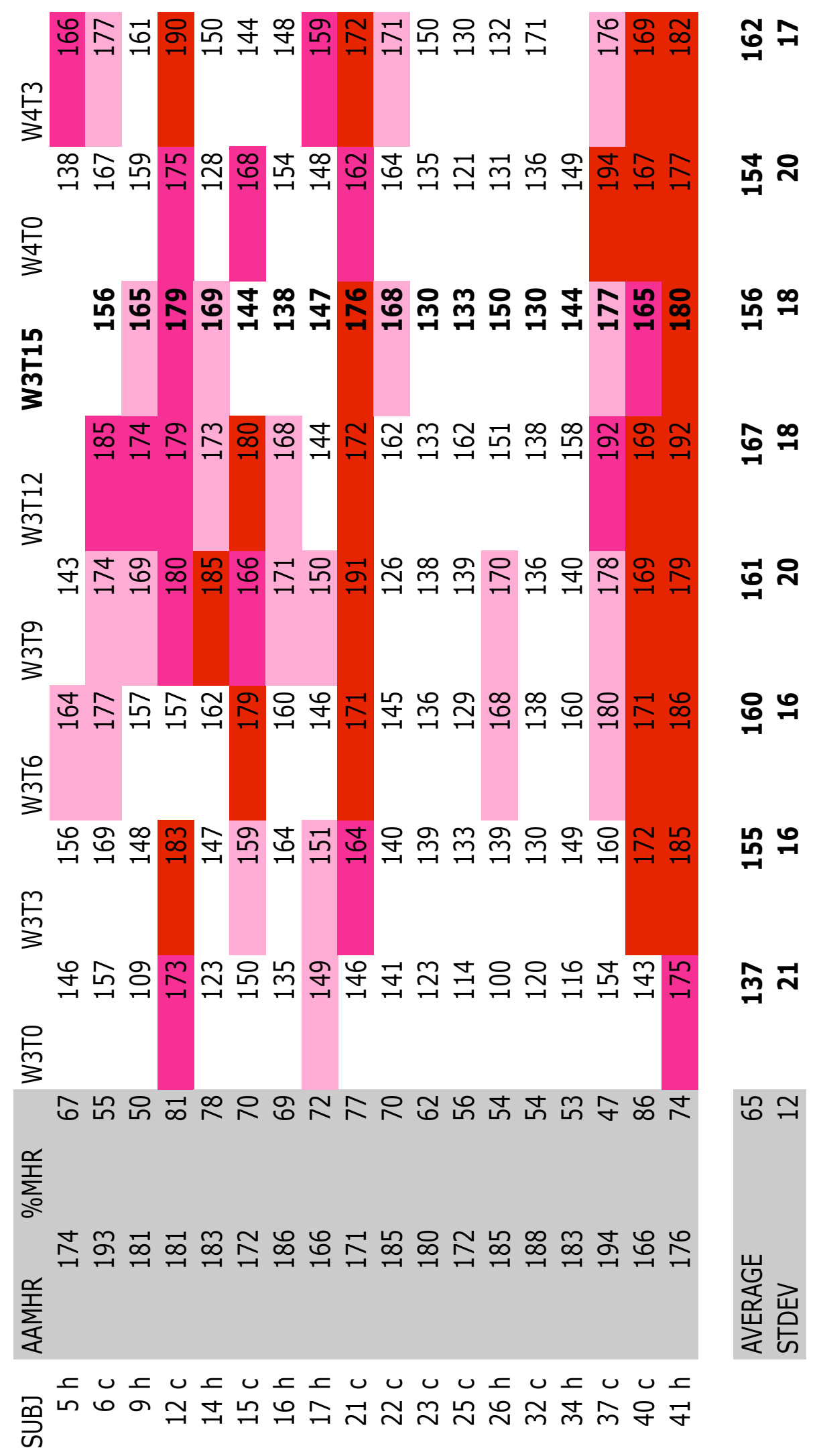




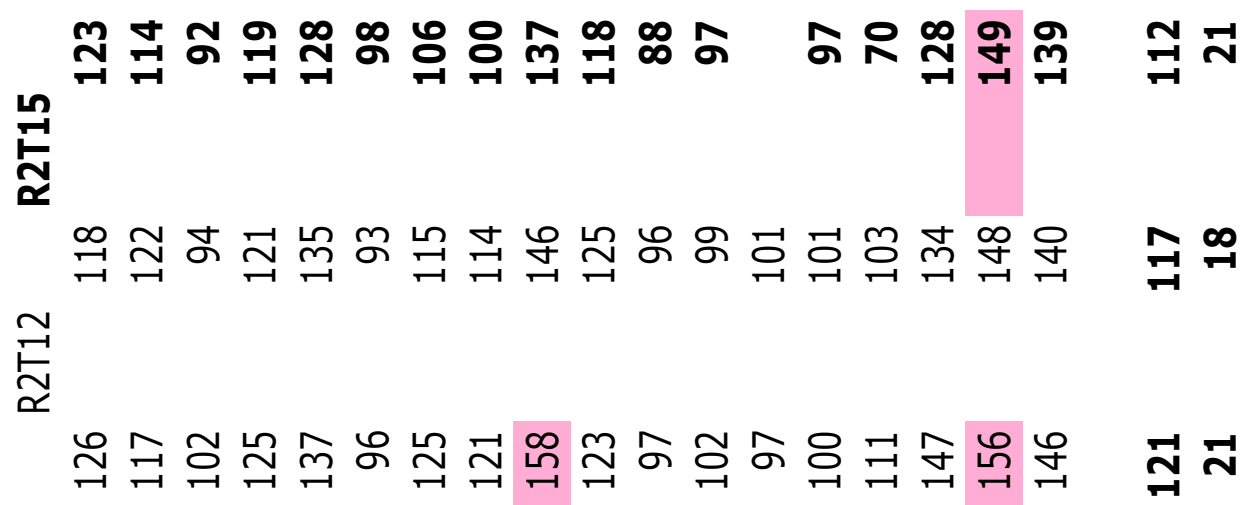
$\stackrel{\frac{g}{2}}{\check{1}}$

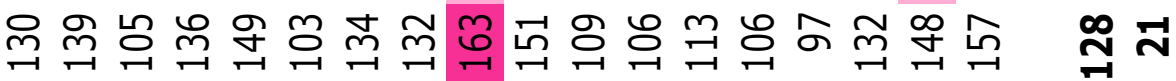

$\stackrel{\frac{6}{2}}{\stackrel{2}{\alpha}}$

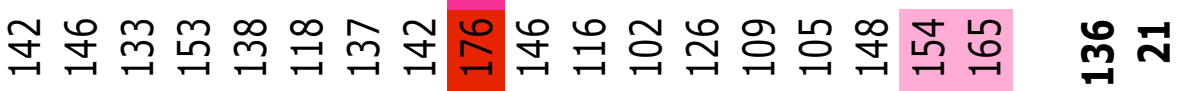

$\stackrel{m}{\frac{m}{2}}$

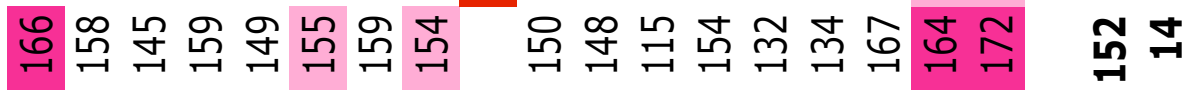

$\stackrel{\circ}{\stackrel{\circ}{ }}$

足

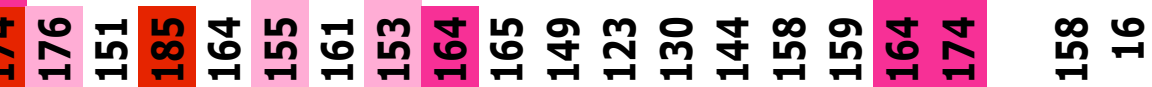

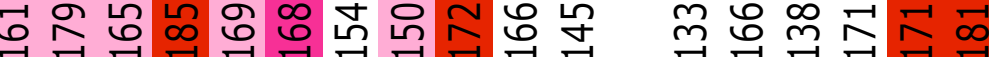

疍

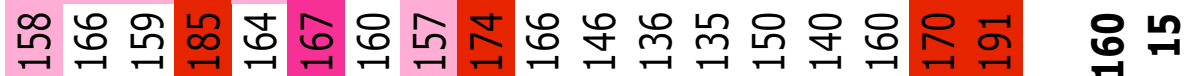

总

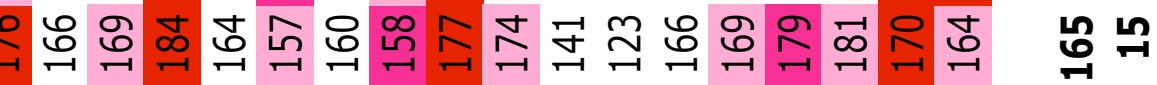

过

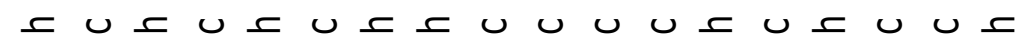
䒜 ம 


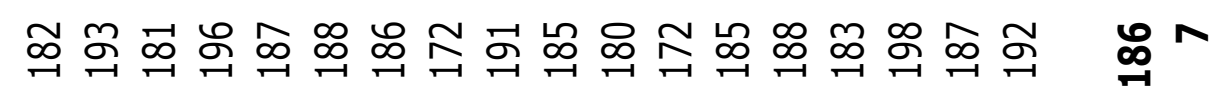

压

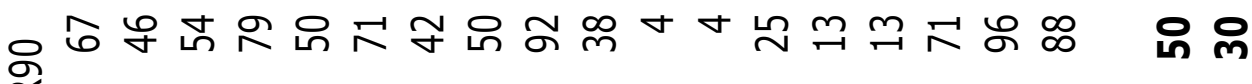

웅

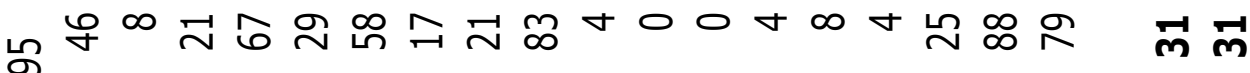
웅

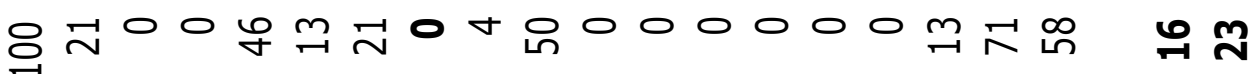
웅

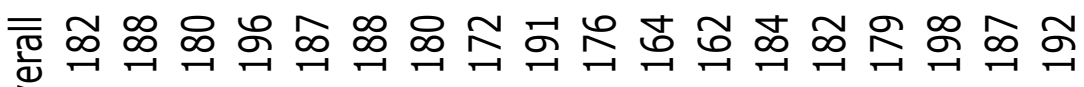

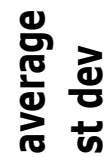
ठ

压

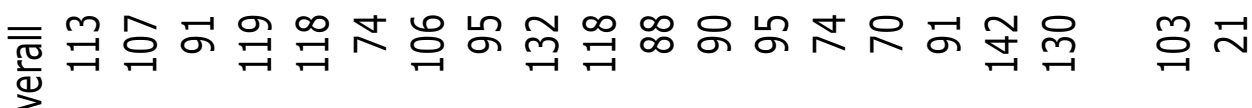
व

हᄐ

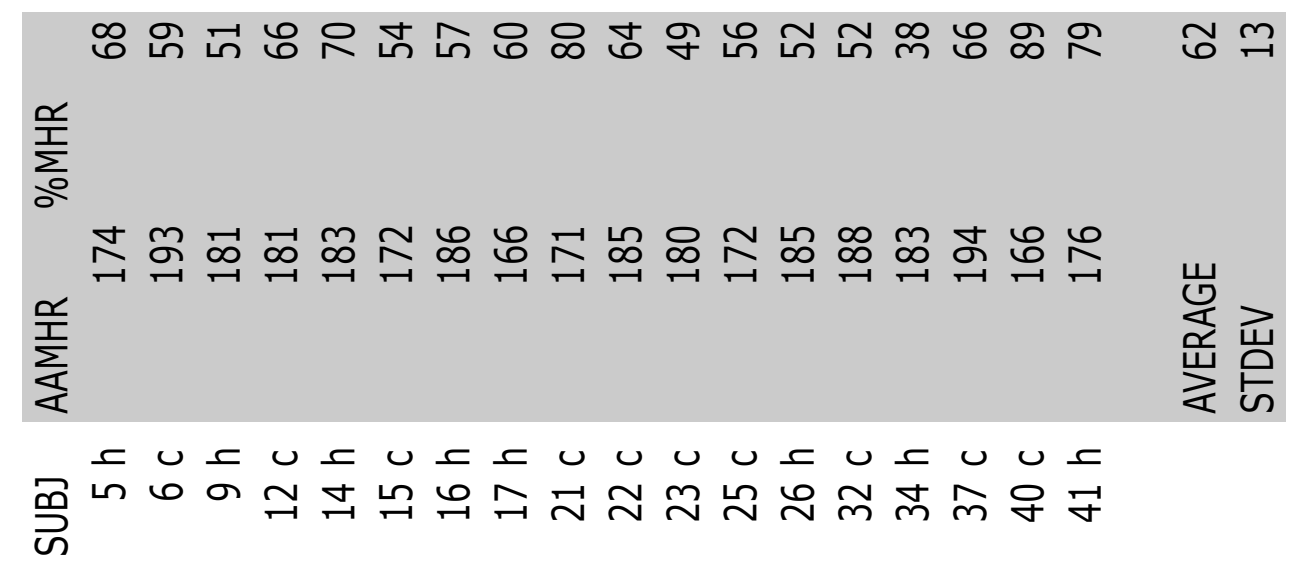



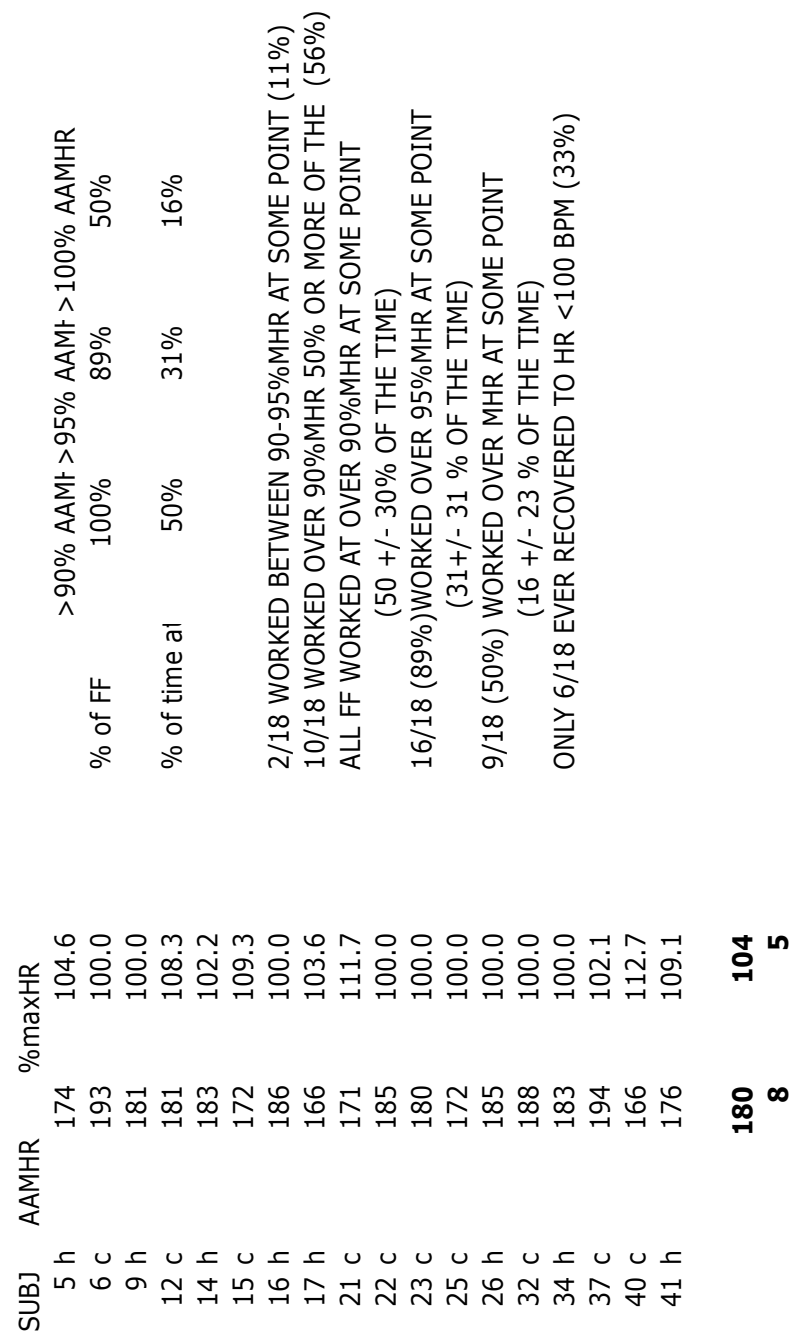


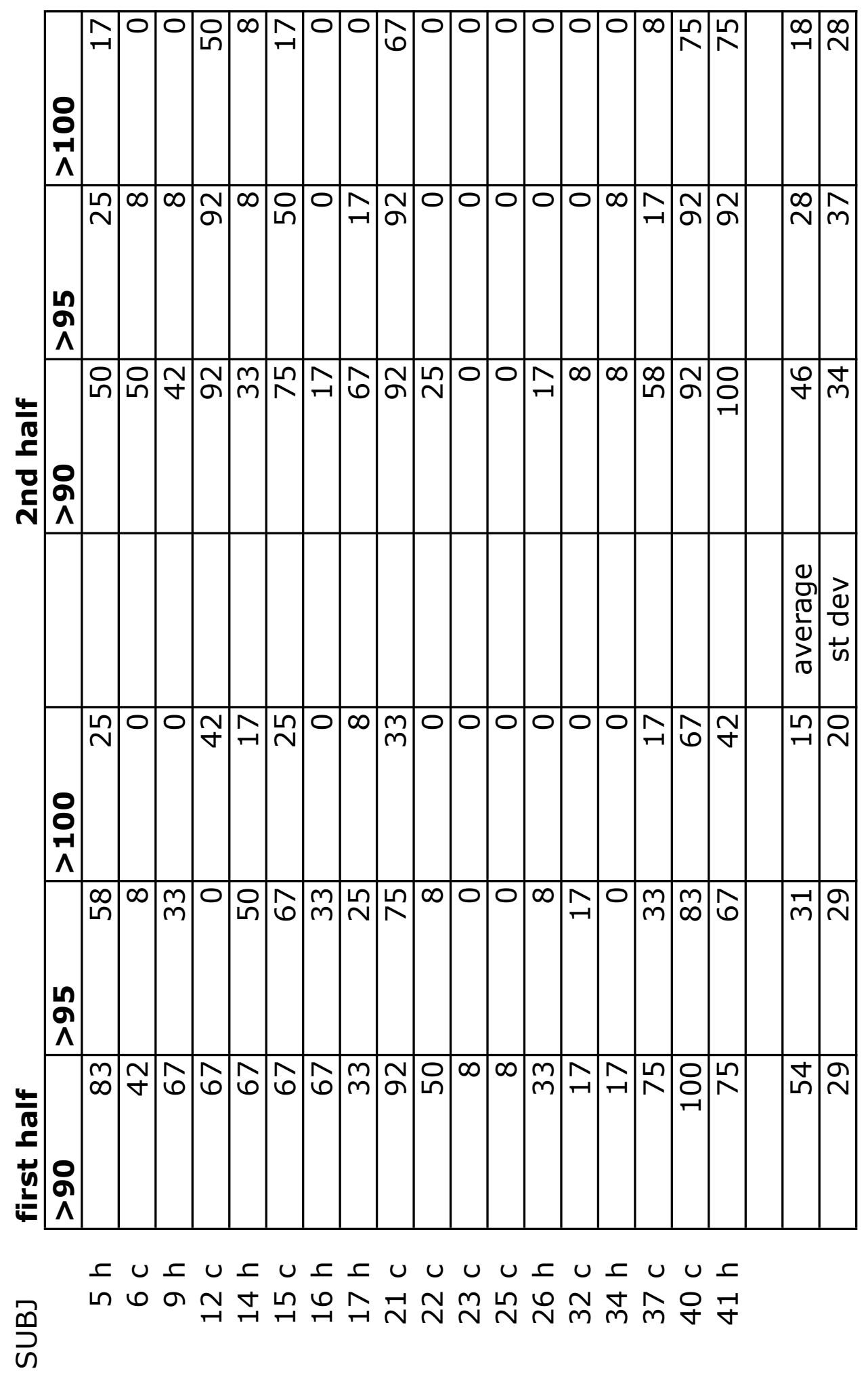


Gastrointestinal temperature
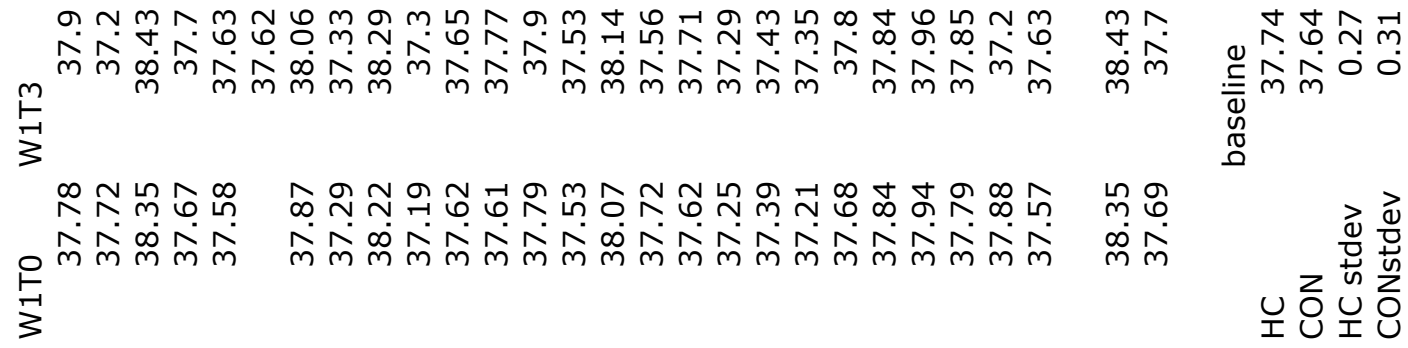

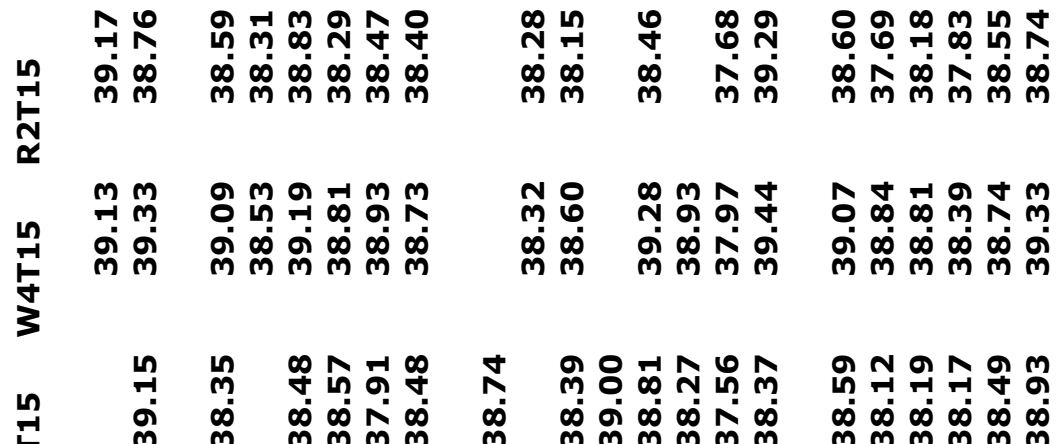

ำ

i்

$\sum_{3}^{m}$

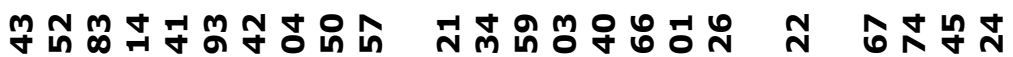
น

กิ

ळి ڤ̆ के $\ddot{x}$

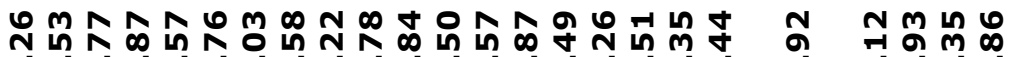

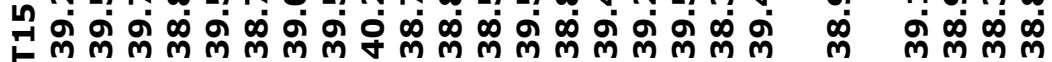

กิ की 3

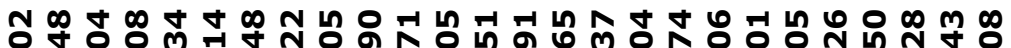

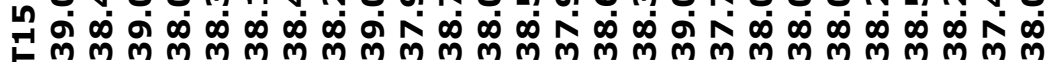
3

소ำ

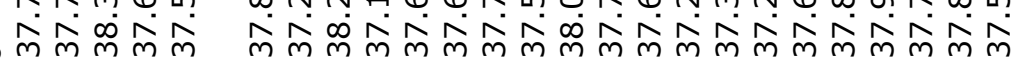

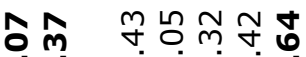
iें लि लें $\stackrel{\circ}{3}$

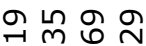
ñ mo

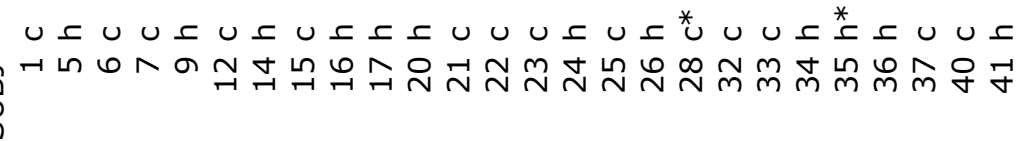



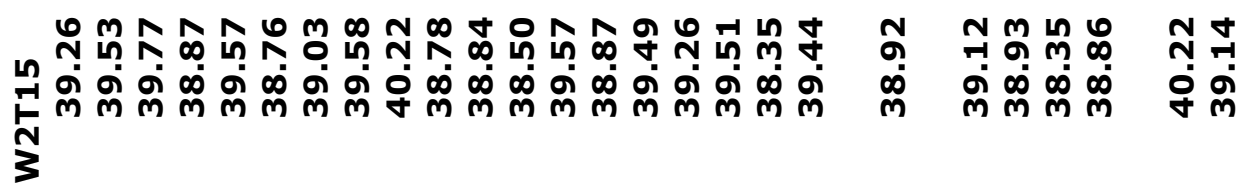

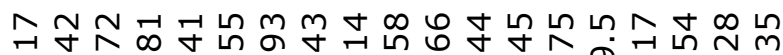

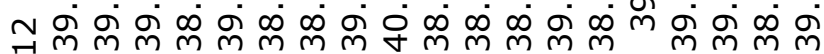

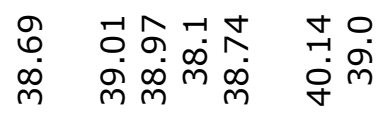

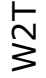

"ேํำ

$\stackrel{\circ}{\stackrel{2}{2}}$

ले

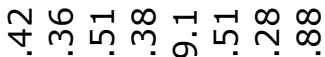

m

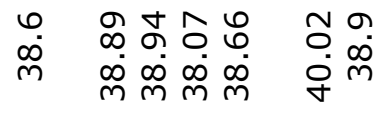

3

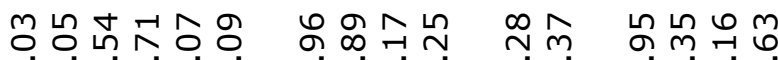

लें

$\infty \rho^{\infty} \infty \dot{m}^{\circ}$

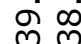

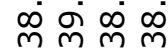

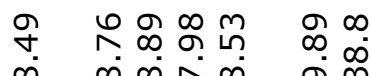

$\stackrel{\stackrel{\circ}{\aleph}}{\lessgtr}$

$m \sigma \hat{m} m \sim \infty \sim ⿻ 上 丨$ $\infty \infty^{\infty}$

$\stackrel{m}{\stackrel{m}{N}}$

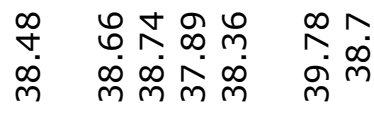

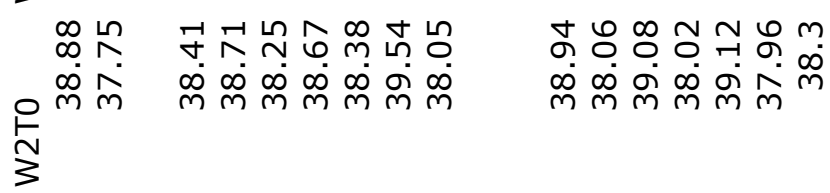

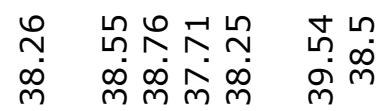

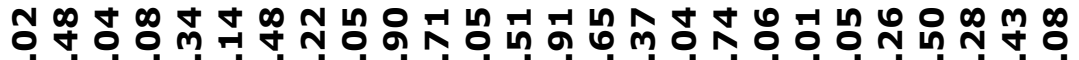
ำ 3

늑 の

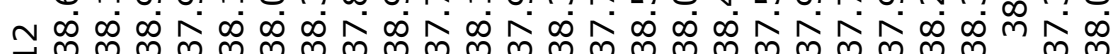
$\stackrel{-}{3}$

ำคณ a $\stackrel{a}{z}$

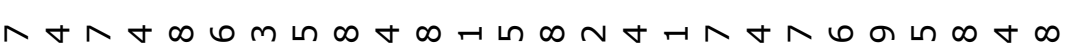

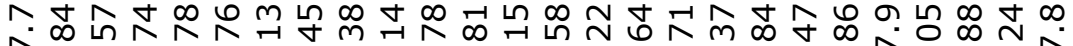
6

m

?

ع ن u 焉

กั

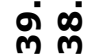

กิ $\mathscr{m} \underset{+}{+}$ $N \infty \infty^{\infty} \infty 0^{\circ}$ n m $\frac{0}{d}$

t十 0 - ⿵ं ${ }^{\circ} 0^{\circ}$ 言

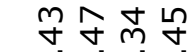
$\stackrel{\infty}{m}^{\circ} 0^{\circ}$

흔

ตे ने:

กำ ชิ $r$ i $\frac{0}{\frac{0}{0}}$

$\begin{array}{ll}n & 0 \\ & \infty \\ m^{\infty} & \infty\end{array}$

讨 华字 N लें 흠

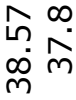
유삼 $\stackrel{\infty}{m} \stackrel{\infty}{m}^{\circ} 0^{\circ}$ 흔 

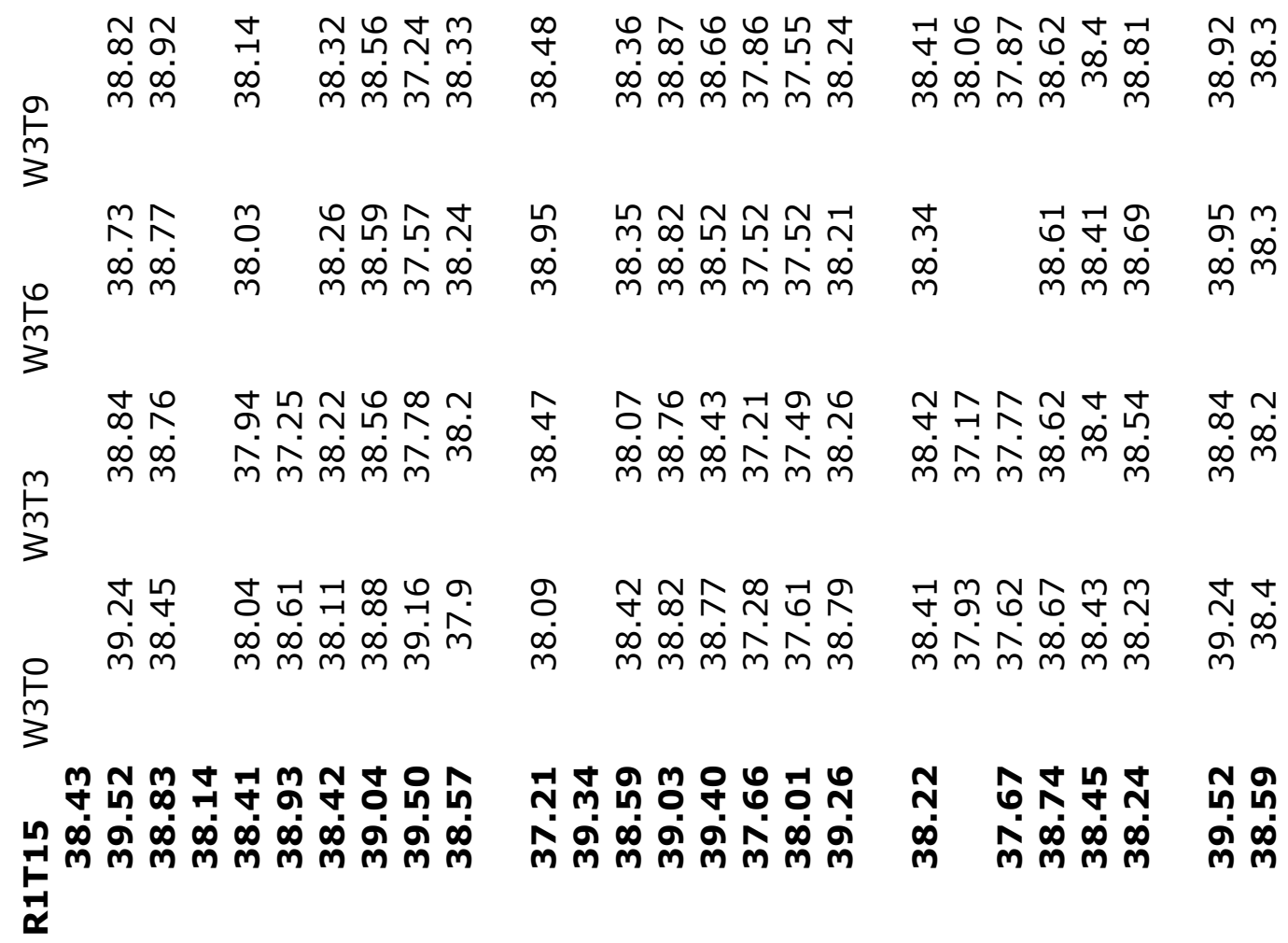

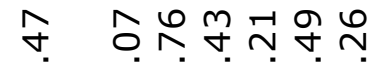

$\infty \dot{m} \infty \infty \hat{m} \hat{m} \dot{m}$

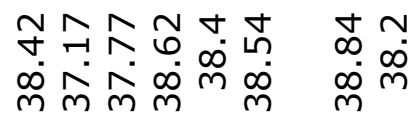

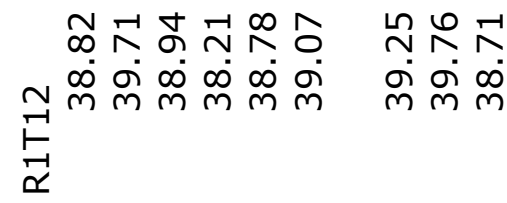

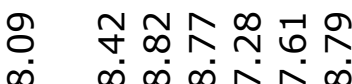

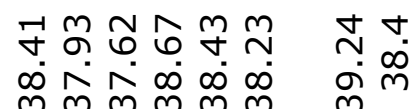

๙ॅ

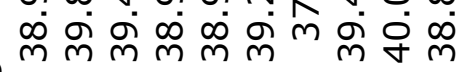

$\frac{\sigma}{\sigma}$

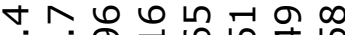
m

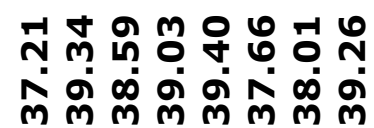

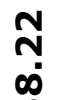

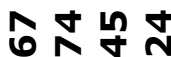
$N \infty \infty$ กิ in $m m m m$

m $m$

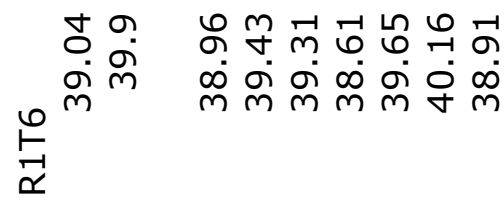

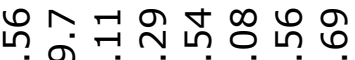
$\infty$ m

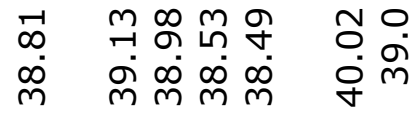

సิ

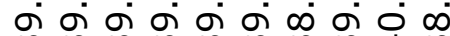
$m$

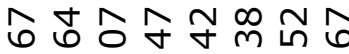
m $\dot{m}$ के

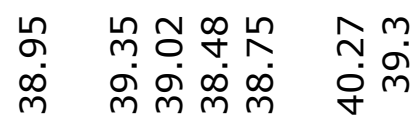

$\stackrel{-}{\alpha}$

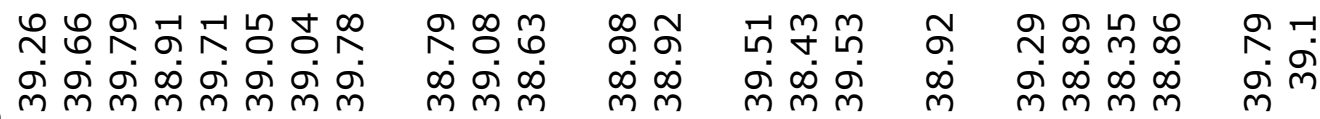
$\stackrel{\circ}{\stackrel{2}{r}}$

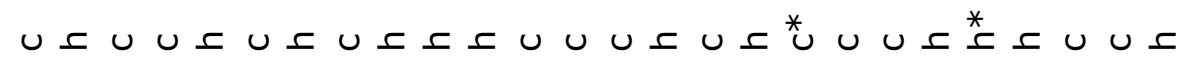
兯 


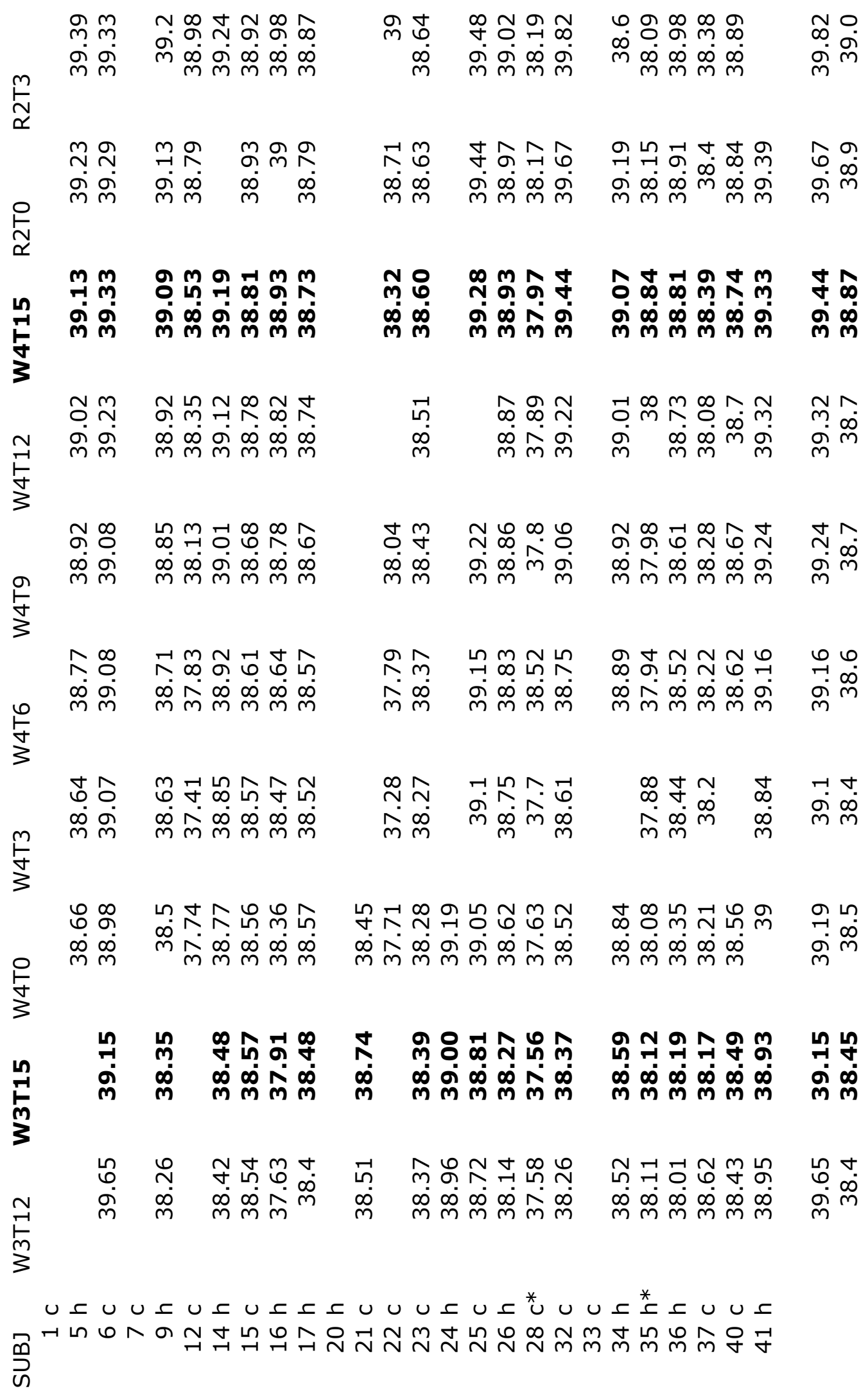




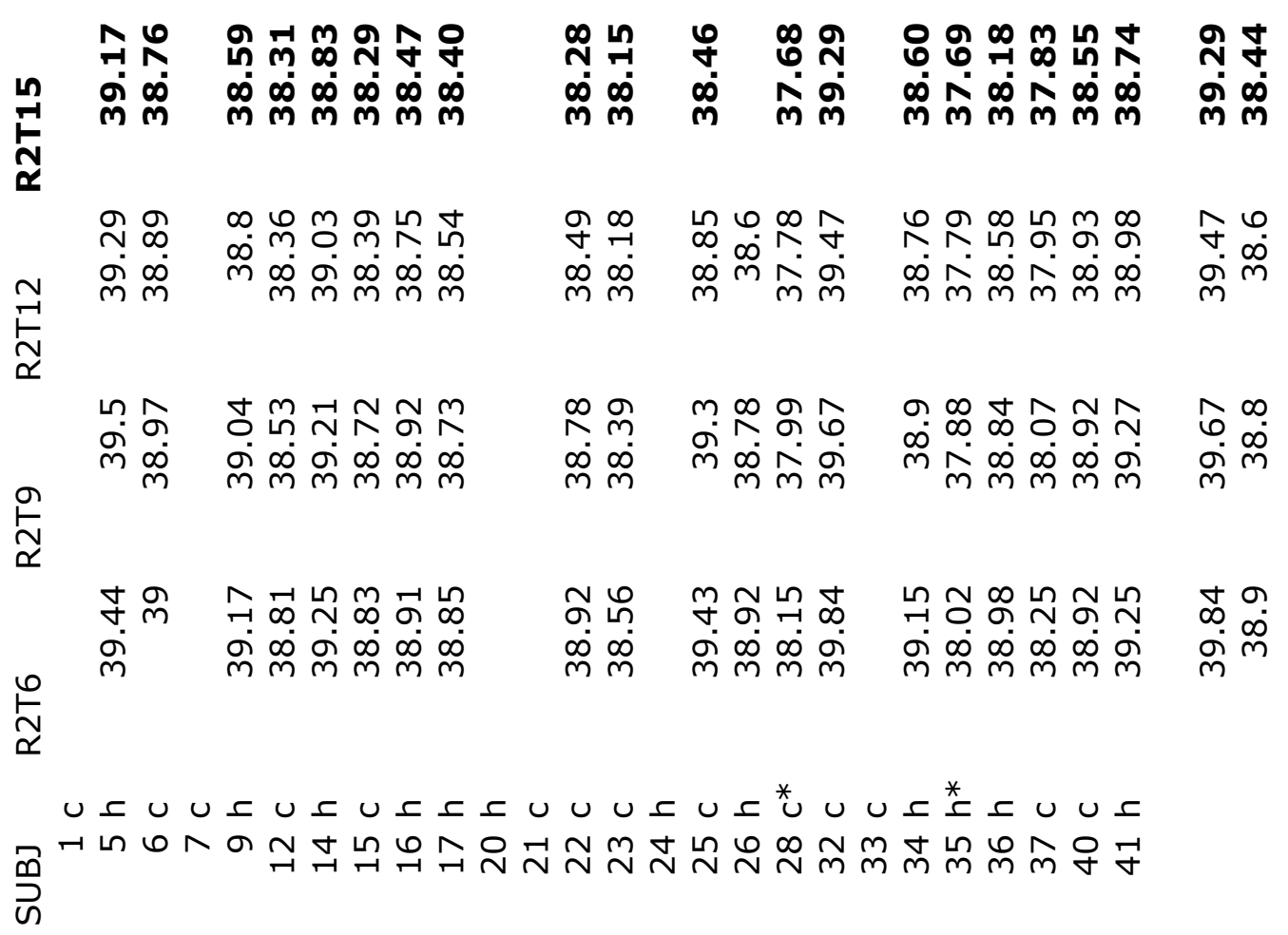


Physiological Strain Index

ஸ்

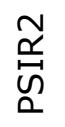

ம்

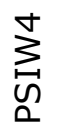

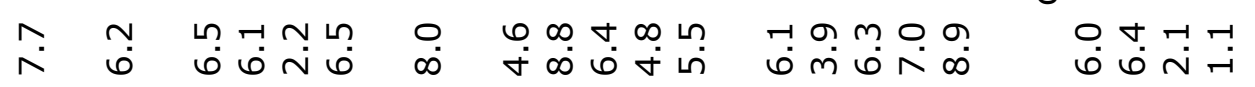

$\sum_{\substack{n \\ n}}^{m} \stackrel{m}{\bar{i}}$

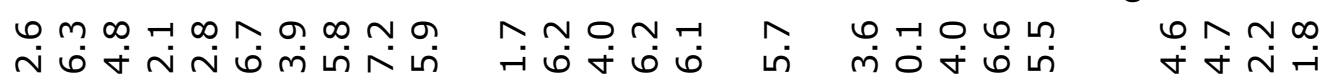

몸

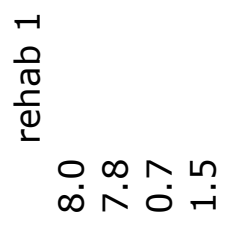

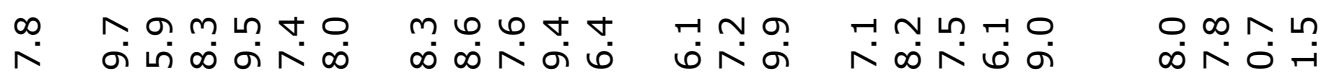

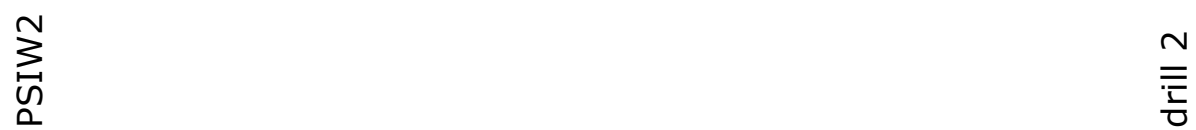

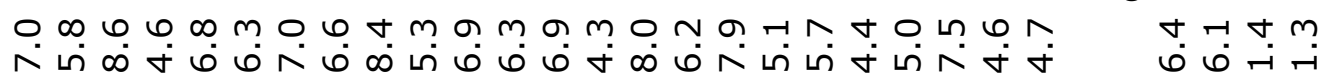

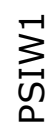

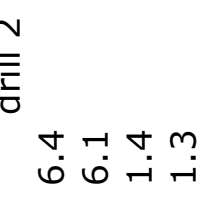

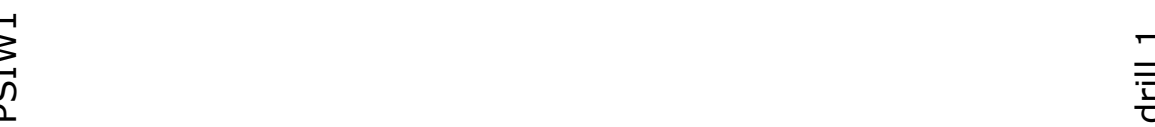

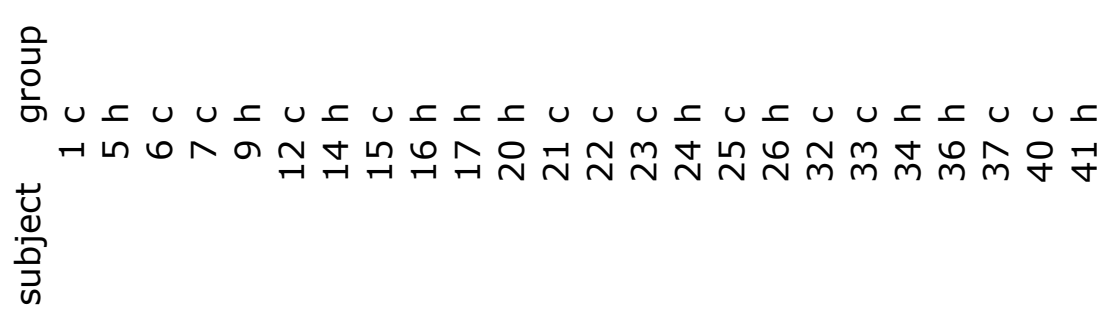

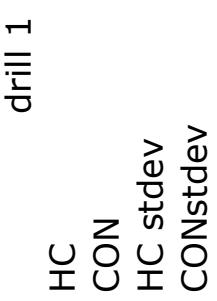


Stroop Test Interference Score
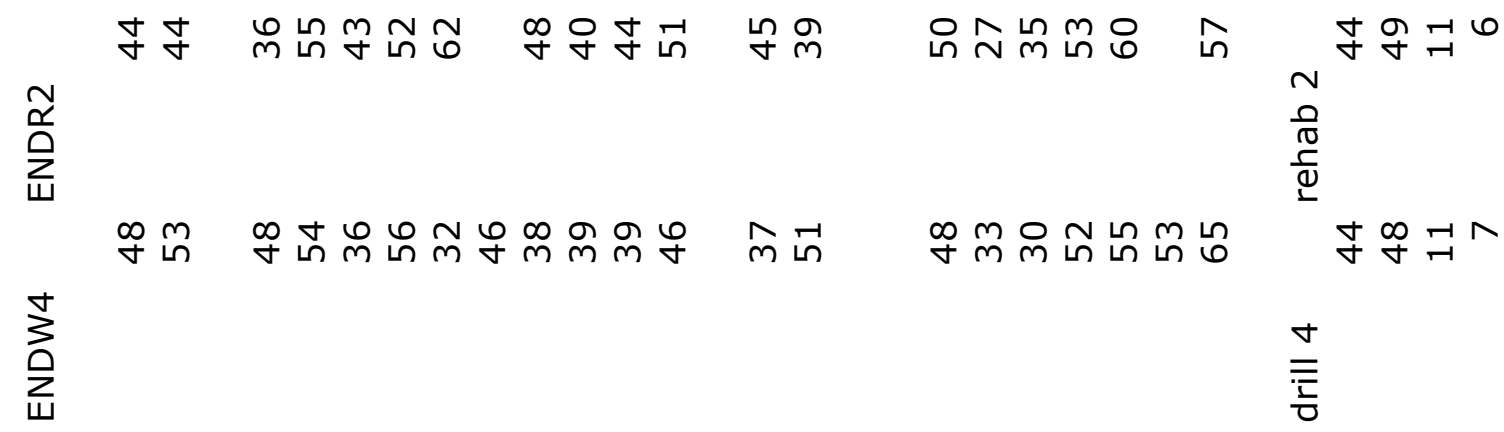

ㅇํำ

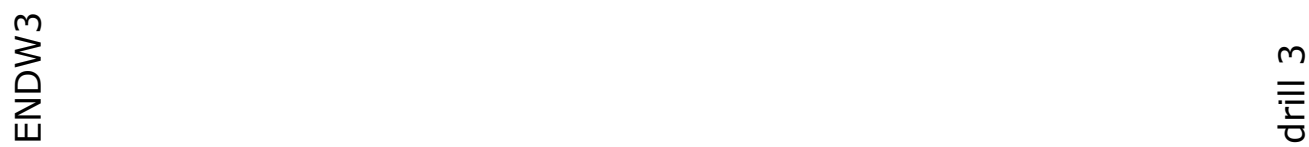

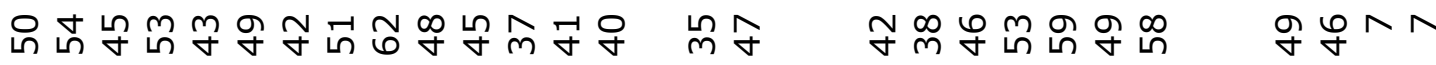
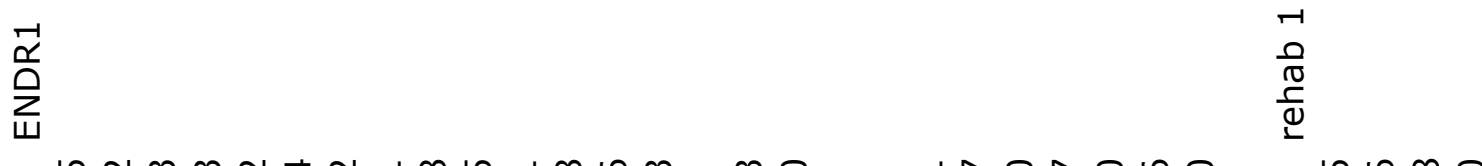

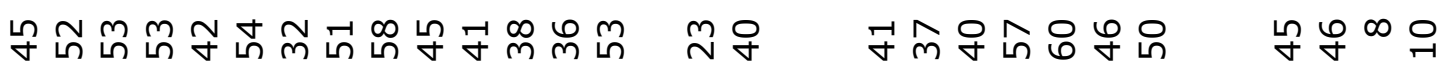

$\sum_{\text {บ }}^{N}$

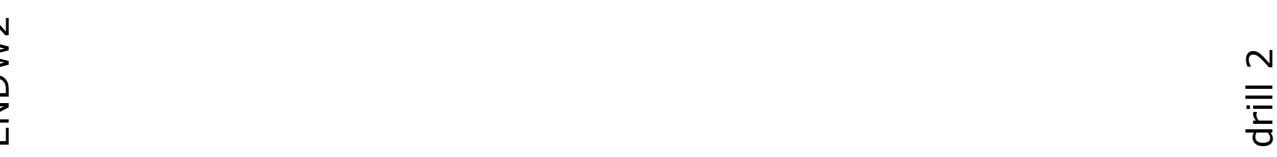

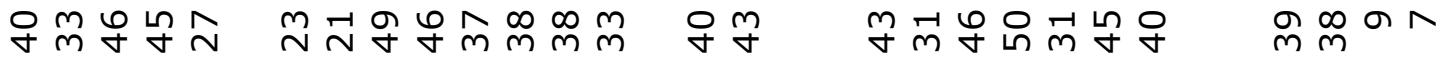

$\sum_{\text {¿ }}^{-1}$

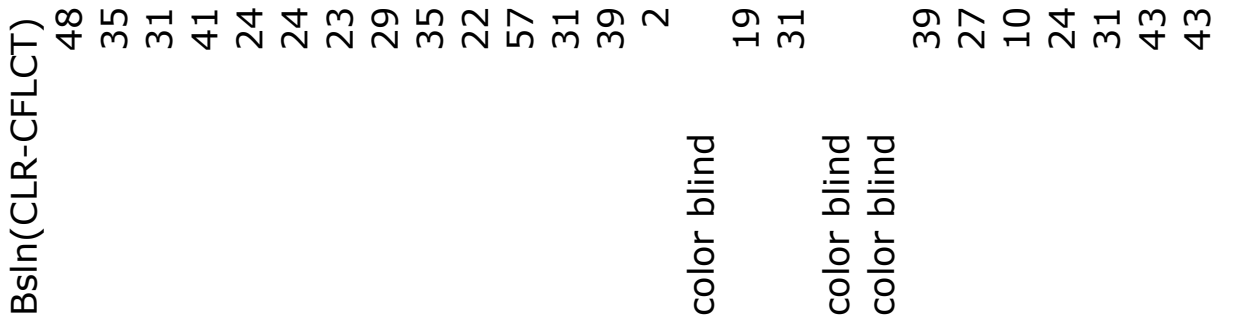

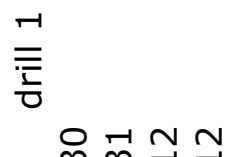

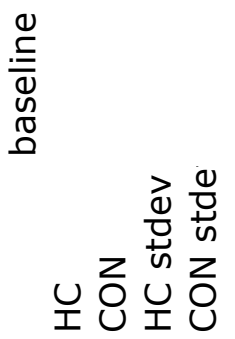

ع

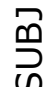

$\neg$ 几 जे 
Rating of Perceived Exertion

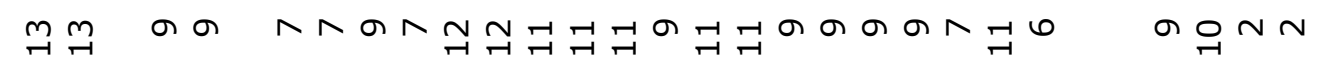

ํㅗㅇ

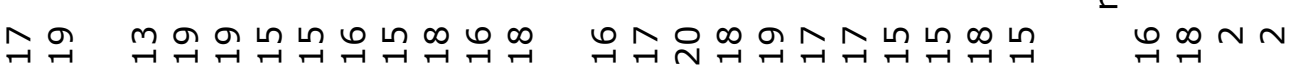

$\sum_{\text {¿ }}^{+}$

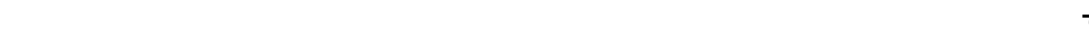

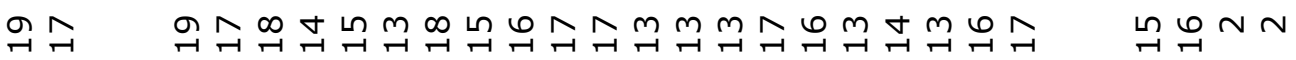

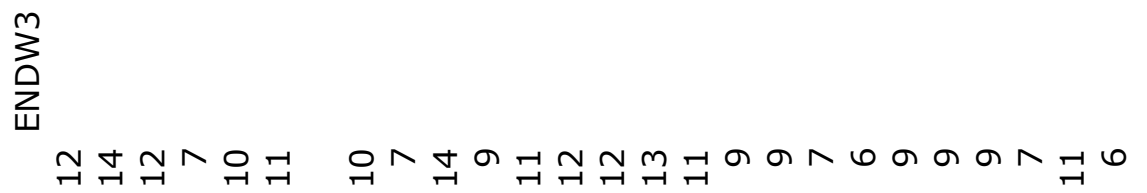

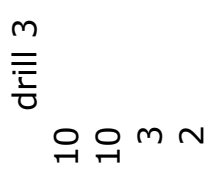

룸

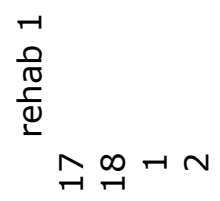

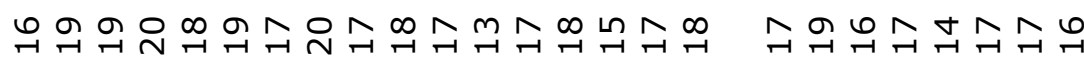

$\sum_{\text {แ }}^{N}$

$\stackrel{n}{\frac{N}{\overline{\frac{1}{0}}}}$

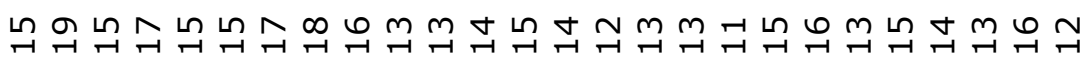
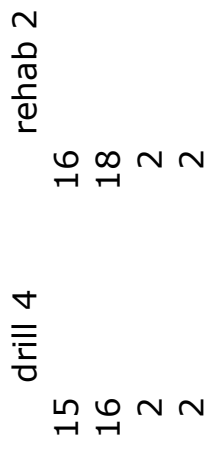

$$
\text { औभती }
$$

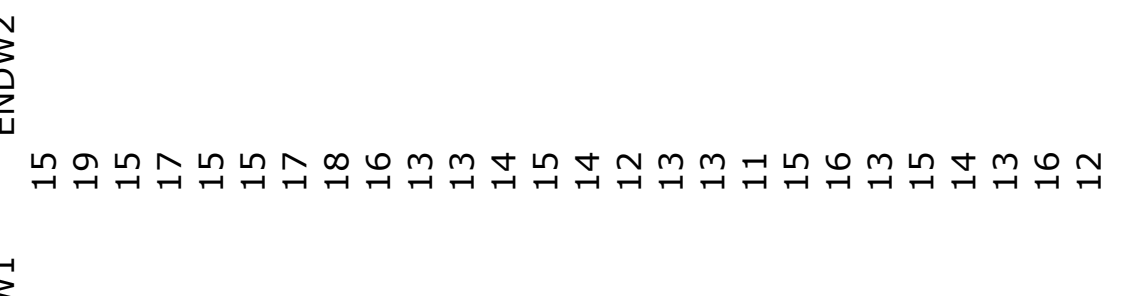

$\sum_{i=1}^{-1}$

aก

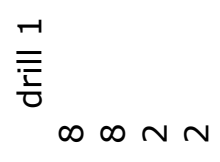

$\underset{\alpha}{\stackrel{u}{\alpha}}$

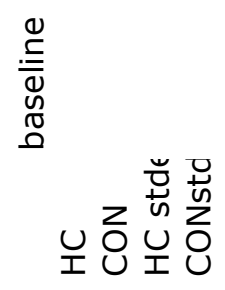

U ๗ั)

$\neg$ ம 
Perceived Thermal Sensation

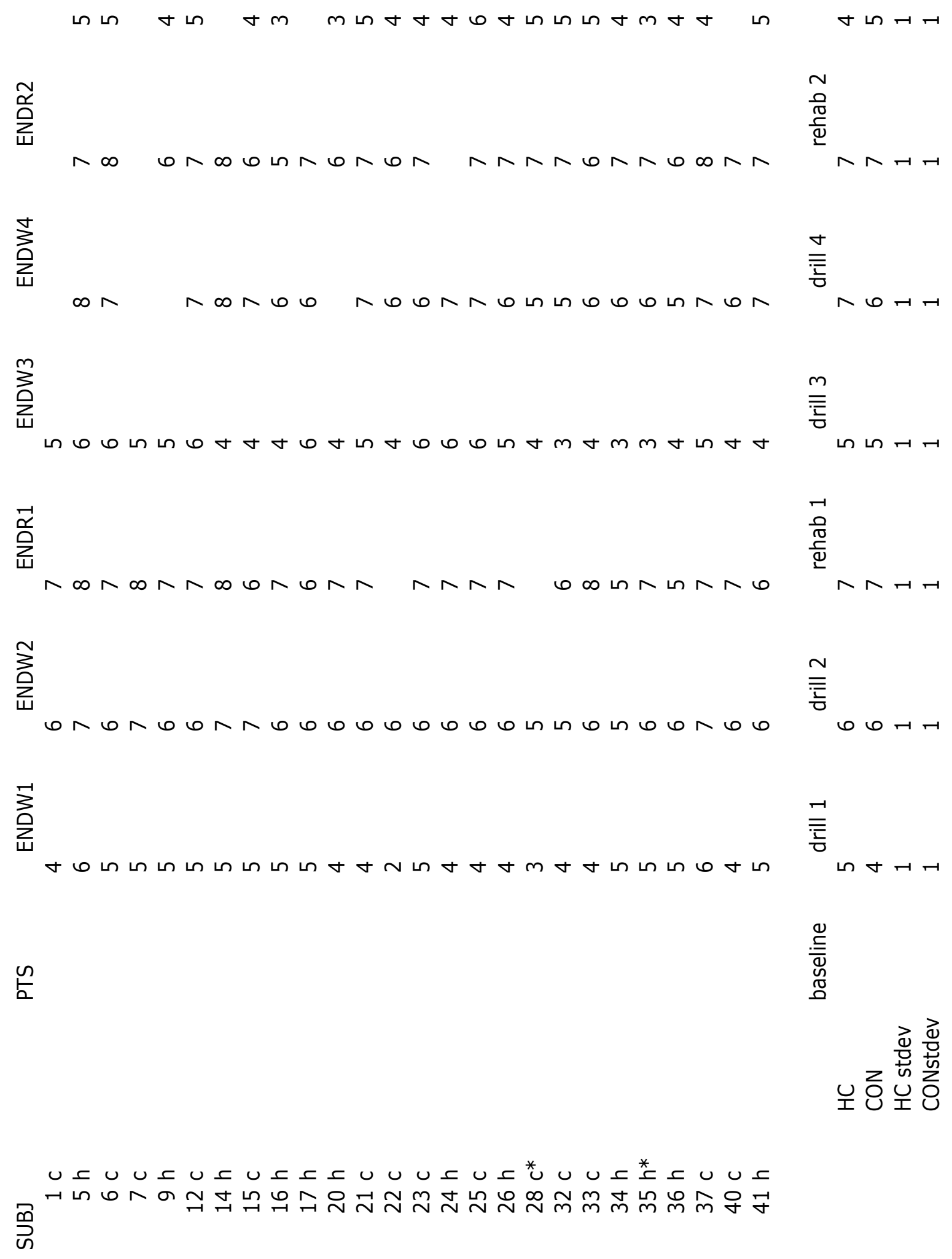


APPENDIX E: STATISTICAL ANALYSIS 


\section{T-Test}

Group Statistics

\begin{tabular}{|c|c|c|c|c|c|}
\hline & EXPGRP & $\mathbf{N}$ & Mean & $\begin{array}{c}\text { Std. } \\
\text { Deviation }\end{array}$ & $\begin{array}{c}\text { Std. Error } \\
\text { Mean }\end{array}$ \\
\hline \multirow[t]{2}{*}{ AGE } & 1 & 14 & 41.43 & 9.104 & 2.433 \\
\hline & 2 & 12 & 40.42 & 5.915 & 1.708 \\
\hline \multirow[t]{2}{*}{ HT } & 1 & 14 & 166.371 & 7.5691 & 2.0229 \\
\hline & 2 & 12 & 169.900 & 6.5818 & 1.9000 \\
\hline \multirow[t]{2}{*}{ BWPRE } & 1 & 14 & 88.7714 & 12.36928 & 3.30583 \\
\hline & 2 & 12 & 96.5417 & 17.16182 & 4.95419 \\
\hline \multirow[t]{2}{*}{ USGPRE } & 1 & 14 & 1.01500 & .005023 & .001342 \\
\hline & 2 & 12 & 1.01617 & .006322 & .001825 \\
\hline \multirow[t]{2}{*}{ USGPost } & 1 & 14 & 1.01793 & .007364 & .001968 \\
\hline & 2 & 12 & 1.02233 & .006243 & .001802 \\
\hline \multirow[t]{2}{*}{ SWL } & 1 & 14 & 2.179 & .7670 & .2050 \\
\hline & 2 & 12 & 2.513 & .7834 & .2261 \\
\hline \multirow[t]{2}{*}{ SWR } & 1 & 14 & 1.089 & .3835 & .1025 \\
\hline & 2 & 12 & 1.256 & .3917 & .1131 \\
\hline \multirow[t]{2}{*}{ PercentDhy } & 1 & 14 & .7464 & .58829 & .15723 \\
\hline & 2 & 12 & .7792 & .91877 & .26523 \\
\hline \multirow[t]{2}{*}{ Fluidconsmd } & 1 & 14 & 1.5214 & .54973 & .14692 \\
\hline & 2 & 12 & 1.7875 & .98538 & .28445 \\
\hline \multirow[t]{2}{*}{ ESTV015 } & 1 & 13 & 50.9146 & 7.44606 & 2.06517 \\
\hline & 2 & 12 & 51.5150 & 7.60960 & 2.19670 \\
\hline \multirow[t]{2}{*}{ GlbsIn } & 1 & 14 & 37.286 & .2969 & .0794 \\
\hline & 2 & 9 & 37.476 & .3989 & .1330 \\
\hline \multirow[t]{2}{*}{ HRbsln } & 1 & 14 & 93.429 & 14.3833 & 3.8441 \\
\hline & 2 & 12 & 90.250 & 13.4646 & 3.8869 \\
\hline \multirow[t]{2}{*}{ SISbsln } & 1 & 12 & 31.42 & 12.420 & 3.585 \\
\hline & 2 & 11 & 30.09 & 12.421 & 3.745 \\
\hline \multirow[t]{2}{*}{ RPEbsIn } & 1 & 14 & 7.71 & 2.091 & .559 \\
\hline & 2 & 12 & 7.58 & 1.832 & .529 \\
\hline \multirow[t]{2}{*}{ PTSbsln } & 1 & 14 & 4.29 & .994 & .266 \\
\hline & 2 & 12 & 4.83 & .577 & .167 \\
\hline
\end{tabular}


Independent Samples Test

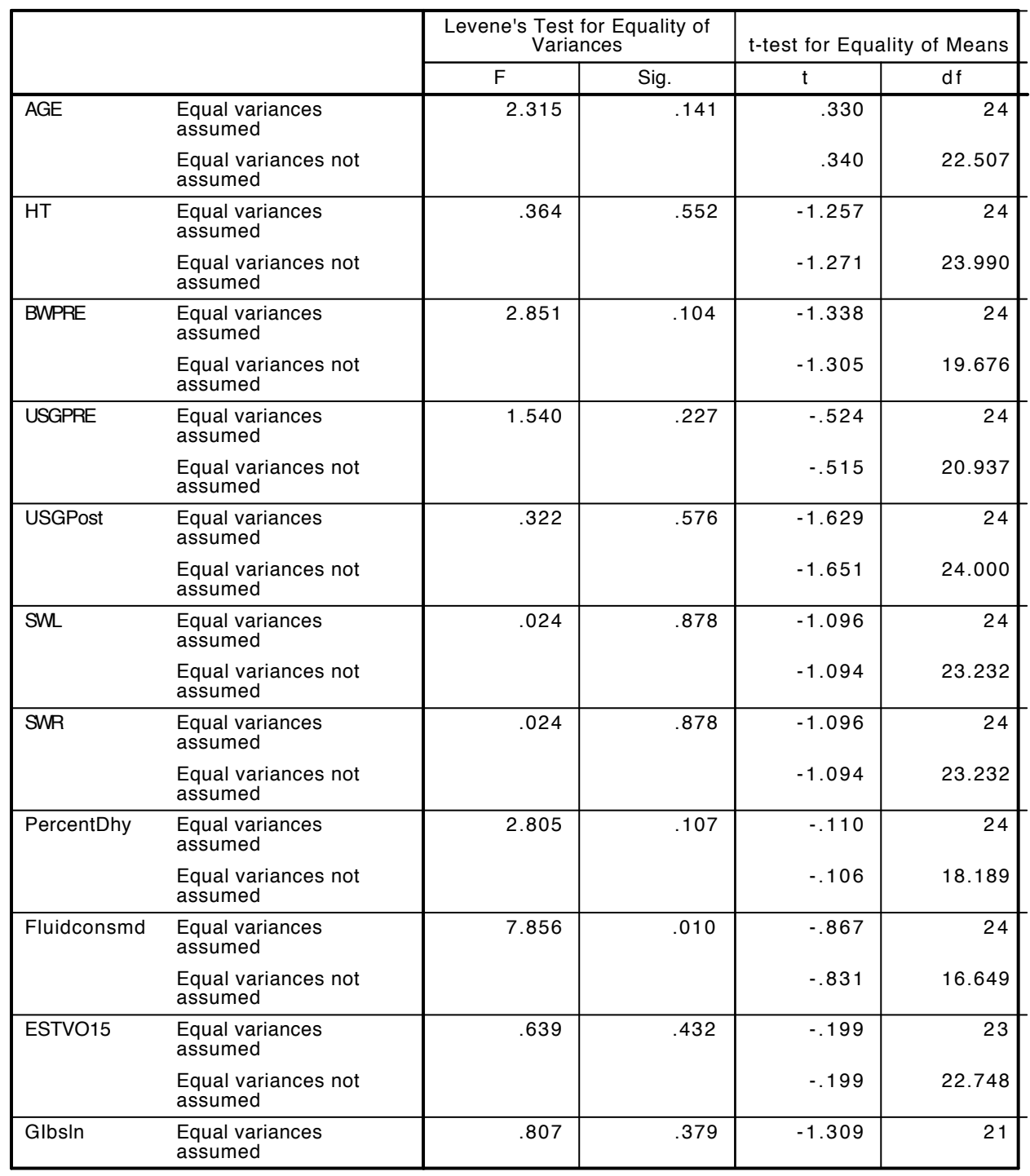


142

Independent Samples Test

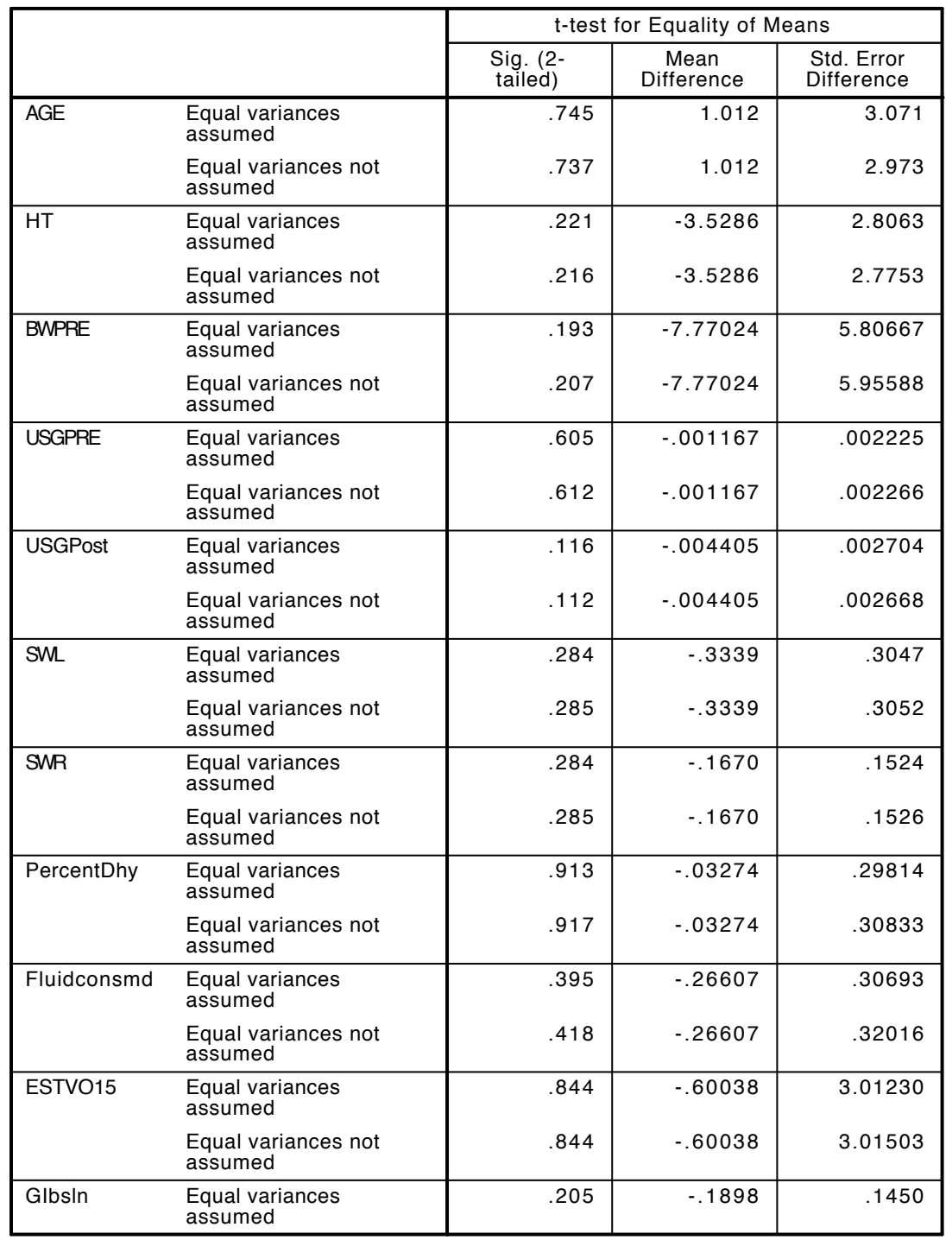


Independent Samples Test

\begin{tabular}{|c|c|c|c|}
\hline & & \multicolumn{2}{|c|}{ t-test for Equality of Means } \\
\hline & & \multicolumn{2}{|c|}{$\begin{array}{l}95 \% \text { Confidence Interval of } \\
\text { the Difference }\end{array}$} \\
\hline & & Lower & Upper \\
\hline \multirow[t]{2}{*}{$\overline{\text { AGE }}$} & $\begin{array}{l}\text { Equal variances } \\
\text { assumed }\end{array}$ & -5.326 & 7.350 \\
\hline & $\begin{array}{l}\text { Equal variances not } \\
\text { assumed }\end{array}$ & -5.145 & 7.169 \\
\hline \multirow[t]{2}{*}{ HT } & $\begin{array}{l}\text { Equal variances } \\
\text { assumed }\end{array}$ & -9.3206 & 2.2634 \\
\hline & $\begin{array}{l}\text { Equal variances not } \\
\text { assumed }\end{array}$ & -9.2566 & 2.1995 \\
\hline \multirow[t]{2}{*}{ BWPRE } & $\begin{array}{l}\text { Equal variances } \\
\text { assumed }\end{array}$ & -19.75462 & 4.21414 \\
\hline & $\begin{array}{l}\text { Equal variances not } \\
\text { assumed }\end{array}$ & -20.20712 & 4.66665 \\
\hline \multirow[t]{2}{*}{ USGPRE } & $\begin{array}{l}\text { Equal variances } \\
\text { assumed }\end{array}$ & -.005759 & .003425 \\
\hline & $\begin{array}{l}\text { Equal variances not } \\
\text { assumed }\end{array}$ & -.005879 & .003546 \\
\hline \multirow[t]{2}{*}{ USGPost } & $\begin{array}{l}\text { Equal variances } \\
\text { assumed }\end{array}$ & -.009985 & .001175 \\
\hline & $\begin{array}{l}\text { Equal variances not } \\
\text { assumed }\end{array}$ & -.009912 & .001103 \\
\hline \multirow[t]{2}{*}{ SWL } & $\begin{array}{l}\text { Equal variances } \\
\text { assumed }\end{array}$ & & .2950 \\
\hline & $\begin{array}{l}\text { Equal variances not } \\
\text { assumed }\end{array}$ & -.9650 & .2971 \\
\hline \multirow[t]{2}{*}{ SWR } & $\begin{array}{l}\text { Equal variances } \\
\text { assumed }\end{array}$ & -.4814 & .1475 \\
\hline & $\begin{array}{l}\text { Equal variances not } \\
\text { assumed }\end{array}$ & -.4825 & .1486 \\
\hline \multirow[t]{2}{*}{ PercentDhy } & $\begin{array}{l}\text { Equal variances } \\
\text { assumed }\end{array}$ & -.64807 & .58260 \\
\hline & $\begin{array}{l}\text { Equal variances not } \\
\text { assumed }\end{array}$ & -.68003 & .61455 \\
\hline \multirow[t]{2}{*}{ Fluidconsmd } & $\begin{array}{l}\text { Equal variances } \\
\text { assumed }\end{array}$ & -.89954 & .36740 \\
\hline & $\begin{array}{l}\text { Equal variances not } \\
\text { assumed }\end{array}$ & -.94263 & .41048 \\
\hline \multirow[t]{2}{*}{ ESTVO15 } & $\begin{array}{l}\text { Equal variances } \\
\text { assumed }\end{array}$ & -6.83180 & 5.63103 \\
\hline & $\begin{array}{l}\text { Equal variances not } \\
\text { assumed }\end{array}$ & -6.84128 & 5.64051 \\
\hline GIbsIn & $\begin{array}{l}\text { Equal variances } \\
\text { assumed }\end{array}$ & -.4914 & .1117 \\
\hline
\end{tabular}


Independent Samples Test

\begin{tabular}{|c|c|c|c|c|c|}
\hline & & \multicolumn{2}{|c|}{$\begin{array}{c}\text { Levene's Test for Equality of } \\
\text { Variances }\end{array}$} & \multicolumn{2}{|c|}{ t-test for Equality of Means } \\
\hline & & $\mathrm{F}$ & Sig. & $t$ & $\mathrm{df}$ \\
\hline GlbsIn & $\begin{array}{l}\text { Equal variances not } \\
\text { assumed }\end{array}$ & & & -1.226 & 13.648 \\
\hline HRbsIn & $\begin{array}{l}\text { Equal variances } \\
\text { assumed } \\
\text { Equal variances not } \\
\text { assumed }\end{array}$ & .025 & .876 & $\begin{array}{l}.578 \\
.581\end{array}$ & $\begin{array}{r}24 \\
23.787\end{array}$ \\
\hline SISbsin & $\begin{array}{l}\text { Equal variances } \\
\text { assumed } \\
\text { Equal variances not } \\
\text { assumed }\end{array}$ & .012 & .914 & $\begin{array}{l}.256 \\
.256\end{array}$ & $\begin{array}{r}21 \\
20.826\end{array}$ \\
\hline RPEbsIn & $\begin{array}{l}\text { Equal variances } \\
\text { assumed } \\
\text { Equal variances not } \\
\text { assumed }\end{array}$ & .101 & .753 & $\begin{array}{l}.168 \\
.170\end{array}$ & $\begin{array}{r}24 \\
23.981\end{array}$ \\
\hline PTSbsln & $\begin{array}{l}\text { Equal variances } \\
\text { assumed } \\
\text { Equal variances not } \\
\text { assumed }\end{array}$ & 2.750 & .110 & $\begin{array}{l}-1.678 \\
-1.746\end{array}$ & $\begin{array}{r}24 \\
21.335\end{array}$ \\
\hline
\end{tabular}

Independent Samples Test

\begin{tabular}{|c|c|c|c|c|}
\hline & & \multicolumn{3}{|c|}{ t-test for Equality of Means } \\
\hline & & $\begin{array}{l}\text { Sig. (2- } \\
\text { tailed) }\end{array}$ & $\begin{array}{c}\text { Mean } \\
\text { Difference }\end{array}$ & $\begin{array}{l}\text { Std. Error } \\
\text { Difference }\end{array}$ \\
\hline GIbsln & $\begin{array}{l}\text { Equal variances not } \\
\text { assumed }\end{array}$ & .241 & -.1898 & .1548 \\
\hline \multirow[t]{2}{*}{ HRbsin } & $\begin{array}{l}\text { Equal variances } \\
\text { assumed }\end{array}$ & .568 & & \\
\hline & $\begin{array}{l}\text { Equal variances not } \\
\text { assumed }\end{array}$ & .566 & 3.1786 & 5.4667 \\
\hline \multirow[t]{2}{*}{ SISbsln } & $\begin{array}{l}\text { Equal variances } \\
\text { assumed }\end{array}$ & .801 & 1.326 & 5.185 \\
\hline & $\begin{array}{l}\text { Equal variances not } \\
\text { assumed }\end{array}$ & .801 & 1.326 & 5.185 \\
\hline \multirow[t]{2}{*}{ RPEbsln } & $\begin{array}{l}\text { Equal variances } \\
\text { assumed }\end{array}$ & .868 & .131 & .778 \\
\hline & $\begin{array}{l}\text { Equal variances not } \\
\text { assumed }\end{array}$ & .866 & .131 & .769 \\
\hline \multirow[t]{2}{*}{ PTSbsln } & $\begin{array}{l}\text { Equal variances } \\
\text { assumed }\end{array}$ & .106 & -.548 & .326 \\
\hline & $\begin{array}{l}\text { Equal variances not } \\
\text { assumed }\end{array}$ & .095 & -.548 & .314 \\
\hline
\end{tabular}


Independent Samples Test

\begin{tabular}{|c|c|c|c|}
\hline & & \multicolumn{2}{|c|}{ t-test for Equality of Means } \\
\hline & & \multicolumn{2}{|c|}{$\begin{array}{l}95 \% \text { Confidence Interval of } \\
\text { the Difference }\end{array}$} \\
\hline & & Lower & Upper \\
\hline GIbsIn & $\begin{array}{l}\text { Equal variances not } \\
\text { assumed }\end{array}$ & -.5228 & .1431 \\
\hline \multirow[t]{2}{*}{ HRbsIn } & $\begin{array}{l}\text { Equal variances } \\
\text { assumed }\end{array}$ & & \\
\hline & $\begin{array}{l}\text { Equal variances not } \\
\text { assumed }\end{array}$ & -8.1095 & 14.4667 \\
\hline \multirow[t]{2}{*}{ SISbsIn } & $\begin{array}{l}\text { Equal variances } \\
\text { assumed }\end{array}$ & -9.457 & 12.108 \\
\hline & $\begin{array}{l}\text { Equal variances not } \\
\text { assumed }\end{array}$ & -9.462 & 12.114 \\
\hline \multirow[t]{2}{*}{ RPEbsin } & $\begin{array}{l}\text { Equal variances } \\
\text { assumed }\end{array}$ & -1.474 & 1.736 \\
\hline & $\begin{array}{l}\text { Equal variances not } \\
\text { assumed }\end{array}$ & -1.457 & 1.719 \\
\hline \multirow[t]{2}{*}{ PTSbsin } & $\begin{array}{l}\text { Equal variances } \\
\text { assumed }\end{array}$ & -1.221 & .126 \\
\hline & $\begin{array}{l}\text { Equal variances not } \\
\text { assumed }\end{array}$ & -1.199 & .104 \\
\hline
\end{tabular}

\section{T-Test}

Group Statistics

\begin{tabular}{|ll|r|r|r|r|}
\hline & EXPGRP & $\mathrm{N}$ & Mean & $\begin{array}{c}\text { Std. } \\
\text { Deviation }\end{array}$ & $\begin{array}{c}\text { Std. Error } \\
\text { Mean }\end{array}$ \\
\hline ESTVO15 & 1 & 12 & 50.2200 & 7.32405 & 2.11427 \\
& 2 & 11 & 52.1864 & 7.59914 & 2.29123 \\
\hline HRbsIn & 1 & 13 & 93.923 & 14.8462 & 4.1176 \\
& 2 & 11 & 88.091 & 11.7427 & 3.5406 \\
\hline
\end{tabular}

Independent Samples Test

\begin{tabular}{|c|c|c|c|c|c|}
\hline & & \multicolumn{2}{|c|}{$\begin{array}{c}\text { Levene's Test for Equality of } \\
\text { Variances }\end{array}$} & \multicolumn{2}{|c|}{ t-test for Equality of Means } \\
\hline & & $F$ & Sig. & $\mathrm{t}$ & $d f$ \\
\hline \multirow[t]{2}{*}{ ESTVO15 } & $\begin{array}{l}\text { Equal variances } \\
\text { assumed }\end{array}$ & .676 & .420 & & 21 \\
\hline & $\begin{array}{l}\text { Equal variances not } \\
\text { assumed }\end{array}$ & & & -.631 & 20.662 \\
\hline \multirow[t]{2}{*}{ HRbsln } & $\begin{array}{l}\text { Equal variances } \\
\text { assumed }\end{array}$ & .113 & .740 & 1.053 & 22 \\
\hline & $\begin{array}{l}\text { Equal variances not } \\
\text { assumed }\end{array}$ & & & 1.074 & 21.923 \\
\hline
\end{tabular}


Independent Samples Test

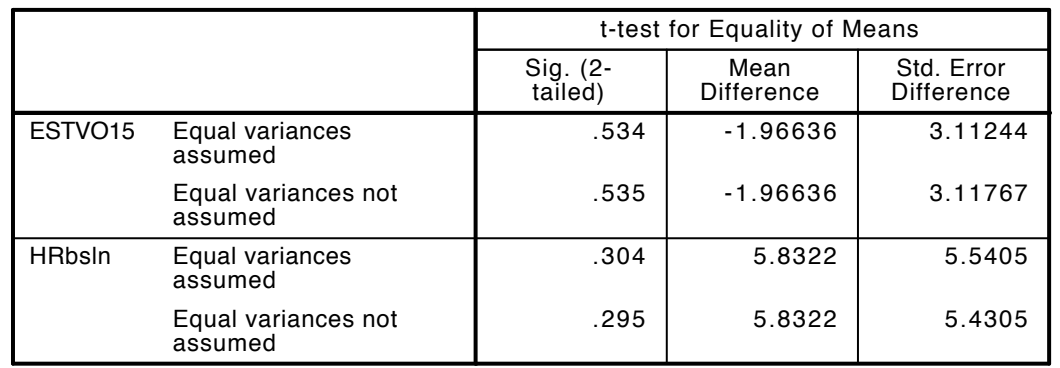

Independent Samples Test

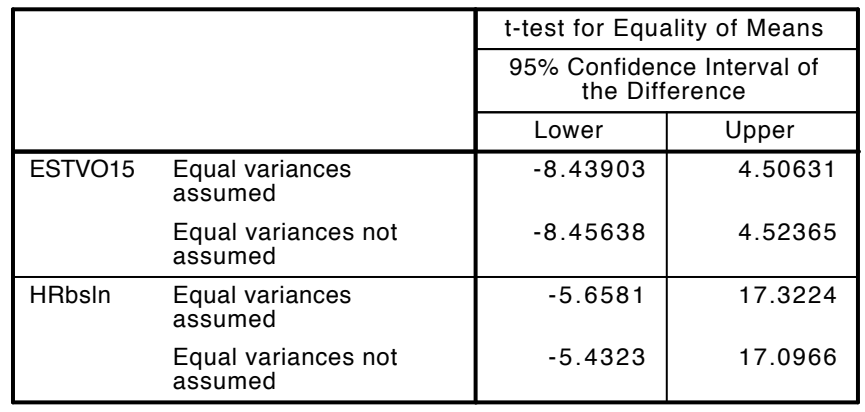

\section{General Linear Model}

Within-Subjects

Factors

Measure:MEASURE_1

\begin{tabular}{|l|l|}
\hline time & $\begin{array}{l}\text { Dependent } \\
\text { Variable }\end{array}$ \\
\hline 1 & GIW1T0 \\
2 & GIW1T15 \\
3 & GIW2T15 \\
4 & GIR1T15 \\
5 & GIW3T15 \\
6 & GIW4T15 \\
7 & GIR2T15 \\
\hline
\end{tabular}

Between-Subjects

Factors

\begin{tabular}{|rl|r|}
\hline & & \multicolumn{1}{|c|}{$N$} \\
\hline EXPGRP & 1 & 10 \\
& 2 & 9 \\
\hline
\end{tabular}




\begin{tabular}{|ll|l|r|r|}
\hline \multicolumn{5}{|c|}{ Descriptive Statistics } \\
\hline EIW1T0 & 1 & Mean & $\begin{array}{c}\text { Std. } \\
\text { Deviation }\end{array}$ & \multicolumn{1}{c|}{$\mathrm{N}$} \\
& 2 & 37.6050 & .37807 & 10 \\
& Total & 37.6547 & .28605 & 9 \\
\hline GIW1T15 & 1 & 38.1700 & .43277 & 19 \\
& 2 & 38.4356 & .40651 & 10 \\
& Total & 38.2958 & .43437 & 9 \\
\hline GIW2T15 & 1 & 39.0880 & .51233 & 19 \\
& 2 & 39.2822 & .46464 & 9 \\
& Total & 39.1800 & .48695 & 19 \\
\hline GIR1T15 & 1 & 38.8590 & .43437 & 10 \\
& 2 & 38.4678 & .66998 & 9 \\
& Total & 38.6737 & .57803 & 19 \\
\hline GIW3T15 & 1 & 38.4930 & .44322 & 10 \\
& 2 & 38.4578 & .33048 & 9 \\
& Total & 38.4763 & .38352 & 19 \\
\hline GIW4T15 & 1 & 38.7410 & .48190 & 10 \\
& 2 & 39.0233 & .19000 & 9 \\
& Total & 38.8747 & .39133 & 19 \\
\hline GIR2T15 & 1 & 38.3600 & .45609 & 10 \\
& 2 & 38.6200 & .28000 & 9 \\
& Total & 38.4832 & .39578 & 19 \\
\hline & & & & \\
\hline
\end{tabular}

Mauchly's Test of Sphericity ${ }^{b}$

Measure:MEASURE_1

\begin{tabular}{|r|r|r|r|r|}
\hline Within Subjects Effect & Mauchly's W & $\begin{array}{c}\text { Approx. Chi- } \\
\text { Square }\end{array}$ & \multicolumn{1}{c|}{ df } & \multicolumn{1}{c|}{ Sig. } \\
\hline time & .069 & 39.606 & 20 & .006 \\
\hline
\end{tabular}

Tests the null hypothesis that the error covariance matrix of the orthonormalized transformed dependent variables is proportional to an identity matrix. 
Mauchly's Test of Sphericity ${ }^{b}$

Measure:MEASURE_1

\begin{tabular}{|r|r|r|r|}
\hline Within Subjects Effect & \multicolumn{3}{|c|}{ Epsilon $^{\text {a }}$} \\
\cline { 2 - 4 } & $\begin{array}{c}\text { Greenhouse- } \\
\text { Geisser }\end{array}$ & Huynh-Feldt & $\begin{array}{c}\text { Lower- } \\
\text { bound }\end{array}$ \\
\hline time & .589 & .806 & .167 \\
\hline
\end{tabular}

Tests the null hypothesis that the error covariance matrix of the orthonormalized transformed dependent variables is proportional to an identity matrix.

a. May be used to adjust the degrees of freedom for the averaged tests of significance. Corrected tests are displayed in the Tests of Within-Subjects Effects table.

b. Design: Intercept + EXPGRP

Within Subjects Design: time

Tests of Within-Subjects Effects

Measure:MEASURE_1

\begin{tabular}{|c|c|c|c|c|c|}
\hline Source & & $\begin{array}{l}\text { Type III Sum } \\
\text { of Squares }\end{array}$ & $d f$ & Mean Square & $\mathrm{F}$ \\
\hline \multirow[t]{4}{*}{ time } & Sphericity Assumed & 26.300 & 6 & 4.383 & 39.029 \\
\hline & Greenhouse-Geisser & 26.300 & 3.534 & 7.443 & 39.029 \\
\hline & Huynh-Feldt & 26.300 & 4.837 & 5.437 & 39.029 \\
\hline & Lower-bound & 26.300 & 1.000 & 26.300 & 39.029 \\
\hline \multirow[t]{4}{*}{ time * EXPGRP } & Sphericity Assumed & 1.680 & 6 & .280 & 2.493 \\
\hline & Greenhouse-Geisser & 1.680 & 3.534 & .475 & 2.493 \\
\hline & Huynh-Feldt & 1.680 & 4.837 & .347 & 2.493 \\
\hline & Lower-bound & 1.680 & 1.000 & 1.680 & 2.493 \\
\hline \multirow[t]{4}{*}{ Error(time) } & Sphericity Assumed & 11.456 & 102 & .112 & \\
\hline & Greenhouse-Geisser & 11.456 & 60.072 & .191 & \\
\hline & Huynh-Feldt & 11.456 & 82.232 & .139 & \\
\hline & Lower-bound & 11.456 & 17.000 & .674 & \\
\hline
\end{tabular}

Tests of Within-Subjects Effects

Measure:MEASURE_1

\begin{tabular}{|ll|r|r|r|r|}
\hline Source & & \multicolumn{1}{|c|}{$\begin{array}{c}\text { Partial Eta } \\
\text { Squared }\end{array}$} & $\begin{array}{c}\text { Noncent. } \\
\text { Parameter }\end{array}$ & $\begin{array}{c}\text { Observed } \\
\text { Power }^{\text {a }}\end{array}$ \\
\hline time & Sphericity Assumed & .000 & .697 & 234.173 & 1.000 \\
& Greenhouse-Geisser & .000 & .697 & 137.913 & 1.000 \\
& Huynh-Feldt & .000 & .697 & 188.788 & 1.000 \\
& Lower-bound & .000 & .697 & 39.029 & 1.000 \\
\hline time * EXPGRP & Sphericity Assumed & .027 & .128 & 14.960 & .815 \\
& Greenhouse-Geisser & .059 & .128 & 8.810 & .638 \\
& Huynh-Feldt & .039 & .128 & 12.060 & .745 \\
& Lower-bound & .133 & .128 & 2.493 & .320 \\
\hline
\end{tabular}

a. Computed using alpha $=.05$ 
Tests of Between-Subjects Effects

Measure:MEASURE 1

Transformed Variable:Average

\begin{tabular}{|l|r|r|r|r|r|r|}
\hline Source & $\begin{array}{c}\text { Type III Sum } \\
\text { of Squares }\end{array}$ & df & Mean Square & F & \multicolumn{1}{c|}{ Sig. } & \multicolumn{1}{c|}{$\begin{array}{c}\text { Partial Eta } \\
\text { Squared }\end{array}$} \\
\hline Intercept & 196821.306 & 1 & 196821.306 & 320299.690 & .000 & 1.000 \\
EXPGRP & .314 & 1 & .314 & .510 & .485 & .029 \\
Error & 10.446 & 17 & .614 & & & \\
\hline
\end{tabular}

Tests of Between-Subjects Effects

Measure:MEASURE_1

Transformed Variab̄le:Average

\begin{tabular}{|l|r|r|}
\hline Source & \multicolumn{1}{|c|}{$\begin{array}{c}\text { Noncent. } \\
\text { Parameter }\end{array}$} & \multicolumn{1}{|c|}{$\begin{array}{c}\text { Observed } \\
\text { Power }^{\mathrm{a}}\end{array}$} \\
\hline Intercept & 320299.690 & 1.000 \\
EXPGRP & .510 & .104 \\
\hline
\end{tabular}

a. Computed using alpha $=.05$

\section{Profile Plots}

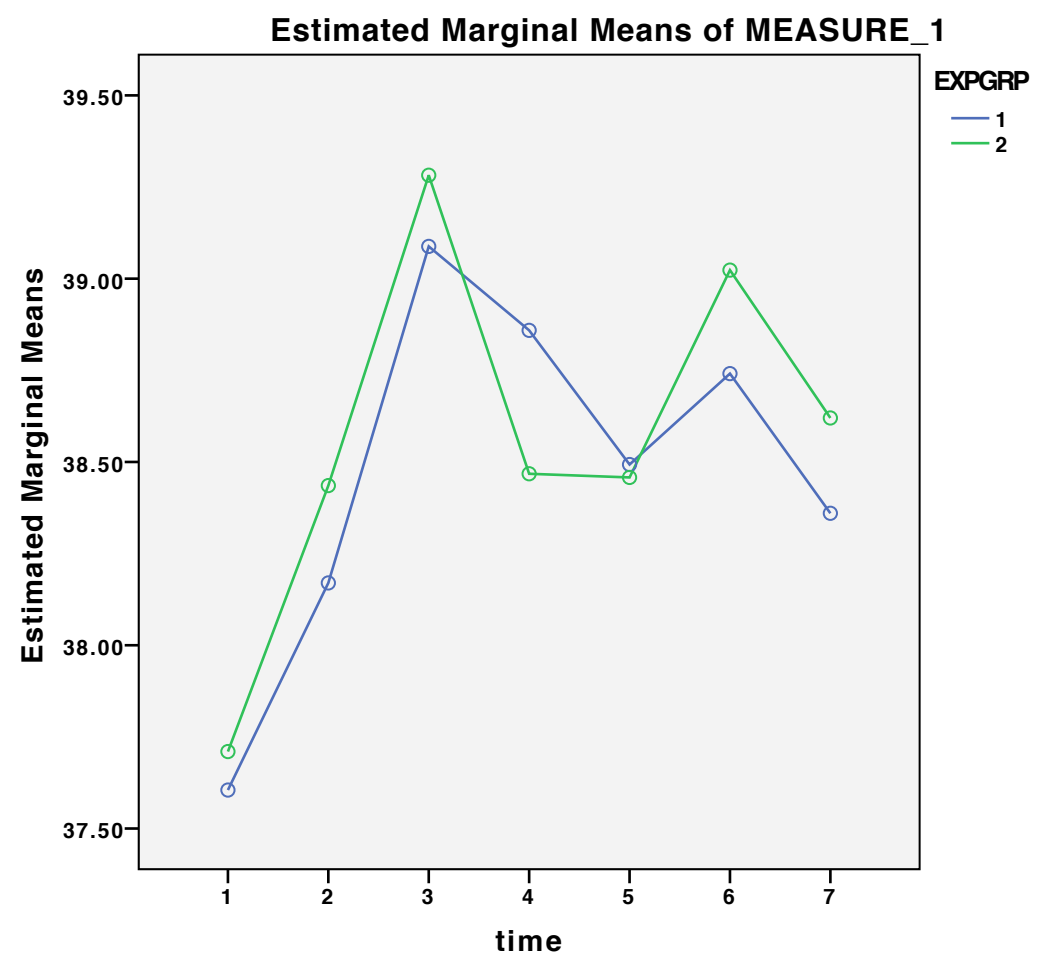

T-Test 
Paired Samples Statistics

\begin{tabular}{|c|c|c|c|c|c|}
\hline & & Mean & $\mathrm{N}$ & $\begin{array}{c}\text { Std. } \\
\text { Deviation }\end{array}$ & $\begin{array}{l}\text { Std. Error } \\
\text { Mean }\end{array}$ \\
\hline \multirow[t]{2}{*}{$\overline{\text { Pair } 1}$} & GIW1T15 & 38.3388 & 24 & .43140 & .08806 \\
\hline & GIW2T15 & 39.1408 & 24 & .46662 & .09525 \\
\hline \multirow[t]{2}{*}{ Pair 2} & GIW1T15 & 38.3226 & 23 & .43362 & .09042 \\
\hline & GIR1T15 & 38.5917 & 23 & .62060 & .12940 \\
\hline \multirow[t]{2}{*}{ Pair 3} & GIW1T15 & 38.2991 & 22 & .41307 & .08807 \\
\hline & GIW3T15 & 38.4959 & 22 & .38483 & .08205 \\
\hline \multirow[t]{2}{*}{ Pair 4} & GIW1T15 & 38.2940 & 20 & 42286 & .09456 \\
\hline & GIW4T15 & 38.8730 & 20 & .38097 & .08519 \\
\hline \multirow[t]{2}{*}{ Pair 5} & GIW1T15 & 38.2940 & 20 & 42286 & .09456 \\
\hline & GIR2T15 & 38.4435 & 20 & .42409 & .09483 \\
\hline \multirow[t]{2}{*}{ Pair 6} & GIW2T15 & 39.1539 & 23 & 47259 & .09854 \\
\hline & GIR1T15 & 38.5917 & 23 & .62060 & .12940 \\
\hline \multirow[t]{2}{*}{ Pair 7} & GIW2T15 & 39.1624 & 21 & 49093 & .10713 \\
\hline & GIW3T15 & 38.5138 & 21 & .38483 & .08398 \\
\hline \multirow[t]{2}{*}{ Pair 8} & GIW2T15 & 39.1800 & 19 & .48695 & .11171 \\
\hline & GIW4T15 & 38.8747 & 19 & .39133 & .08978 \\
\hline \multirow[t]{2}{*}{ Pair 9} & GIW2T15 & 39.1800 & 19 & .48695 & .11171 \\
\hline & GIR2T15 & 38.4832 & 19 & .39578 & .09080 \\
\hline \multirow[t]{2}{*}{ Pair 10} & GIR1T15 & 38.6210 & 21 & .64129 & .13994 \\
\hline & GIW3T15 & 38.5138 & 21 & .38483 & .08398 \\
\hline \multirow[t]{2}{*}{ Pair 11} & GIR1T15 & 38.6737 & 19 & .57803 & .13261 \\
\hline & GIW4T15 & 38.8747 & 19 & .39133 & .08978 \\
\hline \multirow[t]{2}{*}{ Pair 12} & GIR1T15 & 38.6737 & 19 & .57803 & .13261 \\
\hline & GIR2T15 & 38.4832 & 19 & .39578 & .09080 \\
\hline \multirow[t]{2}{*}{ Pair 13} & GIW3T15 & 38.4585 & 20 & .38170 & .08535 \\
\hline & GIW4T15 & 38.8730 & 20 & 38097 & .08519 \\
\hline \multirow[t]{2}{*}{ Pair 14} & GIW3T15 & 38.4585 & 20 & .38170 & .08535 \\
\hline & GIR2T15 & 38.4435 & 20 & .42409 & .09483 \\
\hline \multirow[t]{2}{*}{ Pair 15} & GIW4T15 & 38.8730 & 20 & .38097 & .08519 \\
\hline & GIR2T15 & 38.4435 & 20 & .42409 & .09483 \\
\hline \multirow[t]{2}{*}{ Pair 16} & GIW1T0 & 37.6631 & 26 & .31082 & .06096 \\
\hline & GIW1T15 & 38.3231 & 26 & .41897 & .08217 \\
\hline \multirow[t]{2}{*}{ Pair 17} & GIW1T0 & 37.6746 & 24 & .30754 & .06278 \\
\hline & GIW2T15 & 39.1408 & 24 & .46662 & .09525 \\
\hline \multirow[t]{2}{*}{ Pair 18} & GIW1T0 & 37.6770 & 23 & 31423 & .06552 \\
\hline & GIR1T15 & 38.5917 & 23 & .62060 & .12940 \\
\hline \multirow[t]{2}{*}{ Pair 19} & GIW1T0 & 37.6800 & 22 & .32279 & .06882 \\
\hline & GIW3T15 & 38.4959 & 22 & .38483 & .08205 \\
\hline
\end{tabular}


Paired Samples Statistics

\begin{tabular}{|ll|r|r|r|c|}
\hline & & \multicolumn{1}{|c|}{ Mean } & \multicolumn{1}{c|}{$\mathrm{N}$} & $\begin{array}{c}\text { Std. } \\
\text { Deviation }\end{array}$ & $\begin{array}{c}\text { Std. Error } \\
\text { Mean }\end{array}$ \\
\hline Pair 20 & GIW1T0 & 37.6640 & 20 & .32654 & .07302 \\
& GIW4T15 & 38.8730 & 20 & .38097 & .08519 \\
Pair 21 & GIW1T0 & 37.6640 & 20 & .32654 & .07302 \\
& GIR2T15 & 38.4435 & 20 & .42409 & .09483 \\
\hline
\end{tabular}

Paired Samples Correlations

\begin{tabular}{|ll|r|r|r|}
\hline & & \multicolumn{1}{l|}{ N } & Correlation & Sig. \\
\hline Pair 1 & GIW1T15 \& GIW2T15 & 24 & .750 & .000 \\
Pair 2 & GIW1T15 \& GIR1T15 & 23 & .200 & .360 \\
Pair 3 & GIW1T15 \& GIW3T15 & 22 & .189 & .399 \\
Pair 4 & GIW1T15 \& GIW4T15 & 20 & .328 & .158 \\
Pair 5 & GIW1T15 \& GIR2T15 & 20 & .213 & .367 \\
Pair 6 & GIW2T15 \& GIR1T15 & 23 & .568 & .005 \\
Pair 7 & GIW2T15 \& GIW3T15 & 21 & .205 & .372 \\
Pair 8 & GIW2T15 \& GIW4T15 & 19 & .433 & .064 \\
Pair 9 & GIW2T15 \& GIR2T15 & 19 & .392 & .097 \\
Pair 10 & GIR1T15 \& GIW3T15 & 21 & .256 & .263 \\
Pair 11 & GIR1T15 \& GIW4T15 & 19 & .172 & .482 \\
Pair 12 & GIR1T15 \& GIR2T15 & 19 & .300 & .212 \\
Pair 13 & GIW3T15 \& GIW4T15 & 20 & .512 & .021 \\
Pair 14 & GIW3T15 \& GIR2T15 & 20 & .555 & .011 \\
Pair 15 & GIW4T15 \& GIR2T15 & 20 & .780 & .000 \\
Pair 16 & GIW1T0 \& GIW1T15 & 26 & .571 & .002 \\
Pair 17 & GIW1T0 \& GIW2T15 & 24 & .478 & .018 \\
Pair 18 & GIW1T0 \& GIR1T15 & 23 & .133 & .546 \\
Pair 19 & GIW1T0 \& GIW3T15 & 22 & .248 & .267 \\
Pair 20 & GIW1T0 \& GIW4T15 & 20 & .321 & .168 \\
Pair 21 & GIW1T0 \& GIR2T15 & 20 & .118 & .620 \\
\hline
\end{tabular}


Paired Samples Test

\begin{tabular}{|ll|r|r|c|}
\hline & & \multicolumn{3}{|c|}{ Paired Differences } \\
\cline { 3 - 5 } & & \multicolumn{1}{|c|}{ Mean } & $\begin{array}{c}\text { Std. } \\
\text { Deviation }\end{array}$ & $\begin{array}{c}\text { Std. Error } \\
\text { Mean }\end{array}$ \\
\hline Pair 1 & GIW1T15 - GIW2T15 & -.80208 & .31951 & .06522 \\
Pair 2 & GIW1T15 - GIR1T15 & -.26913 & .68233 & .14228 \\
Pair 3 & GIW1T15 - GIW3T15 & -.19682 & .50847 & .10841 \\
Pair 4 & GIW1T15 - GIW4T15 & -.57900 & .46708 & .10444 \\
Pair 5 & GIW1T15 - GIR2T15 & -.14950 & .53132 & .11881 \\
Pair 6 & GIW2T15 - GIR1T15 & .56217 & .52472 & .10941 \\
Pair 7 & GIW2T15 - GIW3T15 & .64857 & .55809 & .12178 \\
Pair 8 & GIW2T15 - GIW4T15 & .30526 & .47442 & .10884 \\
Pair 9 & GIW2T15 - GIR2T15 & .69684 & .49271 & .11304 \\
Pair 10 & GIR1T15 - GIW3T15 & .10714 & .65801 & .14359 \\
Pair 11 & GIR1T15 - GIW4T15 & -.20105 & .63994 & .14681 \\
Pair 12 & GIR1T15 - GIR2T15 & .19053 & .59450 & .13639 \\
Pair 13 & GIW3T15 - GIW4T15 & -.41450 & .37691 & .08428 \\
Pair 14 & GIW3T15 - GIR2T15 & .01500 & .38213 & .08545 \\
Pair 15 & GIW4T15 - GIR2T15 & .42950 & .27010 & .06040 \\
Pair 16 & GIW1T0 - GIW1T15 & -.66000 & .35135 & .06891 \\
Pair 17 & GIW1T0 - GIW2T15 & -1.46625 & .41834 & .08539 \\
Pair 18 & GIW1T0 - GIR1T15 & -.91478 & .65738 & .13707 \\
Pair 19 & GIW1T0 - GIW3T15 & -.81591 & .43677 & .09312 \\
Pair 20 & GIW1T0 - GIW4T15 & -1.20900 & .41466 & .09272 \\
Pair 21 & GIW1T0 - GIR2T15 & -.77950 & .50379 & .11265 \\
\hline
\end{tabular}


Paired Samples Test

\begin{tabular}{|c|c|c|c|c|}
\hline & \multirow{2}{*}{\multicolumn{2}{|c|}{$\begin{array}{c}\text { Paired Differences } \\
5 \% \text { Confidence Interval of } \\
\text { the Difference }\end{array}$}} & \multirow[b]{3}{*}{$\mathrm{t}$} \\
\hline & & & & \\
\hline & & Lower & Upper & \\
\hline Pair 1 & GIW1T15 - GIW2T15 & -.93700 & -.66717 & -12.298 \\
\hline Pair 2 & GIW1T15 - GIR1T15 & -.56419 & .02593 & -1.892 \\
\hline Pair 3 & GIW1T15 - GIW3T15 & -.42226 & .02862 & -1.816 \\
\hline Pair 4 & GIW1T15 - GIW4T15 & -.79760 & -.36040 & -5.544 \\
\hline Pair 5 & GIW1T15 - GIR2T15 & -.39816 & .09916 & -1.258 \\
\hline Pair 6 & GIW2T15 - GIR1T15 & .33527 & .78908 & 5.138 \\
\hline Pair 7 & GIW2T15 - GIW3T15 & .39453 & .90261 & 5.326 \\
\hline Pair 8 & GIW2T15 - GIW4T15 & .07660 & .53392 & 2.805 \\
\hline Pair 9 & GIW2T15 - GIR2T15 & .45936 & .93432 & 6.165 \\
\hline Pair 10 & GIR1T15 - GIW3T15 & -.19238 & .40666 & .746 \\
\hline Pair 11 & GIR1T15 - GIW4T15 & -.50949 & 10739 & -1.369 \\
\hline Pair 12 & GIR1T15 - GIR2T15 & -.09601 & .47707 & 1.397 \\
\hline Pair 13 & GIW3T15 - GIW4T15 & -.59090 & -.23810 & -4.918 \\
\hline Pair 14 & GIW3T15 - GIR2T15 & -.16384 & .19384 & .176 \\
\hline Pair 15 & GIW4T15 - GIR2T15 & .30309 & .55591 & 7.111 \\
\hline Pair 16 & GIW1T0 - GIW1T15 & -.80191 & -.51809 & -9.578 \\
\hline Pair 17 & GIW1T0 - GIW2T15 & -1.64290 & -1.28960 & -17.171 \\
\hline Pair 18 & GIW1T0 - GIR1T15 & -1.19906 & -.63051 & -6.674 \\
\hline Pair 19 & GIW1T0 - GIW3T15 & -1.00956 & -.62226 & -8.762 \\
\hline Pair 20 & GIW1T0 - GIW4T15 & -1.40307 & -1.01493 & -13.039 \\
\hline Pair 21 & GIW1T0 - GIR2T15 & -1.01528 & -.54372 & -6.920 \\
\hline
\end{tabular}


Paired Samples Test

\begin{tabular}{|ll|r|r|}
\hline & df & $\begin{array}{c}\text { Sig. (2- } \\
\text { tailed) }\end{array}$ \\
\hline Pair 1 & GIW1T15 - GIW2T15 & 23 & .000 \\
Pair 2 & GIW1T15 - GIR1T15 & 22 & .072 \\
Pair 3 & GIW1T15 - GIW3T15 & 21 & .084 \\
Pair 4 & GIW1T15 - GIW4T15 & 19 & .000 \\
Pair 5 & GIW1T15 - GIR2T15 & 19 & .224 \\
Pair 6 & GIW2T15 - GIR1T15 & 22 & .000 \\
Pair 7 & GIW2T15 - GIW3T15 & 20 & .000 \\
Pair 8 & GIW2T15 - GIW4T15 & 18 & .012 \\
Pair 9 & GIW2T15 - GIR2T15 & 18 & .000 \\
Pair 10 & GIR1T15 - GIW3T15 & 20 & .464 \\
Pair 11 & GIR1T15 - GIW4T15 & 18 & .188 \\
Pair 12 & GIR1T15 - GIR2T15 & 18 & .179 \\
Pair 13 & GIW3T15 - GIW4T15 & 19 & .000 \\
Pair 14 & GIW3T15 - GIR2T15 & 19 & .863 \\
Pair 15 & GIW4T15 - GIR2T15 & 19 & .000 \\
Pair 16 & GIW1T0 - GIW1T15 & 25 & .000 \\
Pair 17 & GIW1T0 - GIW2T15 & 23 & .000 \\
Pair 18 & GIW1T0 - GIR1T15 & 22 & .000 \\
Pair 19 & GIW1T0 - GIW3T15 & 21 & .000 \\
Pair 20 & GIW1T0 - GIW4T15 & 19 & .000 \\
Pair 21 & GIW1T0 - GIR2T15 & 19 & .000 \\
\hline
\end{tabular}

\section{General Linear Model}

Within-Subjects

$$
\text { Factors }
$$

Measure:MEASURE 1

\begin{tabular}{|l|l|}
\hline time & $\begin{array}{l}\text { Dependent } \\
\text { Variable }\end{array}$ \\
\hline 1 & HRW1T0 \\
2 & HRW1T15 \\
3 & HRW2T15 \\
4 & HRR1T15 \\
5 & HRW3T15 \\
6 & HRW4T15 \\
7 & HRR2T15 \\
\hline
\end{tabular}




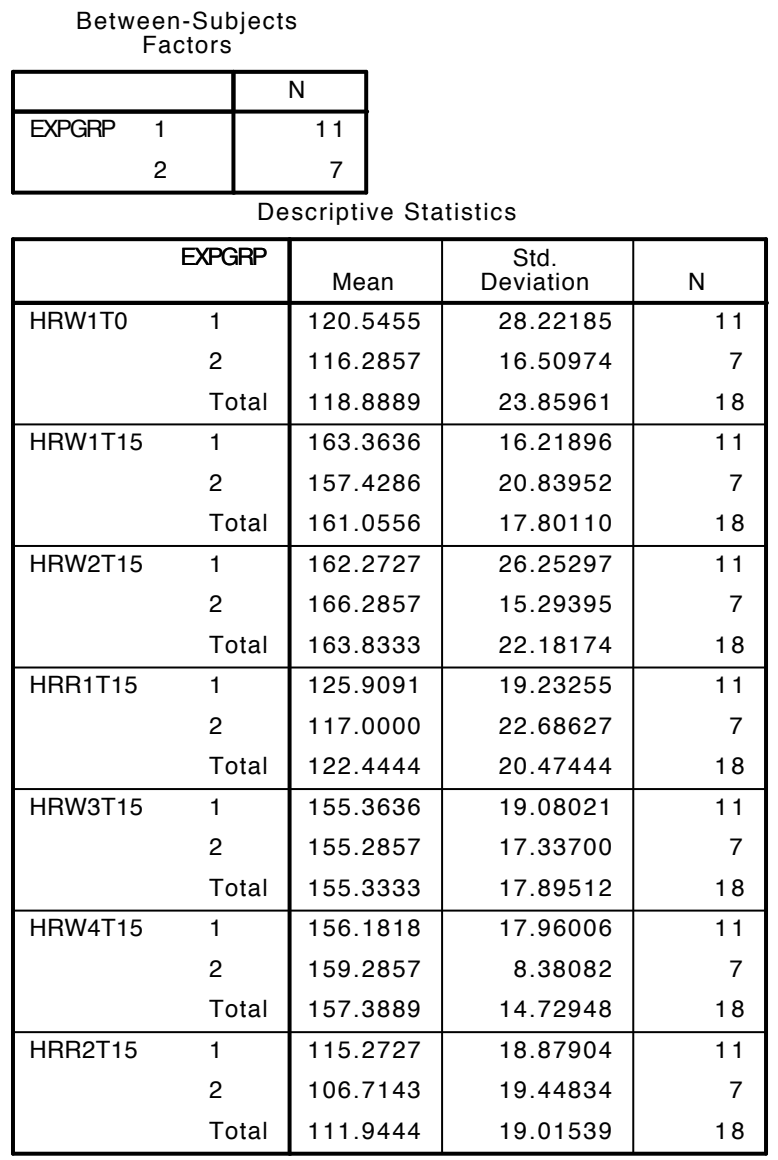

Mauchly's Test of Sphericity ${ }^{b}$

Measure:MEASURE_1

\begin{tabular}{|r|r|r|r|c|}
\hline Within Subjects Effect & Mauchly's W & $\begin{array}{c}\text { Approx. Chi- } \\
\text { Square }\end{array}$ & \multicolumn{1}{c|}{$\mathrm{df}$} & \multicolumn{1}{c|}{ Sig. } \\
\hline time & .112 & 30.162 & 20 & .073 \\
\hline
\end{tabular}

Tests the null hypothesis that the error covariance matrix of the orthonormalized transformed dependent variables is proportional to an identity matrix. 
Mauchly's Test of Sphericity ${ }^{b}$

Measure:MEASURE_1

\begin{tabular}{|r|c|c|c|}
\hline Within Subjects Effect & \multicolumn{3}{|c|}{ Epsilon $^{\text {a }}$} \\
\cline { 2 - 4 } & $\begin{array}{c}\text { Greenhouse- } \\
\text { Geisser }\end{array}$ & Huynh-Feldt & $\begin{array}{c}\text { Lower- } \\
\text { bound }\end{array}$ \\
\hline time & .617 & .877 & .167 \\
\hline
\end{tabular}

Tests the null hypothesis that the error covariance matrix of the orthonormalized transformed dependent variables is proportional to an identity matrix.

a. May be used to adjust the degrees of freedom for the averaged tests of significance. Corrected tests are displayed in the Tests of Within-Subjects Effects table.

b. Design: Intercept + EXPGRP

Within Subjects Design: time

Tests of Within-Subjects Effects

Measure:MEASURE_1

\begin{tabular}{|ll|r|r|r|r|}
\hline Source & \multicolumn{1}{c|}{$\begin{array}{c}\text { Type III Sum } \\
\text { of Squares }\end{array}$} & \multicolumn{1}{c|}{ df } & Mean Square & \multicolumn{1}{c|}{$\mathrm{F}$} \\
\hline time & Sphericity Assumed & 54677.734 & 6 & 9112.956 & 44.559 \\
& Greenhouse-Geisser & 54677.734 & 3.704 & 14760.234 & 44.559 \\
& Huynh-Feldt & 54677.734 & 5.260 & 10394.327 & 44.559 \\
& Lower-bound & 54677.734 & 1.000 & 54677.734 & 44.559 \\
\hline time * EXPGRP & Sphericity Assumed & 731.384 & 6 & 121.897 & .596 \\
& Greenhouse-Geisser & 731.384 & 3.704 & 197.437 & .596 \\
& Huynh-Feldt & 731.384 & 5.260 & 139.037 & .596 \\
& Lower-bound & 731.384 & 1.000 & 731.384 & .596 \\
\hline Error(time) & Sphericity Assumed & 19633.250 & 96 & 204.513 & \\
& Greenhouse-Geisser & 19633.250 & 59.270 & 331.249 & \\
& Huynh-Feldt & 19633.250 & 84.165 & 233.270 & \\
& Lower-bound & 19633.250 & 16.000 & 1227.078 & \\
\hline
\end{tabular}

Tests of Within-Subjects Effects

Measure:MEASURE_1

\begin{tabular}{|ll|r|r|r|r|}
\hline Source & \multicolumn{1}{|c|}{ Sig. } & \multicolumn{1}{c|}{$\begin{array}{c}\text { Partial Eta } \\
\text { Squared }\end{array}$} & $\begin{array}{c}\text { Noncent. } \\
\text { Parameter }\end{array}$ & $\begin{array}{c}\text { Observed } \\
\text { Power }^{\mathrm{a}}\end{array}$ \\
\hline time & Sphericity Assumed & .000 & .736 & 267.356 & 1.000 \\
& Greenhouse-Geisser & .000 & .736 & 165.065 & 1.000 \\
& Huynh-Feldt & .000 & .736 & 234.397 & 1.000 \\
& Lower-bound & .000 & .736 & 44.559 & 1.000 \\
\hline time * EXPGRP & Sphericity Assumed & .733 & .036 & 3.576 & .228 \\
& Greenhouse-Geisser & .654 & .036 & 2.208 & .180 \\
& Huynh-Feldt & .711 & .036 & 3.135 & .213 \\
& Lower-bound & .451 & .036 & .596 & .112 \\
\hline
\end{tabular}

a. Computed using alpha $=.05$ 
Tests of Between-Subjects Effects

Measure:MEASURE 1

Transformed Variable:Average

\begin{tabular}{|l|r|r|r|r|r|r|}
\hline Source & $\begin{array}{c}\text { Type III Sum } \\
\text { of Squares }\end{array}$ & $\mathrm{df}$ & Mean Square & \multicolumn{1}{c|}{$\mathrm{F}$} & \multicolumn{1}{c|}{ Sig. } & \multicolumn{1}{c|}{$\begin{array}{c}\text { Partial Eta } \\
\text { Squared }\end{array}$} \\
\hline Intercept & $2.389 \mathrm{E} 6$ & 1 & $2.389 \mathrm{E} 6$ & 1516.214 & .000 & .990 \\
EXPGRP & 259.920 & 1 & 259.920 & .165 & .690 & .010 \\
Error & 25210.334 & 16 & 1575.646 & & & \\
\hline
\end{tabular}

Tests of Between-Subjects Effects

Measure:MEASURE_1

Transformed Variab̄le:Average

\begin{tabular}{|l|r|r|}
\hline Source & \multicolumn{1}{|c|}{$\begin{array}{c}\text { Noncent. } \\
\text { Parameter }\end{array}$} & \multicolumn{1}{|c|}{$\begin{array}{c}\text { Observed } \\
\text { Power }^{\mathrm{a}}\end{array}$} \\
\hline Intercept & 1516.214 & 1.000 \\
EXPGRP & .165 & .067 \\
\hline
\end{tabular}

a. Computed using alpha $=.05$

\section{Profile Plots}

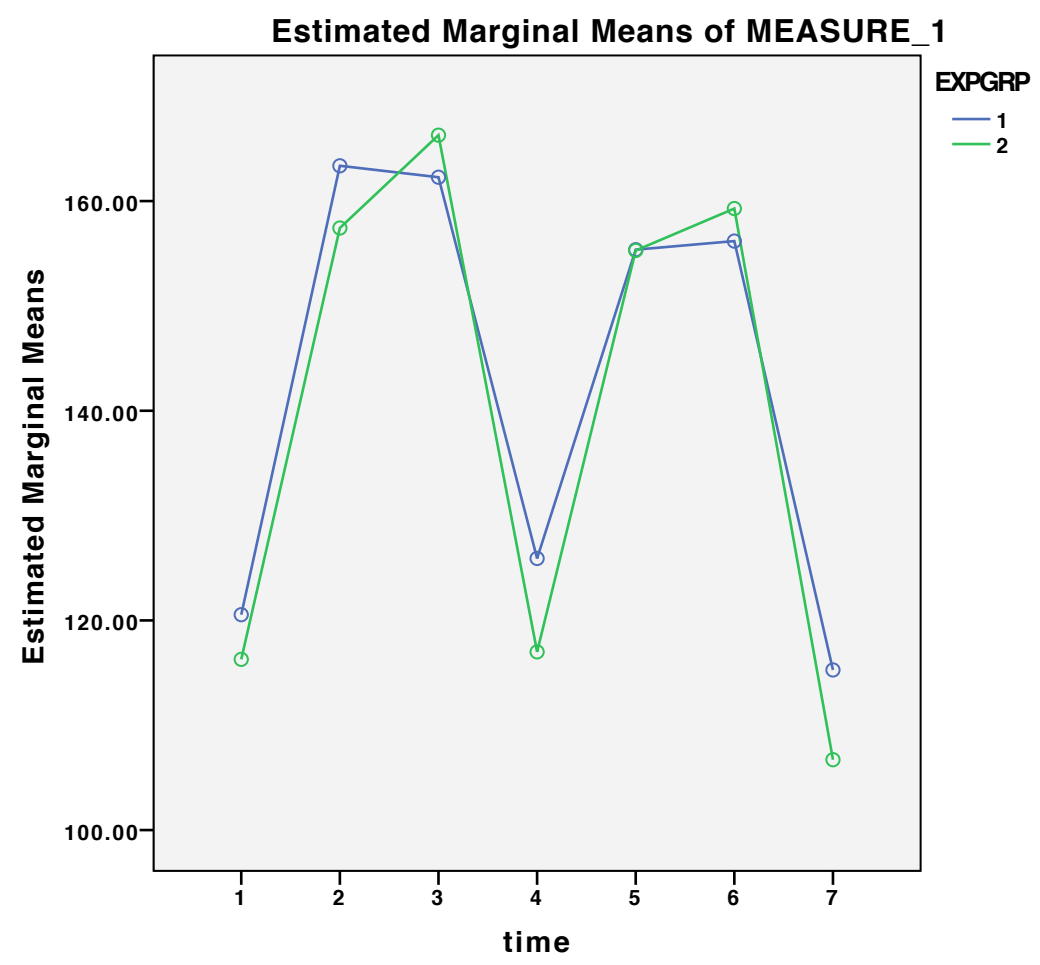

T-Test 
Paired Samples Statistics

\begin{tabular}{|c|c|c|c|c|c|}
\hline & & Mean & $\mathrm{N}$ & $\begin{array}{c}\text { Std. } \\
\text { Deviation }\end{array}$ & $\begin{array}{l}\text { Std. Error } \\
\text { Mean }\end{array}$ \\
\hline \multirow[t]{2}{*}{ Pair 1} & HRW1T15 & 161.3143 & 35 & 15.88890 & 2.68571 \\
\hline & HRW2T15 & 160.6857 & 35 & 21.71171 & 3.66995 \\
\hline \multirow[t]{2}{*}{ Pair 2} & HRW1T15 & 161.3714 & 35 & 15.86169 & 2.68112 \\
\hline & HRR1T15 & 114.5714 & 35 & 19.39874 & 3.27898 \\
\hline \multirow[t]{2}{*}{ Pair 3} & HRW1T15 & 162.0000 & 33 & 16.07405 & 2.79813 \\
\hline & HRW3T15 & 158.2727 & 33 & 16.24091 & 2.82718 \\
\hline \multirow[t]{2}{*}{ Pair 4} & HRW1T15 & 161.0909 & 33 & 15.45227 & 2.68990 \\
\hline & HRW4T15 & 158.1818 & 33 & 13.48484 & 2.34741 \\
\hline \multirow[t]{2}{*}{ Pair 5} & HRW1T15 & 160.9063 & 32 & 15.66249 & 2.76876 \\
\hline & HRR2T15 & 104.0000 & 32 & 18.88676 & 3.33874 \\
\hline \multirow[t]{2}{*}{ Pair 6} & HRW2T15 & 160.1176 & 34 & 21.77261 & 3.73397 \\
\hline & HRR1T15 & 115.2647 & 34 & 19.24532 & 3.30055 \\
\hline \multirow[t]{2}{*}{ Pair 7} & HRW2T15 & 161.0313 & 32 & 21.86835 & 3.86581 \\
\hline & HRW3T15 & 157.4688 & 32 & 15.81952 & 2.79652 \\
\hline \multirow[t]{2}{*}{ Pair 8} & HRW2T15 & 160.8438 & 32 & 21.65434 & 3.82798 \\
\hline & HRW4T15 & 158.1875 & 32 & 13.70057 & 2.42194 \\
\hline \multirow[t]{2}{*}{ Pair 9} & HRW2T15 & 161.6129 & 31 & 21.56336 & 3.87289 \\
\hline & HRR2T15 & 104.0000 & 31 & 19.19896 & 3.44823 \\
\hline \multirow[t]{2}{*}{ Pair 10} & HRR1T15 & 115.3438 & 32 & 19.99292 & 3.53428 \\
\hline & HRW3T15 & 158.0313 & 32 & 16.44048 & 2.90629 \\
\hline \multirow[t]{2}{*}{ Pair 11} & HRR1T15 & 114.5938 & 32 & 19.48177 & 3.44392 \\
\hline & HRW4T15 & 157.6875 & 32 & 13.39340 & 2.36764 \\
\hline \multirow[t]{2}{*}{ Pair 12} & HRR1T15 & 115.0645 & 31 & 19.61791 & 3.52348 \\
\hline & HRR2T15 & 104.4194 & 31 & 19.04691 & 3.42093 \\
\hline \multirow[t]{2}{*}{ Pair 13} & HRW3T15 & 157.5000 & 32 & 15.87248 & 2.80588 \\
\hline & HRW4T15 & 157.6875 & 32 & 13.39340 & 2.36764 \\
\hline \multirow[t]{2}{*}{ Pair 14} & HRW3T15 & 157.7419 & 31 & 16.07476 & 2.88711 \\
\hline & HRR2T15 & 103.3871 & 31 & 18.87269 & 3.38964 \\
\hline \multirow[t]{2}{*}{ Pair 15} & HRW4T15 & 159.0625 & 32 & 12.69985 & 2.24504 \\
\hline & HRR2T15 & 104.0000 & 32 & 18.88676 & 3.33874 \\
\hline \multirow[t]{2}{*}{ Pair 16} & HRW1T0 & 118.6857 & 35 & 19.03367 & 3.21728 \\
\hline & HRW1T15 & 161.9143 & 35 & 15.20908 & 2.57080 \\
\hline \multirow[t]{2}{*}{ Pair 17} & HRW1T0 & 118.6765 & 34 & 19.31983 & 3.31332 \\
\hline & HRW2T15 & 161.0588 & 34 & 21.92403 & 3.75994 \\
\hline \multirow[t]{2}{*}{ Pair 18} & HRW1T0 & 118.9118 & 34 & 19.27216 & 3.30515 \\
\hline & HRR1T15 & 114.6765 & 34 & 19.68036 & 3.37515 \\
\hline \multirow[t]{2}{*}{ Pair 19} & HRW1T0 & 118.8750 & 32 & 19.78880 & 3.49820 \\
\hline & HRW3T15 & 158.7188 & 32 & 16.29414 & 2.88042 \\
\hline
\end{tabular}


Paired Samples Statistics

\begin{tabular}{|cl|c|r|r|r|}
\hline & Mean & N & $\begin{array}{c}\text { Std. } \\
\text { Deviation }\end{array}$ & $\begin{array}{c}\text { Std. Error } \\
\text { Mean }\end{array}$ \\
\hline Pair 20 & HRW1T0 & 118.0938 & 32 & 19.50080 & 3.44729 \\
& HRW4T15 & 158.1875 & 32 & 13.70057 & 2.42194 \\
Pair 21 & HRW1T0 & 118.8387 & 31 & 19.35475 & 3.47622 \\
& HRR2T15 & 105.0968 & 31 & 18.13350 & 3.25687 \\
\hline
\end{tabular}

Paired Samples Correlations

\begin{tabular}{|ll|r|r|r|}
\hline & & $\mathrm{N}$ & Correlation & \multicolumn{1}{l|}{ Sig. } \\
\hline Pair 1 & HRW1T15 \& HRW2T15 & 35 & .149 & .393 \\
Pair 2 & HRW1T15 \& HRR1T15 & 35 & .300 & .080 \\
Pair 3 & HRW1T15 \& HRW3T15 & 33 & .426 & .013 \\
Pair 4 & HRW1T15 \& HRW4T15 & 33 & .202 & .259 \\
Pair 5 & HRW1T15 \& HRR2T15 & 32 & .298 & .098 \\
Pair 6 & HRW2T15 \& HRR1T15 & 34 & .484 & .004 \\
Pair 7 & HRW2T15 \& HRW3T15 & 32 & .409 & .020 \\
Pair 8 & HRW2T15 \& HRW4T15 & 32 & .521 & .002 \\
Pair 9 & HRW2T15 \& HRR2T15 & 31 & .441 & .013 \\
Pair 10 & HRR1T15 \& HRW3T15 & 32 & .385 & .030 \\
Pair 11 & HRR1T15 \& HRW4T15 & 32 & .357 & .045 \\
Pair 12 & HRR1T15 \& HRR2T15 & 31 & .751 & .000 \\
Pair 13 & HRW3T15 \& HRW4T15 & 32 & .511 & .003 \\
Pair 14 & HRW3T15 \& HRR2T15 & 31 & .459 & .009 \\
Pair 15 & HRW4T15 \& HRR2T15 & 32 & .364 & .041 \\
Pair 16 & HRW1T0 \& HRW1T15 & 35 & .514 & .002 \\
Pair 17 & HRW1T0 \& HRW2T15 & 34 & .340 & .049 \\
Pair 18 & HRW1T0 \& HRR1T15 & 34 & .507 & .002 \\
Pair 19 & HRW1T0 \& HRW3T15 & 32 & .597 & .000 \\
Pair 20 & HRW1T0 \& HRW4T15 & 32 & .548 & .001 \\
Pair 21 & HRW1T0 \& HRR2T15 & 31 & .584 & .001 \\
\hline
\end{tabular}


Paired Samples Test

\begin{tabular}{|ll|r|r|c|}
\hline & & \multicolumn{3}{|c|}{ Paired Differences } \\
\cline { 3 - 5 } & & \multicolumn{1}{|c|}{ Mean } & $\begin{array}{c}\text { Std. } \\
\text { Deviation }\end{array}$ & $\begin{array}{c}\text { Std. Error } \\
\text { Mean }\end{array}$ \\
\hline Pair 1 & HRW1T15 - HRW2T15 & .62857 & 24.91997 & 4.21224 \\
Pair 2 & HRW1T15 - HRR1T15 & 46.80000 & 21.05148 & 3.55835 \\
Pair 3 & HRW1T15 - HRW3T15 & 3.72727 & 17.31017 & 3.01331 \\
Pair 4 & HRW1T15 - HRW4T15 & 2.90909 & 18.33774 & 3.19219 \\
Pair 5 & HRW1T15 - HRR2T15 & 56.90625 & 20.63564 & 3.64790 \\
Pair 6 & HRW2T15 - HRR1T15 & 44.85294 & 20.94746 & 3.59246 \\
Pair 7 & HRW2T15 - HRW3T15 & 3.56250 & 21.10181 & 3.73031 \\
Pair 8 & HRW2T15 - HRW4T15 & 2.65625 & 18.64543 & 3.29608 \\
Pair 9 & HRW2T15 - HRR2T15 & 57.61290 & 21.64667 & 3.88786 \\
Pair 10 & HRR1T15 - HRW3T15 & -42.68750 & 20.42206 & 3.61014 \\
Pair 11 & HRR1T15 - HRW4T15 & -43.09375 & 19.30462 & 3.41261 \\
Pair 12 & HRR1T15 - HRR2T15 & 10.64516 & 13.66638 & 2.45455 \\
Pair 13 & HRW3T15 - HRW4T15 & -.18750 & 14.62750 & 2.58580 \\
Pair 14 & HRW3T15 - HRR2T15 & 54.35484 & 18.33675 & 3.29338 \\
Pair 15 & HRW4T15 - HRR2T15 & 55.06250 & 18.52973 & 3.27562 \\
Pair 16 & HRW1T0 - HRW1T15 & -43.22857 & 17.20309 & 2.90785 \\
Pair 17 & HRW1T0 - HRW2T15 & -42.38235 & 23.79587 & 4.08096 \\
Pair 18 & HRW1T0 - HRR1T15 & 4.23529 & 19.33604 & 3.31610 \\
Pair 19 & HRW1T0 - HRW3T15 & -39.84375 & 16.48677 & 2.91448 \\
Pair 20 & HRW1T0 - HRW4T15 & -40.09375 & 16.58091 & 2.93112 \\
Pair 21 & HRW1T0 - HRR2T15 & 13.74194 & 17.13664 & 3.07783 \\
\hline
\end{tabular}




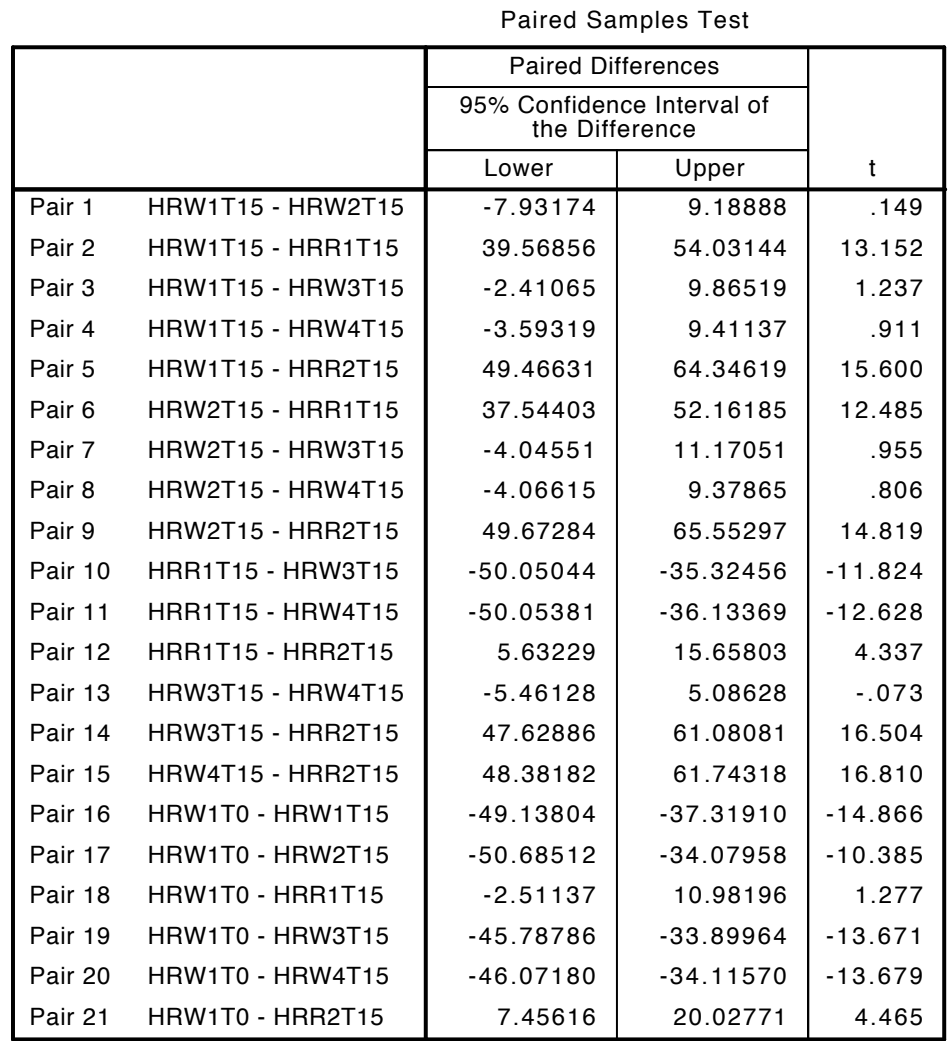


Paired Samples Test

\begin{tabular}{|ll|r|r|}
\hline & & \multicolumn{1}{|c|}{ df } & $\begin{array}{c}\text { Sig. }(2- \\
\text { tailed }\end{array}$ \\
\hline Pair 1 & HRW1T15 - HRW2T15 & 34 & .882 \\
Pair 2 & HRW1T15 - HRR1T15 & 34 & .000 \\
Pair 3 & HRW1T15 - HRW3T15 & 32 & .225 \\
Pair 4 & HRW1T15 - HRW4T15 & 32 & .369 \\
Pair 5 & HRW1T15 - HRR2T15 & 31 & .000 \\
Pair 6 & HRW2T15 - HRR1T15 & 33 & .000 \\
Pair 7 & HRW2T15 - HRW3T15 & 31 & .347 \\
Pair 8 & HRW2T15 - HRW4T15 & 31 & .426 \\
Pair 9 & HRW2T15 - HRR2T15 & 30 & .000 \\
Pair 10 & HRR1T15 - HRW3T15 & 31 & .000 \\
Pair 11 & HRR1T15 - HRW4T15 & 31 & .000 \\
Pair 12 & HRR1T15 - HRR2T15 & 30 & .000 \\
Pair 13 & HRW3T15 - HRW4T15 & 31 & .943 \\
Pair 14 & HRW3T15 - HRR2T15 & 30 & .000 \\
Pair 15 & HRW4T15 - HRR2T15 & 31 & .000 \\
Pair 16 & HRW1T0 - HRW1T15 & 34 & .000 \\
Pair 17 & HRW1T0 - HRW2T15 & 33 & .000 \\
Pair 18 & HRW110 - HRR1T15 & 33 & .210 \\
Pair 19 & HRW110 - HRW3T15 & 31 & .000 \\
Pair 20 & HRW1T0 - HRW4T15 & 31 & .000 \\
Pair 21 & HRW1T0 - HRR2T15 & 30 & .000 \\
\hline
\end{tabular}

\section{General Linear Model}

Within-Subjects

$$
\text { Factors }
$$

Measure:MEASURE_1

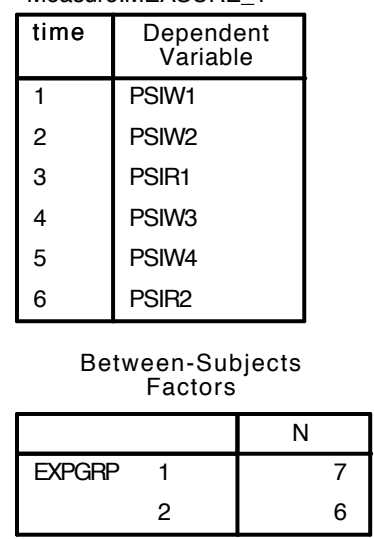


Descriptive Statistics

\begin{tabular}{|ll|l|r|r|}
\hline & EXPGRP & Mean & $\begin{array}{c}\text { Std. } \\
\text { Deviation }\end{array}$ & $\mathrm{N}$ \\
\hline PSIW1 & 1 & 6.1286 & 1.57873 & 7 \\
& 2 & 5.5333 & 1.10212 & 6 \\
& Total & 5.8538 & 1.35930 & 13 \\
\hline PSIW2 & 1 & 7.6714 & 1.62143 & 7 \\
& 2 & 8.0500 & .68920 & 6 \\
& Total & 7.8462 & 1.24540 & 13 \\
\hline PSIR1 & 1 & 5.2857 & 1.03026 & 7 \\
& 2 & 3.6333 & 2.09157 & 6 \\
& Total & 4.5231 & 1.75744 & 13 \\
\hline PSIW3 & 1 & 6.2286 & .99952 & 7 \\
& 2 & 6.3500 & 1.58965 & 6 \\
& Total & 6.2846 & 1.24756 & 13 \\
\hline PSIW4 & 1 & 7.2000 & 1.28323 & 7 \\
& 2 & 7.7833 & .94956 & 6 \\
& Total & 7.4692 & 1.13606 & 13 \\
\hline PSIR2 & 1 & 3.6429 & 1.83925 & 7 \\
& 2 & 3.7500 & 1.66463 & 6 \\
& Total & 3.6923 & 1.68793 & 13 \\
\hline
\end{tabular}

Mauchly's Test of Sphericity ${ }^{b}$

Measure:MEASURE_1

\begin{tabular}{|r|r|r|r|r|}
\hline Within Subjects Effect & Mauchly's W & $\begin{array}{c}\text { Approx. Chi- } \\
\text { Square }\end{array}$ & \multicolumn{1}{c|}{ df } & Sig. \\
\hline time & .088 & 22.154 & 14 & .084 \\
\hline
\end{tabular}

Tests the null hypothesis that the error covariance matrix of the orthonormalized transformed dependent variables is proportional to an identity matrix.

b. Design: Intercept + EXPGRP Within Subjects Design: time 
Mauchly's Test of Sphericity ${ }^{b}$

Measure:MEASURE_1

\begin{tabular}{|r|c|c|c|}
\hline Within Subjects Effect & \multicolumn{3}{|c|}{ Epsilon $^{\text {a }}$} \\
\cline { 2 - 4 } & $\begin{array}{c}\text { Greenhouse- } \\
\text { Geisser }\end{array}$ & Huynh-Feldt & $\begin{array}{c}\text { Lower- } \\
\text { bound }\end{array}$ \\
\hline time & .503 & .723 & .200 \\
\hline
\end{tabular}

Tests the null hypothesis that the error covariance matrix of the orthonormalized transformed dependent variables is proportional to an identity matrix.

a. May be used to adjust the degrees of freedom for the averaged tests of significance. Corrected tests are displayed in the Tests of Within-Subjects Effects table.

b. Design: Intercept + EXPGRP

Within Subjects Design: time

Tests of Within-Subjects Effects

Measure:MEASURE_1

\begin{tabular}{|ll|r|r|r|r|}
\hline Source & \multicolumn{1}{|c|}{$\begin{array}{c}\text { Type III Sum } \\
\text { of Squares }\end{array}$} & \multicolumn{1}{c|}{ df } & Mean Square & \multicolumn{1}{c|}{$\mathrm{F}$} \\
\hline time & Sphericity Assumed & 173.894 & 5 & 34.779 & 26.699 \\
& Greenhouse-Geisser & 173.894 & 2.513 & 69.192 & 26.699 \\
& Huynh-Feldt & 173.894 & 3.614 & 48.116 & 26.699 \\
& Lower-bound & 173.894 & 1.000 & 173.894 & 26.699 \\
\hline time * EXPGRP & Sphericity Assumed & 11.011 & 5 & 2.202 & 1.691 \\
& Greenhouse-Geisser & 11.011 & 2.513 & 4.381 & 1.691 \\
& Huynh-Feldt & 11.011 & 3.614 & 3.047 & 1.691 \\
& Lower-bound & 11.011 & 1.000 & 11.011 & 1.691 \\
\hline Error(time) & Sphericity Assumed & 71.646 & 55 & 1.303 & \\
& Greenhouse-Geisser & 71.646 & 27.645 & 2.592 & \\
& Huynh-Feldt & 71.646 & 39.755 & 1.802 & \\
& Lower-bound & 71.646 & 11.000 & 6.513 & \\
\hline
\end{tabular}

Tests of Within-Subjects Effects

Measure:MEASURE_1

\begin{tabular}{|ll|r|r|r|r|}
\hline Source & Sig. & \multicolumn{1}{c|}{$\begin{array}{c}\text { Partial Eta } \\
\text { Squared }\end{array}$} & $\begin{array}{c}\text { Noncent. } \\
\text { Parameter }\end{array}$ & $\begin{array}{c}\text { Observed } \\
\text { Power }^{2}\end{array}$ \\
\hline time & Sphericity Assumed & .000 & .708 & 133.493 & 1.000 \\
& Greenhouse-Geisser & .000 & .708 & 67.100 & 1.000 \\
& Huynh-Feldt & .000 & .708 & 96.491 & 1.000 \\
& Lower-bound & .000 & .708 & 26.699 & .997 \\
\hline time * EXPGRP & Sphericity Assumed & .152 & .133 & 8.453 & .543 \\
& Greenhouse-Geisser & .198 & .133 & 4.249 & .361 \\
& Huynh-Feldt & .176 & .133 & 6.110 & .448 \\
& Lower-bound & .220 & .133 & 1.691 & .221 \\
\hline
\end{tabular}

a. Computed using alpha $=.05$ 
Tests of Between-Subjects Effects

Measure:MEASURE_1

Transformed Variable:Average

\begin{tabular}{|l|r|r|r|r|r|r|}
\hline Source & $\begin{array}{c}\text { Type III Sum } \\
\text { of Squares }\end{array}$ & \multicolumn{1}{c|}{ df } & Mean Square & \multicolumn{1}{c|}{ F } & \multicolumn{1}{c|}{ Sig. } & \multicolumn{1}{c|}{$\begin{array}{c}\text { Partial Eta } \\
\text { Squared }\end{array}$} \\
\hline Intercept & 2734.082 & 1 & 2734.082 & 477.813 & .000 & .977 \\
EXPGRP & .602 & 1 & .602 & .105 & .752 & .009 \\
Error & 62.943 & 11 & 5.722 & & & \\
\hline
\end{tabular}

Tests of Between-Subjects Effects

Measure:MEASURE_1

Transformed Variab̄le:Average

\begin{tabular}{|l|r|r|}
\hline Source & \multicolumn{1}{|c|}{$\begin{array}{c}\text { Noncent. } \\
\text { Parameter }\end{array}$} & \multicolumn{1}{|c|}{$\begin{array}{c}\text { Observed } \\
\text { Power }^{\mathrm{a}}\end{array}$} \\
\hline Intercept & 477.813 & 1.000 \\
EXPGRP & .105 & .060 \\
\hline
\end{tabular}

a. Computed using alpha $=.05$

\section{Profile Plots}

\section{T-Test}

Paired Samples Statistics

\begin{tabular}{|ll|l|r|r|r|}
\hline & Mean & $\mathrm{N}$ & $\begin{array}{c}\text { Std. } \\
\text { Deviation }\end{array}$ & $\begin{array}{c}\text { Std. Error } \\
\text { Mean }\end{array}$ \\
\hline Pair 1 & PSIW1 & 6.2964 & 28 & 1.30568 & .24675 \\
& PSIW2 & 8.0107 & 28 & 1.45966 & .27585 \\
Pair 2 & PSIW1 & 6.3192 & 26 & 1.29924 & .25480 \\
& PSIR1 & 3.9654 & 26 & 2.27806 & .44676 \\
Pair 3 & PSIW1 & 6.3556 & 27 & 1.30187 & .25055 \\
& PSIW3 & 6.0333 & 27 & 1.40548 & .27049 \\
Pair 4 & PSIW1 & 6.2964 & 28 & 1.24528 & .23534 \\
& PSIW4 & 7.4321 & 28 & 1.14279 & .21597 \\
Pair 5 & PSIW1 & 6.0818 & 22 & 1.27975 & .27284 \\
& PSIR2 & 3.0727 & 22 & 1.87520 & .39979 \\
Pair 6 & PSIW2 & 8.0318 & 22 & 1.21200 & .25840 \\
& PSIR1 & 3.7682 & 22 & 2.13773 & .45577 \\
Pair 7 & PSIW2 & 7.9182 & 22 & 1.50480 & .32082 \\
& PSIW3 & 6.1318 & 22 & 1.12096 & .23899 \\
Pair 8 & PSIW2 & 8.0652 & 23 & 1.53226 & .31950 \\
& PSIW4 & 7.4130 & 23 & 1.17446 & .24489 \\
Pair 9 & PSIW2 & 7.9158 & 19 & 1.59592 & .36613 \\
& PSIR2 & 3.0158 & 19 & 1.91028 & .43825 \\
\hline
\end{tabular}


Paired Samples Statistics

\begin{tabular}{|ll|l|r|r|r|}
\hline & & Mean & $\mathrm{N}$ & $\begin{array}{c}\text { Std. } \\
\text { Deviation }\end{array}$ & $\begin{array}{c}\text { Std. Error } \\
\text { Mean }\end{array}$ \\
\hline Pair 10 & PSIR1 & 3.7714 & 21 & 2.29873 & .50162 \\
& PSIW3 & 6.1476 & 21 & 1.53936 & .33592 \\
Pair 11 & PSIR1 & 4.1136 & 22 & 2.32774 & .49628 \\
& PSIW4 & 7.4864 & 22 & 1.06962 & .22804 \\
Pair 12 & PSIR1 & 4.5895 & 19 & 2.10420 & .48274 \\
& PSIR2 & 3.3105 & 19 & 1.87317 & .42974 \\
Pair 13 & PSIW3 & 5.8440 & 25 & 1.27380 & .25476 \\
& PSIW4 & 7.4200 & 25 & 1.12064 & .22413 \\
Pair 14 & PSIW3 & 6.0053 & 19 & 1.40968 & .32340 \\
& PSIR2 & 2.9105 & 19 & 1.91511 & .43936 \\
Pair 15 & PSIW4 & 7.4818 & 22 & 1.05724 & .22540 \\
& PSIR2 & 3.0727 & 22 & 1.87520 & .39979 \\
\hline
\end{tabular}

Paired Samples Correlations

\begin{tabular}{|ll|r|r|r|}
\hline & & \multicolumn{1}{|c|}{ N } & Correlation & \multicolumn{1}{l|}{ Sig. } \\
\hline Pair 1 & PSIW1 \& PSIW2 & 28 & .423 & .025 \\
Pair 2 & PSIW1 \& PSIR1 & 26 & -.006 & .975 \\
Pair 3 & PSIW1 \& PSIW3 & 27 & -.060 & .765 \\
Pair 4 & PSIW1 \& PSIW4 & 28 & -.094 & .636 \\
Pair 5 & PSIW1 \& PSIR2 & 22 & -.165 & .464 \\
Pair 6 & PSIW2 \& PSIR1 & 22 & .053 & .815 \\
Pair 7 & PSIW2 \& PSIW3 & 22 & .212 & .343 \\
Pair 8 & PSIW2 \& PSIW4 & 23 & .455 & .029 \\
Pair 9 & PSIW2 \& PSIR2 & 19 & .316 & .187 \\
Pair 10 & PSIR1 \& PSIW3 & 21 & .177 & .442 \\
Pair 11 & PSIR1 \& PSIW4 & 22 & .041 & .856 \\
Pair 12 & PSIR1 \& PSIR2 & 19 & .646 & .003 \\
Pair 13 & PSIW3 \& PSIW4 & 25 & .483 & .014 \\
Pair 14 & PSIW3 \& PSIR2 & 19 & .484 & .036 \\
Pair 15 & PSIW4 \& PSIR2 & 22 & .574 & .005 \\
\hline
\end{tabular}




\begin{tabular}{|ll|r|r|r|}
\multicolumn{2}{|c}{} & \multicolumn{3}{c|}{ Paired Samples Test } \\
\cline { 3 - 5 } & & \multicolumn{1}{c|}{ Pean } & \multicolumn{1}{c|}{$\begin{array}{c}\text { Std. } \\
\text { Deviation }\end{array}$} & $\begin{array}{c}\text { Std. Error } \\
\text { Mean }\end{array}$ \\
\hline Pair 1 & PSIW1 - PSIW2 & -1.71429 & 1.49163 & .28189 \\
Pair 2 & PSIW1 - PSIR1 & 2.35385 & 2.62971 & .51573 \\
Pair 3 & PSIW1 - PSIW3 & .32222 & 1.97257 & .37962 \\
Pair 4 & PSIW1 - PSIW4 & -1.13571 & 1.76724 & .33398 \\
Pair 5 & PSIW1 - PSIR2 & 3.00909 & 2.43798 & .51978 \\
Pair 6 & PSIW2 - PSIR1 & 4.26364 & 2.40090 & .51187 \\
Pair 7 & PSIW2 - PSIW3 & 1.78636 & 1.67483 & .35707 \\
Pair 8 & PSIW2 - PSIW4 & .65217 & 1.44564 & .30144 \\
Pair 9 & PSIW2 - PSIR2 & 4.90000 & 2.06559 & .47388 \\
Pair 10 & PSIR1 - PSIW3 & -2.37619 & 2.52961 & .55201 \\
Pair 11 & PSIR1 - PSIW4 & -3.37273 & 2.52137 & .53756 \\
Pair 12 & PSIR1 - PSIR2 & 1.27895 & 1.68575 & .38674 \\
Pair 13 & PSIW3 - PSIW4 & -1.57600 & 1.22416 & .24483 \\
Pair 14 & PSIW3 - PSIR2 & 3.09474 & 1.74467 & .40025 \\
Pair 15 & PSIW4 - PSIR2 & 4.40909 & 1.53620 & .32752 \\
\hline
\end{tabular}

Paired Samples Test

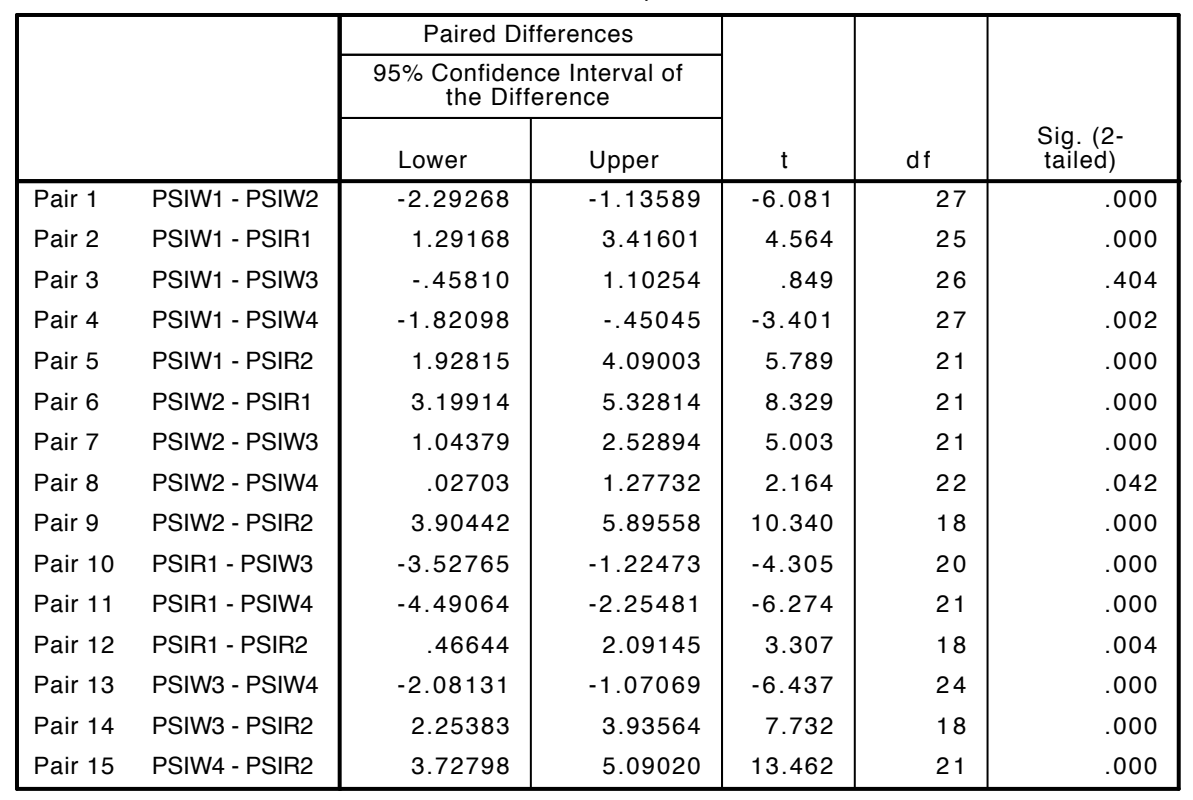

\section{General Linear Model}




$\begin{gathered}\text { Within-Subjects } \\
\text { Factors }\end{gathered}$
Measure:MEASURE_1
\begin{tabular}{|l|l|}
\hline time & $\begin{array}{l}\text { Dependent } \\
\text { Variable }\end{array}$ \\
\hline 1 & SISbsin \\
2 & SISW1 \\
3 & SISW2 \\
4 & SISR1 \\
5 & SISW3 \\
6 & SISW4 \\
7 & SISR2 \\
\hline
\end{tabular}

Between-Subjects Factors

\begin{tabular}{|ll|r|}
\hline & & N \\
\hline EXPGRP & 1 & 8 \\
& 2 & 9 \\
\hline
\end{tabular}

Descriptive Statistics

\begin{tabular}{|ll|r|r|r|}
\hline & EXPGRP & \multicolumn{1}{c|}{ Mean } & \multicolumn{1}{c|}{$\begin{array}{c}\text { Std. } \\
\text { Deviation }\end{array}$} & \multicolumn{1}{c|}{$\mathrm{N}$} \\
\hline SISbsIn & 1 & 27.63 & 12.106 & 8 \\
& 2 & 31.67 & 13.314 & 9 \\
& Total & 29.76 & 12.533 & 17 \\
\hline SISW1 & 1 & 27.8750 & 18.05102 & 8 \\
& 2 & 31.1111 & 14.72620 & 9 \\
& Total & 29.5882 & 15.92976 & 17 \\
\hline SISW2 & 1 & 19.7500 & 15.00238 & 8 \\
& 2 & 25.0000 & 11.66190 & 9 \\
& Total & 22.5294 & 13.18198 & 17 \\
\hline SISR1 & 1 & 20.3750 & 11.71004 & 8 \\
& 2 & 20.7778 & 9.83333 & 9 \\
& Total & 20.5882 & 10.41068 & 17 \\
\hline SISW3 & 1 & 16.7500 & 10.72714 & 8 \\
& 2 & 25.6667 & 9.36750 & 9 \\
& Total & 21.4706 & 10.73614 & 17 \\
\hline SISW4 & 1 & 17.5000 & 12.45564 & 8 \\
& 2 & 27.4444 & 12.45102 & 9 \\
& Total & 22.7647 & 13.09833 & 17 \\
\hline SISR2 & 1 & 15.8750 & 14.07569 & 8 \\
& 2 & 24.8889 & 6.71648 & 9 \\
& Total & 20.6471 & 11.43428 & 17 \\
\hline
\end{tabular}


Mauchly's Test of Sphericity ${ }^{\mathrm{b}}$

Measure:MEASURE_1

\begin{tabular}{|r|r|r|r|r|}
\hline Within Subjects Effect & Mauchly's W & $\begin{array}{c}\text { Approx. Chi- } \\
\text { Square }\end{array}$ & \multicolumn{1}{c|}{ df } & Sig. \\
\hline time & .082 & 31.914 & 20 & .050 \\
\hline
\end{tabular}

Tests the null hypothesis that the error covariance matrix of the orthonormalized transformed dependent variables is proportional to an identity matrix.

b. Design: Intercept + EXPGRP

Within Subjects Design: time

Mauchly's Test of Sphericity ${ }^{b}$

Measure:MEASURE_1

\begin{tabular}{|r|r|r|r|}
\hline Within Subjects Effect & \multicolumn{3}{|c|}{ Epsilon $^{\mathrm{a}}$} \\
\cline { 2 - 4 } & $\begin{array}{c}\text { Greenhouse- } \\
\text { Geisser }\end{array}$ & Huynh-Feldt & $\begin{array}{c}\text { Lower- } \\
\text { bound }\end{array}$ \\
\hline time & .600 & .865 & .167 \\
\hline
\end{tabular}

Tests the null hypothesis that the error covariance matrix of the orthonormalized transformed dependent variables is proportional to an identity matrix.

a. May be used to adjust the degrees of freedom for the averaged tests of significance. Corrected tests are displayed in the Tests of Within-Subjects Effects table.

b. Design: Intercept + EXPGRP

Within Subjects Design: time

Tests of Within-Subjects Effects

Measure:MEASURE_1

\begin{tabular}{|ll|r|r|r|r|}
\hline Source & \multicolumn{1}{|c|}{$\begin{array}{c}\text { Type III Sum } \\
\text { of Squares }\end{array}$} & \multicolumn{1}{c|}{ df } & Mean Square & $\mathrm{F}$ \\
\hline time & Sphericity Assumed & 1679.569 & 6 & 279.928 & 6.681 \\
& Greenhouse-Geisser & 1679.569 & 3.597 & 466.876 & 6.681 \\
& Huynh-Feldt & 1679.569 & 5.188 & 323.739 & 6.681 \\
& Lower-bound & 1679.569 & 1.000 & 1679.569 & 6.681 \\
\hline time * EXPGRP & Sphericity Assumed & 323.199 & 6 & 53.866 & 1.286 \\
& Greenhouse-Geisser & 323.199 & 3.597 & 89.841 & 1.286 \\
& Huynh-Feldt & 323.199 & 5.188 & 62.297 & 1.286 \\
& Lower-bound & 323.199 & 1.000 & 323.199 & 1.286 \\
\hline Error(time) & Sphericity Assumed & 3770.952 & 90 & 41.899 & \\
& Greenhouse-Geisser & 3770.952 & 53.962 & 69.882 & \\
& Huynh-Feldt & 3770.952 & 77.821 & 48.457 & \\
& Lower-bound & 3770.952 & 15.000 & 251.397 & \\
\hline
\end{tabular}


Tests of Within-Subjects Effects

Measure:MEASURE 1

\begin{tabular}{|ll|r|r|r|r|}
\hline Source & \multicolumn{1}{|c|}{ Sig. } & \multicolumn{1}{c|}{$\begin{array}{c}\text { Partial Eta } \\
\text { Squared }\end{array}$} & $\begin{array}{c}\text { Noncent. } \\
\text { Parameter }\end{array}$ & $\begin{array}{c}\text { Observed } \\
\text { Power }^{\text {a }}\end{array}$ \\
\hline time & Sphericity Assumed & .000 & .308 & 40.086 & .999 \\
& Greenhouse-Geisser & .000 & .308 & 24.034 & .981 \\
& Huynh-Feldt & .000 & .308 & 34.661 & .997 \\
& Lower-bound & .021 & .308 & 6.681 & .676 \\
\hline time $^{*}$ EXPGRP & Sphericity Assumed & .272 & .079 & 7.714 & .481 \\
& Greenhouse-Geisser & .288 & .079 & 4.625 & .355 \\
& Huynh-Feldt & .278 & .079 & 6.670 & .441 \\
& Lower-bound & .275 & .079 & 1.286 & .186 \\
\hline
\end{tabular}

a. Computed using alpha $=.05$

Tests of Between-Subjects Effects

Measure:MEASURE_1

Transformed Variable:Average

\begin{tabular}{|l|r|r|r|r|r|r|}
\hline Source & \multicolumn{1}{|c|}{$\begin{array}{c}\text { Type III Sum } \\
\text { of Squares }\end{array}$} & df & Mean Square & \multicolumn{1}{c|}{ F } & \multicolumn{1}{c|}{ Sig. } & \multicolumn{1}{c|}{$\begin{array}{c}\text { Partial Eta } \\
\text { Squared }\end{array}$} \\
\hline Intercept & 66812.964 & 1 & 66812.964 & 79.118 & .000 & .841 \\
EXPGRP & 1007.451 & 1 & 1007.451 & 1.193 & .292 & .074 \\
Error & 12667.103 & 15 & 844.474 & & & \\
\hline
\end{tabular}

Tests of Between-Subjects Effects

Measure:MEASURE_1

Transformed Variable:Average

\begin{tabular}{|l|r|r|}
\hline Source & \multicolumn{1}{|c|}{$\begin{array}{c}\text { Noncent. } \\
\text { Parameter }\end{array}$} & \multicolumn{1}{|c|}{$\begin{array}{c}\text { Observed } \\
\text { Power }^{\mathrm{a}}\end{array}$} \\
\hline Intercept & 79.118 & 1.000 \\
EXPGRP & 1.193 & .176 \\
\hline
\end{tabular}

a. Computed using alpha $=.05$

\section{Profile Plots}




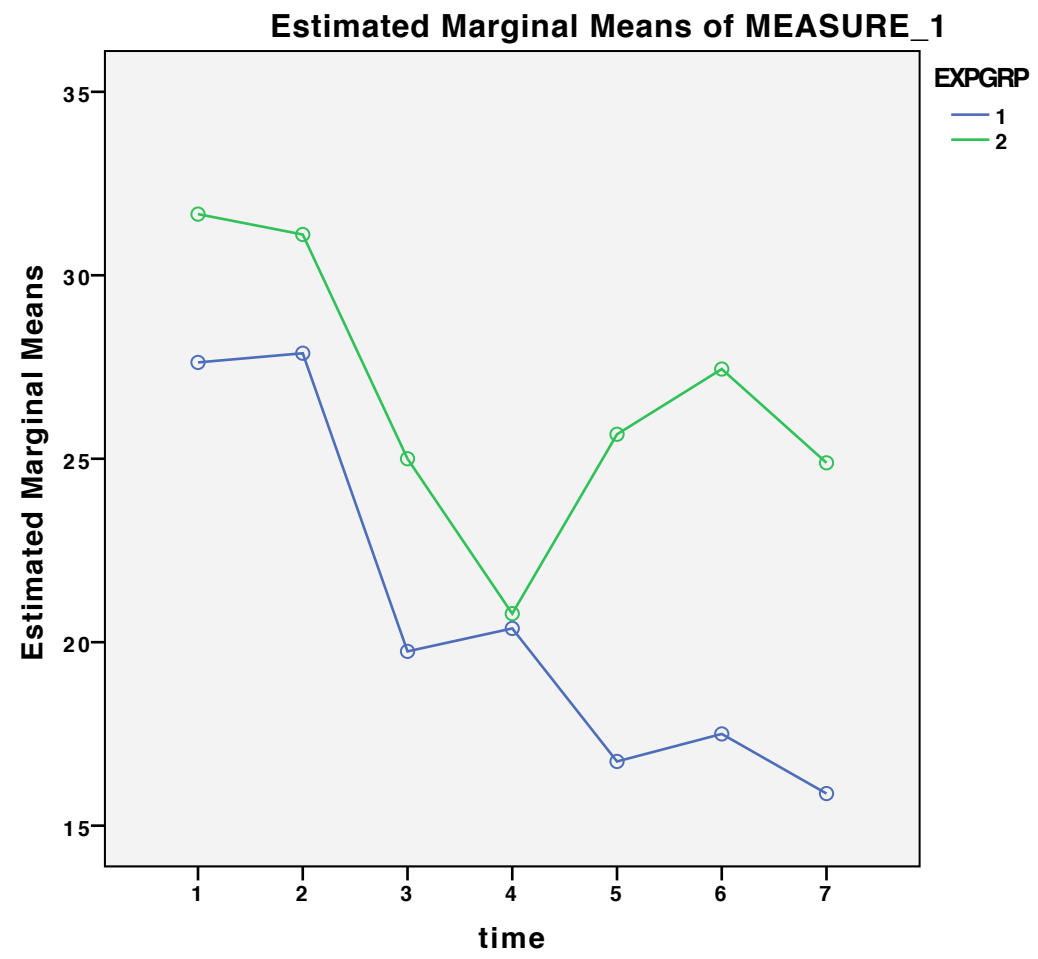

T-Test 
Paired Samples Statistics

\begin{tabular}{|c|c|c|c|c|c|}
\hline & & Mean & $\mathrm{N}$ & $\begin{array}{c}\text { Std. } \\
\text { Deviation }\end{array}$ & $\begin{array}{c}\text { Std. Error } \\
\text { Mean }\end{array}$ \\
\hline \multirow[t]{2}{*}{ Pair 1} & SISbsln & 32.03 & 33 & 12.071 & 2.101 \\
\hline & SISW1 & 30.1212 & 33 & 12.93918 & 2.25242 \\
\hline \multirow[t]{2}{*}{ Pair 2} & SISbsIn & 31.79 & 34 & 11.967 & 2.052 \\
\hline & SISW2 & 24.0882 & 34 & 11.43458 & 1.96101 \\
\hline \multirow[t]{2}{*}{ Pair 3} & SISbsin & 31.79 & 34 & 11.967 & 2.052 \\
\hline & SISR1 & 23.0588 & 34 & 9.37741 & 1.60821 \\
\hline \multirow[t]{2}{*}{ Pair 4} & SISbsin & 30.62 & 29 & 12.137 & 2.254 \\
\hline & SISW3 & 23.3103 & 29 & 9.66992 & 1.79566 \\
\hline \multirow[t]{2}{*}{ Pair 5} & SISbsin & 31.00 & 32 & 11.857 & 2.096 \\
\hline & SISW4 & 22.5938 & 32 & 11.03911 & 1.95146 \\
\hline \multirow[t]{2}{*}{ Pair 6} & SISbsin & 30.90 & 30 & 11.938 & 2.180 \\
\hline & SISR2 & 22.2667 & 30 & 10.33886 & 1.88761 \\
\hline \multirow[t]{2}{*}{ Pair 7} & SISW1 & 30.1212 & 33 & 12.93918 & 2.25242 \\
\hline & SISW2 & 24.4545 & 33 & 11.40748 & 1.98579 \\
\hline \multirow[t]{2}{*}{ Pair 8} & SISW1 & 30.1212 & 33 & 12.93918 & 2.25242 \\
\hline & SISR1 & 23.2424 & 33 & 9.46054 & 1.64687 \\
\hline \multirow[t]{2}{*}{ Pair 9} & SISW1 & 29.3214 & 28 & 13.83247 & 2.61409 \\
\hline & SISW3 & 23.6786 & 28 & 9.63809 & 1.82143 \\
\hline \multirow[t]{2}{*}{ Pair 10} & SISW1 & 29.6452 & 31 & 13.21753 & 2.37394 \\
\hline & SISW4 & 22.9355 & 31 & 11.04818 & 1.98431 \\
\hline \multirow[t]{2}{*}{ Pair 11} & SISW1 & 30.1379 & 29 & 13.34628 & 2.47834 \\
\hline & SISR2 & 22.6552 & 29 & 10.29659 & 1.91203 \\
\hline \multirow[t]{2}{*}{ Pair 12} & SISW2 & 24.0882 & 34 & 11.43458 & 1.96101 \\
\hline & SISR1 & 23.0588 & 34 & 9.37741 & 1.60821 \\
\hline \multirow[t]{2}{*}{ Pair 13} & SISW2 & 23.3793 & 29 & 12.18434 & 2.26258 \\
\hline & SISW3 & 23.3103 & 29 & 9.66992 & 1.79566 \\
\hline \multirow[t]{2}{*}{ Pair 14} & SISW2 & 23.6563 & 32 & 11.64698 & 2.05892 \\
\hline & SISW4 & 22.5938 & 32 & 11.03911 & 1.95146 \\
\hline \multirow[t]{2}{*}{ Pair 15} & SISW2 & 23.7333 & 30 & 11.87560 & 2.16818 \\
\hline & SISR2 & 22.2667 & 30 & 10.33886 & 1.88761 \\
\hline \multirow[t]{2}{*}{ Pair 16} & SISR1 & 22.1724 & 29 & 9.74705 & 1.80998 \\
\hline & SISW3 & 23.3103 & 29 & 9.66992 & 1.79566 \\
\hline \multirow[t]{2}{*}{ Pair 17} & SISR1 & 22.7188 & 32 & 9.56888 & 1.69156 \\
\hline & SISW4 & 22.5938 & 32 & 11.03911 & 1.95146 \\
\hline \multirow[t]{2}{*}{ Pair 18} & SISR1 & 22.9333 & 30 & 9.65592 & 1.76292 \\
\hline & SISR2 & 22.2667 & 30 & 10.33886 & 1.88761 \\
\hline \multirow[t]{2}{*}{ Pair 19} & SISW3 & 23.3103 & 29 & 9.66992 & 1.79566 \\
\hline & SISW4 & 22.3793 & 29 & 11.36226 & 2.10992 \\
\hline
\end{tabular}


Paired Samples Statistics

\begin{tabular}{|ll|r|r|r|r|}
\hline & & Mean & $\mathrm{N}$ & $\begin{array}{c}\text { Std. } \\
\text { Deviation }\end{array}$ & $\begin{array}{c}\text { Std. Error } \\
\text { Mean }\end{array}$ \\
\hline Pair 20 & SISW3 & 23.2857 & 28 & 9.84644 & 1.86080 \\
& SISR2 & 21.8214 & 28 & 10.56919 & 1.99739 \\
Pair 21 & SISW4 & 22.8667 & 30 & 11.29764 & 2.06266 \\
& SISR2 & 22.2667 & 30 & 10.33886 & 1.88761 \\
\hline
\end{tabular}

Paired Samples Correlations

\begin{tabular}{|ll|r|r|r|}
\hline & & \multicolumn{1}{|c|}{$\mathrm{N}$} & Correlation & \multicolumn{1}{l|}{ Sig. } \\
\hline Pair 1 & SISbsIn \& SISW1 & 33 & .604 & .000 \\
Pair 2 & SISbsIn \& SISW2 & 34 & .810 & .000 \\
Pair 3 & SISbsIn \& SISR1 & 34 & .812 & .000 \\
Pair 4 & SISbsIn \& SISW3 & 29 & .697 & .000 \\
Pair 5 & SISbsIn \& SISW4 & 32 & .658 & .000 \\
Pair 6 & SISbsIn \& SISR2 & 30 & .715 & .000 \\
Pair 7 & SISW1 \& SISW2 & 33 & .703 & .000 \\
Pair 8 & SISW1 \& SISR1 & 33 & .668 & .000 \\
Pair 9 & SISW1 \& SISW3 & 28 & .601 & .001 \\
Pair 10 & SISW1 \& SISW4 & 31 & .599 & .000 \\
Pair 11 & SISW1 \& SISR2 & 29 & .607 & .000 \\
Pair 12 & SISW2 \& SISR1 & 34 & .847 & .000 \\
Pair 13 & SISW2 \& SISW3 & 29 & .830 & .000 \\
Pair 14 & SISW2 \& SISW4 & 32 & .740 & .000 \\
Pair 15 & SISW2 \& SISR2 & 30 & .746 & .000 \\
Pair 16 & SISR1 \& SISW3 & 29 & .814 & .000 \\
Pair 17 & SISR1 \& SISW4 & 32 & .703 & .000 \\
Pair 18 & SISR1 \& SISR2 & 30 & .741 & .000 \\
Pair 19 & SISW3 \& SISW4 & 29 & .766 & .000 \\
Pair 20 & SISW3 \& SISR2 & 28 & .769 & .000 \\
Pair 21 & SISW4 \& SISR2 & 30 & .657 & .000 \\
\hline
\end{tabular}




\begin{tabular}{|c|c|c|c|c|}
\hline & & \multicolumn{3}{|c|}{ Paired Differences } \\
\hline & & Mean & $\begin{array}{c}\text { Std. } \\
\text { Deviation }\end{array}$ & $\begin{array}{l}\text { Std. Error } \\
\text { Mean }\end{array}$ \\
\hline Pair 1 & SISbsln - SISW1 & 1.90909 & 11.15617 & 1.94204 \\
\hline Pair 2 & SISbsIn - SISW2 & 7.70588 & 7.23011 & 1.23995 \\
\hline Pair 3 & SISbsIn - SISR1 & 8.73529 & 6.98617 & 1.19812 \\
\hline Pair 4 & SISbsIn - SISW3 & 7.31034 & 8.78759 & 1.63181 \\
\hline Pair 5 & SISbsIn - SISW4 & 8.40625 & 9.49315 & 1.67817 \\
\hline Pair 6 & SISbsln - SISR2 & 8.63333 & 8.54394 & 1.55990 \\
\hline Pair 7 & SISW1 - SISW2 & 5.66667 & 9.49561 & 1.65297 \\
\hline Pair 8 & SISW1 - SISR1 & 6.87879 & 9.66229 & 1.68199 \\
\hline Pair 9 & SISW1 - SISW3 & 5.64286 & 11.13292 & 2.10392 \\
\hline Pair 10 & SISW1 - SISW4 & 6.70968 & 11.03387 & 1.98174 \\
\hline Pair 11 & SISW1 - SISR2 & 7.48276 & 10.82530 & 2.01021 \\
\hline Pair 12 & SISW2 - SISR1 & 1.02941 & 6.08767 & 1.04403 \\
\hline Pair 13 & SISW2 - SISW3 & .06897 & 6.81349 & 1.26523 \\
\hline Pair 14 & SISW2 - SISW4 & 1.06250 & 8.19495 & 1.44868 \\
\hline Pair 15 & SISW2 - SISR2 & 1.46667 & 8.04613 & 1.46902 \\
\hline Pair 16 & SISR1 - SISW3 & -1.13793 & 5.92648 & 1.10052 \\
\hline Pair 17 & SISR1 - SISW4 & .12500 & 8.05525 & 1.42398 \\
\hline Pair 18 & SISR1 - SISR2 & .66667 & 7.21748 & 1.31772 \\
\hline Pair 19 & SISW3 - SISW4 & .93103 & 7.36755 & 1.36812 \\
\hline Pair 20 & SISW3 - SISR2 & 1.46429 & 6.97340 & 1.31785 \\
\hline Pair 21 & SISW4 - SISR2 & .60000 & 9.00038 & 1.64324 \\
\hline
\end{tabular}


Paired Samples Test

\begin{tabular}{|c|c|c|c|c|c|c|}
\hline & \multirow{2}{*}{\multicolumn{2}{|c|}{$\begin{array}{c}\text { Paired Differences } \\
95 \% \text { Confidence Interval of } \\
\text { the Difference }\end{array}$}} & \multirow[b]{3}{*}{$\mathrm{t}$} & \multirow[b]{3}{*}{$d f$} & \multirow[b]{3}{*}{$\begin{array}{l}\text { Sig. (2- } \\
\text { tailed) }\end{array}$} \\
\hline & & & & & & \\
\hline & & Lower & Upper & & & \\
\hline Pair 1 & SISbsln - SISW1 & -2.04672 & 5.86490 & .983 & 32 & .333 \\
\hline Pair 2 & SISbsln - SISW2 & 5.18318 & 10.22859 & 6.215 & 33 & .000 \\
\hline Pair 3 & SISbsIn - SISR1 & 6.29770 & 11.17288 & 7.291 & 33 & .000 \\
\hline Pair 4 & SISbsIn - SISW3 & 3.96773 & 10.65296 & 4.480 & 28 & .000 \\
\hline Pair 5 & SISbsln - SISW4 & 4.98360 & 11.82890 & 5.009 & 31 & .000 \\
\hline Pair 6 & SISbsIn - SISR2 & 5.44298 & 11.82369 & 5.535 & 29 & .000 \\
\hline Pair 7 & SISW1 - SISW2 & 2.29967 & 9.03366 & 3.428 & 32 & .002 \\
\hline Pair 8 & SISW1 - SISR1 & 3.45269 & 10.30489 & 4.090 & 32 & .000 \\
\hline Pair 9 & SISW1 - SISW3 & 1.32596 & 9.95975 & 2.682 & 27 & .012 \\
\hline Pair 10 & SISW1 - SISW4 & 2.66242 & 10.75693 & 3.386 & 30 & .002 \\
\hline Pair 11 & SISW1 - SISR2 & 3.36503 & 11.60048 & 3.722 & 28 & .001 \\
\hline Pair 12 & SISW2 - SISR1 & -1.09468 & 3.15350 & .986 & 33 & .331 \\
\hline Pair 13 & SISW2 - SISW3 & -2.52275 & 2.66068 & .055 & 28 & .957 \\
\hline Pair 14 & SISW2 - SISW4 & -1.89210 & 4.01710 & .733 & 31 & .469 \\
\hline Pair 15 & SISW2 - SISR2 & -1.53781 & 4.47114 & .998 & 29 & .326 \\
\hline Pair 16 & SISR1 - SISW3 & -3.39224 & 1.11638 & -1.034 & 28 & .310 \\
\hline Pair 17 & SISR1 - SISW4 & -2.77923 & 3.02923 & .088 & 31 & .931 \\
\hline Pair 18 & SISR1 - SISR2 & -2.02838 & 3.36172 & .506 & 29 & .617 \\
\hline Pair 19 & SISW3 - SISW4 & -1.87143 & 3.73350 & .681 & 28 & .502 \\
\hline Pair 20 & SISW3 - SISR2 & -1.23972 & 4.16829 & 1.111 & 27 & .276 \\
\hline Pair 21 & SISW4 - SISR2 & -2.76080 & 3.96080 & .365 & 29 & .718 \\
\hline
\end{tabular}

\section{General Linear Model}

Within-Subjects

Factors

Measure:MEASURE_1

\begin{tabular}{|l|l|}
\hline time & $\begin{array}{c}\text { Dependent } \\
\text { Variable }\end{array}$ \\
\hline 1 & PTSbsin \\
2 & PTSW1 \\
3 & PTSW2 \\
4 & PTSR1 \\
5 & PTSW3 \\
6 & PTSW4 \\
7 & PTSR2 \\
\hline
\end{tabular}




\begin{tabular}{|c|c|c|c|c|}
\hline \multicolumn{3}{|c|}{$\begin{array}{c}\text { Between-Subjects } \\
\text { Factors }\end{array}$} & & \\
\hline & & $\mathrm{N}$ & & \\
\hline \multirow[t]{2}{*}{ EXPGRP } & 1 & 9 & & \\
\hline & 2 & 7 & & \\
\hline \multicolumn{5}{|c|}{ Descriptive Statistics } \\
\hline \multicolumn{2}{|r|}{ EXPGRP } & Mean & $\begin{array}{c}\text { Std. } \\
\text { Deviation }\end{array}$ & $\mathrm{N}$ \\
\hline \multirow[t]{3}{*}{ PTSbsln } & 1 & 4.67 & .707 & 9 \\
\hline & 2 & 5.00 & .577 & 7 \\
\hline & Total & 4.81 & 655 & 16 \\
\hline \multirow[t]{3}{*}{ PTSW1 } & 1 & 6.1111 & .60093 & 9 \\
\hline & 2 & 6.0000 & .57735 & 7 \\
\hline & Total & 6.0625 & .57373 & 16 \\
\hline \multirow[t]{3}{*}{ PTSW2 } & 1 & 6.8889 & .60093 & 9 \\
\hline & 2 & 6.4286 & 1.13389 & 7 \\
\hline & Total & 6.6875 & .87321 & 16 \\
\hline \multirow[t]{3}{*}{ PTSR1 } & 1 & 5.0000 & 1.11803 & 9 \\
\hline & 2 & 4.1429 & 1.06904 & 7 \\
\hline & Total & 4.6250 & 1.14746 & 16 \\
\hline \multirow[t]{3}{*}{ PTSW3 } & 1 & 6.5556 & .72648 & 9 \\
\hline & 2 & 6.2857 & .95119 & 7 \\
\hline & Total & 6.4375 & .81394 & 16 \\
\hline \multirow[t]{3}{*}{ PTSW4 } & 1 & 7.0000 & .70711 & 9 \\
\hline & 2 & 6.5714 & .78680 & 7 \\
\hline & Total & 6.8125 & .75000 & 16 \\
\hline \multirow[t]{3}{*}{ PTSR2 } & 1 & 4.7778 & .66667 & 9 \\
\hline & 2 & 4.0000 & .81650 & 7 \\
\hline & Total & 4.4375 & .81394 & 16 \\
\hline
\end{tabular}

Mauchly's Test of Sphericity ${ }^{b}$

Measure:MEASURE_1

\begin{tabular}{|r|r|r|r|c|}
\hline Within Subjects Effect & Mauchly's W & $\begin{array}{c}\text { Approx. Chi- } \\
\text { Square }\end{array}$ & \multicolumn{1}{c|}{$\mathrm{df}$} & \multicolumn{1}{c|}{ Sig. } \\
\hline time & .240 & 16.804 & 20 & .680 \\
\hline
\end{tabular}

Tests the null hypothesis that the error covariance matrix of the orthonormalized transformed dependent variables is proportional to an identity matrix. 
Mauchly's Test of Sphericity ${ }^{b}$

Measure:MEASURE_1

\begin{tabular}{|r|c|c|c|}
\hline Within Subjects Effect & \multicolumn{3}{|c|}{ Epsilon $^{\text {a }}$} \\
\cline { 2 - 4 } & $\begin{array}{c}\text { Greenhouse- } \\
\text { Geisser }\end{array}$ & Huynh-Feldt & $\begin{array}{c}\text { Lower- } \\
\text { bound }\end{array}$ \\
\hline time & .751 & 1.000 & .167 \\
\hline
\end{tabular}

Tests the null hypothesis that the error covariance matrix of the orthonormalized transformed dependent variables is proportional to an identity matrix.

a. May be used to adjust the degrees of freedom for the averaged tests of significance. Corrected tests are displayed in the Tests of Within-Subjects Effects table.

b. Design: Intercept + EXPGRP

Within Subjects Design: time

Tests of Within-Subjects Effects

Measure:MEASURE_1

\begin{tabular}{|c|c|c|c|c|c|}
\hline Source & & $\begin{array}{l}\text { Type III Sum } \\
\text { of Squares }\end{array}$ & $d f$ & Mean Square & $\mathrm{F}$ \\
\hline \multirow[t]{4}{*}{ time } & Sphericity Assumed & 102.100 & 6 & 17.017 & 37.733 \\
\hline & Greenhouse-Geisser & 102.100 & 4.506 & 22.659 & 37.733 \\
\hline & Huynh-Feldt & 102.100 & 6.000 & 17.017 & 37.733 \\
\hline & Lower-bound & 102.100 & 1.000 & 102.100 & 37.733 \\
\hline \multirow[t]{4}{*}{ time * EXPGRP } & Sphericity Assumed & 3.886 & 6 & .648 & 1.436 \\
\hline & Greenhouse-Geisser & 3.886 & 4.506 & .862 & 1.436 \\
\hline & Huynh-Feldt & 3.886 & 6.000 & .648 & 1.436 \\
\hline & Lower-bound & 3.886 & 1.000 & 3.886 & 1.436 \\
\hline \multirow[t]{4}{*}{ Error(time) } & Sphericity Assumed & 37.882 & 84 & .451 & \\
\hline & Greenhouse-Geisser & 37.882 & 63.084 & .601 & \\
\hline & Huynh-Feldt & 37.882 & 84.000 & .451 & \\
\hline & Lower-bound & 37.882 & 14.000 & 2.706 & \\
\hline
\end{tabular}

Tests of Within-Subjects Effects

Measure:MEASURE_1

\begin{tabular}{|ll|r|r|r|r|}
\hline Source & \multicolumn{1}{|c|}{ Sig. } & \multicolumn{1}{c|}{$\begin{array}{c}\text { Partial Eta } \\
\text { Squared }\end{array}$} & $\begin{array}{c}\text { Noncent. } \\
\text { Parameter }\end{array}$ & $\begin{array}{c}\text { Observed } \\
\text { Power }^{\mathrm{a}}\end{array}$ \\
\hline time & Sphericity Assumed & .000 & .729 & 226.397 & 1.000 \\
& Greenhouse-Geisser & .000 & .729 & 170.024 & 1.000 \\
& Huynh-Feldt & .000 & .729 & 226.397 & 1.000 \\
& Lower-bound & .000 & .729 & 37.733 & 1.000 \\
\hline time * EXPGRP & Sphericity Assumed & .211 & .093 & 8.616 & .531 \\
& Greenhouse-Geisser & .228 & .093 & 6.471 & .448 \\
& Huynh-Feldt & .211 & .093 & 8.616 & .531 \\
& Lower-bound & .251 & .093 & 1.436 & .201 \\
\hline
\end{tabular}

a. Computed using alpha $=.05$ 
Tests of Between-Subjects Effects

Measure:MEASURE 1

Transformed Variable:Average

\begin{tabular}{|l|r|r|r|r|r|r|}
\hline Source & \multicolumn{1}{|c|}{$\begin{array}{c}\text { Type III Sum } \\
\text { of Squares }\end{array}$} & df & Mean Square & F & \multicolumn{1}{c|}{ Sig. } & \multicolumn{1}{c|}{$\begin{array}{c}\text { Partial Eta } \\
\text { Squared }\end{array}$} \\
\hline Intercept & 3548.755 & 1 & 3548.755 & 1956.950 & .000 & .993 \\
EXPGRP & 3.719 & 1 & 3.719 & 2.051 & .174 & .128 \\
Error & 25.388 & 14 & 1.813 & & & \\
\hline
\end{tabular}

Tests of Between-Subjects Effects

Measure:MEASURE_1

Transformed Variab̄le:Average

\begin{tabular}{|l|r|r|}
\hline Source & \multicolumn{1}{|c|}{$\begin{array}{c}\text { Noncent. } \\
\text { Parameter }\end{array}$} & \multicolumn{1}{|c|}{$\begin{array}{c}\text { Observed } \\
\text { Power }^{\mathrm{a}}\end{array}$} \\
\hline Intercept & 1956.950 & 1.000 \\
EXPGRP & 2.051 & .266 \\
\hline
\end{tabular}

a. Computed using alpha $=.05$

\section{Profile Plots}

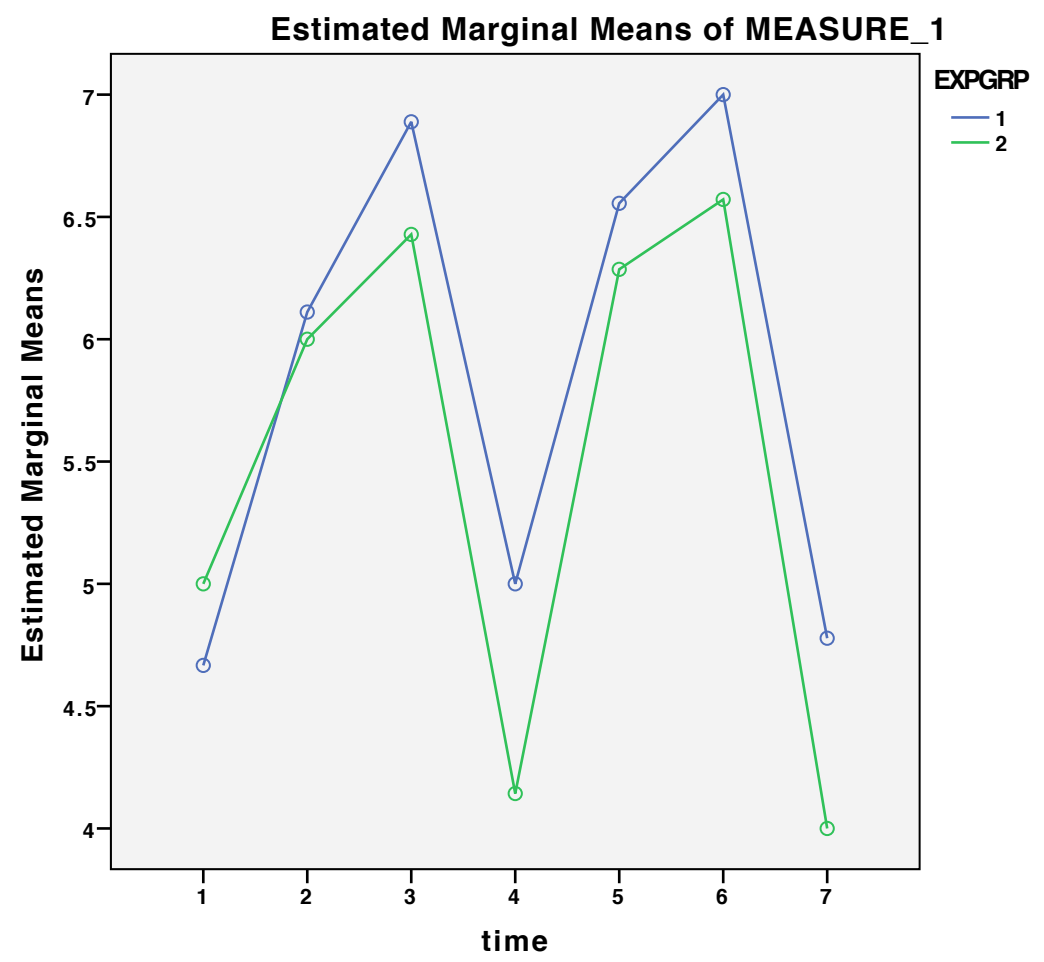

\section{T-Test}


Paired Samples Statistics

\begin{tabular}{|c|c|c|c|c|c|}
\hline & & Mean & $\mathrm{N}$ & $\begin{array}{c}\text { Std. } \\
\text { Deviation }\end{array}$ & $\begin{array}{l}\text { Std. Error } \\
\text { Mean }\end{array}$ \\
\hline \multirow[t]{2}{*}{ Pair 1} & PTSbsin & 4.61 & 38 & .790 & .128 \\
\hline & PTSW1 & 6.1316 & 38 & .57756 & .09369 \\
\hline \multirow[t]{2}{*}{ Pair 2} & PTSbsln & 4.72 & 36 & .615 & .102 \\
\hline & PTSW2 & 6.8611 & 36 & .76168 & .12695 \\
\hline \multirow[t]{2}{*}{ Pair 3} & PTSbsin & 4.61 & 38 & .790 & .128 \\
\hline & PTSR1 & 4.6053 & 38 & 1.00107 & .16239 \\
\hline \multirow[t]{2}{*}{ Pair 4} & PTSbsln & 4.62 & 34 & .817 & .140 \\
\hline & PTSW3 & 6.2941 & 34 & .83591 & .14336 \\
\hline \multirow[t]{2}{*}{ Pair 5} & PTSbsln & 4.63 & 35 & .808 & .136 \\
\hline & PTSW4 & 6.7714 & 35 & .68966 & .11657 \\
\hline \multirow[t]{2}{*}{ Pair 6} & PTSbsln & 4.61 & 33 & .827 & .144 \\
\hline & PTSR2 & 4.0303 & 33 & .95147 & .16563 \\
\hline \multirow[t]{2}{*}{ Pair 7} & PTSW1 & 6.1667 & 36 & .56061 & .09344 \\
\hline & PTSW2 & 6.8611 & 36 & .76168 & 12695 \\
\hline \multirow[t]{2}{*}{ Pair 8} & PTSW1 & 6.1316 & 38 & .57756 & .09369 \\
\hline & PTSR1 & 4.6053 & 38 & 1.00107 & .16239 \\
\hline \multirow[t]{2}{*}{ Pair 9} & PTSW1 & 6.1176 & 34 & .59108 & .10137 \\
\hline & PTSW3 & 6.2941 & 34 & .83591 & .14336 \\
\hline \multirow[t]{2}{*}{ Pair 10} & PTSW1 & 6.1143 & 35 & .58266 & .09849 \\
\hline & PTSW4 & 6.7714 & 35 & .68966 & .11657 \\
\hline \multirow[t]{2}{*}{ Pair 11} & PTSW1 & 6.0909 & 33 & .57899 & .10079 \\
\hline & PTSR2 & 4.0303 & 33 & .95147 & .16563 \\
\hline \multirow[t]{2}{*}{ Pair 12} & PTSW2 & 6.8611 & 36 & .76168 & .12695 \\
\hline & PTSR1 & 4.6389 & 36 & 1.01848 & .16975 \\
\hline \multirow[t]{2}{*}{ Pair 13} & PTSW2 & 6.8125 & 32 & .78030 & .13794 \\
\hline & PTSW3 & 6.3438 & 32 & .82733 & .14625 \\
\hline \multirow[t]{2}{*}{ Pair 14} & PTSW2 & 6.8182 & 33 & .76871 & .13381 \\
\hline & PTSW4 & 6.7879 & 33 & .69631 & .12121 \\
\hline \multirow[t]{2}{*}{ Pair 15} & PTSW2 & 6.8065 & 31 & .74919 & .13456 \\
\hline & PTSR2 & 4.0000 & 31 & .96609 & .17352 \\
\hline \multirow[t]{2}{*}{ Pair 16} & PTSR1 & 4.5882 & 34 & 1.04787 & .17971 \\
\hline & PTSW3 & 6.2941 & 34 & .83591 & .14336 \\
\hline \multirow[t]{2}{*}{ Pair 17} & PTSR1 & 4.5429 & 35 & 1.01003 & .17073 \\
\hline & PTSW4 & 6.7714 & 35 & .68966 & .11657 \\
\hline \multirow[t]{2}{*}{ Pair 18} & PTSR1 & 4.5758 & 33 & 1.03169 & .17959 \\
\hline & PTSR2 & 4.0303 & 33 & .95147 & .16563 \\
\hline \multirow[t]{2}{*}{ Pair 19} & PTSW3 & 6.2727 & 33 & .83937 & .14612 \\
\hline & PTSW4 & 6.8182 & 33 & .68258 & .11882 \\
\hline
\end{tabular}


Paired Samples Statistics

\begin{tabular}{|rl|l|r|r|r|}
\hline & & Mean & $\mathrm{N}$ & $\begin{array}{c}\text { Std. } \\
\text { Deviation }\end{array}$ & $\begin{array}{c}\text { Std. Error } \\
\text { Mean }\end{array}$ \\
\hline Pair 20 & PTSW3 & 6.2581 & 31 & .81518 & .14641 \\
& PTSR2 & 4.0645 & 31 & .96386 & .17311 \\
Pair 21 & PTSW4 & 6.7188 & 32 & .68318 & .12077 \\
& PTSR2 & 4.0313 & 32 & .96668 & .17089 \\
\hline
\end{tabular}

Paired Samples Correlations

\begin{tabular}{|ll|r|r|r|}
\hline & & N & Correlation & \multicolumn{1}{l|}{ Sig. } \\
\hline Pair 1 & PTSbsIn \& PTSW1 & 38 & .532 & .001 \\
Pair 2 & PTSbsIn \& PTSW2 & 36 & .159 & .353 \\
Pair 3 & PTSbsIn \& PTSR1 & 38 & .139 & .404 \\
Pair 4 & PTSbsin \& PTSW3 & 34 & .303 & .082 \\
Pair 5 & PTSbsIn \& PTSW4 & 35 & .318 & .062 \\
Pair 6 & PTSbsIn \& PTSR2 & 33 & -.104 & .566 \\
Pair 7 & PTSW1 \& PTSW2 & 36 & .524 & .001 \\
Pair 8 & PTSW1 \&PTSR1 & 38 & .279 & .090 \\
Pair 9 & PTSW1 \& PTSW3 & 34 & .541 & .001 \\
Pair 10 & PTSW1 \& PTSW4 & 35 & .286 & .095 \\
Pair 11 & PTSW1 \& PTSR2 & 33 & -.175 & .329 \\
Pair 12 & PTSW2 \& PTSR1 & 36 & .375 & .024 \\
Pair 13 & PTSW2 \& PTSW3 & 32 & .303 & .092 \\
Pair 14 & PTSW2 \& PTSW4 & 33 & .276 & .120 \\
Pair 15 & PTSW2 \& PTSR2 & 31 & -.046 & .806 \\
Pair 16 & PTSR1 \& PTSW3 & 34 & .454 & .007 \\
Pair 17 & PTSR1 \& PTSW4 & 35 & .394 & .019 \\
Pair 18 & PTSR1 \& PTSR2 & 33 & .141 & .434 \\
Pair 19 & PTSW3 \& PTSW4 & 33 & .417 & .016 \\
Pair 20 & PTSW3 \& PTSR2 & 31 & .275 & .134 \\
Pair 21 & PTSW4 \& PTSR2 & 32 & .258 & .154 \\
\hline
\end{tabular}




\begin{tabular}{|ll|r|r|r|}
\multicolumn{1}{|c}{} & \multicolumn{3}{c|}{ Paired Samples Test } \\
\cline { 3 - 5 } & & \multicolumn{1}{c|}{ Mean } & $\begin{array}{c}\text { Std. } \\
\text { Deviation }\end{array}$ & $\begin{array}{c}\text { Std. Error } \\
\text { Mean }\end{array}$ \\
\hline Pair 1 & PTSbsIn - PTSW1 & -1.52632 & .68721 & .11148 \\
Pair 2 & PTSbsIn - PTSW2 & -2.13889 & .89929 & .14988 \\
Pair 3 & PTSbsIn - PTSR1 & .00000 & 1.18550 & .19231 \\
Pair 4 & PTSbsIn - PTSW3 & -1.67647 & .97610 & .16740 \\
Pair 5 & PTSbsIn - PTSW4 & -2.14286 & .87927 & .14862 \\
Pair 6 & PTSbsIn - PTSR2 & .57576 & 1.32359 & .23041 \\
Pair 7 & PTSW1 - PTSW2 & -.69444 & .66845 & .11141 \\
Pair 8 & PTSW1 - PTSR1 & 1.52632 & 1.00638 & .16326 \\
Pair 9 & PTSW1 - PTSW3 & -.17647 & .71650 & .12288 \\
Pair 10 & PTSW1 - PTSW4 & -.65714 & .76477 & .12927 \\
Pair 11 & PTSW1 - PTSR2 & 2.06061 & 1.19738 & .20844 \\
Pair 12 & PTSW2 - PTSR1 & 2.22222 & 1.01731 & .16955 \\
Pair 13 & PTSW2 - PTSW3 & .46875 & .94985 & .16791 \\
Pair 14 & PTSW2 - PTSW4 & .03030 & .88335 & .15377 \\
Pair 15 & PTSW2 - PTSR2 & 2.80645 & 1.24952 & .22442 \\
Pair 16 & PTSR1 - PTSW3 & -1.70588 & 1.00089 & .17165 \\
Pair 17 & PTSR1 - PTSW4 & -2.22857 & .97274 & .16442 \\
Pair 18 & PTSR1 - PTSR2 & .54545 & 1.30122 & .22651 \\
Pair 19 & PTSW3 - PTSW4 & -.54545 & .83258 & .14493 \\
Pair 20 & PTSW3 - PTSR2 & 2.19355 & 1.07763 & .19355 \\
Pair 21 & PTSW4 - PTSR2 & 2.68750 & 1.02980 & .18204 \\
\hline
\end{tabular}


Paired Samples Test

\begin{tabular}{|c|c|c|c|c|c|c|}
\hline & \multirow{2}{*}{\multicolumn{2}{|c|}{$\begin{array}{c}\text { Paired Differences } \\
\begin{array}{c}95 \% \text { Confidence Interval of } \\
\text { the Difference }\end{array}\end{array}$}} & \multirow[b]{3}{*}{$\mathrm{t}$} & \multirow[b]{3}{*}{$d f$} & \multirow[b]{3}{*}{$\begin{array}{l}\text { Sig. (2- } \\
\text { tailed) }\end{array}$} \\
\hline & & & & & & \\
\hline & & Lower & Upper & & & \\
\hline Pair 1 & PTSbsIn - PTSW1 & -1.75220 & -1.30043 & -13.691 & 37 & .000 \\
\hline Pair 2 & PTSbsIn - PTSW2 & -2.44317 & -1.83461 & -14.270 & 35 & .000 \\
\hline Pair 3 & PTSbsln - PTSR1 & -.38966 & .38966 & .000 & 37 & 1.000 \\
\hline Pair 4 & PTSbsIn - PTSW3 & -2.01705 & -1.33589 & -10.015 & 33 & .000 \\
\hline Pair 5 & PTSbsln - PTSW4 & -2.44490 & -1.84082 & -14.418 & 34 & .000 \\
\hline Pair 6 & PTSbsln - PTSR2 & .10643 & 1.04508 & 2.499 & 32 & .018 \\
\hline Pair 7 & PTSW1 - PTSW2 & -.92062 & -.46827 & -6.233 & 35 & .000 \\
\hline Pair 8 & PTSW1 - PTSR1 & 1.19553 & 1.85710 & 9.349 & 37 & .000 \\
\hline Pair 9 & PTSW1 - PTSW3 & -.42647 & .07353 & -1.436 & 33 & .160 \\
\hline Pair 10 & PTSW1 - PTSW4 & -.91985 & -.39443 & -5.083 & 34 & .000 \\
\hline Pair 11 & PTSW1 - PTSR2 & 1.63603 & 2.48518 & 9.886 & 32 & .000 \\
\hline Pair 12 & PTSW2 - PTSR1 & 1.87801 & 2.56643 & 13.106 & 35 & .000 \\
\hline Pair 13 & PTSW2 - PTSW3 & .12629 & .81121 & 2.792 & 31 & .009 \\
\hline Pair 14 & PTSW2 - PTSW4 & -.28292 & .34352 & .197 & 32 & .845 \\
\hline Pair 15 & PTSW2 - PTSR2 & 2.34813 & 3.26478 & 12.505 & 30 & .000 \\
\hline Pair 16 & PTSR1 - PTSW3 & -2.05511 & -1.35666 & -9.938 & 33 & .000 \\
\hline Pair 17 & PTSR1 - PTSW4 & -2.56272 & -1.89442 & -13.554 & 34 & .000 \\
\hline Pair 18 & PTSR1 - PTSR2 & .08406 & 1.00685 & 2.408 & 32 & .022 \\
\hline Pair 19 & PTSW3 - PTSW4 & -.84067 & -.25024 & -3.764 & 32 & .001 \\
\hline Pair 20 & PTSW3 - PTSR2 & 1.79827 & 2.58883 & 11.333 & 30 & .000 \\
\hline Pair 21 & PTSW4 - PTSR2 & 2.31622 & 3.05878 & 14.763 & 31 & .000 \\
\hline
\end{tabular}

\section{General Linear Model}

Within-Subjects

$$
\text { Factors }
$$

Measure:MEASURE_1

\begin{tabular}{|l|l|}
\hline time & $\begin{array}{l}\text { Dependent } \\
\text { Variable }\end{array}$ \\
\hline 1 & RPEbsln \\
2 & RPEW1 \\
3 & RPEW2 \\
4 & RPER1 \\
5 & RPEW3 \\
6 & RPEW4 \\
7 & RPER2 \\
\hline
\end{tabular}




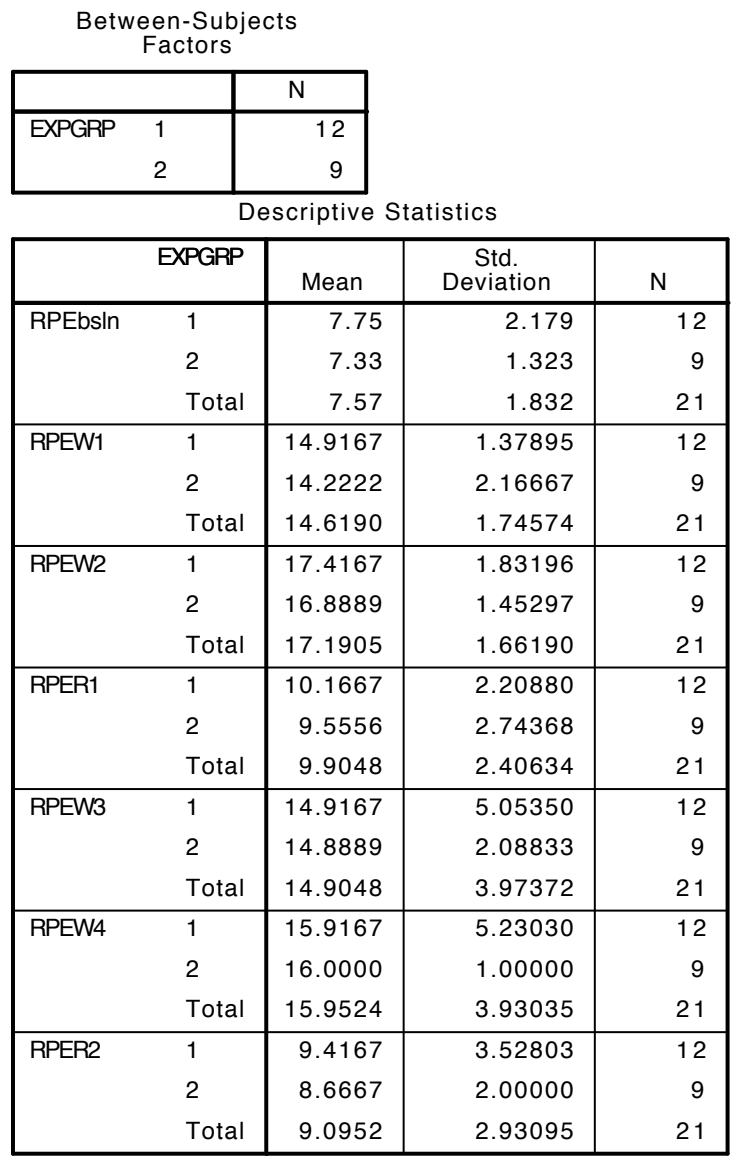

Mauchly's Test of Sphericity ${ }^{b}$

Measure:MEASURE_1

\begin{tabular}{|r|r|r|r|c|}
\hline Within Subjects Effect & Mauchly's W & $\begin{array}{c}\text { Approx. Chi- } \\
\text { Square }\end{array}$ & \multicolumn{1}{c|}{$\mathrm{df}$} & \multicolumn{1}{c|}{ Sig. } \\
\hline time & .010 & 78.094 & 20 & .000 \\
\hline
\end{tabular}

Tests the null hypothesis that the error covariance matrix of the orthonormalized transformed dependent variables is proportional to an identity matrix. 
Mauchly's Test of Sphericity ${ }^{b}$

Measure:MEASURE_1

\begin{tabular}{|r|r|r|r|}
\hline Within Subjects Effect & \multicolumn{3}{|c|}{ Epsilon $^{2}$} \\
\cline { 2 - 4 } & $\begin{array}{c}\text { Greenhouse- } \\
\text { Geisser }\end{array}$ & Huynh-Feldt & $\begin{array}{c}\text { Lower- } \\
\text { bound }\end{array}$ \\
\hline time & .360 & .430 & .167 \\
\hline
\end{tabular}

Tests the null hypothesis that the error covariance matrix of the orthonormalized transformed dependent variables is proportional to an identity matrix.

a. May be used to adjust the degrees of freedom for the averaged tests of significance. Corrected tests are displayed in the Tests of Within-Subjects Effects table.

b. Design: Intercept + EXPGRP

Within Subjects Design: time

Tests of Within-Subjects Effects

Measure:MEASURE_1

\begin{tabular}{|c|c|c|c|c|c|}
\hline Source & & $\begin{array}{l}\text { Type III Sum } \\
\text { of Squares }\end{array}$ & $d f$ & Mean Square & $\mathrm{F}$ \\
\hline \multirow[t]{4}{*}{ time } & Sphericity Assumed & 1786.418 & 6 & 297.736 & 48.556 \\
\hline & Greenhouse-Geisser & 1786.418 & 2.162 & 826.383 & 48.556 \\
\hline & Huynh-Feldt & 1786.418 & 2.577 & 693.150 & 48.556 \\
\hline & Lower-bound & 1786.418 & 1.000 & 1786.418 & 48.556 \\
\hline \multirow[t]{4}{*}{ time * EXPGRP } & Sphericity Assumed & 3.289 & 6 & .548 & .089 \\
\hline & Greenhouse-Geisser & 3.289 & 2.162 & 1.522 & .089 \\
\hline & Huynh-Feldt & 3.289 & 2.577 & 1.276 & .089 \\
\hline & Lower-bound & 3.289 & 1.000 & 3.289 & .089 \\
\hline \multirow[t]{4}{*}{ Error(time) } & Sphericity Assumed & 699.024 & 114 & 6.132 & \\
\hline & Greenhouse-Geisser & 699.024 & 41.073 & 17.019 & \\
\hline & Huynh-Feldt & 699.024 & 48.968 & 14.275 & \\
\hline & Lower-bound & 699.024 & 19.000 & 36.791 & \\
\hline
\end{tabular}

Tests of Within-Subjects Effects

Measure:MEASURE_1

\begin{tabular}{|ll|r|r|r|r|}
\hline Source & Sig. & \multicolumn{1}{|c|}{$\begin{array}{c}\text { Partial Eta } \\
\text { Squared }\end{array}$} & $\begin{array}{c}\text { Noncent. } \\
\text { Parameter }\end{array}$ & $\begin{array}{c}\text { Observed } \\
\text { Power }^{\text {a }}\end{array}$ \\
\hline time & Sphericity Assumed & .000 & .719 & 291.337 & 1.000 \\
& Greenhouse-Geisser & .000 & .719 & 104.965 & 1.000 \\
& Huynh-Feldt & .000 & .719 & 125.141 & 1.000 \\
& Lower-bound & .000 & .719 & 48.556 & 1.000 \\
\hline time * EXPGRP & Sphericity Assumed & .997 & .005 & .536 & .071 \\
& Greenhouse-Geisser & .927 & .005 & .193 & .063 \\
& Huynh-Feldt & .950 & .005 & .230 & .064 \\
& Lower-bound & .768 & .005 & .089 & .059 \\
\hline
\end{tabular}

a. Computed using alpha $=.05$ 
Tests of Between-Subjects Effects

Measure:MEASURE 1

Transformed Variable:Average

\begin{tabular}{|l|r|r|r|r|r|r|}
\hline Source & $\begin{array}{c}\text { Type III Sum } \\
\text { of Squares }\end{array}$ & df & Mean Square & \multicolumn{1}{c|}{ F } & \multicolumn{1}{c|}{ Sig. } & \multicolumn{1}{c|}{$\begin{array}{c}\text { Partial Eta } \\
\text { Squared }\end{array}$} \\
\hline Intercept & 23292.574 & 1 & 23292.574 & 1143.469 & .000 & .984 \\
EXPGRP & 6.370 & 1 & 6.370 & .313 & .583 & .016 \\
Error & 387.032 & 19 & 20.370 & & & \\
\hline
\end{tabular}

Tests of Between-Subjects Effects

Measure:MEASURE_1

Transformed Variab̄le:Average

\begin{tabular}{|l|r|r|}
\hline Source & \multicolumn{1}{|c|}{$\begin{array}{c}\text { Noncent. } \\
\text { Parameter }\end{array}$} & \multicolumn{1}{|c|}{$\begin{array}{c}\text { Observed } \\
\text { Power }^{\mathrm{a}}\end{array}$} \\
\hline Intercept & 1143.469 & 1.000 \\
EXPGRP & .313 & .083 \\
\hline
\end{tabular}

a. Computed using alpha $=.05$

\section{Profile Plots}

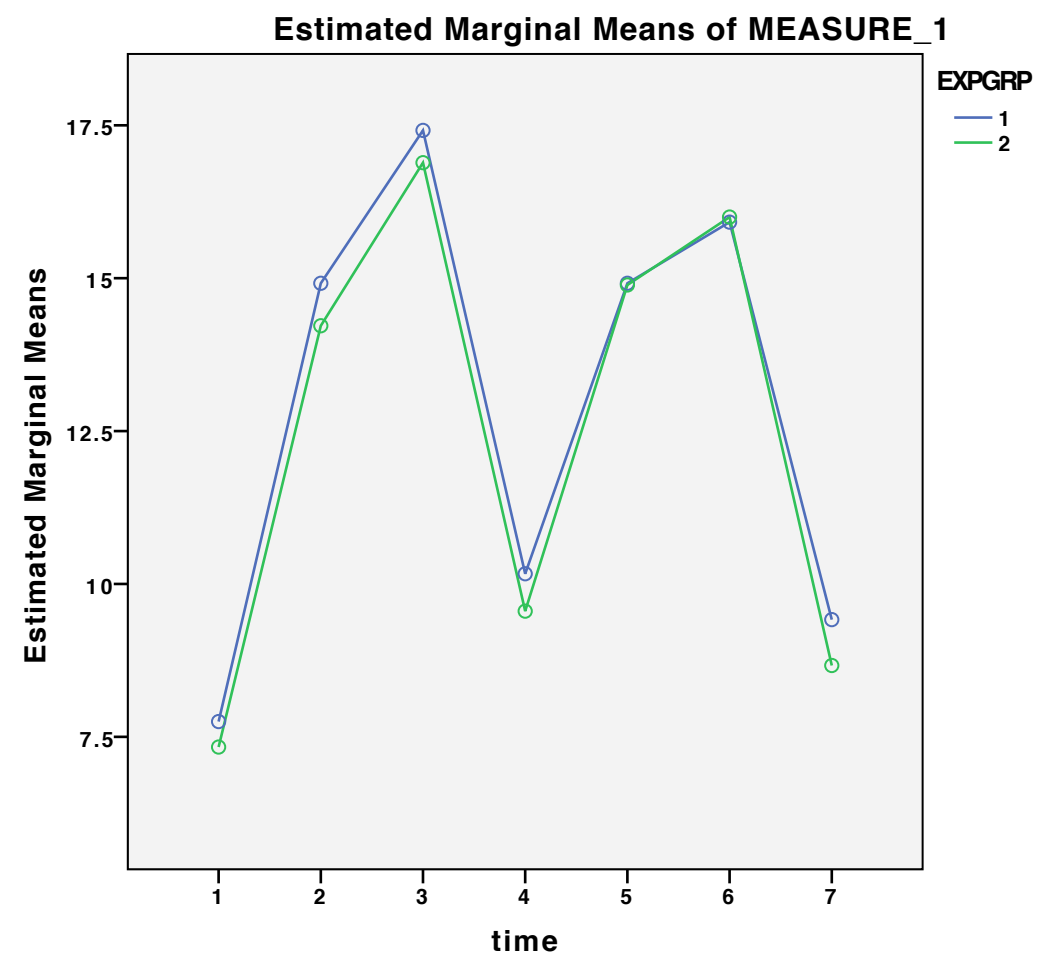

\section{T-Test}


Paired Samples Statistics

\begin{tabular}{|c|c|c|c|c|c|}
\hline & & Mean & $\mathrm{N}$ & $\begin{array}{c}\text { Std. } \\
\text { Deviation }\end{array}$ & $\begin{array}{l}\text { Std. Error } \\
\text { Mean }\end{array}$ \\
\hline \multirow[t]{2}{*}{ Pair 1} & RPEbsin & 7.53 & 38 & 1.782 & .289 \\
\hline & RPEW1 & 14.7632 & 38 & 2.03263 & .32974 \\
\hline \multirow[t]{2}{*}{ Pair 2} & RPEbsin & 7.57 & 37 & 1.788 & .294 \\
\hline & RPEW2 & 17.0811 & 37 & 2.01905 & .33193 \\
\hline \multirow[t]{2}{*}{ Pair 3} & RPEbsin & 7.54 & 37 & 1.804 & .297 \\
\hline & RPER1 & 9.4054 & 37 & 2.91032 & .47845 \\
\hline \multirow[t]{2}{*}{ Pair 4} & RPEbsin & 7.36 & 36 & 1.641 & .274 \\
\hline & RPEW3 & 15.0556 & 36 & 3.26842 & .54474 \\
\hline \multirow[t]{2}{*}{ Pair 5} & RPEbsin & 7.53 & 36 & 1.797 & .299 \\
\hline & RPEW4 & 16.3056 & 36 & 3.35363 & .55894 \\
\hline \multirow[t]{2}{*}{ Pair 6} & RPEbsIn & 7.51 & 35 & 1.837 & .311 \\
\hline & RPER2 & 8.8286 & 35 & 2.52617 & .42700 \\
\hline \multirow[t]{2}{*}{ Pair 7} & RPEW1 & 14.8649 & 37 & 1.96019 & .32225 \\
\hline & RPEW2 & 17.0811 & 37 & 2.01905 & .33193 \\
\hline \multirow[t]{2}{*}{ Pair 8} & RPEW1 & 14.7027 & 37 & 2.02574 & .33303 \\
\hline & RPER1 & 9.4054 & 37 & 2.91032 & .47845 \\
\hline \multirow[t]{2}{*}{ Pair 9} & RPEW1 & 14.6944 & 36 & 2.05384 & .34231 \\
\hline & RPEW3 & 15.0556 & 36 & 3.26842 & .54474 \\
\hline \multirow[t]{2}{*}{ Pair 10} & RPEW1 & 14.7778 & 36 & 2.00159 & .33360 \\
\hline & RPEW4 & 16.3056 & 36 & 3.35363 & .55894 \\
\hline \multirow[t]{2}{*}{ Pair 11} & RPEW1 & 14.6286 & 35 & 2.04487 & .34565 \\
\hline & RPER2 & 8.8286 & 35 & 2.52617 & .42700 \\
\hline \multirow[t]{2}{*}{ Pair 12} & RPEW2 & 17.0833 & 36 & 2.04765 & .34127 \\
\hline & RPER1 & 9.4167 & 36 & 2.95079 & .49180 \\
\hline \multirow[t]{2}{*}{ Pair 13} & RPEW2 & 16.9714 & 35 & 2.00713 & .33927 \\
\hline & RPEW3 & 15.1143 & 35 & 3.29680 & .55726 \\
\hline \multirow[t]{2}{*}{ Pair 14} & RPEW2 & 17.0571 & 35 & 1.98439 & .33542 \\
\hline & RPEW4 & 16.2000 & 35 & 3.34136 & .56479 \\
\hline \multirow[t]{2}{*}{ Pair 15} & RPEW2 & 17.0294 & 34 & 2.03731 & .34940 \\
\hline & RPER2 & 8.7647 & 34 & 2.53531 & .43480 \\
\hline \multirow[t]{2}{*}{ Pair 16} & RPER1 & 9.4571 & 35 & 2.96393 & .50100 \\
\hline & RPEW3 & 15.0000 & 35 & 3.29884 & .55761 \\
\hline \multirow[t]{2}{*}{ Pair 17} & RPER1 & 9.3714 & 35 & 2.90117 & .49039 \\
\hline & RPEW4 & 16.2286 & 35 & 3.37016 & .56966 \\
\hline \multirow[t]{2}{*}{ Pair 18} & RPER1 & 9.5143 & 35 & 2.95427 & .49936 \\
\hline & RPER2 & 8.8286 & 35 & 2.52617 & .42700 \\
\hline \multirow[t]{2}{*}{ Pair 19} & RPEW3 & 15.0000 & 35 & 3.29884 & .55761 \\
\hline & RPEW4 & 16.4000 & 35 & 3.35366 & .56687 \\
\hline
\end{tabular}


Paired Samples Statistics

\begin{tabular}{|rl|r|r|r|r|}
\hline & & \multicolumn{1}{|c|}{ Mean } & $\mathrm{N}$ & \multicolumn{1}{c|}{$\begin{array}{c}\text { Std. } \\
\text { Deviation }\end{array}$} & $\begin{array}{c}\text { Std. Error } \\
\text { Mean }\end{array}$ \\
\hline Pair 20 & RPEW3 & 15.0294 & 34 & 3.34379 & .57346 \\
& RPER2 & 8.8235 & 34 & 2.56398 & .43972 \\
Pair 21 & RPEW4 & 16.1471 & 34 & 3.38564 & .58063 \\
& RPER2 & 8.7647 & 34 & 2.53531 & .43480 \\
\hline
\end{tabular}

Paired Samples Correlations

\begin{tabular}{|ll|r|r|r|}
\hline & & $\mathrm{N}$ & Correlation & \multicolumn{1}{l|}{ Sig. } \\
\hline Pair 1 & RPEbsin \& RPEW1 & 38 & .326 & .046 \\
Pair 2 & RPEbsin \& RPEW2 & 37 & .472 & .003 \\
Pair 3 & RPEbsin \& RPER1 & 37 & .163 & .334 \\
Pair 4 & RPEbsin \& RPEW3 & 36 & -.180 & .295 \\
Pair 5 & RPEbsIn \& RPEW4 & 36 & -.236 & .166 \\
Pair 6 & RPEbsIn \& RPER2 & 35 & -.120 & .493 \\
Pair 7 & RPEW1 \& RPEW2 & 37 & .445 & .006 \\
Pair 8 & RPEW1 \& RPER1 & 37 & -.069 & .687 \\
Pair 9 & RPEW1 \& RPEW3 & 36 & .122 & .479 \\
Pair 10 & RPEW1 \& RPEW4 & 36 & .044 & .797 \\
Pair 11 & RPEW1 \& RPER2 & 35 & .004 & .980 \\
Pair 12 & RPEW2 \& RPER1 & 36 & .093 & .588 \\
Pair 13 & RPEW2 \& RPEW3 & 35 & .192 & .270 \\
Pair 14 & RPEW2 \& RPEW4 & 35 & .273 & .112 \\
Pair 15 & RPEW2 \& RPER2 & 34 & .166 & .349 \\
Pair 16 & RPER1 \& RPEW3 & 35 & .027 & .877 \\
Pair 17 & RPER1 \& RPEW4 & 35 & -.078 & .656 \\
Pair 18 & RPER1 \& RPER2 & 35 & .422 & .012 \\
Pair 19 & RPEW3 \& RPEW4 & 35 & .787 & .000 \\
Pair 20 & RPEW3 \& RPER2 & 34 & .598 & .000 \\
Pair 21 & RPEW4 \& RPER2 & 34 & .724 & .000 \\
\hline
\end{tabular}




\begin{tabular}{|ll|r|r|c|}
\multicolumn{2}{|c|}{} & \multicolumn{3}{|c|}{ Paired Samples Test } \\
\cline { 3 - 5 } & & \multicolumn{1}{|c|}{ Mean } & $\begin{array}{c}\text { Std. } \\
\text { Deviation }\end{array}$ & $\begin{array}{c}\text { Std. Error } \\
\text { Mean }\end{array}$ \\
\hline Pair 1 & RPEbsIn - RPEW1 & -7.23684 & 2.22315 & .36064 \\
Pair 2 & RPEbsIn - RPEW2 & -9.51351 & 1.96669 & .32332 \\
Pair 3 & RPEbsIn - RPER1 & -1.86486 & 3.16370 & .52011 \\
Pair 4 & RPEbsIn - RPEW3 & -7.69444 & 3.91203 & .65200 \\
Pair 5 & RPEbsIn - RPEW4 & -8.77778 & 4.16181 & .69363 \\
Pair 6 & RPEbsIn - RPER2 & -1.31429 & 3.29680 & .55726 \\
Pair 7 & RPEW1 - RPEW2 & -2.21622 & 2.09676 & .34470 \\
Pair 8 & RPEW1 - RPER1 & 5.29730 & 3.65806 & .60138 \\
Pair 9 & RPEW1 - RPEW3 & -.36111 & 3.64223 & .60704 \\
Pair 10 & RPEW1 - RPEW4 & -1.52778 & 3.82836 & .63806 \\
Pair 11 & RPEW1 - RPER2 & 5.80000 & 3.24309 & .54818 \\
Pair 12 & RPEW2 - RPER1 & 7.66667 & 3.43095 & .57183 \\
Pair 13 & RPEW2 - RPEW3 & 1.85714 & 3.51587 & .59429 \\
Pair 14 & RPEW2 - RPEW4 & .85714 & 3.38807 & .57269 \\
Pair 15 & RPEW2 - RPER2 & 8.26471 & 2.97778 & .51069 \\
Pair 16 & RPER1 - RPEW3 & -5.54286 & 4.37468 & .73946 \\
Pair 17 & RPER1 - RPEW4 & -6.85714 & 4.61547 & .78016 \\
Pair 18 & RPER1 - RPER2 & .68571 & 2.96818 & .50171 \\
Pair 19 & RPEW3 - RPEW4 & -1.40000 & 2.17201 & .36714 \\
Pair 20 & RPEW3 - RPER2 & 6.20588 & 2.73894 & .46972 \\
Pair 21 & RPEW4 - RPER2 & 7.38235 & 2.33569 & .40057 \\
\hline
\end{tabular}


Paired Samples Test

\begin{tabular}{|c|c|c|c|c|c|c|}
\hline & \multirow{2}{*}{\multicolumn{2}{|c|}{$\begin{array}{c}\text { Paired Differences } \\
95 \% \text { Confidence Interval of } \\
\text { the Difference }\end{array}$}} & \multirow[b]{3}{*}{$\mathrm{t}$} & \multirow[b]{3}{*}{$d f$} & \multirow[b]{3}{*}{$\begin{array}{l}\text { Sig. (2- } \\
\text { tailed) }\end{array}$} \\
\hline & & & & & & \\
\hline & & Lower & Upper & & & \\
\hline Pair 1 & RPEbsIn - RPEW1 & -7.96757 & -6.50611 & -20.067 & 37 & .000 \\
\hline Pair 2 & RPEbsIn - RPEW2 & -10.16924 & -8.85779 & -29.424 & 36 & .000 \\
\hline Pair 3 & RPEbsIn - RPER1 & -2.91970 & -.81003 & -3.586 & 36 & .001 \\
\hline Pair 4 & RPEbsIn - RPEW3 & -9.01808 & -6.37080 & -11.801 & 35 & .000 \\
\hline Pair 5 & RPEbsIn - RPEW4 & -10.18593 & -7.36962 & -12.655 & 35 & .000 \\
\hline Pair 6 & RPEbsIn - RPER2 & -2.44678 & -.18179 & -2.358 & 34 & .024 \\
\hline Pair 7 & RPEW1 - RPEW2 & -2.91531 & -1.51712 & -6.429 & 36 & .000 \\
\hline Pair 8 & RPEW1 - RPER1 & 4.07764 & 6.51695 & 8.809 & 36 & .000 \\
\hline Pair 9 & RPEW1 - RPEW3 & -1.59347 & .87124 & -.595 & 35 & .556 \\
\hline Pair 10 & RPEW1 - RPEW4 & -2.82311 & -.23245 & -2.394 & 35 & .022 \\
\hline Pair 11 & RPEW1 - RPER2 & 4.68596 & 6.91404 & 10.580 & 34 & .000 \\
\hline Pair 12 & RPEW2 - RPER1 & 6.50580 & 8.82753 & 13.407 & 35 & .000 \\
\hline Pair 13 & RPEW2 - RPEW3 & .64940 & 3.06489 & 3.125 & 34 & .004 \\
\hline Pair 14 & RPEW2 - RPEW4 & -.30670 & 2.02098 & 1.497 & 34 & .144 \\
\hline Pair 15 & RPEW2 - RPER2 & 7.22571 & 9.30370 & 16.184 & 33 & .000 \\
\hline Pair 16 & RPER1 - RPEW3 & -7.04561 & -4.04010 & -7.496 & 34 & .000 \\
\hline Pair 17 & RPER1 - RPEW4 & -8.44261 & -5.27168 & -8.789 & 34 & .000 \\
\hline Pair 18 & RPER1 - RPER2 & -.33389 & 1.70532 & 1.367 & 34 & .181 \\
\hline Pair 19 & RPEW3 - RPEW4 & -2.14611 & -.65389 & -3.813 & 34 & .001 \\
\hline Pair 20 & RPEW3 - RPER2 & 5.25022 & 7.16154 & 13.212 & 33 & .000 \\
\hline Pair 21 & RPEW4 - RPER2 & 6.56739 & 8.19731 & 18.430 & 33 & .000 \\
\hline
\end{tabular}

\section{Correlations}


Descriptive Statistics

\begin{tabular}{|l|c|r|r|}
\hline & \multicolumn{1}{|c|}{ Mean } & $\begin{array}{c}\text { Std. } \\
\text { Deviation }\end{array}$ & $\mathrm{N}$ \\
\hline GIW1T15 & 38.3231 & .41897 & 26 \\
GIW2T15 & 39.1408 & .46662 & 24 \\
GIR1T15 & 38.5917 & .62060 & 23 \\
GIW3T15 & 38.4959 & .38483 & 22 \\
GIW4T15 & 38.8730 & .38097 & 20 \\
GIR2T15 & 38.4435 & .42409 & 20 \\
PTSW1 & 6.0769 & .56022 & 26 \\
PTSW2 & 6.8333 & .81650 & 24 \\
PTSR1 & 4.6538 & 1.01754 & 26 \\
PTSW3 & 6.4091 & .85407 & 22 \\
PTSW4 & 6.7826 & .73587 & 23 \\
PTSR2 & 4.3333 & .79582 & 21 \\
\hline
\end{tabular}

Correlations

\begin{tabular}{|ll|r|r|r|r|r|}
\hline & & GIW1T15 & GIW2T15 & GIR1T15 & GIW3T15 & GIW4T15 \\
\hline GIW1T15 & Pearson Correlation & 1 & .750 & .200 & .189 & .328 \\
& Sig. (2-tailed) & & .000 & .360 & .399 & .158 \\
& $\mathrm{~N}$ & 26 & 24 & 23 & 22 & 20 \\
\hline GIW2T15 & Pearson Correlation & .750 & 1 & .568 & .205 & .433 \\
& Sig. (2-tailed) & .000 & & .005 & .372 & .064 \\
& $\mathrm{~N}$ & 24 & 24 & 23 & 21 & 19 \\
\hline GIR1T15 & Pearson Correlation & .200 & .568 & 1 & .256 & .172 \\
& Sig. (2-tailed) & .360 & .005 & & .263 & .482 \\
& $\mathrm{~N}$ & 23 & 23 & 23 & 21 & 19 \\
\hline GIW3T15 & Pearson Correlation & .189 & .205 & .256 & 1 & .512 \\
& Sig. (2-tailed) & .399 & .372 & .263 & & .021 \\
& $\mathrm{~N}$ & 22 & 21 & 21 & 22 & 20 \\
\hline GIW4T15 & Pearson Correlation & .328 & .433 & .172 & .512 & 1 \\
& Sig. (2-tailed) & .158 & .064 & .482 & .021 & \\
& $\mathrm{~N}$ & 20 & 19 & 19 & 20 & 20 \\
\hline GIR2T15 & Pearson Correlation & .213 & .392 & .300 & .555 & .780 \\
& Sig. (2-tailed) & .367 & .097 & .212 & .011 & .000 \\
& $\mathrm{~N}$ & 20 & 19 & 19 & 20 & 20 \\
\hline PTSW1 & Pearson Correlation & .178 & .151 & .146 & .242 & .038 \\
& Sig. (2-tailed) & .385 & .480 & .507 & .278 & .873 \\
$\mathrm{~N}$ & 26 & 24 & 23 & 22 & 20 \\
\hline
\end{tabular}

${ }^{* *}$. Correlation is significant at the 0.01 level (2-tailed).

*. Correlation is significant at the 0.05 level (2-tailed). 
Correlations

\begin{tabular}{|ll|r|r|r|r|r|}
\hline & & GIR2T15 & PTSW1 & PTSW2 & PTSR1 & PTSW3 \\
\hline GIW1T15 & Pearson Correlation & .213 & .178 & .134 & .181 & .253 \\
& Sig. (2-tailed) & .367 & .385 & .533 & .377 & .256 \\
& $\mathrm{~N}$ & 20 & 26 & 24 & 26 & 22 \\
\hline GIW2T15 & Pearson Correlation & .392 & .151 & .062 & .063 & .130 \\
& Sig. (2-tailed) & .097 & .480 & .782 & .771 & .585 \\
& $\mathrm{~N}$ & 19 & 24 & 22 & 24 & 20 \\
\hline GIR1T15 & Pearson Correlation & .300 & .146 & .206 & .161 & .242 \\
& Sig. (2-tailed) & .212 & .507 & .370 & .462 & .304 \\
& $\mathrm{~N}$ & 19 & 23 & 21 & 23 & 20 \\
\hline GIW3T15 & Pearson Correlation & .555 & .242 & .122 & .389 & .581 \\
& Sig. (2-tailed) & .011 & .278 & .607 & .074 & .006 \\
& $\mathrm{~N}$ & 20 & 22 & 20 & 22 & 21 \\
\hline GIW4T15 & Pearson Correlation & .780 & .038 & -.006 & -.027 & .329 \\
& Sig. (2-tailed) & .000 & .873 & .980 & .909 & .168 \\
& $\mathrm{~N}$ & 20 & 20 & 18 & 20 & 19 \\
\hline GIR2T15 & Pearson Correlation & 1 & .022 & .120 & .070 & .313 \\
& Sig. (2-tailed) & & .927 & .636 & .769 & .192 \\
& $\mathrm{~N}$ & 20 & 20 & 18 & 20 & 19 \\
\hline Pearson Correlation & .022 & 1 & .546 & .329 & .735 \\
& Sig. (2-tailed) & .927 & & .006 & .100 & .000 \\
$\mathrm{~N}$ & 20 & 26 & 24 & 26 & 22 \\
\hline
\end{tabular}

${ }^{* \star}$. Correlation is significant at the 0.01 level (2-tailed).

*. Correlation is significant at the 0.05 level (2-tailed).

Correlations

\begin{tabular}{|ll|r|r|}
\hline & & PTSW4 & PTSR2 \\
\hline GIW1T15 & Pearson Correlation & -.172 & -.364 \\
& Sig. (2-tailed) & .432 & .104 \\
& $\mathrm{~N}$ & 23 & 21 \\
\hline GIW2T15 & Pearson Correlation & -.390 & -.283 \\
& Sig. (2-tailed) & .080 & .241 \\
& $\mathrm{~N}$ & 21 & 19 \\
\hline GIR1T15 & Pearson Correlation & -.181 & .017 \\
& Sig. (2-tailed) & .445 & .945 \\
& $\mathrm{~N}$ & 20 & 18 \\
\hline GIW3T15 & Pearson Correlation & .240 & .391 \\
& Sig. (2-tailed) & .295 & .098 \\
& $\mathrm{~N}$ & 21 & 19 \\
\hline GIW4T15 & Pearson Correlation & .118 & .255 \\
& Sig. (2-tailed) & .619 & .324 \\
& $\mathrm{~N}$ & 20 & 17 \\
\hline GIR2T15 & Pearson Correlation & .078 & .390 \\
& Sig. (2-tailed) & .743 & .122 \\
& $\mathrm{~N}$ & 20 & 17 \\
\hline PTSW1 & Pearson Correlation & .134 & -.115 \\
& Sig. (2-tailed) & .543 & .621 \\
& $\mathrm{~N}$ & 23 & 21 \\
\hline
\end{tabular}


Correlations

\begin{tabular}{|ll|r|r|r|r|r|}
\hline & & GIW1T15 & GIW2T15 & GIR1T15 & GIW3T15 & GIW4T15 \\
\hline PTSW2 & Pearson Correlation & .134 & .062 & .206 & .122 & -.006 \\
& Sig. (2-tailed) & .533 & .782 & .370 & .607 & .980 \\
& $\mathrm{~N}$ & 24 & 22 & 21 & 20 & 18 \\
\hline PTSR1 & Pearson Correlation & .181 & .063 & .161 & .389 & -.027 \\
& Sig. (2-tailed) & .377 & .771 & .462 & .074 & .909 \\
& $\mathrm{~N}$ & 26 & 24 & 23 & 22 & 20 \\
\hline PTSW3 & Pearson Correlation & .253 & .130 & .242 & .581 & .329 \\
& Sig. (2-tailed) & .256 & .585 & .304 & .006 & .168 \\
& $\mathrm{~N}$ & 22 & 20 & 20 & 21 & 19 \\
\hline PTSW4 & Pearson Correlation & -.172 & -.390 & -.181 & .240 & .118 \\
& Sig. (2-tailed) & .432 & .080 & .445 & .295 & .619 \\
& $\mathrm{~N}$ & 23 & 21 & 20 & 21 & 20 \\
\hline PTSR2 & Pearson Correlation & -.364 & -.283 & .017 & .391 & .255 \\
& Sig. (2-tailed) & .104 & .241 & .945 & .098 & .324 \\
& $\mathrm{~N}$ & 21 & 19 & 18 & 19 & 17 \\
\hline
\end{tabular}

${ }^{* *}$. Correlation is significant at the 0.01 level (2-tailed).

Correlations

\begin{tabular}{|ll|r|r|r|r|r|}
\hline & GIR2T15 & PTSW1 & \multicolumn{1}{c|}{ PTSW2 } & PTSR1 & PTSW3 \\
\hline PTSW2 & Pearson Correlation & .120 & .546 & 1 & .349 & .561 \\
& Sig. (2-tailed) & .636 & .006 & & .094 & .010 \\
& $\mathrm{~N}$ & 18 & 24 & 24 & 24 & 20 \\
\hline PTSR1 & Pearson Correlation & .070 & .329 & .349 & 1 & .473 \\
& Sig. (2-tailed) & .769 & .100 & .094 & & .026 \\
& $\mathrm{~N}$ & 20 & 26 & 24 & 26 & 22 \\
\hline PTSW3 & Pearson Correlation & .313 & .735 & .561 & .473 & 1 \\
& Sig. (2-tailed) & .192 & .000 & .010 & .026 & \\
& $\mathrm{~N}$ & 19 & 22 & 20 & 22 & 22 \\
\hline PTSW4 & Pearson Correlation & .078 & .134 & .164 & .288 & .409 \\
& Sig. (2-tailed) & .743 & .543 & .476 & .183 & .066 \\
& $\mathrm{~N}$ & 20 & 23 & 21 & 23 & 21 \\
\hline PTSR2 & Pearson Correlation & .390 & -.115 & .133 & .391 & .266 \\
& Sig. (2-tailed) & .122 & .621 & .588 & .080 & .272 \\
& $\mathrm{~N}$ & 17 & 21 & 19 & 21 & 19 \\
\hline
\end{tabular}

${ }^{\star \star}$. Correlation is significant at the 0.01 level (2-tailed).

*. Correlation is significant at the 0.05 level (2-tailed). 
Correlations

\begin{tabular}{|ll|r|r|}
\hline & & PTSW4 & \multicolumn{1}{c|}{ PTSR2 } \\
\hline PTSW2 & Pearson Correlation & .164 & .133 \\
& Sig. (2-tailed) & .476 & .588 \\
& $\mathrm{~N}$ & 21 & 19 \\
\hline PTSR1 & Pearson Correlation & .288 & .391 \\
& Sig. (2-tailed) & .183 & .080 \\
& $\mathrm{~N}$ & 23 & 21 \\
\hline PTSW3 & Pearson Correlation & .409 & .266 \\
& Sig. (2-tailed) & .066 & .272 \\
& $\mathrm{~N}$ & 21 & 19 \\
\hline PTSW4 & Pearson Correlation & 1 & .451 \\
& Sig. (2-tailed) & & .046 \\
& $\mathrm{~N}$ & 23 & 20 \\
\hline PTSR2 & Pearson Correlation & .451 & 1 \\
& Sig. (2-tailed) & .046 & \\
& $\mathrm{~N}$ & 20 & 21 \\
\hline
\end{tabular}

*. Correlation is significant at the 0.05 level (2-tailed). 
Oneway: day by session

\begin{tabular}{|c|c|c|}
\hline \multicolumn{3}{|c|}{ Notes } \\
\hline Output Created & & 03-Feb-2011 12:46:41 \\
\hline \multicolumn{3}{|l|}{ Comments } \\
\hline \multirow[t]{5}{*}{ Input } & Active Dataset & DataSet0 \\
\hline & Filter & $<$ none $>$ \\
\hline & Weight & $<$ none $>$ \\
\hline & Split File & $<$ none $>$ \\
\hline & $\begin{array}{l}\mathrm{N} \text { of Rows in Working } \\
\text { Data File }\end{array}$ & 19 \\
\hline \multirow[t]{2}{*}{$\begin{array}{l}\text { Missing Value } \\
\text { Handling }\end{array}$} & Definition of Missing & $\begin{array}{l}\text { User-defined missing values are } \\
\text { treated as missing. }\end{array}$ \\
\hline & Cases Used & $\begin{array}{l}\text { Statistics for each analysis are } \\
\text { based on cases with no missing } \\
\text { data for any variable in the } \\
\text { analysis. }\end{array}$ \\
\hline Syntax & & $\begin{array}{l}\text { ONEWAY wbgt BY Day.session } \\
\text { /MISSING ANALYSIS. }\end{array}$ \\
\hline \multirow[t]{2}{*}{ Resources } & Processor Time & 00:00:00.000 \\
\hline & Elapsed Time & $00: 00: 00.000$ \\
\hline
\end{tabular}

ANOVA

wbgt
\begin{tabular}{|l|r|r|r|r|r|}
\hline & $\begin{array}{c}\text { Sum of } \\
\text { Squares }\end{array}$ & df & Mean Square & F & Sig. \\
\hline Between Groups & 31.912 & 5 & 6.382 & 3.748 & .025 \\
Within Groups & 22.140 & 13 & 1.703 & & \\
Total & 54.052 & 18 & & & \\
\hline
\end{tabular}

\section{Oneway: first sessions}

\begin{tabular}{|c|c|c|}
\hline \multicolumn{3}{|c|}{ Notes } \\
\hline Output Created & & 03-Feb-2011 12:40:17 \\
\hline \multicolumn{3}{|l|}{ Comments } \\
\hline \multirow[t]{5}{*}{ Input } & Active Dataset & DataSet0 \\
\hline & Filter & Session = 1 (FILTER) \\
\hline & Weight & $<$ none $>$ \\
\hline & Split File & $<$ none $>$ \\
\hline & $\begin{array}{l}\mathrm{N} \text { of Rows in Working } \\
\text { Data File }\end{array}$ & 10 \\
\hline \multirow[t]{2}{*}{$\begin{array}{l}\text { Missing Value } \\
\text { Handling }\end{array}$} & Definition of Missing & $\begin{array}{l}\text { User-defined missing values are } \\
\text { treated as missing. }\end{array}$ \\
\hline & Cases Used & $\begin{array}{l}\text { Statistics for each analysis are } \\
\text { based on cases with no missing } \\
\text { data for any variable in the } \\
\text { analysis. }\end{array}$ \\
\hline Syntax & & $\begin{array}{l}\text { ONEWAY wbgt BY Day } \\
\text { /MISSING ANALYSIS. }\end{array}$ \\
\hline \multirow[t]{2}{*}{ Resources } & Processor Time & $00: 00: 00.016$ \\
\hline & Elapsed Time & $00: 00: 00.015$ \\
\hline
\end{tabular}


ANOVA

wbgt

\begin{tabular}{|l|r|r|r|r|c|}
\hline & \multicolumn{1}{|c|}{$\begin{array}{c}\text { Sum of } \\
\text { Squares }\end{array}$} & \multicolumn{1}{c|}{$\mathrm{df}$} & Mean Square & $\mathrm{F}$ & Sig. \\
\hline Between Groups & 3.826 & 2 & 1.913 & 2.152 & .187 \\
Within Groups & 6.223 & 7 & .889 & & \\
Total & 10.049 & 9 & & & \\
\hline
\end{tabular}

Oneway: second sessions

\begin{tabular}{|c|c|c|}
\hline \multicolumn{3}{|c|}{ Notes } \\
\hline $\begin{array}{l}\text { Output Created } \\
\text { Comments }\end{array}$ & & 03-Feb-2011 12:41:46 \\
\hline \multirow[t]{5}{*}{ Input } & Active Dataset & DataSet0 \\
\hline & Filter & Session $=2$ (FILTER) \\
\hline & Weight & $<$ none $>$ \\
\hline & Split File & $<$ none $>$ \\
\hline & $\begin{array}{l}\mathrm{N} \text { of Rows in Working } \\
\text { Data File }\end{array}$ & 9 \\
\hline \multirow[t]{2}{*}{$\begin{array}{l}\text { Missing Value } \\
\text { Handling }\end{array}$} & Definition of Missing & $\begin{array}{l}\text { User-defined missing values are } \\
\text { treated as missing. }\end{array}$ \\
\hline & Cases Used & $\begin{array}{l}\text { Statistics for each analysis are } \\
\text { based on cases with no missing } \\
\text { data for any variable in the } \\
\text { analysis. }\end{array}$ \\
\hline Syntax & & $\begin{array}{l}\text { ONEWAY wbgt BY Day } \\
\text { /MISSING ANALYSIS } \\
\text { /POSTHOC=TUKEY ALPHA(0.05). }\end{array}$ \\
\hline \multirow[t]{2}{*}{ Resources } & Processor Time & $00: 00: 00.031$ \\
\hline & Elapsed Time & $00: 00: 00.031$ \\
\hline
\end{tabular}

ANOVA

\begin{tabular}{|l|r|r|r|r|c|}
\hline & \multicolumn{1}{|c|}{$\begin{array}{c}\text { Sum of } \\
\text { Squares }\end{array}$} & \multicolumn{1}{c|}{ df } & Mean Square & F & Sig. \\
\hline Between Groups & 28.083 & 2 & 14.042 & 5.293 & .047 \\
Within Groups & 15.917 & 6 & 2.653 & & \\
Total & 44.000 & 8 & & & \\
\hline
\end{tabular}

Post Hoc Tests:

second session day 1 was different from second session day 3 
Multiple Comparisons

wbgt

Tukey HSD

\begin{tabular}{|c|c|c|c|c|c|c|}
\hline \multirow[b]{2}{*}{ (I) Day } & \multirow[b]{2}{*}{ (J) Day } & \multirow{2}{*}{$\begin{array}{c}\text { Mean } \\
\text { Difference (I- } \\
\text { J) }\end{array}$} & \multirow[b]{2}{*}{ Std. Error } & \multirow[b]{2}{*}{ Sig. } & \multicolumn{2}{|c|}{ 95\% Confidence Interval } \\
\hline & & & & & Lower Bound & Upper Bound \\
\hline \multirow[t]{2}{*}{1} & 2 & -1.167 & 1.487 & .725 & -5.73 & 3.40 \\
\hline & 3 & $-3.917^{\star}$ & 1.244 & .045 & -7.73 & -.10 \\
\hline \multirow[t]{2}{*}{2} & 1 & 1.167 & 1.487 & .725 & -3.40 & 5.73 \\
\hline & 3 & -2.750 & 1.411 & .206 & -7.08 & 1.58 \\
\hline \multirow[t]{2}{*}{3} & 1 & 3.917 & 1.244 & .045 & .10 & 7.73 \\
\hline & 2 & 2.750 & 1.411 & .206 & -1.58 & 7.08 \\
\hline
\end{tabular}

*. The mean difference is significant at the 0.05 level.

\section{Homogeneous Subsets}

wbgt

Tukey HSD
\begin{tabular}{|l|r|r|r|}
\hline \multirow{2}{*}{ Day } & \multirow{2}{*}{$\mathrm{N}$} & \multicolumn{2}{|c|}{$\begin{array}{c}\text { Subset for } \\
\text { alpha }=0.05\end{array}$} \\
\cline { 3 - 4 } & & 1 & $\mathrm{~N}$ \\
\hline 1 & 3 & 25.33 & \\
2 & 2 & 26.50 & \\
3 & 4 & 29.25 & \\
Sig. & & .067 & \\
\hline
\end{tabular}

Means for groups in homogeneous subsets are displayed.

Oneway: day 1, first to second session.

\begin{tabular}{|c|c|c|}
\hline \multicolumn{3}{|c|}{ Notes } \\
\hline $\begin{array}{l}\text { Output Created } \\
\text { Comments }\end{array}$ & Comments & 03-Feb-2011 12:51:29 \\
\hline \multirow[t]{5}{*}{ Input } & Active Dataset & DataSet0 \\
\hline & Filter & Day.session $=1$ (FILTER) \\
\hline & Weight & $<$ none $>$ \\
\hline & Split File & $<$ none $>$ \\
\hline & $\begin{array}{l}\mathrm{N} \text { of Rows in Working } \\
\text { Data File }\end{array}$ & 6 \\
\hline \multirow[t]{2}{*}{$\begin{array}{l}\text { Missing Value } \\
\text { Handling }\end{array}$} & Definition of Missing & $\begin{array}{l}\text { User-defined missing values are } \\
\text { treated as missing. }\end{array}$ \\
\hline & Cases Used & $\begin{array}{l}\text { Statistics for each analysis are } \\
\text { based on cases with no missing } \\
\text { data for any variable in the } \\
\text { analysis. }\end{array}$ \\
\hline Syntax & & $\begin{array}{l}\text { ONEWAY wbgt BY Session } \\
\text { /MISSING ANALYSIS. }\end{array}$ \\
\hline \multirow[t]{2}{*}{ Resources } & Processor Time & 00:00:00.015 \\
\hline & Elapsed Time & $00: 00: 00.015$ \\
\hline
\end{tabular}


ANOVA

wbgt

\begin{tabular}{|l|r|r|r|r|r|}
\hline & $\begin{array}{c}\text { Sum of } \\
\text { Squares }\end{array}$ & $\mathrm{df}$ & Mean Square & \multicolumn{1}{c|}{$\mathrm{F}$} & Sig. \\
\hline Between Groups & 1.602 & 1 & 1.602 & 4.348 & .105 \\
Within Groups & 1.473 & 4 & .368 & & \\
Total & 3.075 & 5 & & & \\
\hline
\end{tabular}

Oneway: day 2, first to second session

\begin{tabular}{|c|c|c|}
\hline \multicolumn{3}{|c|}{ Notes } \\
\hline $\begin{array}{l}\text { Output Created } \\
\text { Comments }\end{array}$ & & 03-Feb-2011 12:52:21 \\
\hline \multirow[t]{5}{*}{ Input } & Active Dataset & DataSet0 \\
\hline & Filter & Day.session = 2 (FILTER) \\
\hline & Weight & $<$ none $>$ \\
\hline & Split File & $<$ none $>$ \\
\hline & $\begin{array}{l}\mathrm{N} \text { of Rows in Working } \\
\text { Data File }\end{array}$ & 5 \\
\hline \multirow[t]{2}{*}{$\begin{array}{l}\text { Missing Value } \\
\text { Handling }\end{array}$} & Definition of Missing & $\begin{array}{l}\text { User-defined missing values are } \\
\text { treated as missing. }\end{array}$ \\
\hline & Cases Used & $\begin{array}{l}\text { Statistics for each analysis are } \\
\text { based on cases with no missing } \\
\text { data for any variable in the } \\
\text { analysis. }\end{array}$ \\
\hline Syntax & & $\begin{array}{l}\text { ONEWAY wbgt BY Session } \\
\text { /MISSING ANALYSIS. }\end{array}$ \\
\hline \multirow[t]{2}{*}{ Resources } & Processor Time & $00: 00: 00.000$ \\
\hline & Elapsed Time & 00:00:00.016 \\
\hline
\end{tabular}

ANOVA

wbgt

\begin{tabular}{|l|r|r|r|r|r|}
\hline & $\begin{array}{c}\text { Sum of } \\
\text { Squares }\end{array}$ & $\mathrm{df}$ & Mean Square & $\mathrm{F}$ & Sig. \\
\hline Between Groups & 1.633 & 1 & 1.633 & .535 & .518 \\
Within Groups & 9.167 & 3 & 3.056 & & \\
Total & 10.800 & 4 & & & \\
\hline
\end{tabular}

\section{Oneway: day 3 , first to} second session 


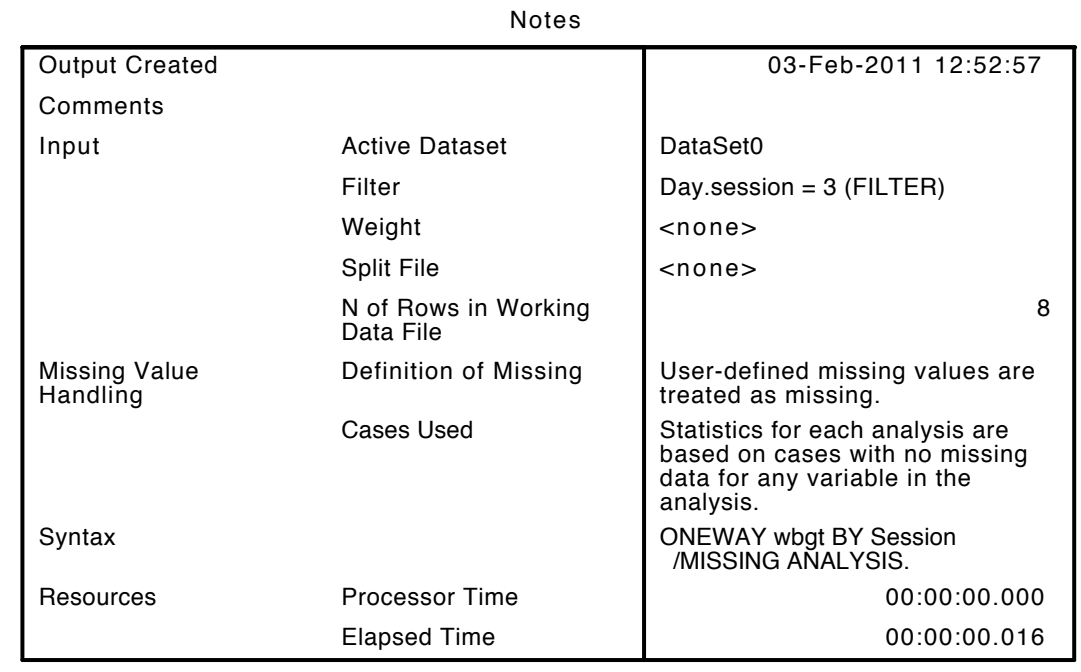

ANOVA

\begin{tabular}{|l|r|r|r|r|c|}
\hline & \multicolumn{1}{|c|}{$\begin{array}{c}\text { Sum of } \\
\text { Squares }\end{array}$} & \multicolumn{1}{c|}{$\mathrm{df}$} & Mean Square & $\mathrm{F}$ & Sig. \\
\hline Between Groups & 4.500 & 1 & 4.500 & 2.348 & .176 \\
Within Groups & 11.500 & 6 & 1.917 & & \\
Total & 16.000 & 7 & & & \\
\hline
\end{tabular}




\section{APPENDIX F: RECOMMENDATIONS}

Improvements for methodology

- Use nude weights to improve accuracy of percent dehydration, sweat loss, and sweat rate calculations.

- Increase the number of participants to increase power. With the current number of participants we cannot be certain that the lack of statistically significant findings is actually due to no change or the small number of participants.

- Length of time of exchange periods and their procedures should be held more constant (ie, the time between the first/second and third/fourth drills should be kept constant, as well as what happened, such as kneeling, standing, consuming fluid, etc.)

- The number of times the Stroop test is administered should be reduced: before protocol, start and end of first rehab, start of second rehab, post protocol. While we found no statistical significance in head cooling's effect on cognitive function in this study, and we are looking at how it is affected at work at rest, we can remove the testing point in the exchange to help decrease and hold constant the amount of time at the exchange point and still have data regarding cognitive function at the end of two drills and the end of 15 minutes of rest.

- Test reaction time rather than ability to tolerate interference for cognitive function.

- Test every participant the same day, or not allow participants to know what day they will participate to reduce the amount of information regarding the study passed between firefighters 
- Collect WBGT more often, outdoors and indoors, so that more descriptive data is available to create a better picture of the weather outdoors and the tower's environment.

Progression in the research field

- Effects of head cooling in firefighters when there is an external motivator, such as a live fire drill, goal oriented tasks, or an actual emergency call where the intensity of their work is not selfdetermined

- Relationship between perceived thermal sensation and gastrointestinal temperature when other means of accessory cooling are used

- Describe the hydration behaviors of firefighters via random urine sample collection (USG) with an accompanied survey on perceived knowledge of exertional heat illness and hydration behaviors versus actual knowledge

- Describe heart rates of firefighters during live fire drills and on a fire call, compared to maximum predicted heart rate

- Physiological and perceived effects of varying lengths of rehab periods on reduction of core body temperature

- Physiological and perceived effects of neck cooling during work and/or rehab - Physiological and perceived effects of fan and water mist on face during rehab 